\title{
Integrated Computational Study of Radiation Damage Effects in Grade 92 Steel and Alloy 709
}

Approved for public release. Distribution is unlimited.
Haixuan Xu

University of Tennessee-

Knoxville

Lizhen Tan

Oak Ridge National Laboratory

Li He

Kumar Sridharan

University of Wisconsin-Madison

December 2018 


\title{
DOCUMENT AVAILABILITY
}

Reports produced after January 1, 1996, are generally available free via US Department of Energy (DOE) SciTech Connect.

Website www.osti.gov

Reports produced before January 1, 1996, may be purchased by members of the public from the following source:

\author{
National Technical Information Service \\ 5285 Port Royal Road \\ Springfield, VA 22161 \\ Telephone 703-605-6000 (1-800-553-6847) \\ TDD 703-487-4639 \\ Fax 703-605-6900 \\ E-mail info@ntis.gov \\ Website http://classic.ntis.gov/
}

Reports are available to DOE employees, DOE contractors, Energy Technology Data Exchange representatives, and International Nuclear Information System representatives from the following source:

Office of Scientific and Technical Information

PO Box 62

Oak Ridge, TN 37831

Telephone 865-576-8401

Fax 865-576-5728

E-mail reports@osti.gov

Website http://www.osti.gov/contact.html

This report was prepared as an account of work sponsored by an
agency of the United States Government. Neither the United States
Government nor any agency thereof, nor any of their employees,
makes any warranty, express or implied, or assumes any legal liability
or responsibility for the accuracy, completeness, or usefulness of any
information, apparatus, product, or process disclosed, or represents
that its use would not infringe privately owned rights. Reference herein
to any specific commercial product, process, or service by trade name,
trademark, manufacturer, or otherwise, does not necessarily constitute
or imply its endorsement, recommendation, or favoring by the United
States Government or any agency thereof. The views and opinions of
authors expressed herein do not necessarily state or reflect those of
the United States Government or any agency thereof. 


\title{
Final Report
}

\section{PROJECT TITLE: Integrated Computational Study of Radiation Damage Effects in} Grade 92 Steel and Alloy 709

\author{
Haixuan Xu (PI) \\ Department of Materials Science and Engineering, The University of Tennessee Knoxville \\ Lizhen Tan (Co-PI) \\ Materials Science and Technology Division, Oak Ridge National Laboratory \\ Li He and Kumar Sridharan (Co-PI) \\ Department of Engineering Physics, University of Wisconsin-Madison
}

\author{
U.S. Department of Energy \\ Office of Nuclear Energy, Nuclear Energy University Program (NEUP) \\ Project No. NEUP 14-6436 \\ Contract No. DOE DE-NE0008271
}

Project Period: October 2014 to September 2018 


\section{CONTENTS}

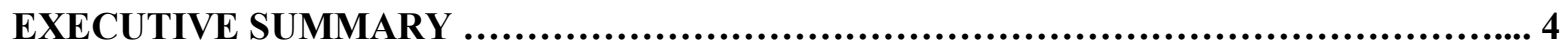

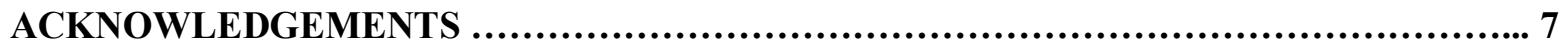

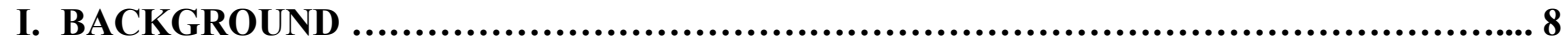

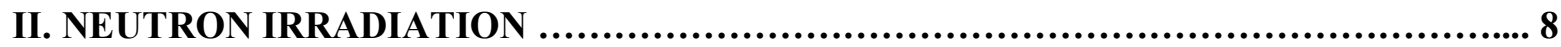

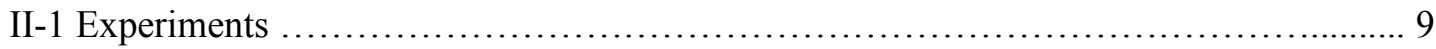

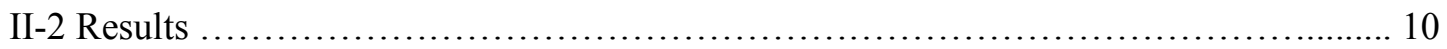

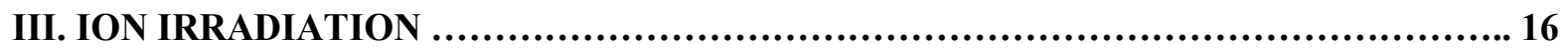

III-1 Ion Irradiation Experiments ............................................... 16

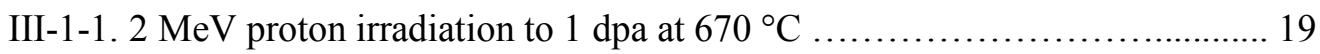

III-1-2. $2 \mathrm{MeV}$ proton irradiation to $0.5 \mathrm{dpa}$ and $1.5 \mathrm{dpa}$ at $670^{\circ} \mathrm{C}$.................. 21

III-1-3. 3.7 MeV iron irradiation to $50 \mathrm{dpa}$ at $350{ }^{\circ} \mathrm{C} \ldots \ldots \ldots \ldots \ldots \ldots \ldots \ldots . \ldots . \ldots . \ldots 22$

III-1-4. $2 \mathrm{MeV}$ proton irradiation to $0.01 \mathrm{dpa}$ at $380{ }^{\circ} \mathrm{C}$ and $0.1 \mathrm{dpa}$ at $510{ }^{\circ} \mathrm{C} \ldots \ldots 24$

III-1-5. $2 \mathrm{MeV}$ proton irradiation to $0.01 \mathrm{dpa}$ and $0.1 \mathrm{dpa}$ at $670{ }^{\circ} \mathrm{C}$............... 26

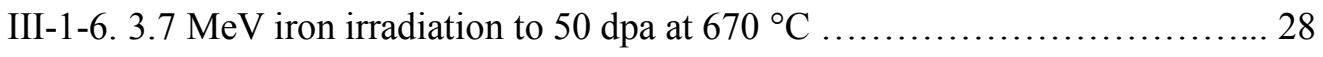

III-1-7. 3.7 MeV iron irradiation to $2.5 \mathrm{dpa}$ and $15 \mathrm{dpa}$ at $350^{\circ} \mathrm{C} \ldots \ldots \ldots \ldots \ldots . . . . . .30$

III-1-8. $2 \mathrm{MeV}$ proton irradiation to $0.01 \mathrm{dpa}$ and $1 \mathrm{dpa}$ at $510^{\circ} \mathrm{C} \ldots \ldots \ldots \ldots \ldots . . . . .33$

III-1-9. 3.7 MeV iron irradiation to $2.5 \mathrm{dpa}$ and $15 \mathrm{dpa}$ at $670{ }^{\circ} \mathrm{C}$................ 37

III-1-10. 3.5 MeV iron irradiation to $75 \mathrm{dpa}$ at $600{ }^{\circ} \mathrm{C}$, defocused beam .............. 40

III-2. Characterization of Alloys before and after Irradiation.......................... 41

III-2-1. Proton-irradiated 316H, alloy 709 and FeCrNi (model 709) ............... 44

III-2-2. TEM analysis of as-received and $\mathrm{Fe}^{2+}$-irradiated alloys 709 and

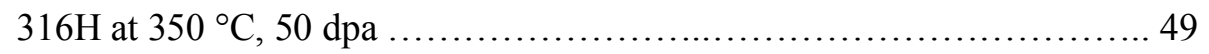

III-2-3. $\mathrm{Fe}^{2+}$-irradiated 709 and crept/ thermally aged $709(1101,1106)$

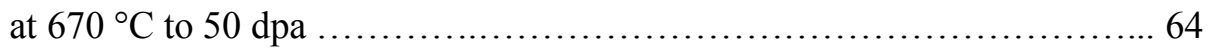

III-2-4. As-received and $\mathrm{Fe}^{2+}$ irradiated G91 and G92 at $350{ }^{\circ} \mathrm{C}, 50 \mathrm{dpa}$.............79

III-2-5. Defocused ion beam irradiation of alloy 709 to $75 \mathrm{dpa}$ at $600{ }^{\circ} \mathrm{C}$............ 86

III-2-6. A new swelling measurement method with TEM and EELS .............. 88

III-3. Mechanical Property Testing of Alloys ......................................... 90

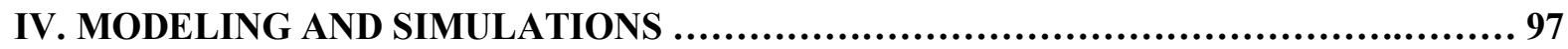

IV-1 Interaction between Displacement Cascades and Dislocations ...................... 97 
IV-1-1. Methodology and Simulation Setup .............................. 98

IV-1-2. Simulation Results ............................................. 103

IV-1-3. Peierls Stress Simulation ......................................... 107

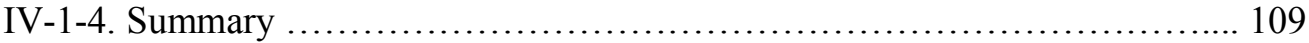

IV. 2 Dynamics of Point Defect near Dislocations ................................ 110

IV-2-1. Simulation Setup and Computational Details......................... 112

IV-2-2. Results and Discussions........................................ 115

IV-2-3. Summary ...................................................... 127

V. SUPPORTED AND CONTRIBUTING STUDENTS AND POSTDOCS ................ 128

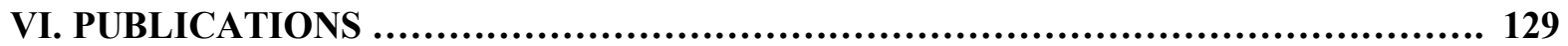

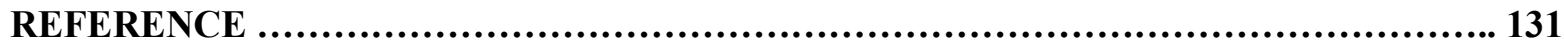




\section{EXECUTIVE SUMMARY}

Radiation resistance of austenitic alloy 709 (named as A709) and ferritic-martensitic steel Grade 92 (G92) were investigated in this project using 316H and Grade 91 (G91) as references, respectively. In the meantime, a model 709 (M709) alloy (Fe-20Cr-24Ni) was prepared to study the matrix response to irradiation. Samples machined from the tab section of three creep-ruptured A709 samples, i.e., 17,106 $\mathrm{h}$ at $600{ }^{\circ} \mathrm{C}, 12,014 \mathrm{~h}$ at $650{ }^{\circ} \mathrm{C}$, and $16,448 \mathrm{~h}$ at $700{ }^{\circ} \mathrm{C}$, were included in this work to evaluate radiation effect on the long-term "thermally aged" samples. Primarily $\mathrm{Fe}^{2+}$ ion irradiation was conducted at 350, 600 and $670{ }^{\circ} \mathrm{C}$ for up to 75 displacements per atom (dpa), together with a few proton irradiation experiments at $380-670{ }^{\circ} \mathrm{C}$ for up to $1.5 \mathrm{dpa}$. Additionally, four neutron-irradiated NF709 samples (3.22-8 dpa at $430-$ $469{ }^{\circ} \mathrm{C}$ ) were examined. The samples were examined by transmission electron microscopy (TEM), scanning electron microscopy (SEM) and energy dispersive x-ray spectroscopy (EDS) for microstructures and nanoindentation for radiation-hardening.

Unlike the negligible hardening after irradiation at $670{ }^{\circ} \mathrm{C}$, irradiation to nominal $2.5-50$ dpa at $350{ }^{\circ} \mathrm{C}$ resulted in radiation-hardening of $13.5 \pm 5.4 \%$ for $A 709$, which was comparable to that of $13.4 \pm 6.2 \%$ for M709 and moderately lower than that of $20.1 \pm 5.6 \%$ for $316 \mathrm{H}$. The radiation-hardening induced by the same irradiation condition to the "thermally aged" samples was comparable to A709, which were hardened by $15.0 \pm 8.2 \%, 13.5 \pm 6.0 \%$, and $10.1 \pm 6.1 \%$ for the 600,650 , and $700{ }^{\circ} \mathrm{C}$ aged samples, respectively. The radiation-hardening of A709 is significantly lower than that ( $\sim 94 \pm 9 \%)$ of neutron-irradiated NF709 to 8 dpa at $\sim 430^{\circ} \mathrm{C}$.

Microstructural characterization indicated dislocation loops, type $1 / 3<111>$, in $316 \mathrm{H}$ and A709 after irradiation at $350{ }^{\circ} \mathrm{C}$. The loop size and density in A709 were slightly smaller than that in $316 \mathrm{H}$, e.g., $14.2 \pm 0.6 \mathrm{~nm}$ with $5.2 \times 10^{22} \mathrm{~m}^{-3}$ in $\mathrm{A} 709$ vs. $15 \pm 1 \mathrm{~nm}$ with $8.3 \times 10^{22} \mathrm{~m}^{-3}$ in $316 \mathrm{H}$ after 50 dpa. However, only line dislocations were developed in the samples irradiated at $600-670{ }^{\circ} \mathrm{C}$. A small amount $\left(\sim 2.8 \times 10^{12} \mathrm{~m}^{-3}\right)$ of $\mathrm{Nb}(\mathrm{CN})$ precipitates in a size of $\sim 72 \mathrm{~nm}$ were observed in the as-received A709, which were reduced to $\sim 1.6 \times 10^{12} \mathrm{~m}^{-3}$ with a larger size of $\sim 90 \mathrm{~nm}$ after irradiation to $50 \mathrm{dpa}$ at $350{ }^{\circ} \mathrm{C}$. A new type of precipitates $\mathrm{CrNbN}$ (Z-phase) in $\sim 10 \mathrm{~nm}$ was introduced by the rastered beam irradiation to $50 \mathrm{dpa}$ at $670{ }^{\circ} \mathrm{C}$ but not by the defocused beam irradiation to $75 \mathrm{dpa}$ at $600{ }^{\circ} \mathrm{C}$. Additionally, some $(\mathrm{CrMo})_{\mathrm{x}} \mathrm{C}_{\mathrm{y}}$ type precipitates were observed in both the high-temperature irradiated A709 samples, which is believed to be the precursor of $\mathrm{M}_{23} \mathrm{C}_{6}$. In contrast, a significant amount of multiple types precipitates was identified in 600-700 ${ }^{\circ} \mathrm{C}$ aged $\mathrm{A} 709$ samples, e.g., $(\mathrm{CrMo})_{23} \mathrm{C}_{6},(\mathrm{CrMo})_{3} \mathrm{Ni}_{2} \mathrm{Si}, \mathrm{Nb}(\mathrm{CN}), \mathrm{CrNbN}$, and Ni/Si-rich particles. Large $(\mathrm{CrMo})_{23} \mathrm{C}_{6}$ and $(\mathrm{CrMo})_{3} \mathrm{Ni}_{2} \mathrm{Si}$ particles, in $\sim 1 \mu \mathrm{m}$, grew along grain boundaries, which covered $\sim 53 \%$ 
and $\sim 42 \%$ grain boundary length, respectively, leaving only $\sim 5 \%$ of bare grain boundaries. The $670{ }^{\circ} \mathrm{C}$ irradiation did not result in noticeable changes to the thermal-induced precipitates, except for further $\mathrm{Cr}$ enrichment in $(\mathrm{CrMo})_{23} \mathrm{C}_{6}$ and $(\mathrm{CrMo})_{3} \mathrm{Ni}_{2} \mathrm{Si}$. Other than dislocations and precipitates, radiation-induced segregation was also characterized and exhibited a consistent trend with general austenitic alloys. The $670{ }^{\circ} \mathrm{C}$ irradiation resulted in significant void swelling in M709 but not in the other alloys. Compared to the $\mathrm{Fe}^{2+}$-irradiated $\mathrm{A} 709$ to $50 \mathrm{dpa}$ at $350{ }^{\circ} \mathrm{C}$, the neutron-irradiated $\mathrm{NF} 709$ to $8 \mathrm{dpa}$ at $\sim 430{ }^{\circ} \mathrm{C}$ exhibited smaller loops of $9 \pm 5 \mathrm{~nm}$ with a higher density of $(1.2 \pm 0.1) \times 10^{23} \mathrm{~m}^{-3}$, introduced a noticeable amount of tiny voids in $\sim 1 \mathrm{~nm}$ with a density of $(9 \pm 3) \times 10^{22} \mathrm{~m}^{-3}$ and $\mathrm{Cr}_{23} \mathrm{C}_{6}$ particles with retained $\mathrm{Nb}(\mathrm{CN})$. The large number of voids and slightly more loops would contribute a large fraction of hardening in the neutronirradiated NF709 but would not increase the hardening to $\sim 94 \pm 9 \%$ of NF709 from $13.5 \pm 5.4 \%$ of A709. The irradiation temperature and other factors should have play important roles.

In contrast to the austenitic alloys, the radiation-hardening under the same irradiation condition for G91 and G92 did not saturate up to $50 \mathrm{dpa}$. G91 generally exhibited slightly higher radiation-hardening than G92, e.g., $32.6 \pm 5.1 \%$ vs. $27.8 \pm 5.5 \%$ after 50 dpa at $350{ }^{\circ} \mathrm{C}$, which has the same trend as the neutronirradiated counterparts at $469^{\circ} \mathrm{C}(\underline{1})$. The same types of precipitates such as $\mathrm{M}_{23} \mathrm{C}_{6}[\mathrm{M}=\mathrm{Cr} / \mathrm{Mo} / \mathrm{V} /(\mathrm{W})]$ and $\mathrm{MX}(\mathrm{M}=\mathrm{V} / \mathrm{Nb}, \mathrm{X}=\mathrm{C} / \mathrm{N})$ were observed in the as-received $\mathrm{G} 91$ and $\mathrm{G} 92$. Amorphization occurred in $\mathrm{M}_{23} \mathrm{C}_{6}$ after irradiation to $>\sim 40 \mathrm{dpa}$ at $350^{\circ} \mathrm{C}$. Compared to G91, larger dislocation loops with a lower density were observed in G92 after the irradiation at $350{ }^{\circ} \mathrm{C}$. The dislocation loops were identified to be primarily $<100>$ type, but G92 has more $1 / 2<111>$ loops than G91, which are generally consistent with the neutronirradiated counterparts at $469{ }^{\circ} \mathrm{C}(\underline{1})$. The loops acted as the primary cause of radiation-hardening. The lower loop density and more glissile $1 / 2<111>$ loops in G92 benefited its lower hardening compared to G91.

To understand the irradiation-induced hardening, atomistic simulations of nano-indentation processes were carried out and the results were compared with the experimental results. Molecular dynamics simulations and experimental microstructural analysis correlated the anisotropic nanoindentation-creep behavior with the different dislocation substructures formed during indentation, which resulted from the dislocation reactions of certain active slip systems that are determined by the indented grain orientations. In addition, the interactions between irradiation induced displacement cascades and dislocations are investigated as an additional hardening mechanism different from the conventional radiation-induced hardening $(\mathrm{RIH})$ models. It is found that the displacement cascades in systems containing dislocations tend to generate more total defects compared with bulk systems, but eventually lead to less surviving defects in the material's matrix due to interactions with dislocations. The changes in atomic structures of the dislocations after interacting 
with cascades are analyzed to understand how the primary damage affects dislocations and the mechanical property of the irradiated materials.

Modeling efforts towards understanding the fundamental interactions between point defects and dislocations were conducted to understand the microstructural evolution of the irradiated materials. The interaction between dislocations and point defects is crucial for many physical properties and phenomena in materials, such as dislocation bias and void swelling, creep, and impurity segregation around dislocations. Conventional dislocation-point defect interaction models use approximations based on elasticity theory and/or based on assumptions that transition states energies can be deduced from the binding energies of the defects. In this study, we employed the transport properties of point defects near dislocations based on the actual saddle point configuration of vacancies and self-interstitial atoms as a function of position with respect to screw and edge dislocations in a model system (bcc iron) using the self-evolving atomistic kinetic Monte Carlo method. These simulations reveal defect dynamics near dislocations are highly anisotropic and correlated, particularly for dumbbells in the compressive field of the edge dislocation, which could result in zones near dislocation cores where dumbbells are less efficiently absorbed compared with vacancies. These modelling efforts provides fundamental insights that are essential for understanding microstructural evolution and mechanical properties of metallic materials.

In summary, A709 had less radiation-hardening than $316 \mathrm{H}$. The noticeable discrepancy in radiationhardening between the ion-irradiated A709 and neutron-irradiated NF709 needs further justification. Unlike $316 \mathrm{H}$ does not have precipitates (prior-to or after irradiation), A709 experienced noticeable evolutions of precipitates induced by ion irradiation and thermal aging. For example, the density of the pre-existing $\mathrm{Nb}(\mathrm{CN})$ precipitates was reduced with enlarged particle sizes after irradiation. Thermal aging at $600-700{ }^{\circ} \mathrm{C}$ resulted in $\sim 95 \%$ coverage of grain boundaries by coarse precipitates of $(\mathrm{CrMo})_{23} \mathrm{C}_{6}$ and $(\mathrm{CrMo})_{3} \mathrm{Ni}_{2} \mathrm{Si}_{\text {, }}$ which were further enriched by $\mathrm{Cr}$ after irradiation. Such a high grain boundary coverage would deteriorate the ductility (e.g., creep rupture ductility) and toughness of A709. G92 exhibited slightly lower radiationhardening than G91, which is consistent with the trend of neutron-irradiated counterparts and is attributable to the different dislocation loops. 


\section{ACKNOWLEDGEMENTS}

This work was supported by the US DOE Office of Nuclear Energy's Nuclear Energy University Program (NEUP) under Contract No. DE-NE0008271 and contract number DE-AC05-00OR22725.

We acknowledge Drs. Y. Yamamoto and T.-L. Sham are appreciated for providing the A709 material for the testing.

This research used resources of the National Energy Research Scientific Computing Center, a DOE Office of Science User Facility supported by the Office of Science of the U.S. Department of Energy under Contract No. DE-AC02- 05CH11231. The DOE Office of Nuclear Energy Nuclear Science User Facility (NSUF) through Rapid Turnaround Examination (RTE) projects FY17-804 and FY17-1014 is appreciated for providing the ATR-irradiated samples and facility access. 


\section{BACKGROUND}

Grade 92 and Alloy 709 are being developed as candidate alloys for the Sodium-cooled Fast Reactor (SFR). Grade 92 has a tempered martensitic microstructure, and is composed of a high density of lath boundaries and dislocations that are usually pinned by $\mathrm{Cr}$-rich $\mathrm{M}_{23} \mathrm{C}_{6}$ and vanadium nitride nanoprecipitates. In contrast, Alloy 709 is composed of large equiaxial grains $(50-100 \mu \mathrm{m})$ with some scattered nitrides and carbides, similar to conventional austenitic stainless steels. Both materials have shown satisfactory or superior performance in regards to a variety of mechanical properties and liquid sodium compatibility as compared to reference steels, Grade 91 and type 316 stainless steel. However, knowledge of their radiation resistance is very limited. The only neutron irradiation experiment of NF616 (Nippon steel trademark of Grade 92) carried out at $300^{\circ} \mathrm{C}$ reported less hardening but a higher ductile-brittle transition temperature (DBTT) shift than Grade 91 steel (2). No microstructural information correlating these mechanical property changes to radiation-induced changes was reported. In situ $1 \mathrm{MeV} \mathrm{Kr}$ ion irradiation in Grade 92 at $200^{\circ} \mathrm{C}$ showed a defect cluster density increase with dose saturating at $\sim 6$ displacement per atom (dpa) (3). The size of the clusters was generally independent of irradiation dose. The cluster evolution is consistent with the $2 \mathrm{MeV}$ proton irradiated $\mathrm{NF} 616$ at $500^{\circ} \mathrm{C}(\underline{4})$. Unlike the $200^{\circ} \mathrm{C} \mathrm{Kr}$ ion irradiation, the $500^{\circ} \mathrm{C}$ proton irradiation generated TEM resolvable dislocation loops with size increasing up to 2 dpa and reaching saturation at 3 dpa while loop density increased monotonically with dose (4). On the other hand, reports on neutron radiation resistance of Alloy 709 are not publicly available. The preliminary neutron irradiation experiment on Nb-stabilized Fe-20Cr-25Ni (similar to Alloy 709 ) at $500-850^{\circ} \mathrm{C}$ with a flux of approximately $5.0 \times 10^{12}$ neutrons $/ \mathrm{cm}^{2} / \mathrm{s}$ fast $(>2.9 \mathrm{MeV})$ and $6.0 \times 10^{13}$ neutrons $/ \mathrm{cm}^{2} / \mathrm{s}$ thermal showed only a small effect on rupture stress, but strong reductions in ductility with a minimum at $\sim 650^{\circ} \mathrm{C}(\underline{5})$. Proton irradiation $(3.2 \mathrm{MeV})$ of a model alloy $\mathrm{Fe}-20 \mathrm{Cr}-24 \mathrm{Ni}$ at $400^{\circ} \mathrm{C}$ exhibited radiation-induced segregation (RIS) with $\mathrm{Cr}$ depletion at grain boundaries, which rapidly approached steady state within $\sim 0.5$ dpa whereas saturation was not achieved at $3 \mathrm{dpa}$ for $304 \mathrm{~L}(\underline{6})$. The RIS in the proton-irradiated model alloy was also observed to be temperature dependent with peak RIS at $500^{\circ} \mathrm{C}$, but very little RIS was observed below $300^{\circ} \mathrm{C}$ and above $700^{\circ} \mathrm{C}(\underline{7})$.

\section{NEUTRON IRRADIATION}

NF709 is a commercial grade of Alloy 709, which was developed and marketed by Nippon Steel. Neutron irradiation results of NF709 type of steel is scarce, except for limited results of simple Nb/Ti-stabilized $20 \mathrm{Cr}-25 \mathrm{Ni}$ alloys that exhibited radiation-induced $(\mathrm{Ni}, \mathrm{Si})$-rich and $(\mathrm{Ni}, \mathrm{Nb}, \mathrm{Si})$-rich precipitates after irradiation at $360-480{ }^{\circ} \mathrm{C}$ and $440-640{ }^{\circ} \mathrm{C}$, respectively ( $(\underline{)})$, and radiation embrittlement at $\sim 650{ }^{\circ} \mathrm{C}$ during 
tests at $550-900{ }^{\circ} \mathrm{C}(\underline{9}, \underline{10})$. To test the advanced austenitic stainless steel, NF709 was included in the University of Wisconsin Pilot Irradiation Project using the Advanced Test Reactor (ATR). The composition of the NF709 material is listed in Table II-1. The material was received from Oak Ridge National Laboratory, which was supplied by Nippon Steel and received hot-rolling to a $12.7 \mathrm{~mm}$ thick plate, followed by annealing in air at $1107^{\circ} \mathrm{C}$ for 20 min and water quenching at Oak Ridge National Laboratory.

Table II-1. Composition of NF709 in weight percent (wt\%).

\begin{tabular}{|c|c|c|c|c|c|c|c|c|c|c|c|c|c|c|}
\hline & $\mathrm{B}$ & $\mathrm{C}$ & $\mathrm{N}$ & $\mathrm{Si}$ & $\mathrm{P}$ & $\mathrm{S}$ & $\mathrm{Cr}$ & $\mathrm{Mn}$ & $\mathrm{Ni}$ & $\mathrm{Nb}$ & $\mathrm{Mo}$ & $\mathrm{Ti}$ & $\mathrm{Cu}$ & Ref. \\
\hline Reported & 0.0047 & 0.078 & 0.102 & 0.47 & 0.016 & 0.0001 & 20.41 & 0.99 & 26.0 & 0.34 & 1.50 & - & - & $\underline{(11})$ \\
\hline Re-analyzed & 0.0014 & 0.076 & 0.11 & 0.42 & 0.016 & 0.0001 & 20.50 & 0.76 & 25.7 & 0.32 & 1.52 & 0.033 & 0.365 & $\underline{(12})$ \\
\hline
\end{tabular}

Discs of NF709 in $3 \mathrm{~mm}$ diameter and $\sim 0.2 \mathrm{~mm}$ thickness were irradiated in ATR. Two proposals were awarded for post-irradiation examination of the irradiated samples under the Nuclear Scientific User Facility - Rapid Turnaround Examination (NSUF-RTE) program. The first NSUF-RTE 17-728 realized that the so-called NF709 samples were actually alloy D9. Therefore, the second NSUF-RTE 17-1014 was pursued to analyze the so-called D9 samples, which turned out to be NF709 samples. The examined irradiation conditions of the NF709 samples are listed in Table II-2.

Table II-2. Examined ATR-irradiated NF709 samples.

\begin{tabular}{|c|c|c|c|c|}
\hline Sample & $\mathrm{T}_{\text {Target }}\left({ }^{\circ} \mathrm{C}\right)$ & $\begin{array}{c}\text { Dose } \\
(\mathrm{dpa})\end{array}$ & $\mathrm{T}_{\text {As-run }}\left({ }^{\circ} \mathrm{C}\right)$ & $\begin{array}{c}\text { Dose } \\
(\mathrm{dpa})\end{array}$ \\
\hline L3 & 400 & 3 & 450 & 3.22 \\
\hline L4 & 400 & 6 & 447.5 & 4.93 \\
\hline L5 & 500 & 3 & 469 & 4.45 \\
\hline L6 & 500 & 6 & 429.5 & 8 \\
\hline
\end{tabular}

\section{II-1 Experiments}

The samples were flash-polished for focused ion beam (FIB) lamellae lift-out and nanoindentation measurements. Conventional transmission electron microscopy (CTEM) was conducted on the FIB lamellae using different imaging techniques to characterize dislocation loops, voids, and precipitates. A Hysitron TI 950 nanoindenter was employed to conduct nanoindentation measurements at room 
temperature using a Berkovich tip. To minimize the influence from the surface condition, the indentation depth was controlled to be $\sim 500 \mathrm{~nm}$ through a maximum force of $40 \mathrm{mN}$. The loading rate was $0.05 \mathrm{mN} / \mathrm{s}$, consistent with our previous studies on similar materials $(\underline{13})$. The hardness and elastic modulus were calculated using the method described by Oliver and Pharr (14).

\section{II-2 Results}

The FIB-integrated secondary electron detector and energy dispersive x-ray spectroscopy (EDS) were used to characterize the samples. Fig. II-1 shows an example using the sample L4. The secondary electron image shows the grains with many twin boundaries. The EDS spectrum yielded a quantitative result of $49.80 \mathrm{Fe}-$ 21.22 Cr-25.45 Ni-1.69Mo-0.99Nb-0.85Si, which approximately consistent the alloy chemistry as presented in Table II-1.
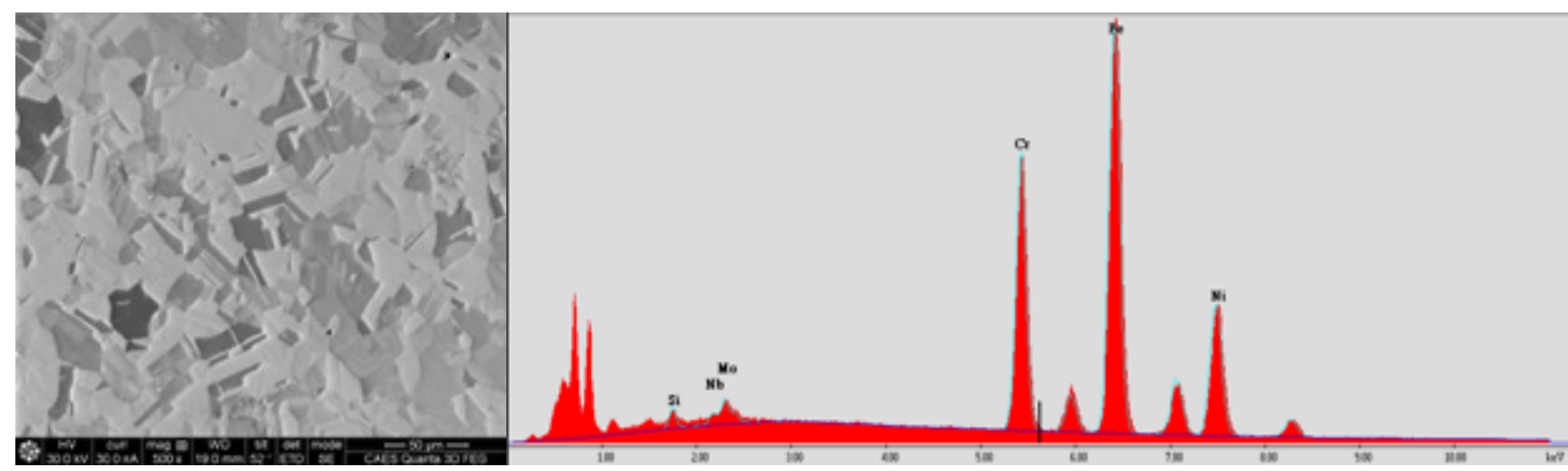

Fig. II-1. Secondary electron image and representative EDS spectrum of the sample L4.

Fig. II-2 shows the distributions of radiation-induced dislocation loops under different radiation conditions. In the dark-field (DF) images, the dislocation loops are observed as bright short lines near their edge-on orientation at the rel-rod condition using the $\{311\}$ two-beam condition near $<011>$ zone axis (15). Considering that approximately one-fourth of the loops are in contrast at one of the rel-rod conditions (15), the density of loops in the NF709 material under the irradiation conditions of this study is quite considerable. The loop size and density are comparable for the four samples, with size nearly $10 \mathrm{~nm}$ and density close to the order of $10^{23} \mathrm{~m}^{-3}$. 

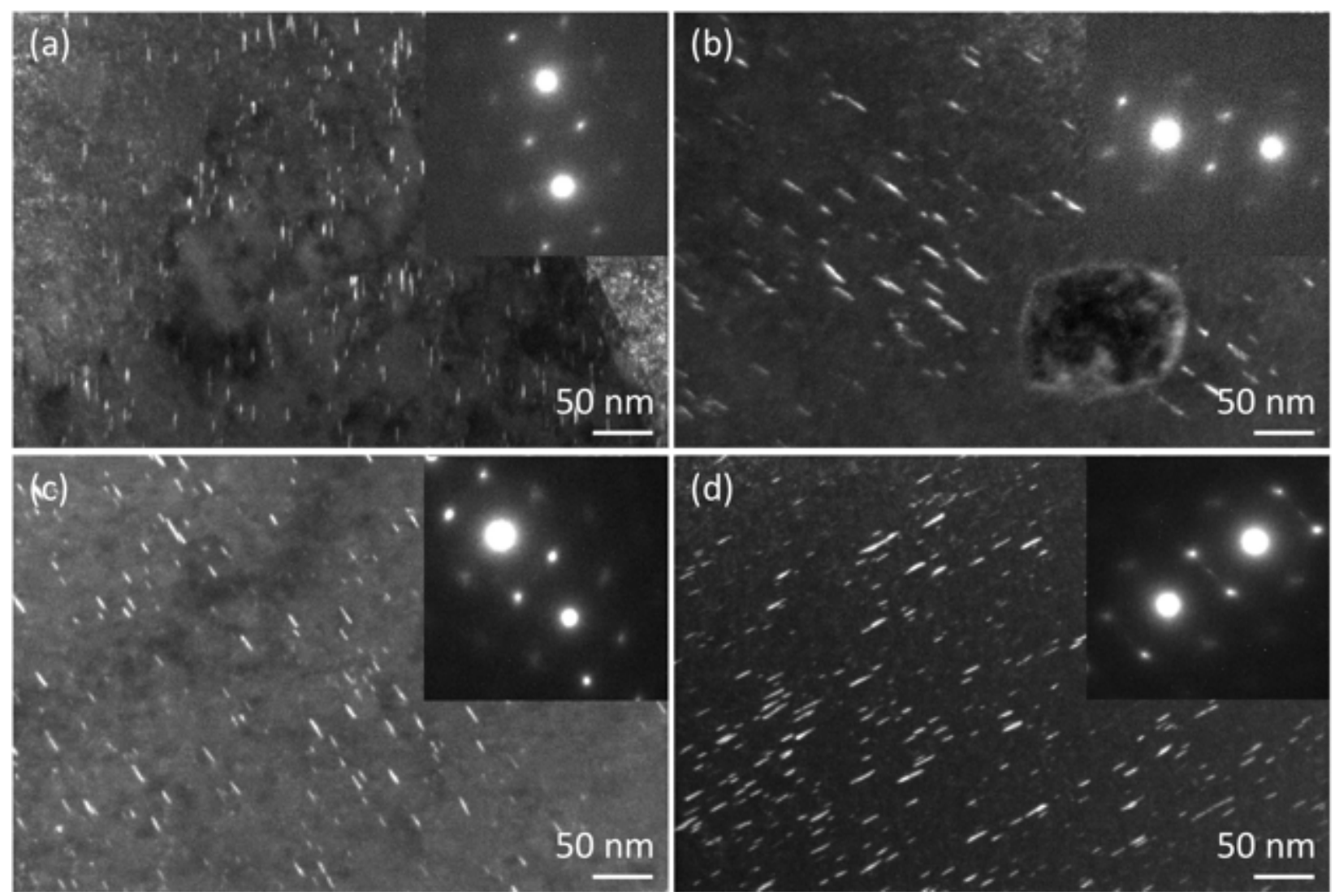

Fig. II-2. DF TEM images showing dislocation loops for the (a) L3, (b) L4, (c) L5 and (d) L6 samples. The inset shows corresponding electron-diffraction patterns of the rel-rod conditions.

Radiation-induced void formation was observed and analyzed by means of bright-field (BF) imaging at different focuses. The voids have bright and dark contracts in the underfocus and overfocus conditions, respectively. The presence of voids can thus be identified by comparing an underfocus micrograph, and an overfocus micrograph of the same region side by side. Fig. II-3 shows BF images of the four samples at a high magnification with a underfocus of $-500 \mathrm{~nm}$, where all the voids have a bright contract. Some of the voids are pointed out by the white arrows in Fig. II-3. While the samples L3, L4, and L6 show comparable void sizes, some of the voids in the sample L5 are significantly larger. 

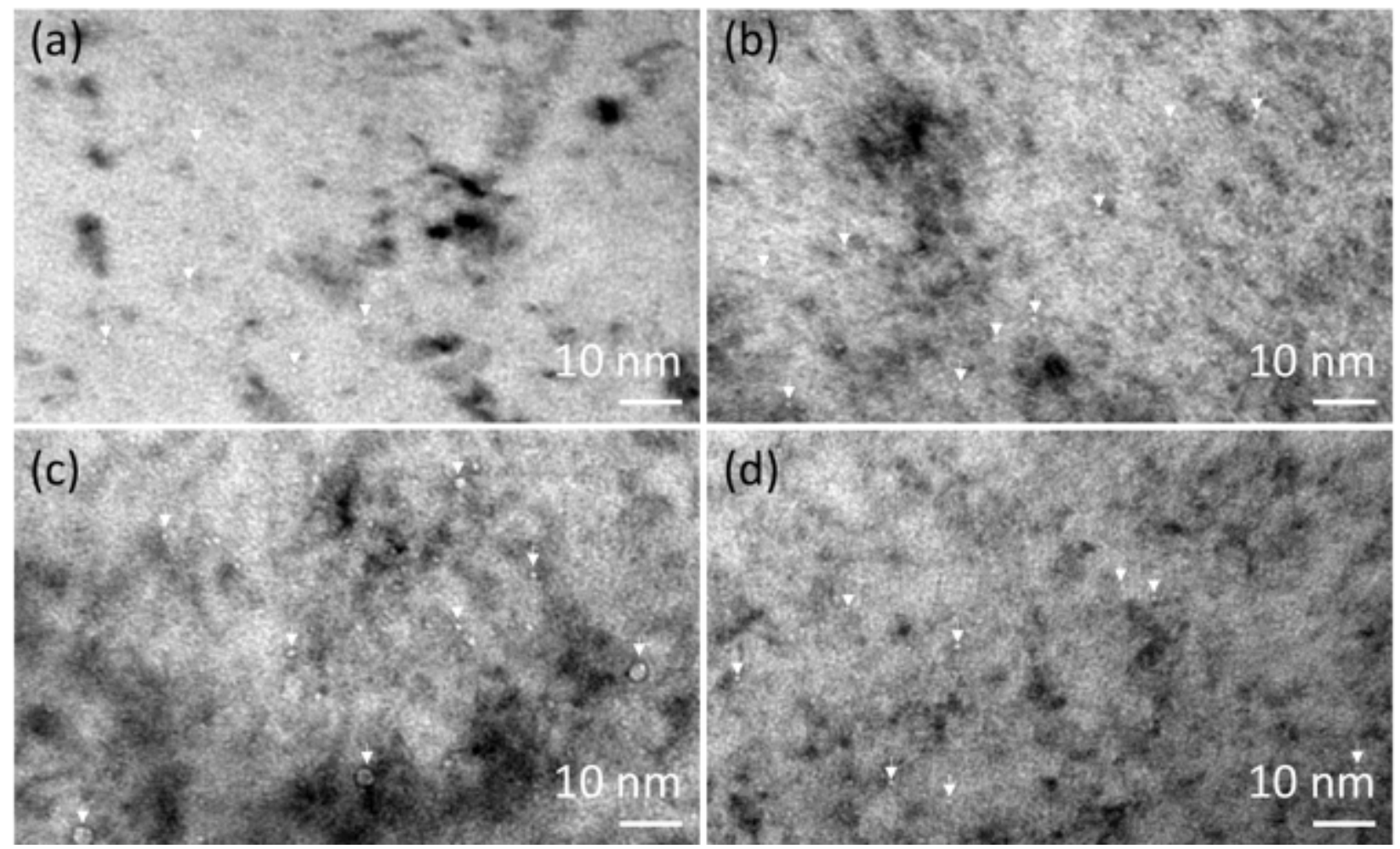

Fig. II-3. BF TEM images obtained at $-500 \mathrm{~nm}$ underfocus condition, showing voids in the (a) L3, (b) L4, (c) L5 and (d) L6 samples. The white arrows mark some of the voids.

By analyzing several micrographs for each sample, statistics of the void size and density was calculated. The void size and number density are quite consistent being around $1 \mathrm{~nm}$ and $1 \times 10^{23} \mathrm{~m}^{-3}$, respectively, for all the four samples. The void swelling as a function of radiation dose and temperature for the four samples is plotted in Fig. II-4a and II-4b, respectively. Although the sample L6 was irradiated at $\sim 20{ }^{\circ} \mathrm{C}$ lower than the samples L3 and L4, it observed more swelling due to the higher level of radiation damage.

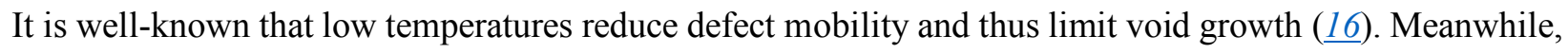
higher irradiation dose produced more defects for void growth $(\underline{16})(\underline{17})$. Apparently, the higher irradiation temperature of $469^{\circ} \mathrm{C}$ for the sample L5 enhanced its void swelling. As shown in Fig. II-3c, the voids larger than $2 \mathrm{~nm}$ in diameter are scattered in the sample L5, contributing significantly to its swelling. The void growth kinetics is more temperature-sensitive at $469^{\circ} \mathrm{C}$ than that in the temperature range of $\sim 430-450$ ${ }^{\circ} \mathrm{C}$. 

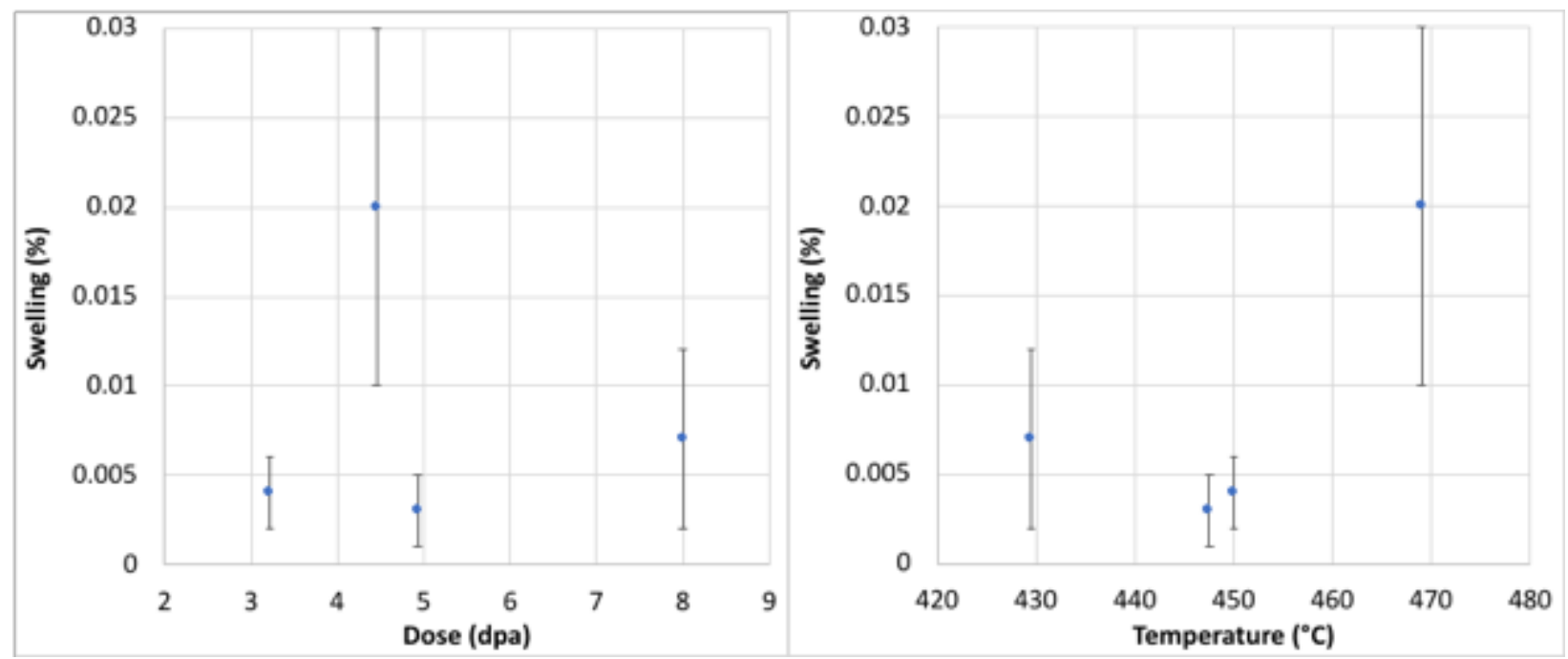

Fig. II-4. Void swelling as a function of (a) neutron dose and (b) irradiation temperature for the four ATRirradiation NF709 samples.

Fig. II-5 shows some particles observed in the irradiated samples. The particles, having a diameter of $\sim 80$ $\mathrm{nm}$, were observed in all of the samples with different irradiation conditions. The number density of the particles is on the order of $10^{19} \mathrm{~m}^{-3}$ regardless of the irradiation conditions. The chemical composition of the particles was characterized using EDS, which indicates that the particles are $\mathrm{Nb}(\mathrm{C}, \mathrm{N})$. Together with the converged-beam electron diffraction (CBED) pattern shown in Fig. II-5a inset, it is suggested that the particles have a face-centered cubic crystal structure with a lattice parameter of $0.441 \mathrm{~nm}$.
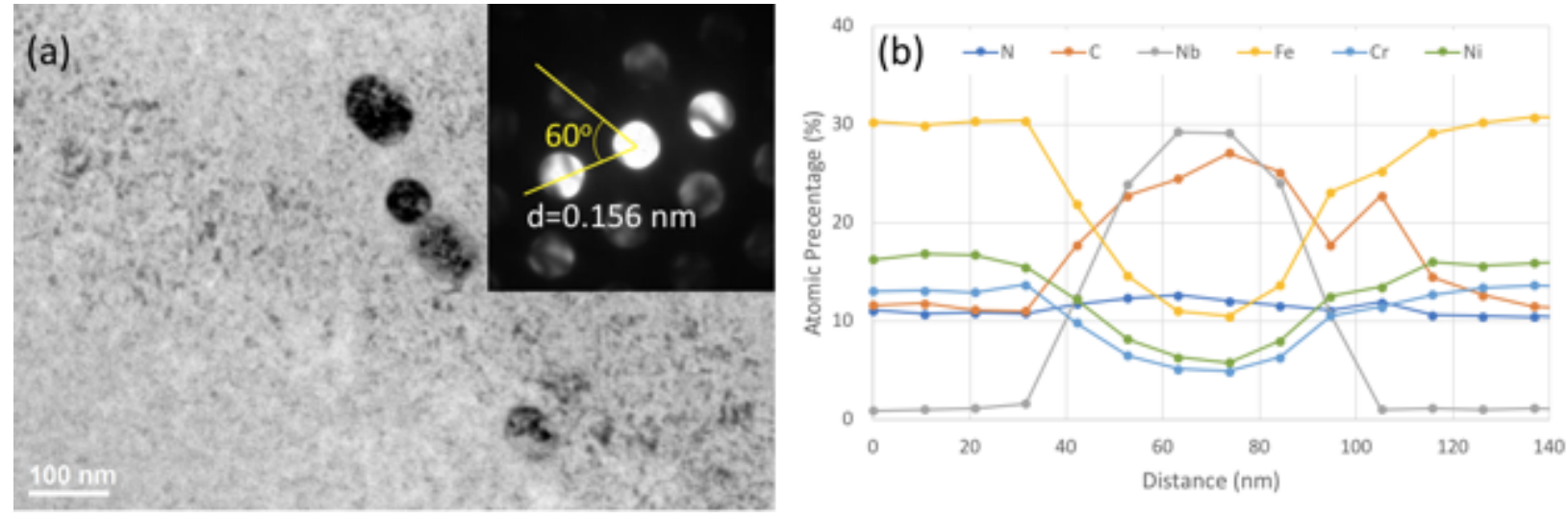

Fig. II-5. (a) A BF image showing the particles observed in the irradiated samples with their CBED pattern as the inset. (b) A composition profile of a precipitate obtained using EDS line scan. 
Other than $\mathrm{Nb}(\mathrm{C}, \mathrm{N})$ type $\mathrm{MX}$ matrix precipitates, grain boundary precipitates in different forms were also observed in the irradiated samples as shown in Fig. II-6. Some of the precipitates observed in the L3 sample look like a thin firm at grain boundaries, as shown in Fig. II-6a. Whereas the precipitates formed in the L5 samples have a globular morphology, as shown in Fig. II6b-c on the grain boundary and at a triple junction, respectively. Although not shown in Fig. II-6, such precipitates were also observed at grain boundaries in the L4 and L6 samples. The grain boundary precipitates were characterized to be $\mathrm{Cr}_{23} \mathrm{C}_{6}$ type carbides according to their selected-area electron diffraction patterns. The varied morphologies of the grain boundary $\mathrm{Cr}_{23} \mathrm{C}_{6}$ particles are believed to be governed by the grain boundary types that have different lattice mismatches with $\mathrm{Cr}_{23} \mathrm{C}_{6}$.
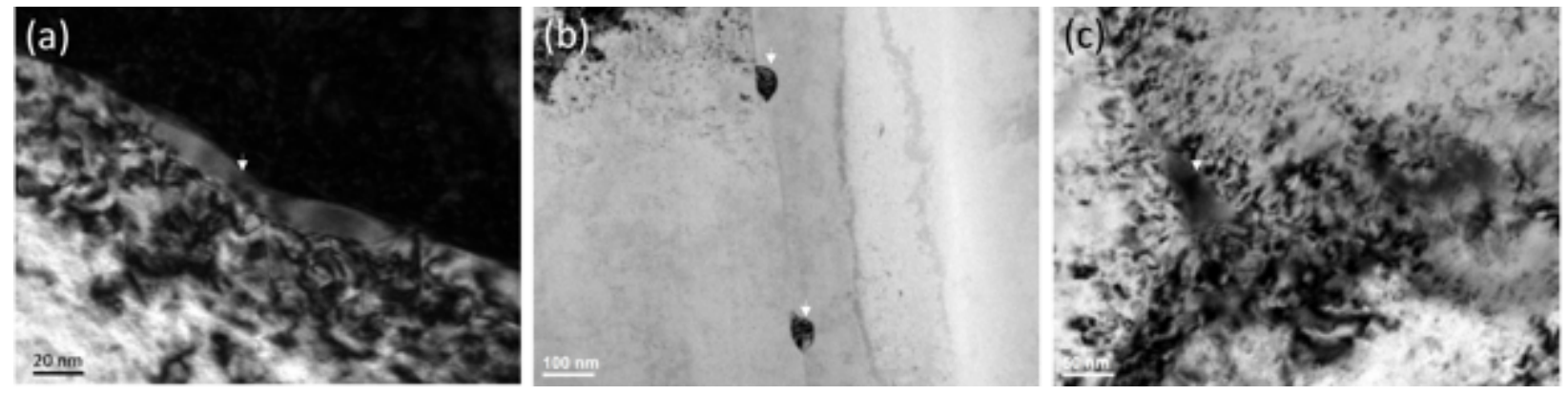

Fig. II-6. Grain boundary carbides, marked by white arrows, in (a) L3, and (b-c) L5 samples

Table II-3 summarizes the hardness and elastic modulus of the neutron-irradiated samples measured using nanoindentation, together with the statistical results of the voids and dislocation loops characterized in the four samples. The non-irradiated NF709 was reported to have a hardness $(\mathrm{H})$ of $2.94 \pm 0.14 \mathrm{GPa}$ and elastic modulus (E) of $197.8 \pm 6.6 \mathrm{GPa}(\underline{12})$. Comparing to the non-irradiated results of NF709, the radiationhardening $(\Delta \mathrm{H} / \mathrm{H})$ and changes in elastic modulus $(\Delta \mathrm{E} / \mathrm{E})$ of the irradiated samples are included in Table II-3. Fig. II-7 plots the radiation-hardening and changes in modulus as a function of irradiation dose and temperature of the four samples. It clearly shows that radiation-hardening increased with higher dose and lower temperature. However, the dose or temperature dependence of the changes in modulus is not evident. Each data point in Table II-3 and Fig. II-7 is the mean value of at least 20 tests with the uncertainty representing the standard deviation. 
Table II-3. Summary of the hardness, elastic modulus, voids and dislocation loops of all the four ATRirradiated NF709 samples.

\begin{tabular}{|c|c|c|c|c|c|}
\hline \multicolumn{2}{|c|}{ Sample ID } & L3 & L4 & L5 & L6 \\
\hline \multirow{2}{*}{ Conditions } & Temperature $\left({ }^{\circ} \mathrm{C}\right)$ & 450 & 447.5 & 469 & 429.5 \\
\hline & Dose (dpa) & 3.22 & 4.93 & 4.45 & 8 \\
\hline \multirow{4}{*}{$\begin{array}{l}\text { Mechanical } \\
\text { properties }\end{array}$} & $\mathrm{H}(\mathrm{GPa})$ & $4.3 \pm 0.5$ & $4.7 \pm 0.3$ & $4.4 \pm 0.4$ & $5.7 \pm 0.5$ \\
\hline & $\mathrm{E}(\mathrm{GPa})$ & $210 \pm 10$ & $220 \pm 10$ & $190 \pm 10$ & $180 \pm 10$ \\
\hline & $\Delta \mathrm{H} / \mathrm{H}(\%)$ & $46 \pm 6$ & $60 \pm 5$ & $50 \pm 5$ & $94 \pm 9$ \\
\hline & $\Delta \mathrm{E} / \mathrm{E}(\%)$ & $6.1 \pm 0.4$ & $11.2 \pm 0.6$ & $-(3.9 \pm 0.2)$ & $-(9.0 \pm 0.6)$ \\
\hline \multirow{3}{*}{ Voids } & Diameter (nm) & $0.9 \pm 0.2$ & $0.7 \pm 0.2$ & $1.4 \pm 0.7$ & $1.0 \pm 0.3$ \\
\hline & Density $\left(\times 10^{22} / \mathrm{m}^{3}\right)$ & $9 \pm 1$ & $14 \pm 7$ & $9 \pm 3$ & $9 \pm 3$ \\
\hline & Swelling (\%) & $0.004 \pm 0.002$ & $0.003 \pm 0.002$ & $0.02 \pm 0.01$ & $0.007 \pm 0.005$ \\
\hline \multirow{2}{*}{$\begin{array}{l}\text { Dislocation } \\
\text { Loops }\end{array}$} & Size $(\mathrm{nm})$ & $8 \pm 4$ & $9 \pm 5$ & $8 \pm 4$ & $9 \pm 5$ \\
\hline & Density $\left(\times 10^{22} / \mathrm{m}^{3}\right)$ & $9 \pm 6$ & $13 \pm 2$ & $9 \pm 6$ & $12 \pm 1$ \\
\hline
\end{tabular}



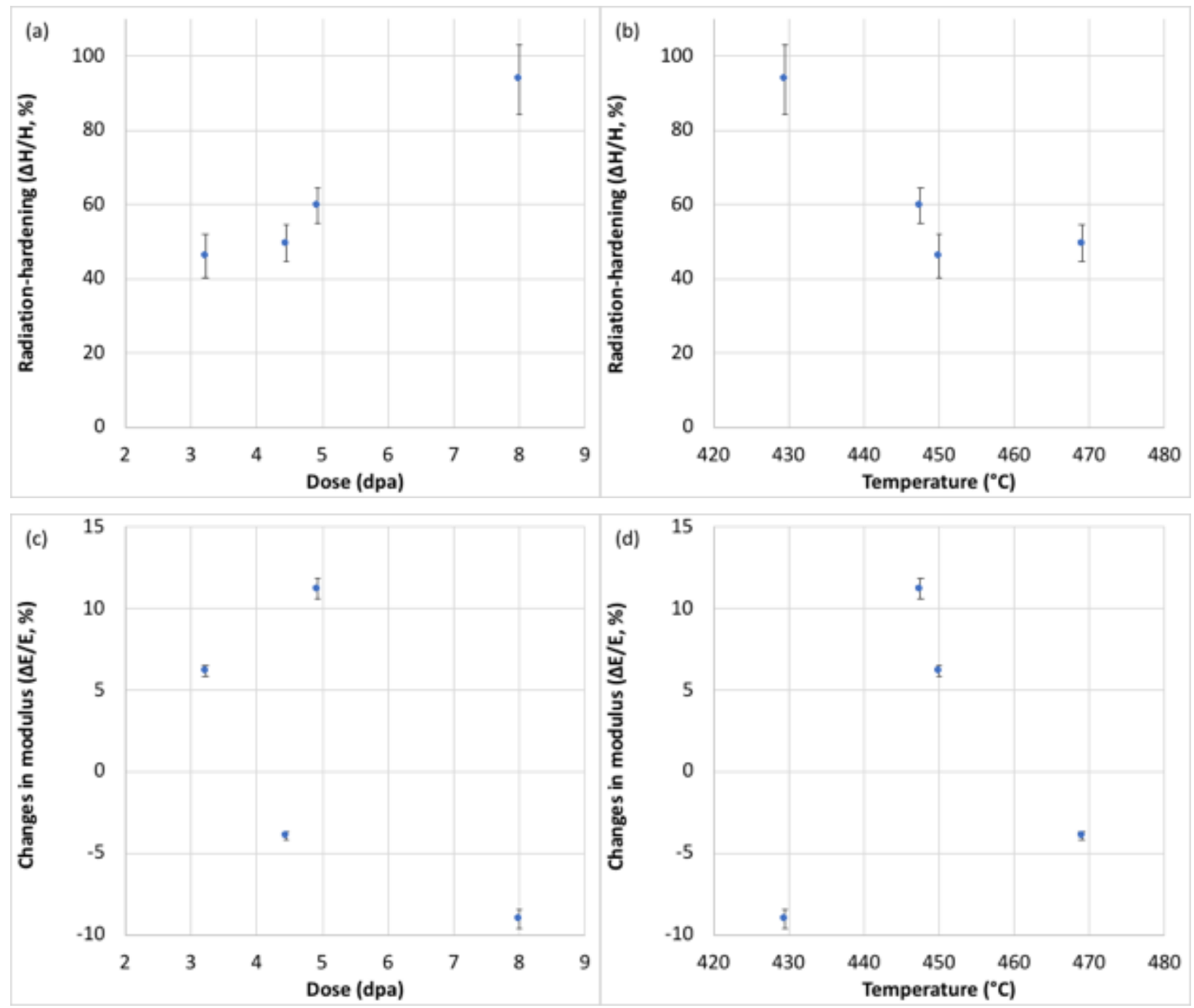

Fig. II-7. Radiation-hardening and changes in modulus as a function of irradiation dose and temperature of the four ATR-irradiation NF709 samples.

\section{ION IRRADIATION}

\section{III-I. Ion Irradiation Experiments}

All ion irradiations have been completed as listed in Table III-1-1. Irradiated samples are listed in Table III-1-2. Alloys include 709, FeCrNi (model 709), 316H, G91 and G92, and three creep-ruptured 709 samples designated as 1101, 1105, and 1106. The creep-ruptured samples can be regarded as thermally aged at conditions of 17,106 hours at $600{ }^{\circ} \mathrm{C}(1101), 12,014$ hours at $650{ }^{\circ} \mathrm{C}(1105)$, and 16,448 hours at $700{ }^{\circ} \mathrm{C}(1106)$. 
Irradiation conditions are chosen at low $\left(350^{\circ} \mathrm{C}\right)$, medium $\left(510^{\circ} \mathrm{C}\right)$, and elevated temperature $\left(670^{\circ} \mathrm{C}\right)$ to various damage levels. Most irradiations were performed with rastered ion beam to achieve large irradiation area (about $2 \mathrm{~cm}^{2}$ ). Rastering frequency is horizontally $64 \mathrm{~Hz}$ and vertically $517 \mathrm{~Hz}$. To test rastered vs. stationary beam effect, one stationary defocused beam irradiation was carried out.

Table III-1-1. Ion irradiation conditions.

\begin{tabular}{|l|l|l|l|l|l|}
\hline Ion & $\begin{array}{l}\text { Energy } \\
(\mathrm{MeV})\end{array}$ & $\begin{array}{l}\text { Damage rate } \\
(\mathrm{dpa} / \mathrm{s})\end{array}$ & $\begin{array}{l}\text { Temperature } \\
\left({ }^{\circ} \mathrm{C}\right)\end{array}$ & $\begin{array}{l}\mathrm{Dpa}^{*} \\
\text { rastering }\end{array}$ \\
\hline Proton & 2 & $(2.1-4.2) \times 10^{-6}$ & 510 & $0.01,0.1,1$ & Yes \\
\hline Proton & 2 & $(4.4-5) \times 10^{-6}$ & 670 & $0.01,0.1,0.5,1,1.5$ & Yes \\
\hline $\mathrm{Fe}^{2+}$ & 3.7 & $(2.5-4) \times 10^{-3}$ & 350 & $2.5,15,50$ & Yes \\
\hline $\mathrm{Fe}^{2+}$ & 3.7 & $(2-4) \times 10^{-3}$ & 670 & $2.5,15,50$ & Yes \\
\hline $\mathrm{Fe}^{2+}$ & 3.5 & $8.6 \times 10^{-4}$ & 600 & 75 & No \\
\hline
\end{tabular}

* Dpa values are at $10 \mu \mathrm{m}$ depth for proton irradiation, and $0.46 \mu \mathrm{m}$ for iron irradiation

Table III-1-2. Irradiation sample list.

\begin{tabular}{|c|c|c|c|}
\hline Ion & $\begin{array}{c}\text { Temperature } \\
\left({ }^{\circ} \mathrm{C}\right)\end{array}$ & Dpa & Samples \\
\hline Proton & 670 & 1 & 316H-1, 709-1, FeCrNi-2, G91-1, G92-1 \\
\hline Proton & 670 & 1.5 & 316H-2, 709-2, FeCrNi-1, G91-2, G92-2 \\
\hline Proton & 670 & 0.5 & 316H-3, 709-3, FeCrNi-3, G91-3, G92-3 \\
\hline $\mathrm{Fe}^{2+}$ & 350 & 50 & 316H-4, 709-4, FeCrNi-4, G91-4, G92-4 \\
\hline Proton & 510 & 0.1 & 316H-P1, 709-7, FeCrNi-5, G91-5, G92-5 \\
\hline Proton & 380 & 0.01 & 316H-P2, 709-9, FeCrNi-6, G91-7, G92-6 \\
\hline Proton & 670 & 0.1 & 316H-P3, 709-10, FeCrNi-7, G91-8, G92-7 \\
\hline Proton & 670 & 0.01 & 316H-P4, 709-12, FeCrNi-9, G91-9, G92-9 \\
\hline $\mathrm{Fe}^{2+}$ & 670 & 50 & 316H-P5, 709-6, FeCrNi-8, G91-10, G92-8, 1101-1, 1105-1, 1106-1 \\
\hline $\mathrm{Fe}^{2+}$ & 350 & 15 & 316H-10, 709-5, FeCrNi-10, G91-11, G92-11, 1101-2, 1105-2, 1106-2 \\
\hline $\mathrm{Fe}^{2+}$ & 350 & 2.5 & 316H-11, 709-8, FeCrNi-11, G91-12, G92-12, 1101-3, 1105-3, 1106-3 \\
\hline Proton & 510 & 1 & 316H-12, 709-11, FeCrNi-12, G91-6, G92-10, 1101-4, 1105-4, 1106-4 \\
\hline Proton & 510 & 0.01 & 316H-13, 709-14, FeCrNi-13, G91-13, G92-13, 1101-5, 1105-5, 1106-5 \\
\hline $\mathrm{Fe}^{2+}$ & 670 & 15 & 316H-14, 709-15, FeCrNi-14, G91-14, G92-14, 1101-6, 1105-6, 1106-6 \\
\hline
\end{tabular}




\begin{tabular}{|c|c|c|c|}
\hline $\mathrm{Fe}^{2+}$ & 670 & 2.5 & $316 \mathrm{H}-15,709-16$, FeCrNi-15, G91-15, G92-15, 1101-7, 1105-7, 1106-7 \\
\hline $\mathrm{Fe}^{2+}$ & 600 & 75 & $316 \mathrm{H}-16,709-17$ \\
\hline
\end{tabular}

\section{Sample preparation}

\section{a. Polishing}

The polishing procedure can be broken into three main sections: grinding, polishing, and chemical cleaning. For the grinding procedure, SiC paper from Allied of 400, 600, 800, 1200 grit are used. When manually polishing, the sample is rotated 90 degrees between each grit paper and polished until all previous scratches are removed. Following the grinding stage, the samples are polished using a diamond suspension. A PLANB Rigid Back Magnetic System Disc, Diamat Rigid Magnetic Disc, Final-POL Magnetic Disc, and FinalA cloth from Allied with 9, 3, and $1 \mu \mathrm{m}, 0.5 \mu \mathrm{m}, 0.25 \mu \mathrm{m}, 0.1 \mu \mathrm{m}, 0.05 \mu \mathrm{m}$ diamond polish are used. After the samples are hand polished, they are cleaned in an ultrasonic using the following procedure: 5 min in an acetone bath, $5 \mathrm{~min}$ in a detergent bath (Micro-90 detergent), and $5 \mathrm{~min}$ in an ethanol bath.

\section{b. Roughness Measurements}

A Zygo New View white light interferometer (referred to as Zygo) is being used to investigate the surface roughness of samples after polishing. Roughness $\leq 20 \mathrm{~nm}$ defines that sample was properly polished. When comparing the samples, all the Zygo measurements are taken under the same parameters to maintain consistency, as outlined in Table III-1-3 For each alloy five measurements are taken at various locations in the center of one sample, and then the average is recorded.

Table III-1-3. Zygo Parameters

\begin{tabular}{|l|l|}
\hline Parameter & Settings \\
\hline Objective & $20 \mathrm{x}$ \\
\hline Zoom & $0.5 \mathrm{x}$ \\
\hline Min-Mod & $5 \%$ \\
\hline Scan Length & $150 \mu \mathrm{m}$ bipolar $(12 \mathrm{~s})$ \\
\hline Camera Mode & $640 \times 480200 \mathrm{~Hz}$ \\
\hline Surface Correction (Remove) & Cylinder or Sphere \\
\hline
\end{tabular}




\section{Irradiation details}

Ion irradiation has been conducted at the University of Wisconsin-Madison's Ion Beam Laboratory with a NEC 1.7MV Tandem accelerator.

\section{III-1-1. $2 \mathrm{MeV}$ proton irradiation to $1 \mathrm{dpa}$ at $670^{\circ} \mathrm{C}$}

10 samples, two from each of five alloys 709, FeCrNi (model 709), 316H, G91 and G92, have been irradiated by $2 \mathrm{MeV}$ protons. The samples were attached to a stainless-steel sample holder using watersoluble carbon paste. The incident ion beam, normal to the sample face, was rastered across a well-defined aperture exposing the samples uniformly to the $\mathrm{H}$ ions. The beam current ranged between 22-24 $\mu \mathrm{A}$ (see Fig. III-1-1) resulting in a proton flux of about $7.7 \mathrm{e} 13 \mathrm{p} /\left(\mathrm{cm}^{2}-\mathrm{s}\right)$ and dpa rate $5 \mathrm{e}-6 \mathrm{dpa} / \mathrm{s}$. The sample temperature of $670^{\circ} \mathrm{C} \pm 20^{\circ} \mathrm{C}$ was maintained through a combination of beam and external heating recorded on the right and left sides of the sample holder using two type-K thermocouples (see Fig. III-1-1). The irradiation chamber pressure was at or below $1 \times 10^{-6}$ Torr before and during the irradiation. The implantation with $2.0 \mathrm{MeV}$ protons was done up to a fluence of $1.5 \times 10^{19} \mathrm{ion} / \mathrm{cm}^{2}$, which correspond to damage levels of $1 \mathrm{dpa}$ at the depth of $10 \mu \mathrm{m}$ (Fig. III-1-2). Sample layout in the sample holder and surface appearance before and after irradiation are shown in Fig. 1-3 and 1-4.

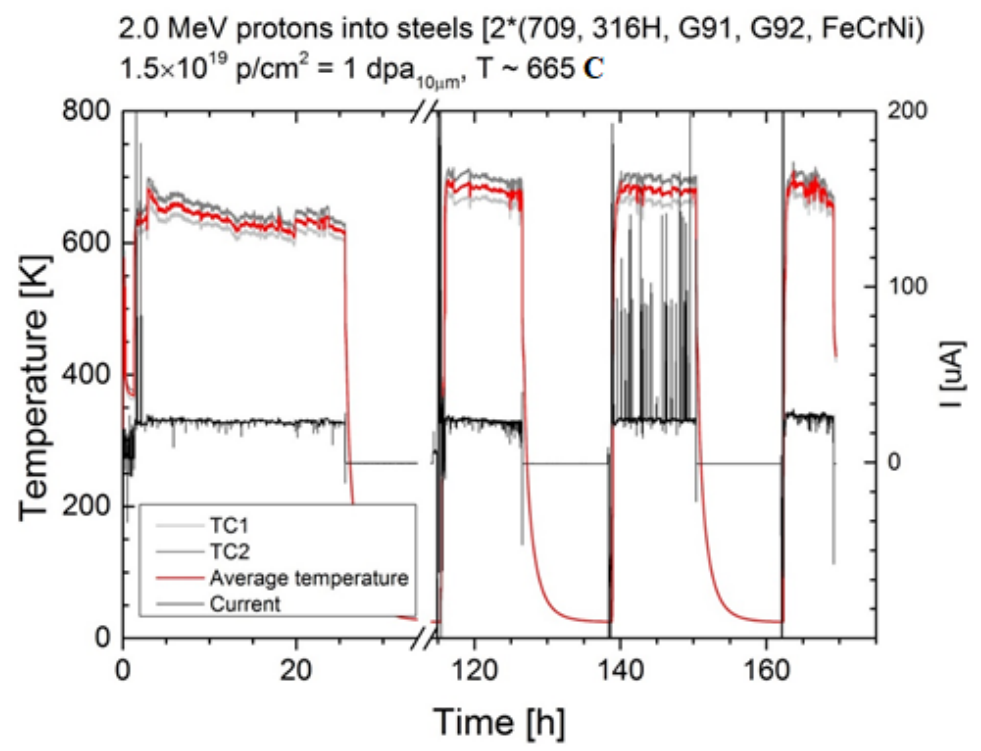

Fig. III-1-1. Temperature and current profile for $2 \mathrm{MeV}$ proton irradiation up to $1.5 \mathrm{e} 19 \mathrm{p} / \mathrm{cm}^{2}$ at $670{ }^{\circ} \mathrm{C}$. 


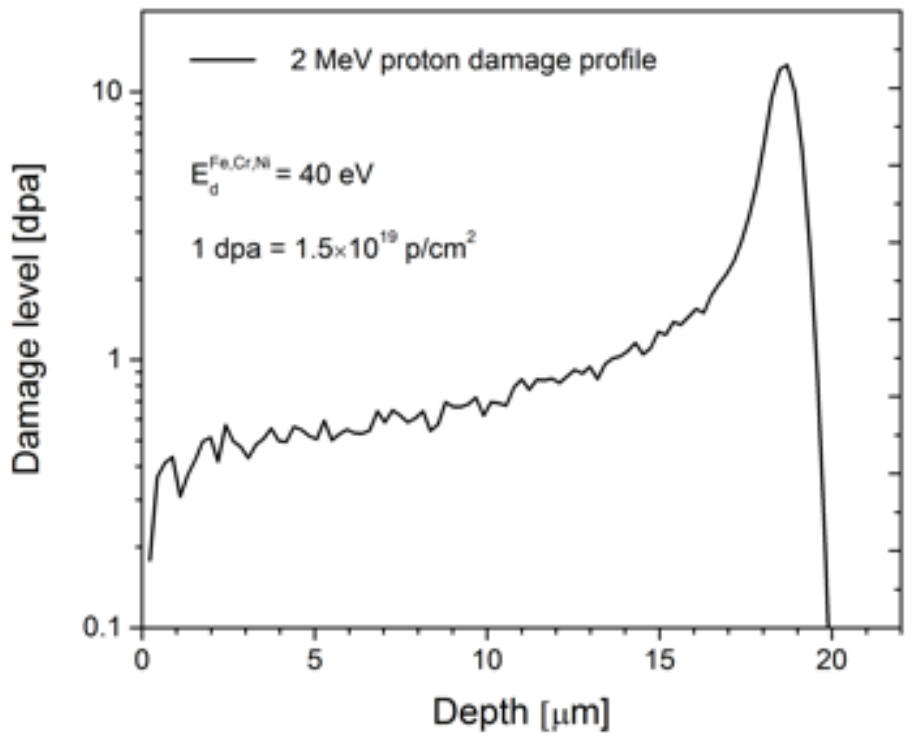

Fig. III-1-2. Damage profiles in the Fe-20Cr-25Ni alloy (model Alloy 709), density $8 \mathrm{~g} / \mathrm{cm}^{3}$, irradiated with $2 \mathrm{MeV}$ protons to damage level of 0.5 (at $10 \mu \mathrm{m}$ ). Calculations were performed using SRIM-2012.03 with the Kinchin-Pease option and assuming the displacement threshold energies to be $40 \mathrm{eV}$ for $\mathrm{Fe}, \mathrm{Cr}$ and $\mathrm{Ni}$.

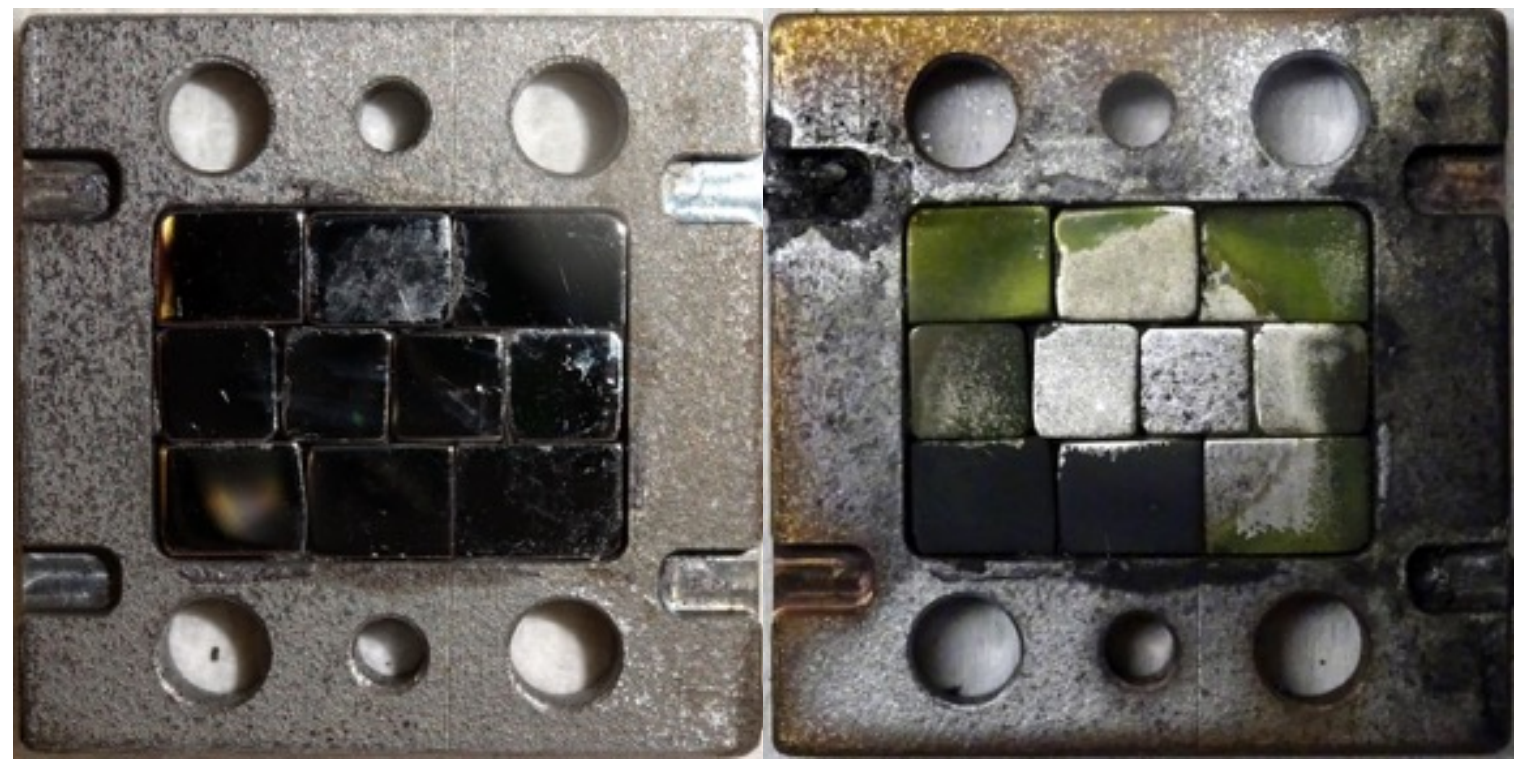

Fig. III-1-3. Steel samples before and after $2 \mathrm{MeV}$ proton irradiation up to $1.5 \mathrm{e} 19 \mathrm{p} / \mathrm{cm} 2$ at $670{ }^{\circ} \mathrm{C}$. 


\begin{tabular}{|c|c|c|c|}
\hline $\begin{array}{c}92 \\
5 * 4 * 1\end{array}$ & \multicolumn{2}{|c|}{$\begin{array}{c}92 \\
5 * 4 * 1\end{array}$} & $\begin{array}{c}91 \\
6 * 4 * 1\end{array}$ \\
\hline $\begin{array}{c}709 \\
4 * 4 * 1\end{array}$ & $\begin{array}{c}709 \\
4 * 4 * 1\end{array}$ & $\begin{array}{c}316 \mathrm{H} \\
4 * 4 * 1\end{array}$ & $\begin{array}{l}316 \mathrm{H} \\
4 * 4 * 1\end{array}$ \\
\hline $\begin{array}{l}709 \mathrm{~m} \\
5 * 4 * 1\end{array}$ & & & $\begin{array}{c}91 \\
6 * 4 * 1\end{array}$ \\
\hline
\end{tabular}

Fig. III-1-4. Sample layout (and sample size) for $2 \mathrm{MeV}$ proton irradiation up to $1.5 \mathrm{e} 19 \mathrm{p} / \mathrm{cm} 2$ at $670{ }^{\circ} \mathrm{C}$.

\section{III-1-2. $2 \mathrm{MeV}$ proton irradiation to $0.5 \mathrm{dpa}$ and $1.5 \mathrm{dpa}$ at $670^{\circ} \mathrm{C}$}

10 samples, two from each of five alloys 709, FeCrNi (model 709), 316H, G91 and G92, have been irradiated by $2 \mathrm{MeV}$ protons. Half of the samples were already pre-irradiated up to a damage level of $1 \mathrm{dpa}$. The average beam current was $21 \mu \mathrm{A}$ (see Fig. III-1-5) resulting in a proton flux of about $6.6 \mathrm{e} 13 \mathrm{p} /\left(\mathrm{cm}^{2} \mathrm{~s}\right)$ and dpa rate $4.4 \mathrm{e}-6 \mathrm{dpa} / \mathrm{s}$. The sample temperature was $680^{\circ} \mathrm{C} \pm 20^{\circ} \mathrm{C}$. The irradiation chamber pressure was at or below $5 \times 10^{-5}$ Torr before and during the irradiation. The implantation with $2.0 \mathrm{MeV}$ protons was done up to a fluence of $7.5 \times 10^{18}$, which correspond to damage levels of $0.5 \mathrm{dpa}$ at the depth of $10 \mu \mathrm{m}$. Sample layout in the sample holder and surface appearance before and after irradiation are shown in Fig. 1-6 and 1-7. The surfaces of two samples, namely FeCrNi-3 and 709-3, became discolored which is a sign of oxidation.

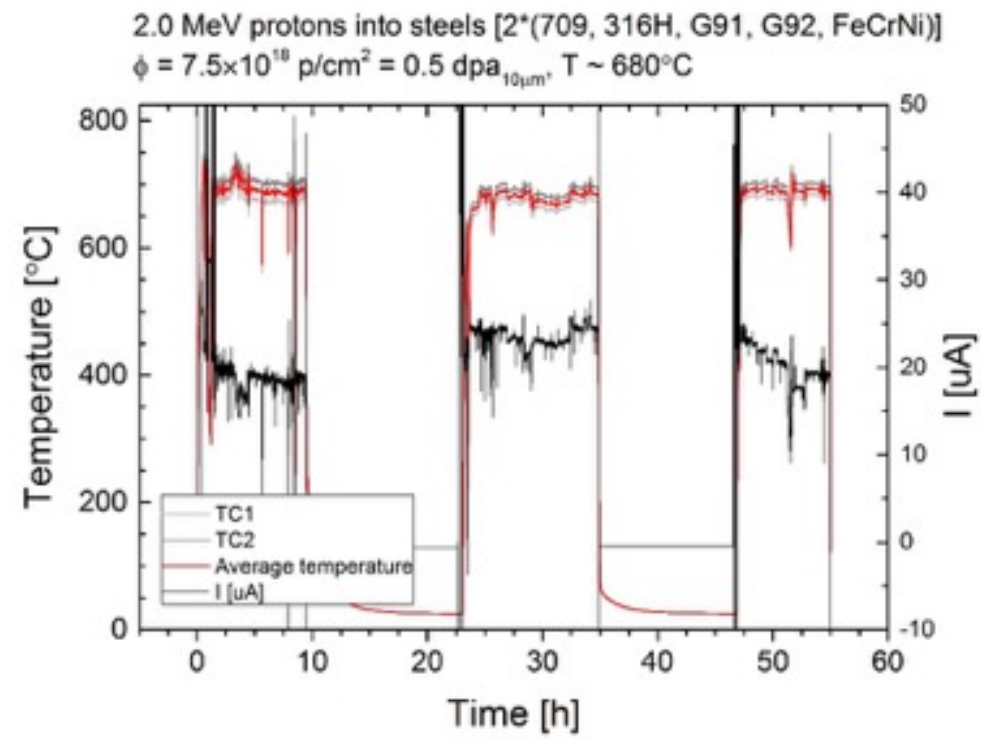

Fig. III-1-5. Temperature and current profile for $2 \mathrm{MeV}$ proton irradiation up to $7.5 \mathrm{e} 18 \mathrm{p} / \mathrm{cm}^{2}$ at $680{ }^{\circ} \mathrm{C}$. 

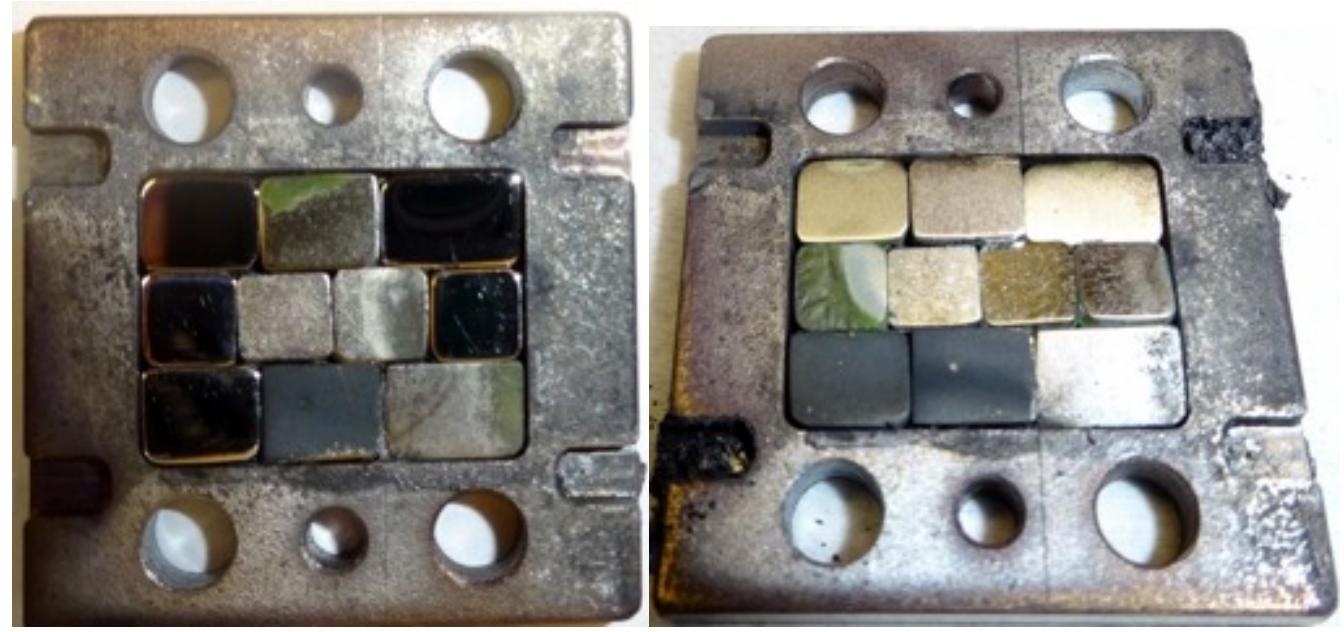

Fig. III-1-6 Steel samples before and after $2 \mathrm{MeV}$ proton irradiation up to $7.5 \mathrm{e} 18 \mathrm{p} / \mathrm{cm}^{2}$ at $680{ }^{\circ} \mathrm{C}$

\begin{tabular}{|c|c|c|c|}
\hline $92-3$ & \multicolumn{2}{|c|}{$92-2$} & \multicolumn{2}{c|}{$91-3$} \\
$5 * 4 * 1$ & \multicolumn{2}{|c|}{$5^{*} 4 * 1$} & \multicolumn{2}{|c|}{$6^{*} 4 * 1$} \\
\hline $709-3$ & $709-2$ & $316 \mathrm{H}-2$ & $316 \mathrm{H}-3$ \\
$4 * 4 * 1$ & $4 * 4 * 1$ & $4 * 4 * 1$ & $4 * 4 * 1$ \\
\hline $709 \mathrm{~m}-3$ & $709 \mathrm{~m}-1$ & & $91-2$ \\
$5 * 4 * 1$ & $5 * 4 * 1$ & & $6 * 4 * 1$ \\
\hline
\end{tabular}

Fig. III-1-7 Sample layout for $2 \mathrm{MeV}$ proton irradiation up to $7.5 \mathrm{e} 18 \mathrm{p} / \mathrm{cm}^{2}$ at $680{ }^{\circ} \mathrm{C}$.

\section{$\underline{\text { III-1-3. 3.7 } \mathrm{MeV} \text { iron irradiation to } 50 \mathrm{dpa} \text { at } 350{ }^{\circ} \mathrm{C}}$}

5 samples, one from each of five alloys 709, FeCrNi (model 709), 316H, G91 and G92, have been irradiated by $3.7 \mathrm{MeV} \mathrm{Fe}^{2+}$. The average beam current was $1.3 \mu \mathrm{A}$ (see Fig. III-1-8) resulting in a Fe flux of about $4 \mathrm{e} 12 \mathrm{Fe} /\left(\mathrm{cm}^{2} \mathrm{~s}\right)$ and dpa rate $2 \mathrm{e}-3 \mathrm{dpa} / \mathrm{s}$ at $0.46 \mu \mathrm{m}$ depth. The sample temperature of $350^{\circ} \mathrm{C} \pm 20^{\circ} \mathrm{C}$. The irradiation chamber pressure was at or below $8 \times 10^{-6}$ Torr before and during the irradiation. The implantation 
with $3.7 \mathrm{MeV}$ iron was done up to a fluence of $1 \times 10^{17}$, which correspond to damage levels of 100 dpa at peak damage, $50 \mathrm{dpa}$ at $0.46 \mu \mathrm{m}$ depth, as calculated by SRIM (Kinchin-Pease option) assuming the displacement energy of $40 \mathrm{eV}$. Sample layout in the sample holder and surface appearance before and after irradiation are shown in Fig. III-1-9. The surfaces of samples 316-4 and G92-4 have blackened during Feirradiation.

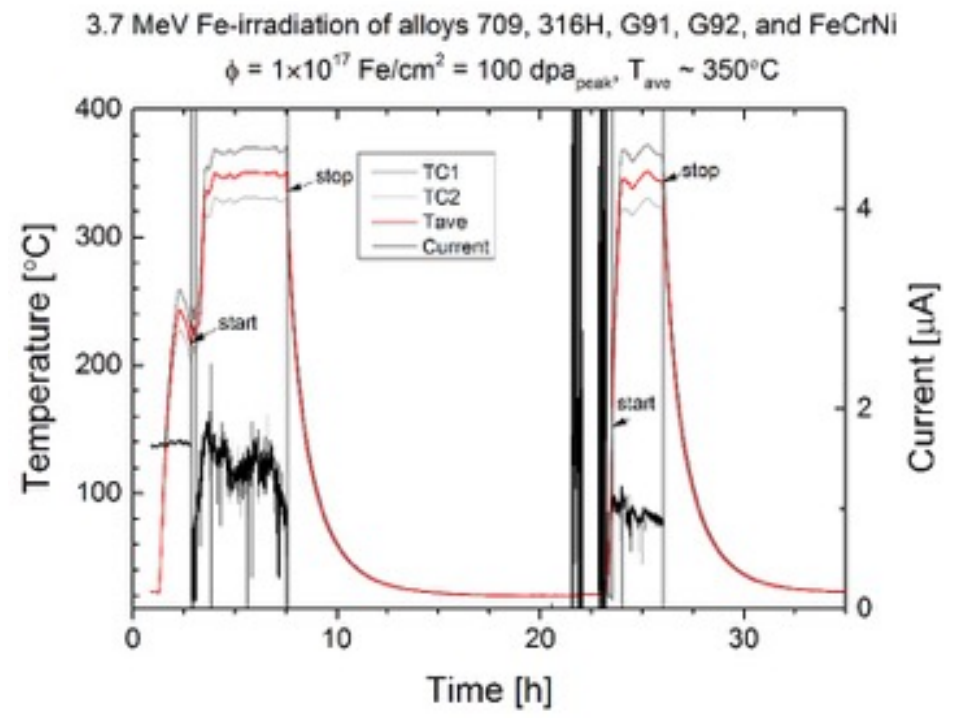

Fig. III-1-8 Temperature and current profile for $3.7 \mathrm{MeV}$ Fe-irradiation up to $1 \mathrm{e} 17 \mathrm{Fe} / \mathrm{cm}^{2}$ at $350{ }^{\circ} \mathrm{C}$.

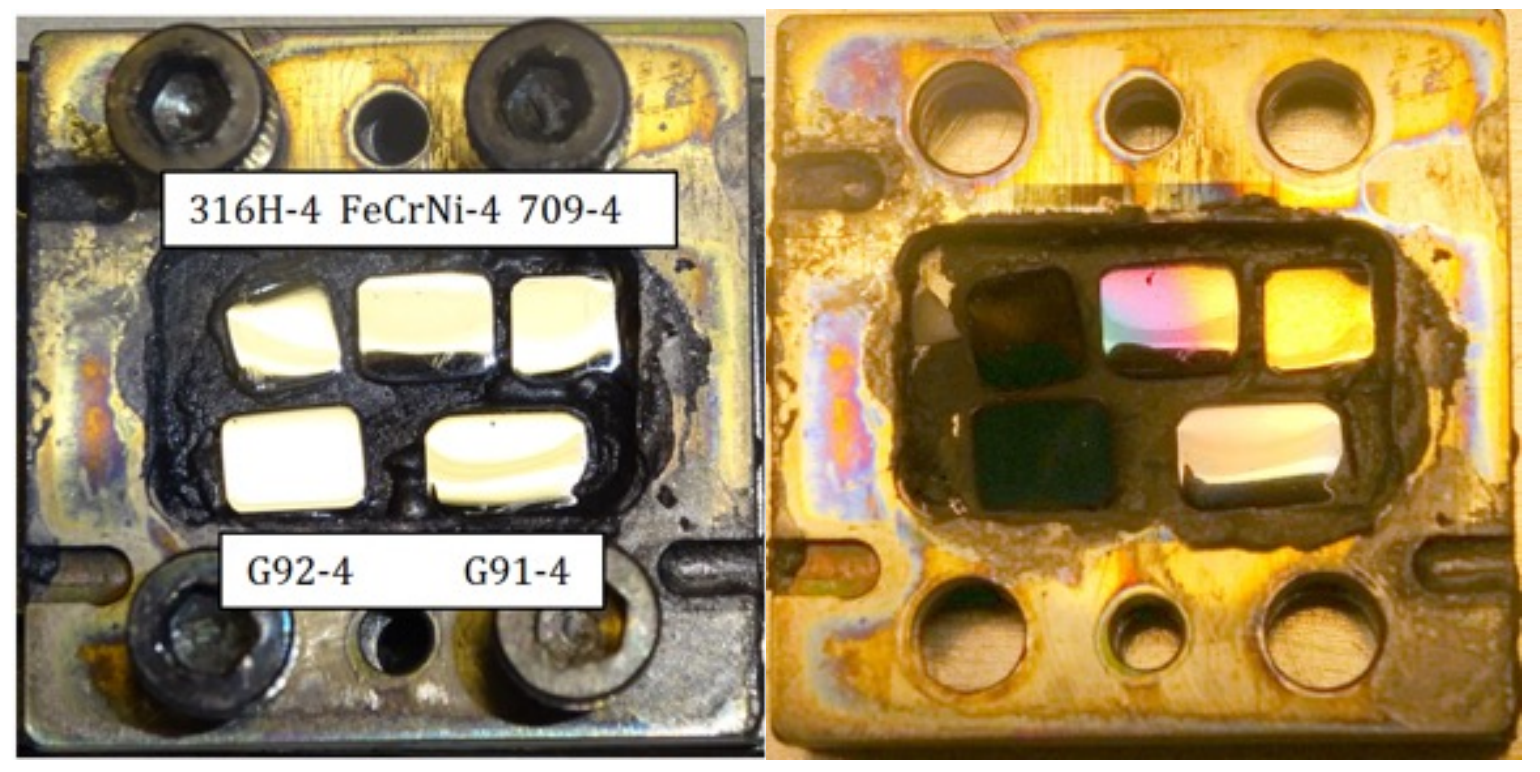

Fig. III-1-9 Steel samples before and after 3.7 MeV Fe-irradiation up to $1 \mathrm{e} 17 \mathrm{Fe} / \mathrm{cm}^{2}$ at $350^{\circ} \mathrm{C}$. 


\section{III-1-4. $2 \mathrm{MeV}$ proton irradiation to $0.01 \mathrm{dpa}$ at $380^{\circ} \mathrm{C}$ and $0.1 \mathrm{dpa}$ at $510{ }^{\circ} \mathrm{C}$}

Proton irradiation conditions for alloys 709, FeCrNi, 316H, G91 and G92 were:

Energy and Irradiating Ion Species: $2.0 \mathrm{MeV} \mathrm{H}^{+}$irradiation

Damage Level: Nominal $0.01 \mathrm{dpa}$ and $0.1 \mathrm{dpa}$ (at $10 \mu \mathrm{m}$ depth, as shown in Fig. III-1-10(a), (b), respectively).

Irradiation Temperature: $383 \pm 90{ }^{\circ} \mathrm{C}$ (the high variation is due to heating method change, from ion beam heating to combination of ion beam heating and external heating) for $0.01 \mathrm{dpa}$, as shown in Fig. III-1-11(a), and $512 \pm 19^{\circ} \mathrm{C}$ for 0.1 dpa as shown in Fig. III-1-11(b).

Irradiation Flux: $(5.9 \pm 0.9) \times 10^{13} \mathrm{ion} / \mathrm{cm}^{2} / \mathrm{s}(0.01 \mathrm{dpa})$ and $(5.9 \pm 0.4) \times 10^{13} \mathrm{ion} / \mathrm{cm}^{2} / \mathrm{s}(0.1 \mathrm{dpa})$. Vacuum/Base Pressure: $4.4 \times 10^{-7}$ Torr (base vacuum), $8 \times 10^{-6}-3.2 \times 10^{-6}$ Torr (irradiation vacuum during $0.01 \mathrm{dpa}$ irradiation), $3.6 \times 10^{-6}-7.6 \times 10^{-7}$ Torr ( $0.1 \mathrm{dpa}$ irradiation vacuum)

Damage rate: $4.05 \times 10^{-6} \mathrm{dpa} / \mathrm{s}(0.01 \mathrm{dpa}, 10 \mu \mathrm{m}$ depth $), 4.17 \times 10^{-6} \mathrm{dpa} / \mathrm{s}(0.1 \mathrm{dpa}, 10 \mu \mathrm{m}$ depth $)$

Fig. III-1-10 shows the damage profiles of $2.0 \mathrm{MeV}$ proton irradiation in Fe-20Cr-25Ni (model 709 alloy) calculated with the Kinchin-Pease Model in the Stopping and Range of Ions in Matter (SRIM) software. To achieve damage levels of $0.01 \mathrm{dpa}$ and $0.1 \mathrm{dpa}$ at $10 \mu \mathrm{m}$ depth where the damage profile is flat (damage vs. depth slope is small) fluences of $1.5 \times 10^{17} \mathrm{Fe}^{2+} / \mathrm{cm}^{2}$ and $1.5 \times 10^{18} \mathrm{Fe}^{2+} / \mathrm{cm}^{2}$ were used, respectively.

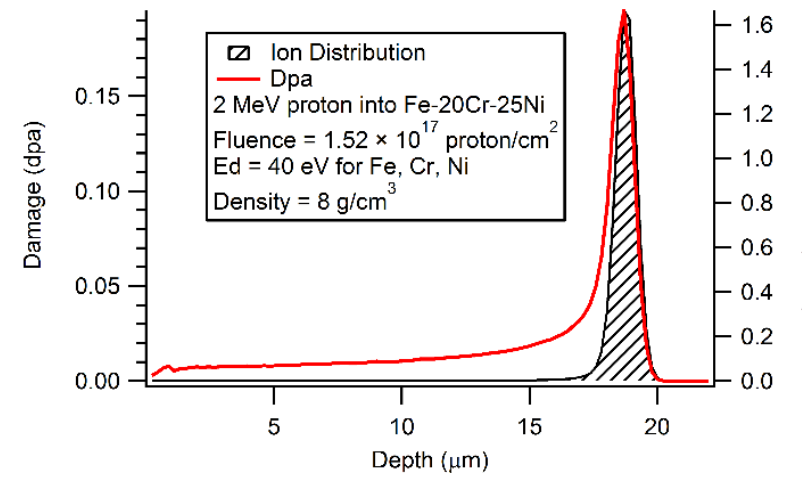

(a)

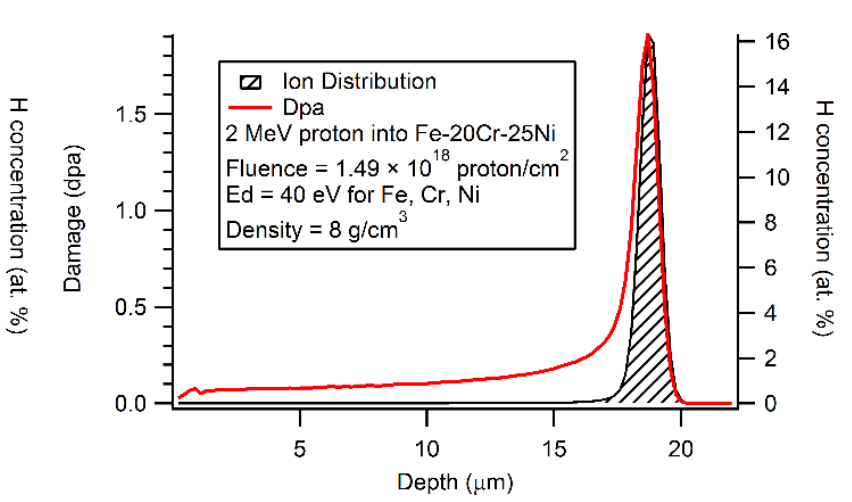

(b)

Fig. III-1-10. $2 \mathrm{MeV}$ proton induced damage in Fe-20Cr-25Ni, one of the five alloys being ion irradiated. Damage and proton implantation profile for: (a) 0.01 dpa irradiation. (b) 0.1 dpa irradiation. The damage levels were designed to occur at $10 \mu \mathrm{m}$ depth for both cases. $E_{d}$ is atom displacement energy.

Irradiation temperature and flux are shown in Fig. III-1-11. Temperature values represent an average value from two thermocouple readings from opposite corners of the sample stage. Flux was calculated using ion 
beam current and beam scanning area $\left(2 \mathrm{~cm}^{2}\right)$. We aimed at $520^{\circ} \mathrm{C}$ at both 0.01 dpa and 0.1 dpa irradiations. For $0.1 \mathrm{dpa}$ irradiation temperature rise was solely from ion beam induced heating. However, ion beam only induced heating up to about $400{ }^{\circ} \mathrm{C}$ during 0.01 dpa irradiation. External heating was later applied during $0.01 \mathrm{dpa}$ run. Overall the temperature is $383 \pm 90{ }^{\circ} \mathrm{C}$ and flux is $(5.9 \pm 0.9) \times 10^{13} \mathrm{ion} / \mathrm{cm}^{2} / \mathrm{s}$ at 0.01 dpa irradiation as shown in Fig. III-1-11(a). For 0.1 dpa irradiation, Fig. 1-11(b) shows that temperature is $512 \pm 19^{\circ} \mathrm{C}$ and flux is $(5.9 \pm 0.4) \times 10^{13} \mathrm{ion} / \mathrm{cm}^{2} / \mathrm{s}$.

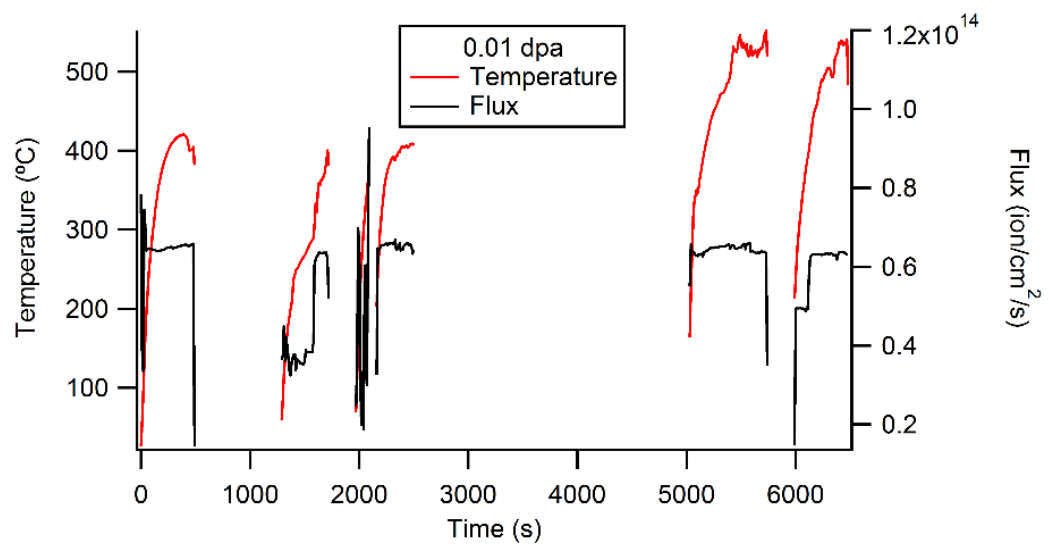

(a)

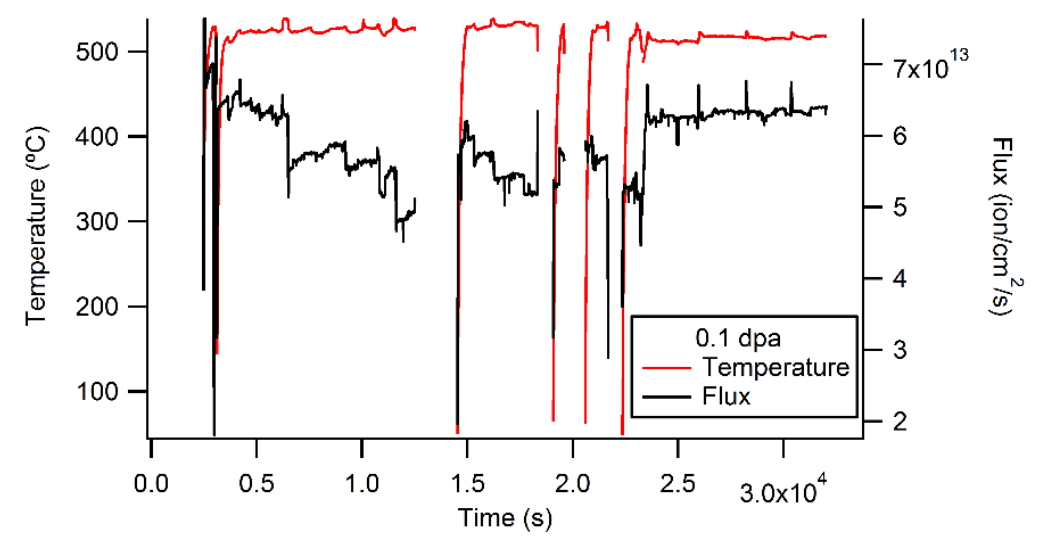

(b)

Fig. III-1-11. Temperature and flux during $2 \mathrm{MeV}$ proton irradiations: (a) 0.01 dpa irradiation. (b) 0.1 dpa.

Fig. III-1-12 shows the photographs of the samples after 0.01 dpa irradiation at $380{ }^{\circ} \mathrm{C}$ (Fig. III-1-12a) and after 0.1 dpa at $510^{\circ} \mathrm{C}$ (Fig. III-1-12b). Samples are labeled as "alloy label - number". A part of each sample was masked from irradiation. Part of FeCrNi-5 after 0.1 dpa $510{ }^{\circ} \mathrm{C}$ irradiation developed a yellow tint, indicating oxidation. All other irradiated samples were reflective, which provides a qualitative indication that oxide layer formed during irradiation is thin. 


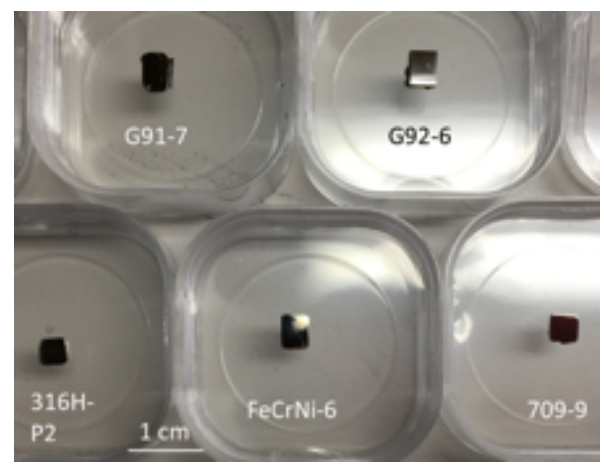

(a)

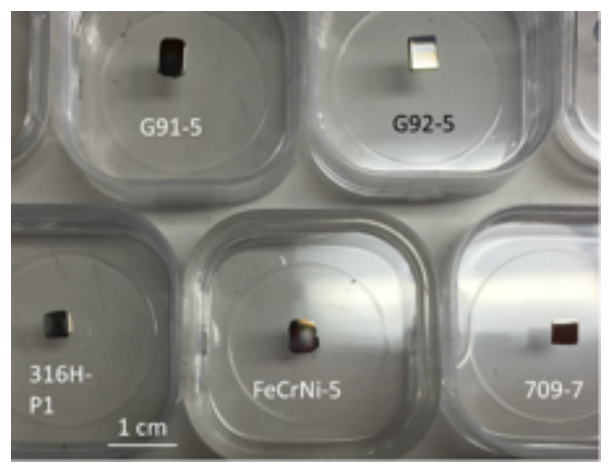

(b)

Fig. III-1-12. Photographs of samples after proton irradiations: (a) $0.01 \mathrm{dpa} 380{ }^{\circ} \mathrm{C}$. (b) $0.1 \mathrm{dpa} 510{ }^{\circ} \mathrm{C}$.

\section{$\underline{\text { III-1-5. } 2 \mathrm{MeV} \text { proton irradiation to } 0.01 \mathrm{dpa} \text { and } 0.1 \mathrm{dpa} \text { at } 670{ }^{\circ} \mathrm{C}}$}

The irradiation conditions for alloys 709, FeCrNi, 316H, G91 and G92 were:

Energy and Irradiating Ion Species: $2.0 \mathrm{MeV} \mathrm{H}^{+}$irradiation

Damage Level: Nominal $0.01 \mathrm{dpa}$ and $0.1 \mathrm{dpa}$ (at $10 \mu \mathrm{m}$ depth, as shown in Fig. III-1-13(a), (b), respectively).

Irradiation Temperature: $675 \pm 5^{\circ} \mathrm{C}$ (steady state) for $0.01 \mathrm{dpa}$, as shown in Fig. III-1-14(a), and $674 \pm 7{ }^{\circ} \mathrm{C}$ for $0.1 \mathrm{dpa}$ as shown in Fig. III-1-14(b).

Irradiation Flux: $(5.8 \pm 1.0) \times 10^{13} \mathrm{ion} / \mathrm{cm}^{2} / \mathrm{s}(0.01 \mathrm{dpa})$ and $(6.4 \pm 0.2) \times 10^{13} \mathrm{ion} / \mathrm{cm}^{2} / \mathrm{s}(0.1 \mathrm{dpa})$. Vacuum/Base Pressure: $<7 \times 10^{-7}$ Torr (base vacuum), $3.4 \times 10^{-6}-2.3 \times 10^{-6}$ Torr (irradiation vacuum during $0.01 \mathrm{dpa}$ irradiation), $5.6 \times 10^{-6}-6.4 \times 10^{-7}$ Torr $(0.1 \mathrm{dpa}$ irradiation vacuum)

Damage rate: $4.10 \times 10^{-6} \mathrm{dpa} / \mathrm{s}(0.01 \mathrm{dpa}, 10 \mu \mathrm{m}$ depth $), 4.46 \times 10^{-6} \mathrm{dpa} / \mathrm{s}(0.1 \mathrm{dpa}, 10 \mu \mathrm{m} \mathrm{depth})$

To achieve damage levels of $0.01 \mathrm{dpa}$ and $0.1 \mathrm{dpa}$ at $10 \mu \mathrm{m}$ depth, fluences of $1.5 \times 10^{17} \mathrm{Fe}^{2+} / \mathrm{cm}^{2}$ and $1.5 \times 10^{18} \mathrm{Fe}^{2+} / \mathrm{cm}^{2}$, respectively, were used. 


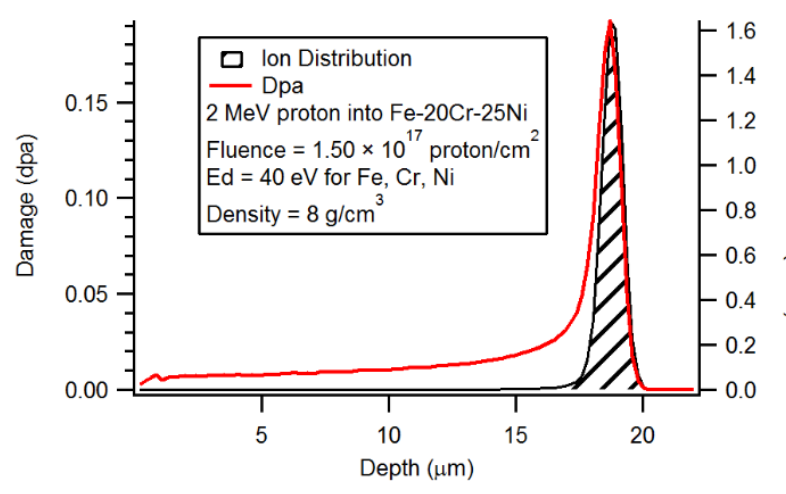

(a)

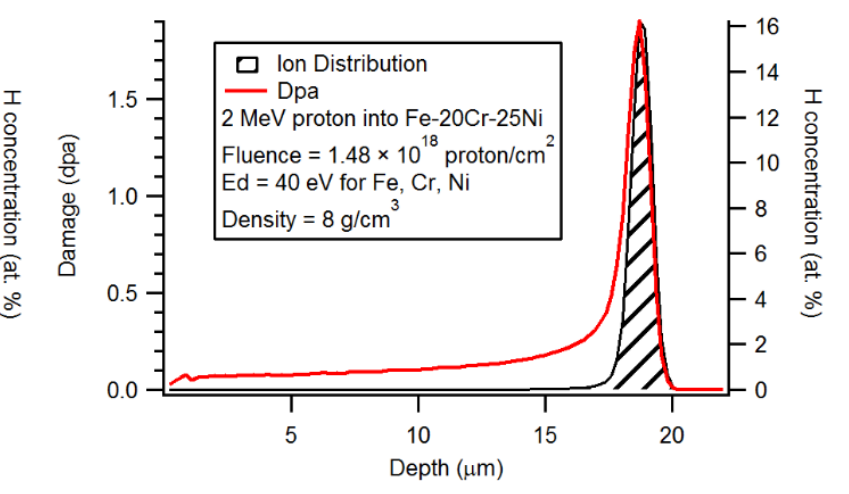

(b)

Fig. III-1-13 $2 \mathrm{MeV}$ proton induced damage in Fe-20Cr-25Ni, one of the five alloys being ion irradiated. Damage and proton implantation profile for: (a) 0.01 dpa irradiation. (b) 0.1 dpa irradiation. The damage levels were designed to occur at $10 \mu \mathrm{m}$ depth for both cases. $E_{d}$ is atom displacement energy.

Irradiation temperature and flux are shown in Fig. III-1-14. Flux was calculated using ion beam current and beam scanning area $\left(2 \mathrm{~cm}^{2}\right)$.

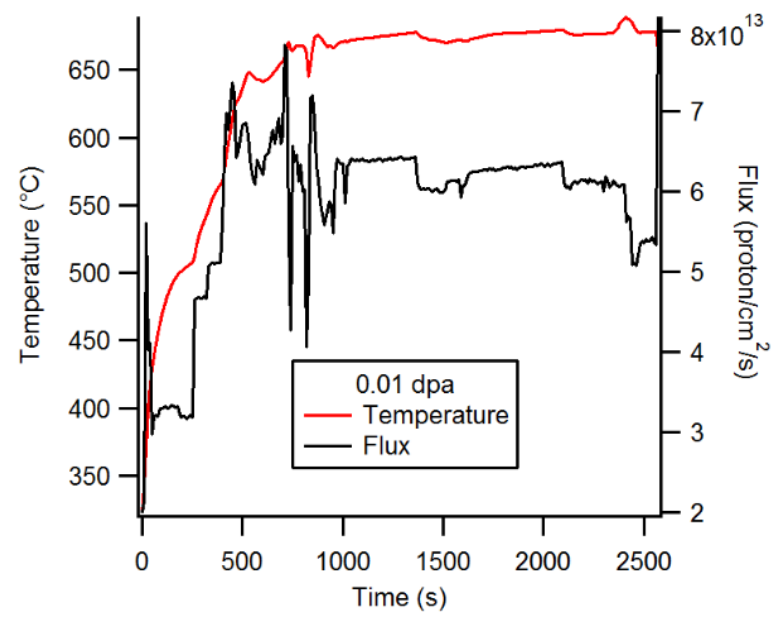

(a)

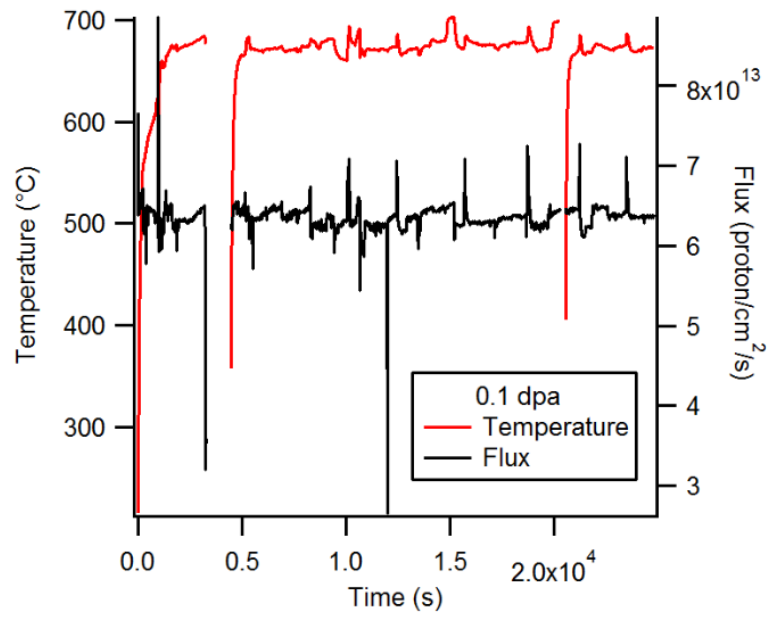

(b)

Fig. III-1-14. Temperature and flux during $2 \mathrm{MeV}$ proton irradiations: (a) 0.01 dpa irradiation. (b) 0.1 dpa.

Fig. III-1-15 shows photographs of the samples before irradiation (Fig. III-1-15a), and after 0.01 dpa (Fig. III-1-15b) and 0.1 dpa (Fig. III-1-15c) at $675^{\circ} \mathrm{C}$. A part of each sample was masked from irradiation. An illustration of rectangular masks is shown in Fig. III-1-15b. 


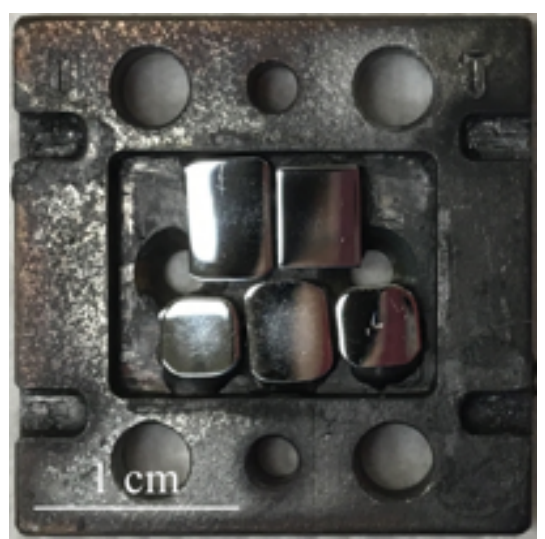

(a)

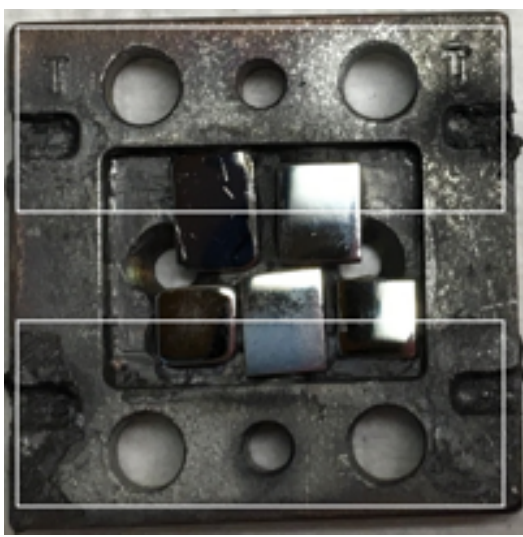

(b)

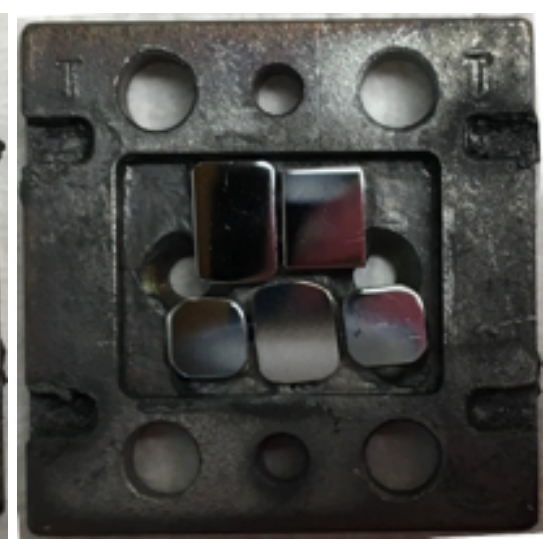

(c)

Fig. III-1-15. Photographs of samples before and after irradiation: (a) before irradiation, (b) after 0.01 dpa irradiation at $675^{\circ} \mathrm{C}$, (c) after $0.1 \mathrm{dpa}$ irradiation at $674^{\circ} \mathrm{C}$. The upper rows are (from to right): G91, G92. The lower rows are (from left to right): $316 \mathrm{H}, \mathrm{FeCrNi}$, and 709. (a), (c) are the same samples. The white boxes in (b) represent the boundaries of the mask in both irradiations.

\section{III-1-6. 3.7 MeV iron irradiation to $50 \mathrm{dpa}$ at $670{ }^{\circ} \mathrm{C}$}

Iron irradiation has been conducted for alloys 709, $\mathrm{FeCrNi}, 316 \mathrm{H}, \mathrm{G} 91$ and G92, and three creep-ruptured 709 samples: 1101, 1105, and 1106. The creep-ruptured samples can be regarded as thermally aged at conditions of 17,106 hours at $600{ }^{\circ} \mathrm{C}(1101), 12,014$ hours at $650{ }^{\circ} \mathrm{C}(1105)$, and 16,448 hours at $700{ }^{\circ} \mathrm{C}$ (1106). The irradiation conditions were:

Energy and Irradiating Ion Species: $3.7 \mathrm{MeV} \mathrm{Fe}^{2+}$ irradiation

Damage Level: peak $100 \mathrm{dpa}$ at $1.0 \mu \mathrm{m}$ depth, as shown in Fig. III-1-16.

Irradiation Temperature: $667 \pm 10^{\circ} \mathrm{C}$, as shown in Fig. III-1-17.

Irradiation Flux: $(3.9 \pm 0.5) \times 10^{12} \mathrm{ion} / \mathrm{cm}^{2} / \mathrm{s}$, as shown in Fig. III-1-17.

Vacuum/Base Pressure: $4 \times 10^{-7}$ Torr (base vacuum)

Damage rate: peak $2.0 \times 10^{-3} \mathrm{dpa} / \mathrm{s}(0.46 \mu \mathrm{m}$ depth $)$

Fig. III-1-16 shows the damage profile of $3.7 \mathrm{MeV} \mathrm{Fe}^{2+}$ irradiation in Fe-20Cr-25Ni calculated with the Kinchin-Pease Model in the Stopping and Range of Ions in Matter (SRIM) software. To achieve peak damage level of $50 \mathrm{dpa}$ at $0.46 \mu \mathrm{m}$, fluence of $9.77 \times 10^{16} \mathrm{Fe}^{2+} / \mathrm{cm}^{2}$ was used. 


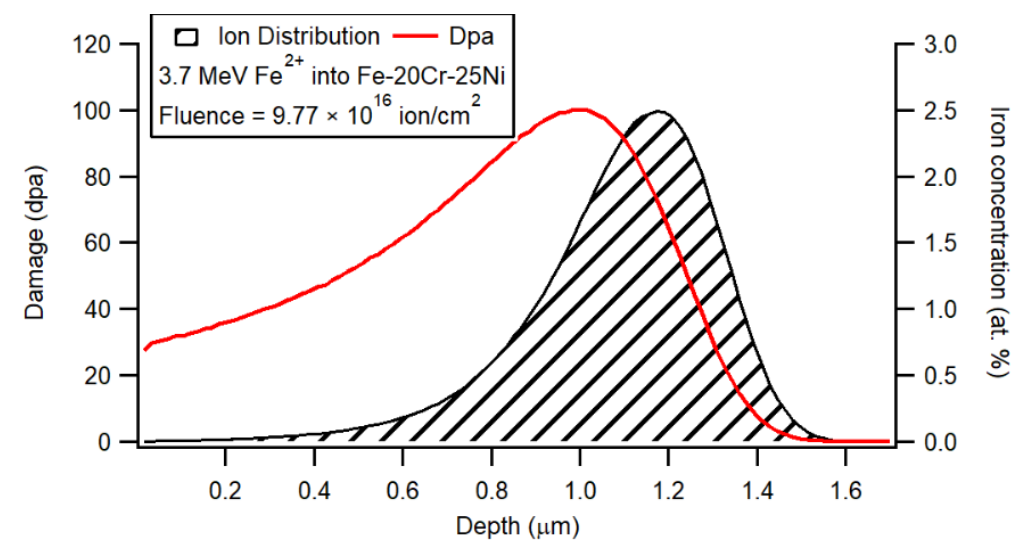

Fig. III-1-16. 3.7 $\mathrm{MeV} \mathrm{Fe}^{2+}$ induced damage and implantation profile in Fe-20Cr-25Ni, a model alloy representing alloy 709 . The peak damage is $100 \mathrm{dpa}$. $E_{d}$ is atom displacement energy.

Irradiation temperature and flux are shown in Fig. III-1-17. Temperature values represent thermocouple reading attached to the sample stage. Ion irradiation flux was calculated using ion beam current and beam scanning area $\left(2 \mathrm{~cm}^{2}\right)$.

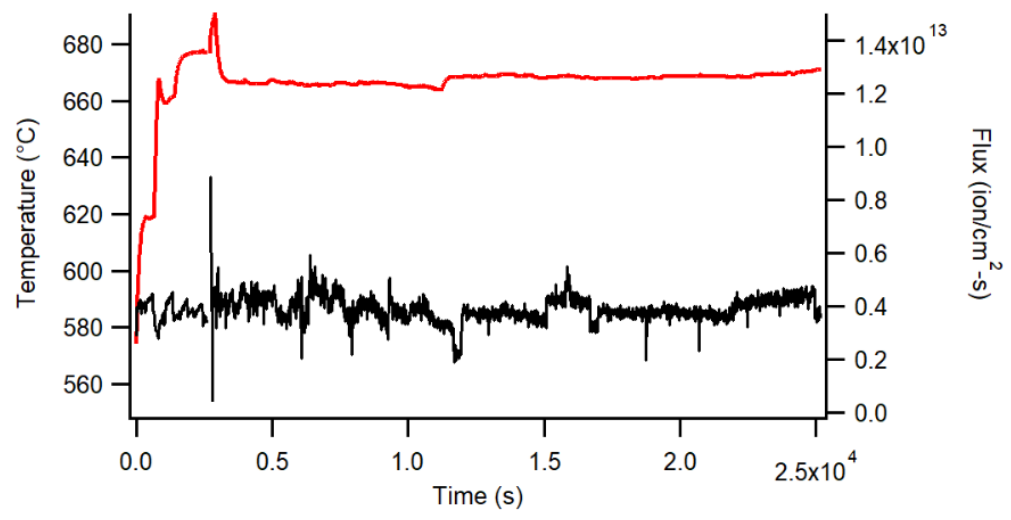

Fig. III-1-17 Temperature and flux during 3.7 $\mathrm{MeV} \mathrm{Fe}^{2+}$ irradiation.

Fig. III-1-18 shows photographs of the samples before irradiation (Fig. III-1-18a), and after $\mathrm{Fe}^{2+}$ irradiation of $50 \mathrm{dpa}$ at $670{ }^{\circ} \mathrm{C}$ (Fig. III-1-18b). Part of each sample was masked from irradiation. As shown in Fig. III-1-18b and III-1-18c, the sample area exposed to ions was located at center of the stage. Irradiated regions are shinny and show slightly different contrast from unirradiated regions. Oxidation appears to be insignificant and there was no apparent color change at unirradiated regions of the sample before and after irradiation. 


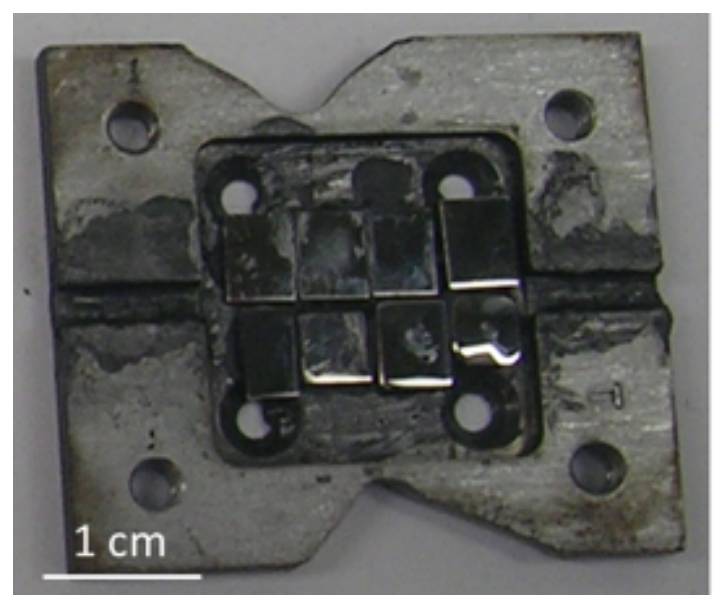

(a)
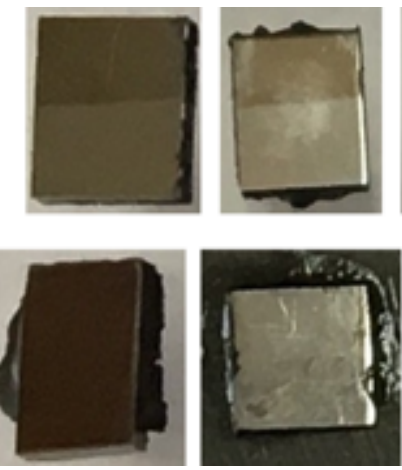

(c)

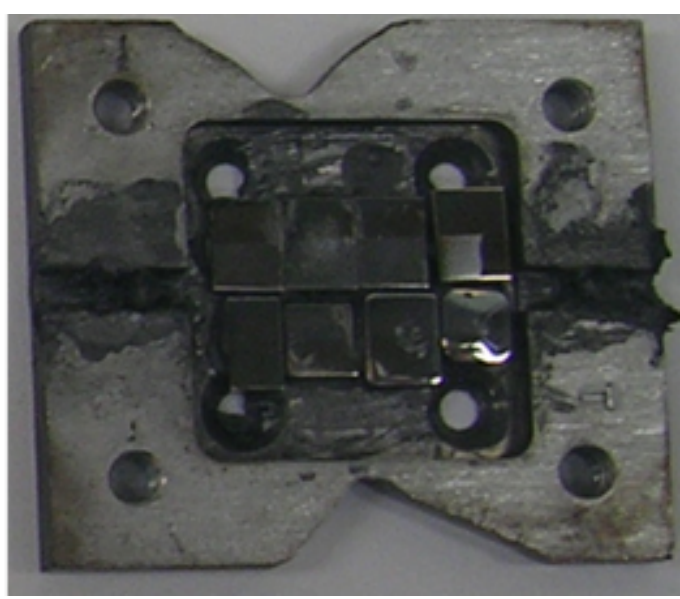

(b)
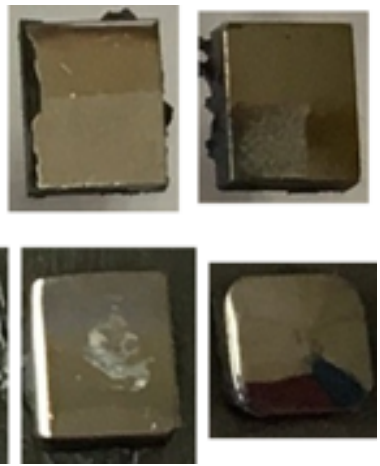

Fig. III-1-18. Photographs of samples: (a) before irradiation, (b, c) after $\mathrm{Fe}^{2+} 50$ dpa irradiation at $670{ }^{\circ} \mathrm{C}$. The upper row (from to right): 1101-1, 1105-1, 1106-1, G92-8. The lower row (from left to right): G91-10, 709-6, FeCrNi-8, and 316H-P5. Sample names are alloy designation followed by “-x”.

\section{$\underline{\text { III-1-7. 3.7 MeV iron irradiation to } 2.5 \mathrm{dpa} \text { and } 15 \mathrm{dpa} \text { at } 350{ }^{\circ} \mathrm{C}}$}

From this irradiation on silver paste replaces carbon paste to glue samples on stage to reduce contamination due to low diffusion of silver in steel compared to carbon. The irradiation conditions for eight alloys 709 , FeCrNi (model 709), 316H, G91 and G92, and three creep-ruptured 709 samples designated as 1101, 1105, and 1106 were:

Energy and Irradiating Ion Species: $3.7 \mathrm{MeV} \mathrm{Fe}^{2+}$ ion irradiation

Damage Level: Run 1, 15 dpa at $0.46 \mu \mathrm{m}$ depth, as shown in Fig. III-1-19(a).

Run 2, 2.5 dpa at $0.46 \mu \mathrm{m}$ depth, as shown in Fig. III-1-19(b). 
Irradiation Temperature: $345 \pm 12^{\circ} \mathrm{C}(15 \mathrm{dpa}), 355 \pm 5^{\circ} \mathrm{C}(2.5 \mathrm{dpa})$, as shown in Fig. III-1-20. Irradiation Flux: $(2.6 \pm 1.2) \times 10^{12} \mathrm{ion} / \mathrm{cm}^{2} / \mathrm{s}(15 \mathrm{dpa}),(2.5 \pm 0.1) \times 10^{12} \mathrm{ion} / \mathrm{cm}^{2} / \mathrm{s}(2.5 \mathrm{dpa})$, as shown in Fig. III-1-20.

Vacuum/Base Pressure: $5 \times 10^{-7}$ Torr (base vacuum), $1.6 \times 10^{-6}-7.6 \times 10^{-7}$ Torr (15 dpa irradiation), $1.6 \times 10^{-6}$ Torr (2.5 dpa irradiation).

Damage rate: $1.4 \times 10^{-3} \mathrm{dpa} / \mathrm{s}(0.46 \mu \mathrm{m}$ depth, $15 \mathrm{dpa}), 1.3 \times 10^{-3} \mathrm{dpa} / \mathrm{s}(0.46 \mu \mathrm{m}$ depth, $2.5 \mathrm{dpa})$.

To achieve peak damage level of $15 \mathrm{dpa}$ and $2.5 \mathrm{dpa}$ at $0.46 \mu \mathrm{m}$ depth fluences of $3.15 \times 10^{16} \mathrm{Fe}^{2+} / \mathrm{cm}^{2}$ and $4.63 \times 10^{15} \mathrm{Fe}^{2+} / \mathrm{cm}^{2}$ were used.

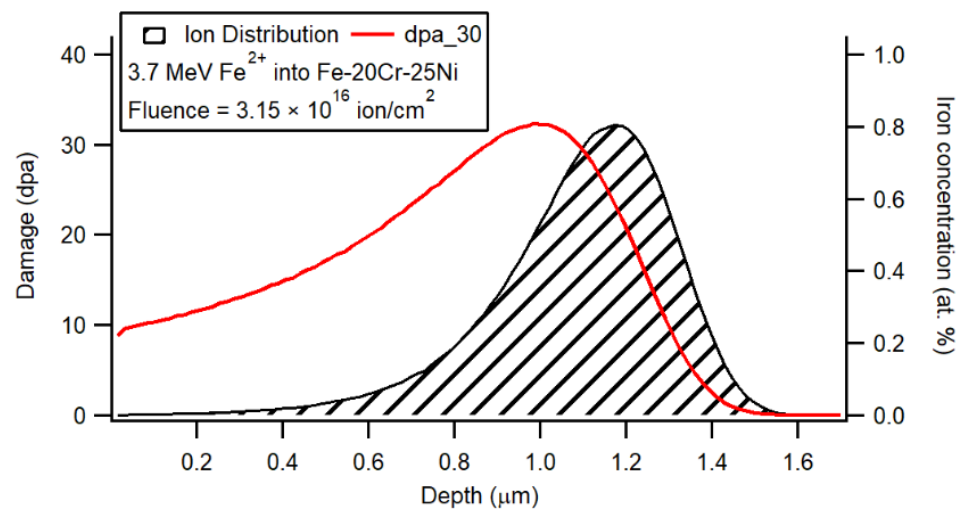

(a)

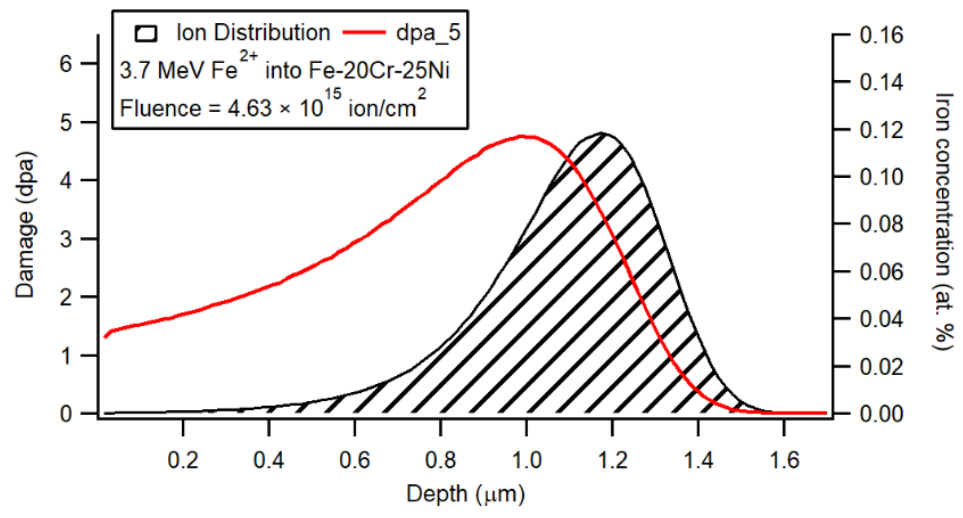

(b)

Fig. III-1-19. 3.7 $\mathrm{MeV} \mathrm{Fe}^{2+}$ ion-induced damage and implantation profiles in Fe-20Cr-25Ni, a model alloy representing alloy 709. The peak damage is $30 \mathrm{dpa}$ (a) and $5 \mathrm{dpa}$ (b). Damages at $0.46 \mu \mathrm{m}$ are $15 \mathrm{dpa}$ and 2.5 dpa, respectively. 
Irradiation temperature and flux are shown in Fig. III-1-20. Ion irradiation flux was calculated using ion beam current and beam scanning area $\left(3.6 \mathrm{~cm}^{2}\right.$ for $15 \mathrm{dpa}$ irradiation, $2.9 \mathrm{~cm}^{2}$ for $2.5 \mathrm{dpa}$ irradiation).

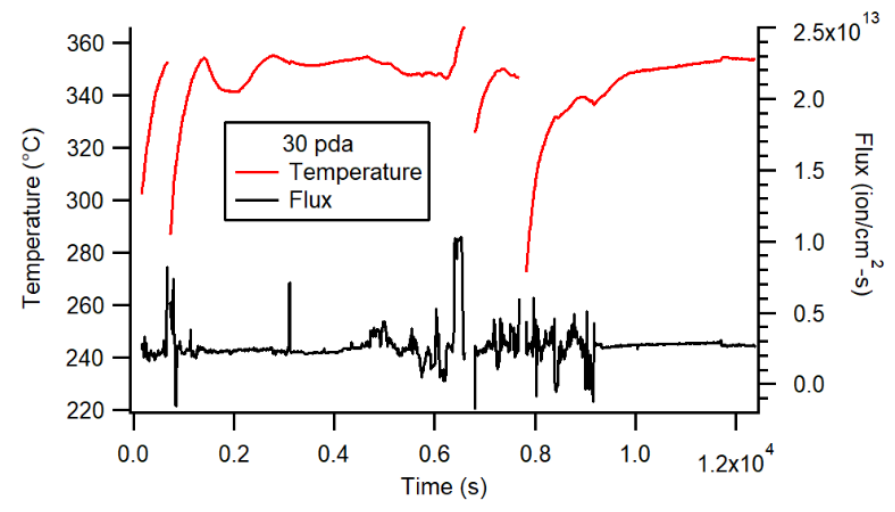

(a)

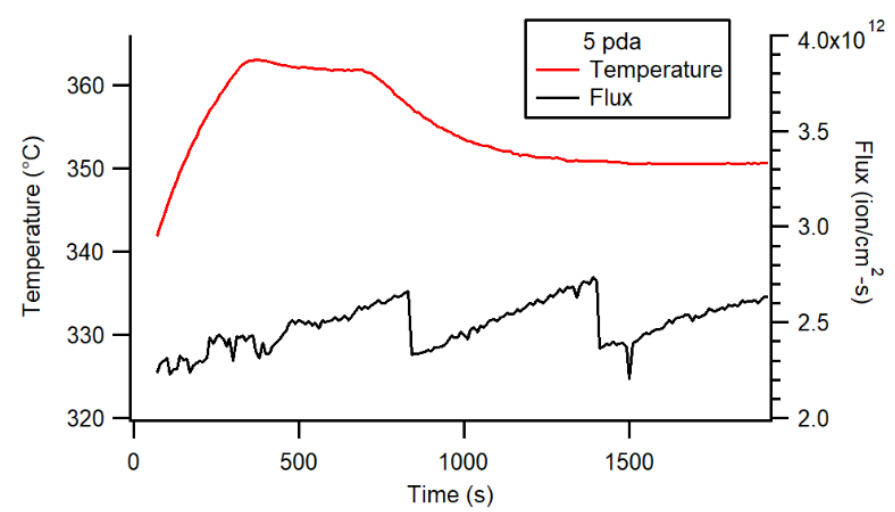

(b)

Fig. III-1-20. Temperature and ion flux during 3.7 $\mathrm{MeV} \mathrm{Fe}^{2+}$ ion irradiations: (a) 30 dpa peak damage (15 dpa at $0.46 \mu \mathrm{m}$ depth); (b) 5 dpa peak damage (2.5 dpa at $0.46 \mu \mathrm{m}$ depth).

Fig. III-1-21 shows photographs of the samples after $\mathrm{Fe}^{2+}$ irradiation of 15 dpa (Fig. III-1-21a) and 2.5 dpa (Fig. III-1-21b) at $350{ }^{\circ} \mathrm{C}$. Part of every sample was masked from irradiation. Unirradiated parts were scribed with " $x$ " after irradiation. Both unirradiated and irradiated regions are shinny and show no apparent difference in color. 


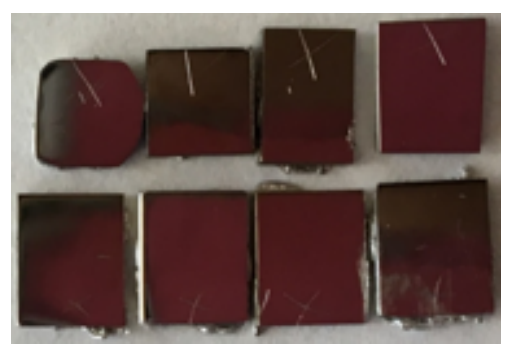

(a)

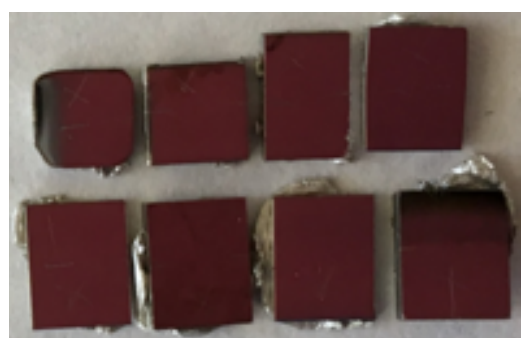

(b)

Fig. III-1-21. Photographs of samples after $\mathrm{Fe}^{2+}$ irradiation at $350{ }^{\circ} \mathrm{C}$ to 15 dpa (a) and $2.5 \mathrm{dpa}$ (b). The upper row (from to right) in (a): 316H-10, 709-5, FeCrNi-10, G91-11. The lower row (from left to right) in (a): 1101-2, 1105-2, 1106-2, and G92-11. The upper row (from to right) in (b): 316H-11, 709-8, FeCrNi11, G91-12. The lower row (from left to right) in (a): 1101-3, 1105-3, 1106-3, and G92-12.

\section{$\underline{\text { III-1-8. } 2 \mathrm{MeV} \text { proton irradiation to } 0.01 \mathrm{dpa} \text { and } 1 \mathrm{dpa} \text { at } 510{ }^{\circ} \mathrm{C}}$}

Thermal camera was applied to measure irradiation temperature at the sample surface. To calibrate sample emissivity, samples and stage were heated to a steady-state temperature inside the irradiation chamber. Two thermocouples were attached to the stage at opposite corners and read the temperature. Emissivity was found when camera and thermocouple readings are the same. Fig. III-1-22 shows emissivity of the alloys with changing temperature. At $510{ }^{\circ} \mathrm{C}$, the emissivity of the samples is 0.56 .

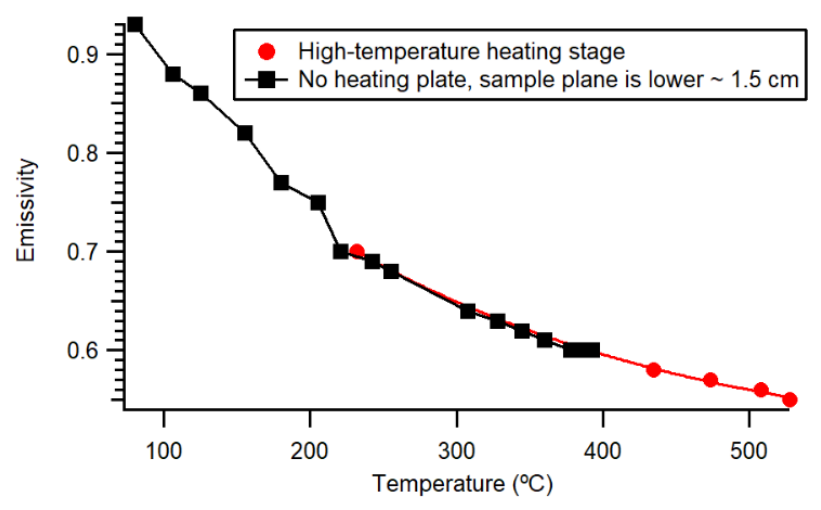

(a)

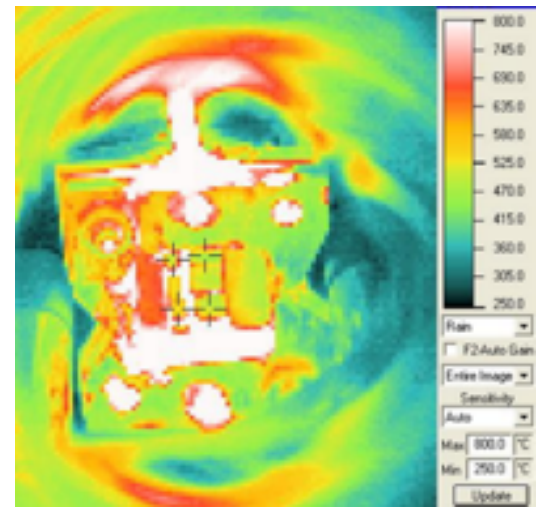

(b)

Fig. III-1-22. Thermal camera setting for irradiation temperature measurement. (a) Emissivity of irradiated alloys vs. temperature. (b) Camera temperature image. 
Irradiation conditions were:

\section{Energy and Irradiating Ion Species: $2 \mathrm{MeV} \mathrm{H}^{+}$}

\section{Damage Level:}

Run 1, 1.06 dpa at $10 \mu \mathrm{m}$ depth, as shown in Fig. III-1-23(a).

Run 2, 0.010 dpa at $10 \mu \mathrm{m}$ depth, as shown in Fig. III-1-23(b).

\section{Irradiation Temperature:}

$1 \mathrm{dpa}, 510 \pm 4{ }^{\circ} \mathrm{C}(1 \mathrm{dpa})$, as shown in Fig. III-1-24(b).

$0.01 \mathrm{dpa}, 509 \pm 10{ }^{\circ} \mathrm{C}$ (steady-state). Temperature rose from ion beam heating. When temperature increased to $500{ }^{\circ} \mathrm{C}, 47.5 \%$ of total fluence was completed. Fig. III-1-25 shows temperature and current change with time.

Irradiation Flux:

$1 \mathrm{dpa},(4.6 \pm 1.1) \times 10^{13} \mathrm{ion} / \mathrm{cm}^{2} / \mathrm{s}$

$0.01 \mathrm{dpa},(5.4 \pm 1.8) \times 10^{13} \mathrm{ion} / \mathrm{cm}^{2} / \mathrm{s}$

\section{Vacuum/Base Pressure:}

$1 \mathrm{dpa},(4-2.5) \times 10^{-7}$ Torr (base vacuum), $2.7 \times 10^{-6}-2.8 \times 10^{-7}$ Torr (irradiation).

$0.01 \mathrm{dpa}, 4.3 \times 10^{-7}$ Torr (base vacuum), $3.5 \times 10^{-6}$ Torr (irradiation).

\section{Damage rate:}

$1 \mathrm{dpa}, 3.33 \times 10^{-6} \mathrm{dpa} / \mathrm{s}(10 \mu \mathrm{m}$ depth $)$

$0.01 \mathrm{dpa}, 3.81 \times 10^{-6} \mathrm{dpa} / \mathrm{s}(10 \mu \mathrm{m}$ depth $)$.

To achieve peak damage level of $1 \mathrm{dpa}$ and $0.01 \mathrm{dpa}$, fluences of $1.5 \times 10^{19} \mathrm{ion} / \mathrm{cm}^{2}$ and $1.42 \times 10^{17} \mathrm{ion} / \mathrm{cm}^{2}$ were used, respectively.

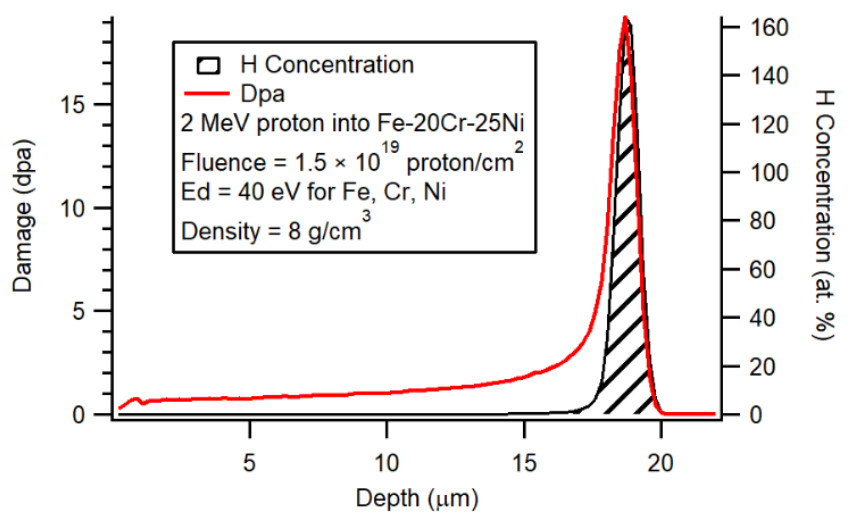

(a) 


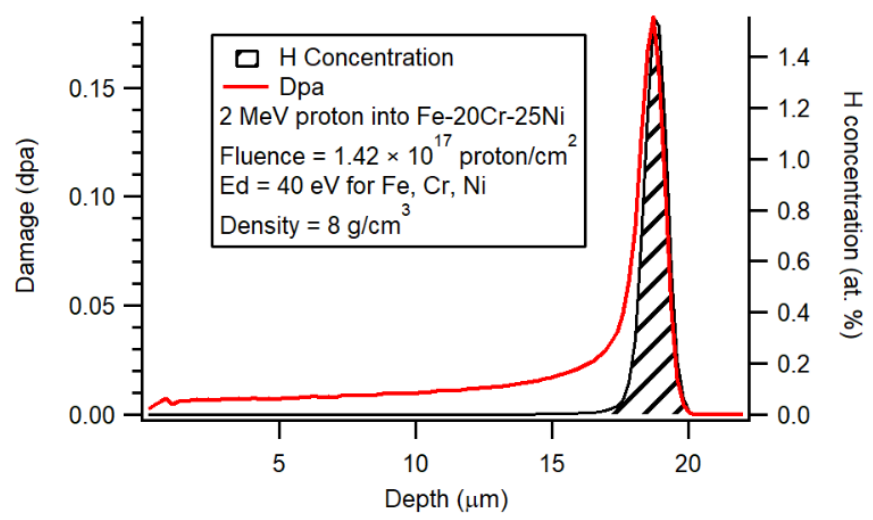

(b)

Fig. III-1-23. $2 \mathrm{MeV} \mathrm{H}^{+}$ion-induced damage and implantation profiles in $\mathrm{Fe}-20 \mathrm{Cr}-25 \mathrm{Ni}$, a model alloy representing alloy 709. The damage at $10 \mu \mathrm{m}$ depth is $1 \mathrm{dpa}$ (a) and $0.01 \mathrm{dpa}(\mathrm{b})$.

Temperature was measured using two methods: thermal camera, and two thermocouples attached to opposite corners of the sample stage.

Irradiation of 1 dpa was carried out during work days and stopped at night. Fig. III-1-24(a) shows the fluence progress through time. Temperature and flux are shown in Fig. III-1-24(b). Ion irradiation flux was calculated using ion beam current and beam scanning area $2 \mathrm{~cm}^{2}$.

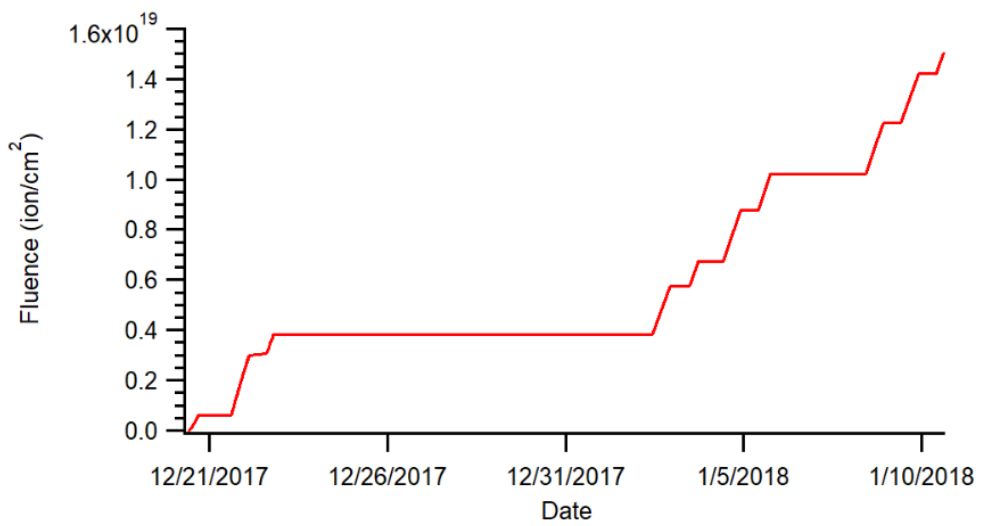

(a) 


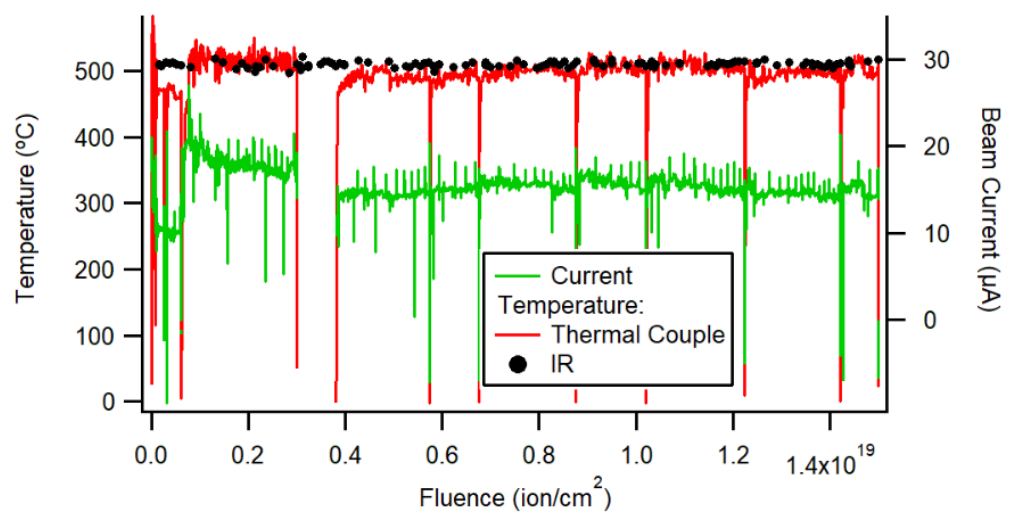

(b)

Fig. III-1-24. $2 \mathrm{MeV} \mathrm{H}^{+}$ion irradiation of 1 dpa: (a) Fluence vs. time; (b) Temperature and beam current vs. fluence.

Fig. III-1-25 displays temperature and current at 0.01 dpa irradiation. Temperature rose slowly with beam heating. When the temperature was above $500{ }^{\circ} \mathrm{C}, 47.5 \%$ of total fluence was already completed.

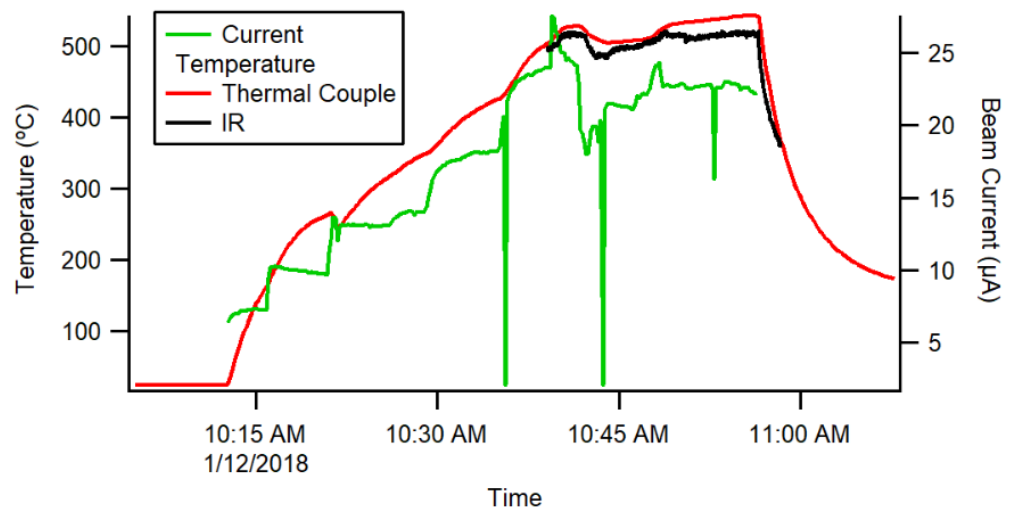

Fig. III-1-25. $2 \mathrm{MeV} \mathrm{H}^{+}$ion irradiation of 0.01 dpa: temperature and beam current vs. time.

Fig. III-1-26 shows photographs of the samples after $\mathrm{H}^{+}$irradiation to 1 dpa (Fig. III-1-26a) and 0.01 dpa (Fig. III-1-26b) at $510{ }^{\circ} \mathrm{C}$. Part of every sample was masked from irradiation. Unirradiated parts were scribed with " $x$ " after irradiation. Samples irradiated at 1 dpa shows bluish color indicating oxidation. The 0.01 dpa irradiated samples are shiny and show no apparent difference in color between unirradiated and irradiated surfaces. 


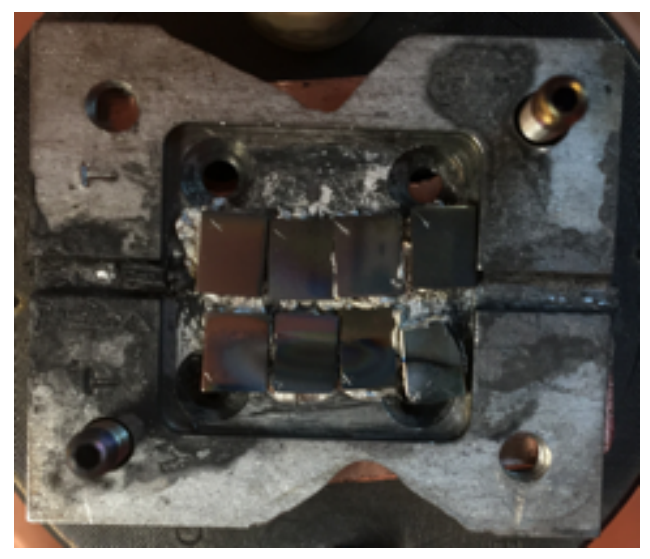

(a)

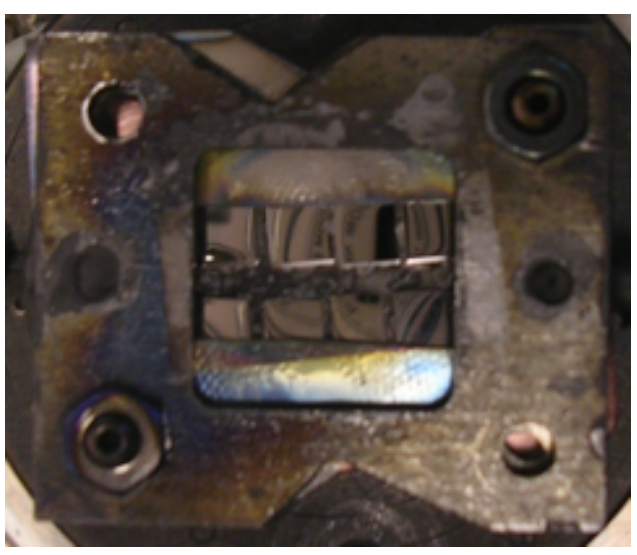

(b)

Fig. III-1-26. Photographs of samples after $\mathrm{H}^{+}$irradiation at $510{ }^{\circ} \mathrm{C}$ to $1 \mathrm{dpa}$ (a) and $0.01 \mathrm{dpa}$ (b). The upper row (from left to right) in (a): G92-10, 1101-4, 1106-4, 1105-4. The lower row (from left to right) in (a): 709-11, FeCrNi-12, 316H-12, and G91-6. The upper row (from left to right) in (b): G92-13, 1101-5, 11065, 1105-5. The lower row (from left to right) in (b): 709-14, 316H-13, FeCrNi-13, and G91-13.

\section{III-1-9. 3.7 MeV iron irradiation to $2.5 \mathrm{dpa}$ and $15 \mathrm{dpa}$ at $670{ }^{\circ} \mathrm{C}$}

Irradiation conditions were:

Energy and Irradiating Ion Species: $3.7 \mathrm{MeV} \mathrm{Fe}^{2+}$

Damage Level:

Run 1, 15 dpa at $0.46 \mu \mathrm{m}$ depth, as shown in Fig. III-1-27(a).

Run 2, 2.5 dpa at $0.45 \mu \mathrm{m}$ depth, as shown in Fig. III-1-27(b).

\section{Irradiation Temperature:}

$15 \mathrm{dpa}, 668 \pm 1{ }^{\circ} \mathrm{C}$ (thermocouple reading), as shown in Fig. III-1-28(a).

$2.5 \mathrm{dpa}, 668 \pm 1{ }^{\circ} \mathrm{C}$ (thermocouple reading), as shown in Fig. III-1-28(b).

\section{Irradiation Flux:}

$15 \mathrm{dpa},(3.6 \pm 0.3) \times 10^{12} \mathrm{ion} / \mathrm{cm}^{2} / \mathrm{s}$

$2.5 \mathrm{dpa},(1.8 \pm 0.2) \times 10^{12} \mathrm{ion} / \mathrm{cm}^{2} / \mathrm{s}$

\section{Vacuum/Base Pressure:}

$2.5 \mathrm{dpa}, 4.5 \times 10^{-7}$ Torr (base vacuum), $1.6 \times 10^{-6}$ Torr (irradiation).

\section{Damage rate:}

$15 \mathrm{dpa}, 1.86 \times 10^{-3} \mathrm{dpa} / \mathrm{s}(0.46 \mu \mathrm{m}$ depth $)$

$2.5 \mathrm{dpa}, 8.96 \times 10^{-4} \mathrm{dpa} / \mathrm{s}(0.45 \mu \mathrm{m}$ depth$)$. 
To achieve damage levels of $15 \mathrm{dpa}$ and $2.5 \mathrm{dpa}$ at $0.46 \mu \mathrm{m}$ depth fluences of $2.9 \times 10^{16} \mathrm{ion} / \mathrm{cm}^{2}$ and $5.0 \times 10^{15}$ ion $/ \mathrm{cm}^{2}$ were used, respectively.

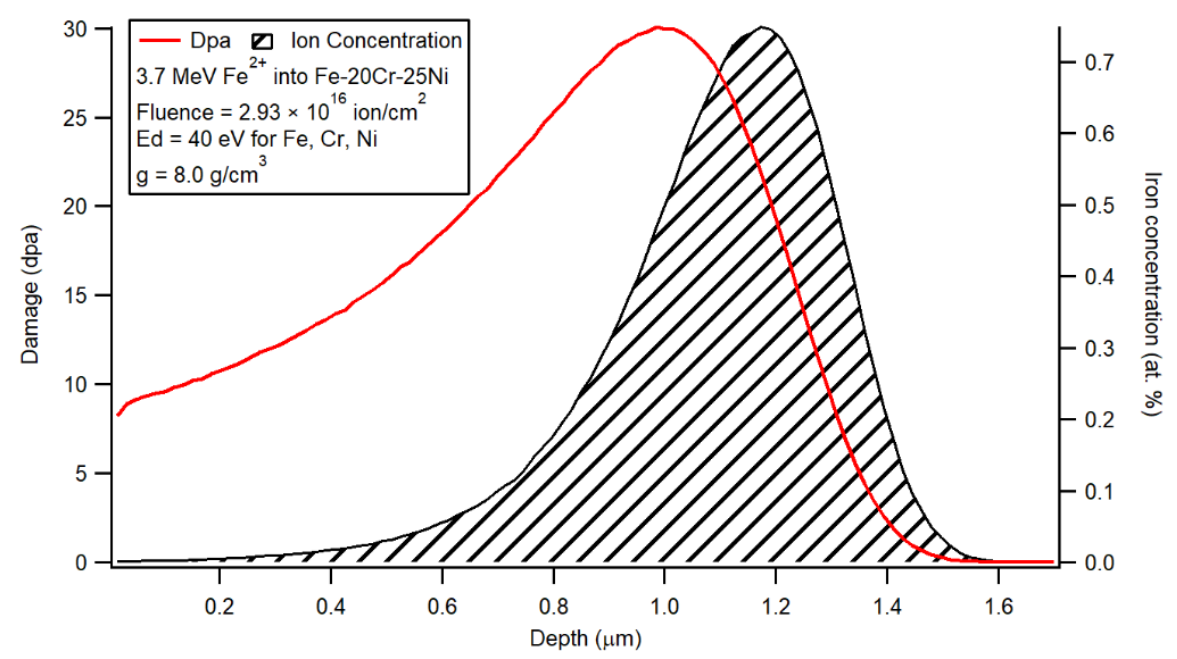

(a)

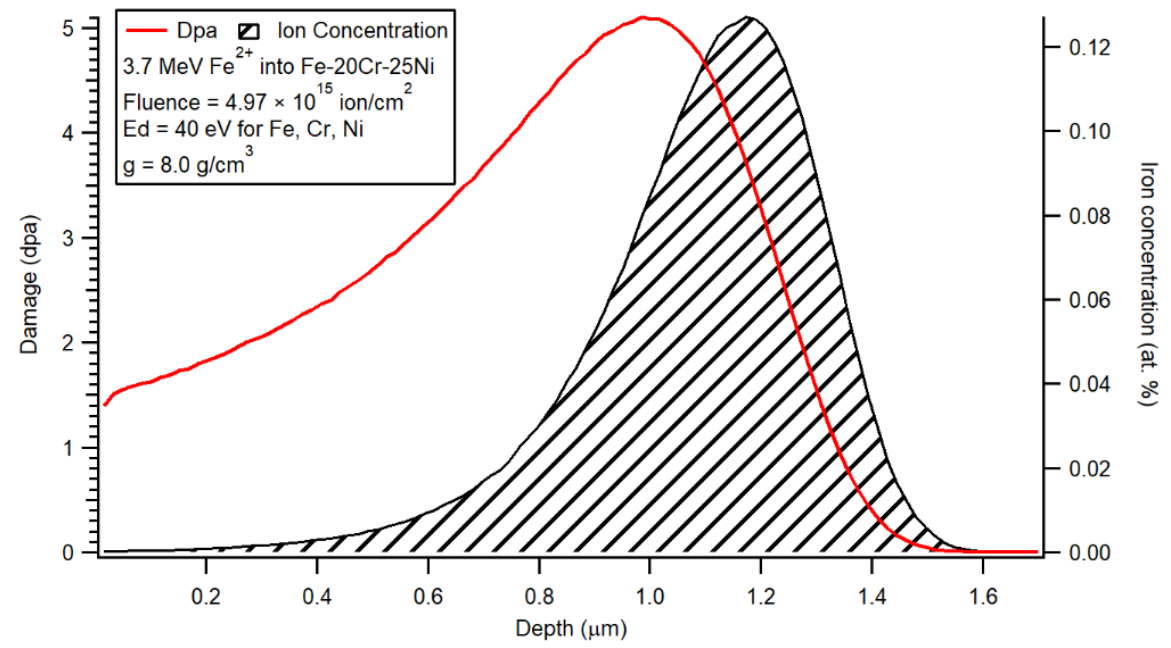

(b)

Fig. III-1-27. 3.7 $\mathrm{MeV} \mathrm{Fe}^{2+}$ ion-induced damage and implantation profiles in Fe-20Cr-25Ni, a model alloy representing alloy 709 . The damage at $0.46 \mu \mathrm{m}$ depth is $15 \mathrm{dpa}$ (a) and $2.5 \mathrm{dpa}$ (b).

As shown in Fig. III-1-28, the difference between thermal camera and thermocouple readings were $<10^{\circ} \mathrm{C}$. Ion irradiation flux was calculated using ion beam current and beam scanning area $2.89 \mathrm{~cm}^{2}$. 


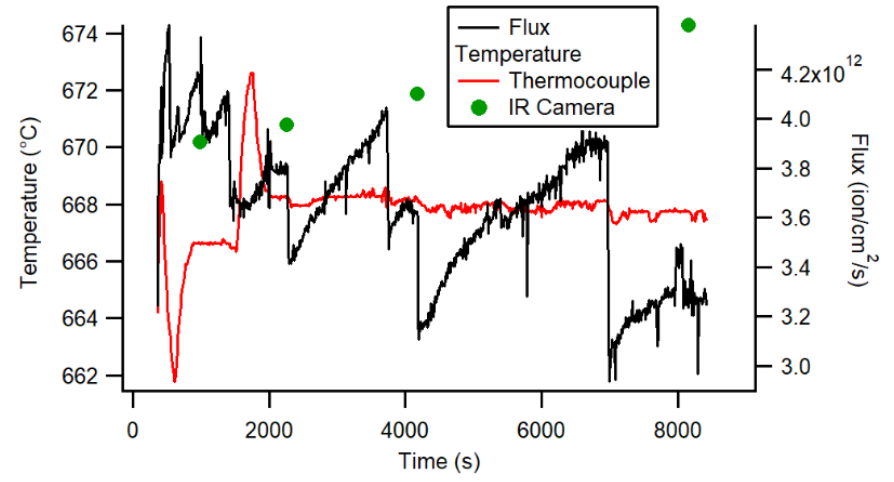

(a)

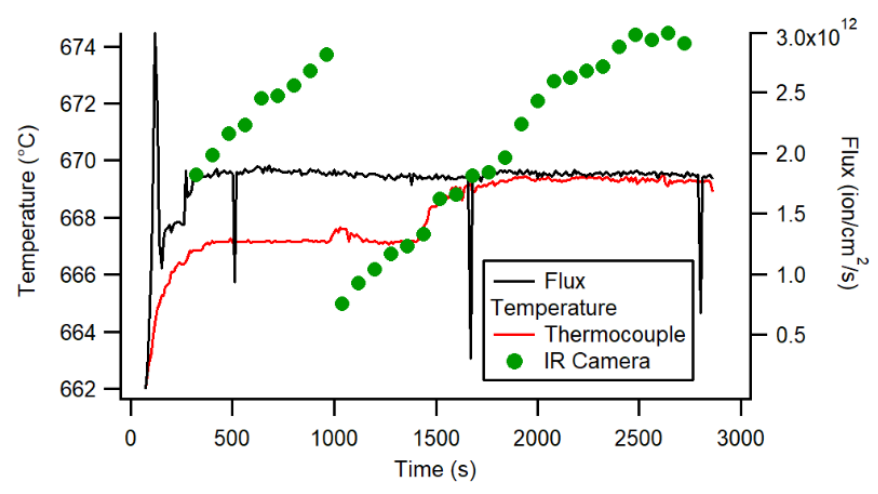

(b)

Fig. III-1-28. 3.7 $\mathrm{MeV} \mathrm{Fe}^{2+}$ ion irradiation. Temperature and ion flux at (a) $15 \mathrm{dpa}$ and (b) $2.5 \mathrm{dpa}$.

Fig. III-1-29 shows photographs of the samples after $\mathrm{Fe}^{2+}$ irradiation to $15 \mathrm{dpa}$ (Fig. III-1-29a) and 2.5 dpa (Fig. III-1-29b) at $670^{\circ} \mathrm{C}$. There was silver paste at sample backside. It was used for gluing samples to stage. About one half of every sample surface was masked from irradiation. Unirradiated parts were scribed with " $x$ " after irradiation. Irradiated areas of all samples are shiny and show no apparent difference in color with unirradiated areas.

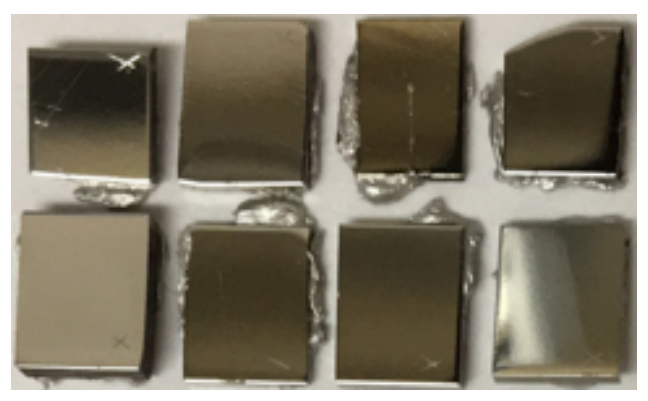

(a)

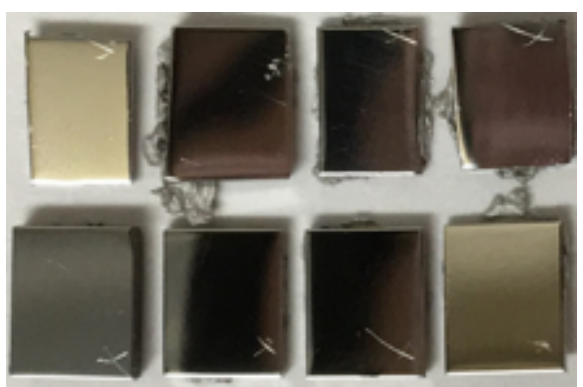

(b) 
Fig. III-1-29. Photographs of samples after $\mathrm{Fe}^{2+}$ irradiation at $670{ }^{\circ} \mathrm{C}$ to $15 \mathrm{dpa}$ (a) and $2.5 \mathrm{dpa}$ (b). The upper row (from left to right) in (a): 709-15, 316H-14, FeCrNi-14, G91-14. The lower row (from left to right) in (a): G92-14, 1101-6, 1105-6, and 1106-6. The upper row (from left to right) in (b): 709-16, 316H15, FeCrNi-15, G91-15. The lower row (from left to right) in (a): G92-15, 1101-7, 1105-7, and 1106-7.

\section{$\underline{\text { III-1-10. 3.5 MeV iron irradiation to } 75 \mathrm{dpa} \text { at } 600{ }^{\circ} \mathrm{C} \text {, defocused beam }}$}

This irradiation used non-rastered and defocused ion beam with an irradiation size $5 \mathrm{~mm} \times 5 \mathrm{~mm}$. Fig. III1-30 shows SRIM calculation of irradiation damage.

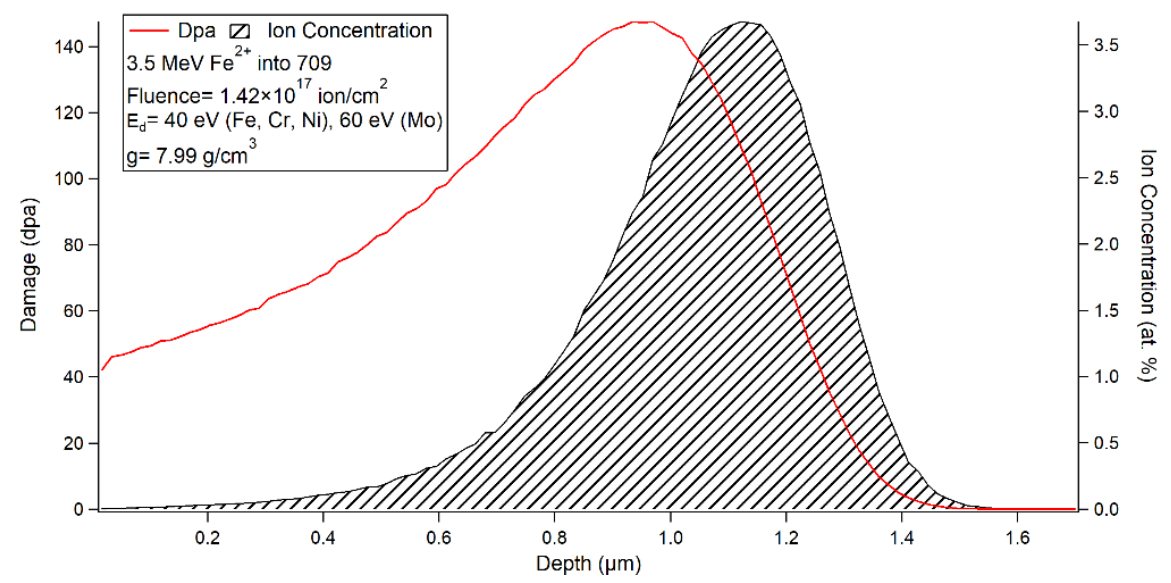

Fig. III-1-30. Damage and ion implantation concentration of $3.5 \mathrm{MeV} \mathrm{Fe}^{2+}$ into 709 (19.7Cr-25Ni-1.5Mo, Fe balance in wt. \%), calculated with SRIM.

Irradiation conditions were:

Energy and Irradiating Ion Species: $3.5 \mathrm{MeV} \mathrm{Fe}^{2+}$

Damage Level: $75 \mathrm{dpa}$ at $0.43 \mu \mathrm{m}$ depth, maximum $147 \mathrm{dpa}$ at $0.95 \mu \mathrm{m}$, as shown in Fig. III-1-30.

Irradiation Temperature: $599 \pm 1{ }^{\circ} \mathrm{C}$ (thermocouple reading), as shown in Fig. III-1-31.

Ion fluence: $1.42 \times 10^{17} \mathrm{ion} / \mathrm{cm}^{2}$

Irradiation Flux: $(1.7 \pm 0.4) \times 10^{12} \mathrm{ion} / \mathrm{cm}^{2} / \mathrm{s}$, as shown in Fig. III-1-31.

Vacuum/Base Pressure: $2.5 \times 10^{-7}$ Torr (base vacuum), $2.2 \times 10^{-6}-3.8 \times 10^{-7}$ Torr (irradiation).

Damage rate: $8.7 \times 10^{-4} \mathrm{dpa} / \mathrm{s}(0.43 \mu \mathrm{m}$ depth $)$ 


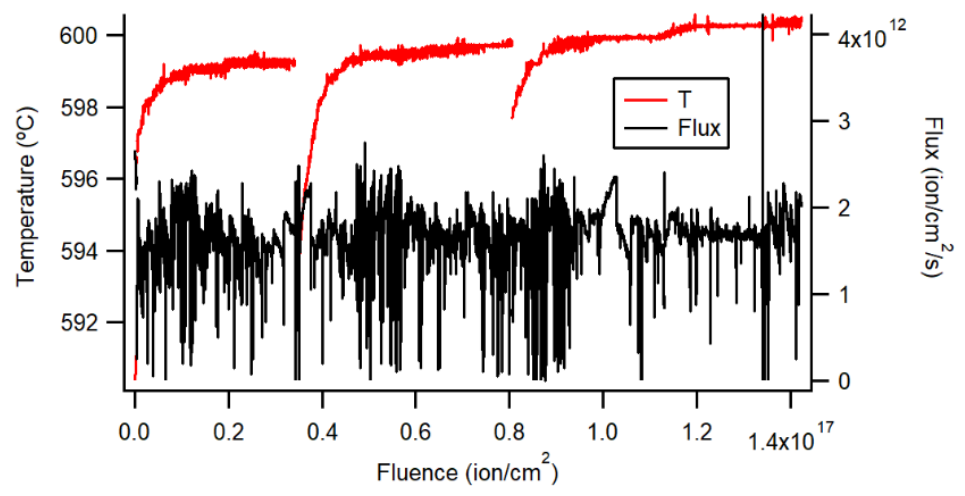

Fig. III-1-31. Temperature and ion flux during 3.5 $\mathrm{MeV} \mathrm{Fe}^{2+}$ irradiation of $316 \mathrm{H}$ and 709 with defocused beam.

Fig. III-1-32 shows images of samples 316H-16 and 709-17 after irradiation. Color changes from silver before irradiation to blue (709-17, both unirradiated and irradiated regions, with irradiation boundary at the dashed line) and blue and bronze $(316 \mathrm{H}-16)$, indicating oxidation.

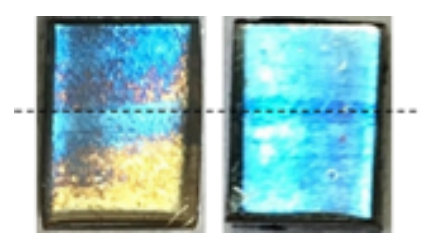

Fig. III-1-32. Picture of samples 316H-16 (left) and 709-17 (right) after $3.5 \mathrm{MeV} \mathrm{Fe}{ }^{2+}$ irradiation to 75 dpa at $0.43 \mu \mathrm{m}$ depth (peak $150 \mathrm{dpa}$ ) at $600{ }^{\circ} \mathrm{C}$ with defocused beam. The dashed line indicates irradiation boundary where the top is irradiated and below region is unirradiated.

\section{III-2. Characterization of Alloys before and after Irradiation}

Ion-irradiated alloys have been characterized with transmission electron microscopy (TEM) and scanning electron microscopy (SEM), including 709, FeCrNi (model 709), 316H, G91, G92, and three creep-ruptured 709 samples designated as 1101 (thermally aged for 17,106 hours at $\left.600{ }^{\circ} \mathrm{C}\right)$, and $1106(16,448$ hours at $700{ }^{\circ} \mathrm{C}$ ). Tables III-2-1 and III-2-2 list the observed microstructures before and after ion irradiations. 
Table III-2-1. Microstructures of austenitic alloys before and after ion irradiation.

\begin{tabular}{|c|c|c|c|c|c|}
\hline Condition & 316H & 709 & 1101 & 1106 & FeCrNi \\
\hline $\begin{array}{l}\text { As- } \\
\text { received or } \\
\text { undamaged }\end{array}$ & $\begin{array}{l}\text { Dislocations } \\
\left(1.2 \times 10^{13} \mathrm{~m}^{-2}\right)\end{array}$ & $\begin{array}{l}\text { Dislocations } \\
\text { Precipitates: } \\
\mathrm{Nb}(\mathrm{CN}) \leq 100 \mathrm{~nm}\end{array}$ & $\begin{array}{l}\mathrm{M}_{23} \mathrm{C}_{6} \\
\mathrm{M}_{3} \mathrm{Ni}_{2} \mathrm{Si} 30 \\
\mathrm{~nm} \text { to }>1 \mu \mathrm{m} \\
\mathrm{Nb}(\mathrm{CN}) \sim 10 \\
\mathrm{~nm}\end{array}$ & $\begin{array}{l}\mathrm{M}_{23} \mathrm{C}_{6}, \\
\mathrm{M}_{3} \mathrm{Ni}_{2} \mathrm{Si}, \\
(\mathrm{NbCr})(\mathrm{CN}), \\
\mathrm{Ni}_{\mathrm{x}} \mathrm{Si}_{\mathrm{y}}\end{array}$ & $\begin{array}{l}\text { Dislocations } \\
\left(3.3 \times 10^{12} \mathrm{~m}^{-2}\right)\end{array}$ \\
\hline $\begin{array}{l}\mathrm{Fe}^{2+} \\
\text { rastered } \\
50 \mathrm{dpa} \\
350^{\circ} \mathrm{C}\end{array}$ & $\begin{array}{l}\text { Frank loops }(15 \pm \\
1 \mathrm{~nm} 8.3 \times 10^{22} \mathrm{~m}^{-3} \\
\text { at } 50 \mathrm{dpa}) \\
\mathrm{Ni}, \text { Si segregated, } \\
\mathrm{Cr}, \text { Fe depleted at } \\
\text { grain boundary } \\
\text { (GB) }\end{array}$ & $\begin{array}{l}\text { Frank loops } \\
(14.2 \pm 0.6 \mathrm{~nm} \text {, } \\
5.2 \times 10^{22} \mathrm{~m}^{-3} \text { at } 58 \\
\mathrm{dpa}) ; \\
\text { Ni segregated, } \mathrm{Cr} \\
\text { depleted at } \mathrm{GB}\end{array}$ & & & \\
\hline $\begin{array}{l}\mathrm{Fe}^{2+} \\
\text { rastered } \\
50 \mathrm{dpa} \\
670^{\circ} \mathrm{C}\end{array}$ & & $\begin{array}{l}\text { Dislocations } \\
\mathrm{Nb}(\mathrm{CN}) \sim 100 \mathrm{~nm} \\
(\mathrm{NbCr})(\mathrm{CN}) \sim \\
10 \mathrm{~nm} \\
(\mathrm{CrMo})_{\mathrm{x}} \mathrm{C}_{\mathrm{y}} \text { at } \mathrm{GB} \\
\mathrm{Ni}, \mathrm{Mn} \\
\text { segregated, } \mathrm{Cr}, \mathrm{Fe} \\
\text { depleted at } \mathrm{GB}\end{array}$ & $\begin{array}{l}\text { Dislocations } \\
\text { No new } \\
\text { precipitates. } \\
\text { Irradiation } \\
\text { enriched } \mathrm{Cr} \text { in } \\
\mathrm{M}_{23} \mathrm{C}_{6} \text { and } \\
\mathrm{M}_{3} \mathrm{Ni}_{2} \mathrm{Si} \text {. }\end{array}$ & $\begin{array}{l}\text { Dislocations } \\
\text { No new } \\
\text { precipitates. }\end{array}$ & $\begin{array}{l}\text { Dislocation; } \\
\text { Void swelling } \\
14 \%) \\
\text { Ni segregated, } \\
\mathrm{Cr}, \mathrm{Fe} \\
\text { depleted at } \\
\text { GB and voids }\end{array}$ \\
\hline $\begin{array}{l}\mathrm{Fe}^{2+} \\
\text { defocused } \\
75 \mathrm{dpa} \\
600^{\circ} \mathrm{C}\end{array}$ & & $\begin{array}{l}\mathrm{Nb}(\mathrm{CN}) \sim 100 \\
\mathrm{~nm} ;(\mathrm{CrMoMn})_{\mathrm{x}} \mathrm{C}_{\mathrm{y}} \\
\text { at } \mathrm{GB} ; \\
\mathrm{Ni}, \mathrm{Si} \text { rich at } \\
\text { irradiated GB; Ni } \\
\text { rich, Cr depleted } \\
\text { at unirradiated } \mathrm{GB}\end{array}$ & & & \\
\hline $\begin{array}{l}\mathrm{H}^{+} \text {rastered } \\
0.01 \mathrm{dpa} \\
380^{\circ} \mathrm{C}\end{array}$ & & & & & $\begin{array}{l}\text { No apparent } \\
\text { change }\end{array}$ \\
\hline
\end{tabular}




\begin{tabular}{|l|l|l|l|l|l|}
\hline $\begin{array}{l}\mathrm{H}^{+} \text {rastered } \\
0.01 \mathrm{dpa} \\
670{ }^{\circ} \mathrm{C}\end{array}$ & & & & & $\begin{array}{l}\text { No apparent } \\
\text { change }\end{array}$ \\
\hline
\end{tabular}

Table III-2-2. Microstructures of ferritic-martensitic alloys before and after ion irradiation.

\begin{tabular}{|l|l|l|}
\hline Condition & G91 & G92 \\
\hline $\begin{array}{l}\text { As- } \\
\text { received }\end{array}$ & $(\mathrm{CrMoV})_{23} \mathrm{C}_{6},(\mathrm{VNb})(\mathrm{CN})$ & $(\mathrm{CrWMoV})_{23} \mathrm{C}_{6},(\mathrm{VNb})(\mathrm{CN})$ \\
\hline $\mathrm{Fe}^{2+}$ & $(\mathrm{CrMoV})_{23} \mathrm{C}_{6}$ amorphized; & $(\mathrm{CrWMoV})_{23} \mathrm{C}_{6}$ amorphized; \\
rastered, & Dislocation loops (mainly $<100>)$ and black spot & $<100>$ and $\boldsymbol{a} / \mathbf{2}<111>100 p s \quad(50 \mathrm{dpa}$, \\
$50 \quad \mathrm{dpa}$, & defects $\left(46 \mathrm{dpa}, 3.2 \pm 1.8 \mathrm{~nm}, 9.8 \times 10^{22} \mathrm{~m}^{-3}\right.$ for & $\left.9.1 \pm 6.4 \mathrm{~nm}, 4.5 \times 10^{22} \mathrm{~m}^{-3}\right) ;$ \\
$350{ }^{\circ} \mathrm{C}$ & features $>1.5 \mathrm{~nm}) ;$ & $\mathrm{Ni}, \mathrm{Si}, \mathrm{Cr}$ segregated, Fe depleted at GB \\
& $\mathrm{Ni}, \mathrm{Si}, \mathrm{Cr}$ segregated, Fe depleted at GB & \\
\hline
\end{tabular}

\section{Summary of ion irradiation effects}

\section{A. Dislocations}

- Dislocation loops appeared after $350{ }^{\circ} \mathrm{C} 50 \mathrm{dpa} \mathrm{Fe}^{2+}$ irradiation: Frank loops (Burgers' vector $\mathrm{a} / 3<111>$ ) in austenitic alloys $(316 \mathrm{H}, 709)$, and $<100>$, a/2<111 $>$ Burgers' vector loops in ferriticmartensitic alloys (G91, G92).

- Frank loops in alloy 709 appear to be less than that in $316 \mathrm{H}$ after $350{ }^{\circ} \mathrm{C} 50 \mathrm{dpa} \mathrm{Fe}{ }^{2+}$ irradiation. The average size of Frank loops in 709, $14.2 \pm 0.6 \mathrm{~nm}$, is slightly smaller than that in $316 \mathrm{H}, 15 \pm 1$ nm.

- Dislocation loops in G92 are significantly larger than that in G91 after $350{ }^{\circ} \mathrm{C} 50$ dpa $\mathrm{Fe}^{2+}$ irradiation.

- Dislocation loops disappeared after $50-75 \mathrm{dpa} \mathrm{Fe}^{2+}$ irradiation at $600-670{ }^{\circ} \mathrm{C}$ in austenitic alloys.

\section{B. Radiation-induced segregation}

- $\mathrm{Ni}, \mathrm{Si}$ segregation is observed at grain boundaries in both austenitic and ferritic-martensitic alloys at $50 \mathrm{dpa}$ to $75 \mathrm{dpa} \mathrm{Fe}^{2+}$ irradiation from $350{ }^{\circ} \mathrm{C}$ to $670{ }^{\circ} \mathrm{C}$. $\mathrm{Cr}$ and $\mathrm{Fe}$ depletion are often found in austenitic alloy grain boundaries.

- $\mathrm{Ni}$, Si segregated at grain boundaries outside the surface region damaged by $75 \mathrm{dpa} \mathrm{Fe}{ }^{2+}$ irradiation at $600{ }^{\circ} \mathrm{C}$, i.e., undamaged grain boundaries in alloy 709 . 


\section{Precipitates}

- Precipitates in as-received alloy 709 are $\mathrm{Nb}(\mathrm{CN})$. After $\mathrm{Fe}^{2+}$ irradiation at $670{ }^{\circ} \mathrm{C}$ to 50 dpa with rastered beam, $(\mathrm{NbCr})(\mathrm{CN})$ particles emerged, about $10 \mathrm{~nm}$ in size. $(\mathrm{CrMo})_{\mathrm{x}}(\mathrm{CN})_{\mathrm{y}}$ particles exist along grain boundaries in $670{ }^{\circ} \mathrm{C} 50 \mathrm{dpa}$ rastered beam irradiation, as well as along undamaged grain boundary in 709 that experienced the same thermal history of $\mathrm{Fe}^{2+}$ defocused beam irradiation to 75 dpa at $600{ }^{\circ} \mathrm{C}$ for 24 hours.

- Precipitates in crept/ thermally aged 709 at $600-700{ }^{\circ} \mathrm{C}$ about 17,000 hours (sample 1101,1106 ) are mainly $(\mathrm{CrMo})_{23} \mathrm{C}_{6},(\mathrm{CrMo})_{3} \mathrm{Ni}_{2} \mathrm{Si}, \mathrm{Nb}(\mathrm{CN})$, or $(\mathrm{NbCr})(\mathrm{CN})$. Ni, Si-rich particles are also found in $1106\left(16,448\right.$ hours at $\left.700{ }^{\circ} \mathrm{C}\right)$. Large $(\mathrm{CrMo})_{23} \mathrm{C}_{6}$ and $(\mathrm{CrMo})_{3} \mathrm{Ni}_{2} \mathrm{Si}$ particles, about $1 \mu \mathrm{m}$, grow along grain boundaries (GB). The occupation rate of two kinds of particles at GB are $42 \%$ of GB length for $(\mathrm{CrMo})_{3} \mathrm{Ni}_{2} \mathrm{Si}, 53 \%$ for $(\mathrm{CrMo})_{23} \mathrm{C}_{6}$, leaving $5 \%$ of bare GB.

- $\mathrm{Fe}^{2+}$ rastered irradiation at $670{ }^{\circ} \mathrm{C}$ to $50 \mathrm{dpa}$ did not generate new kinds of precipitates in either 1101 or 1106 (thermally annealed alloy 709).

- Precipitates are $(\mathrm{CrMoV})_{23} \mathrm{C}_{6}$ and $(\mathrm{VNb})(\mathrm{CN})$ in as-received $\mathrm{G} 91$, and $(\mathrm{CrWMoV})_{23} \mathrm{C}_{6},(\mathrm{VNb})(\mathrm{CN})$ in as-received $\mathrm{G} 92 . \mathrm{Fe}^{2+}$ rastered irradiation at $350{ }^{\circ} \mathrm{C} 50$ dpa amorphized $\mathrm{M}_{23} \mathrm{C}_{6}$ particles in both alloys.

\section{Voids}

- Significant void swelling took place in $\mathrm{FeCrNi}$ (model 709) after $\mathrm{Fe}^{2+}$ rastered irradiation at $670{ }^{\circ} \mathrm{C}$ $50 \mathrm{dpa}$. No voids have been found in other irradiated TEM samples (Tables 1 and 2).

\section{Experimental details}

\section{III-2-1. Proton-irradiated 316H, alloy 709 and FeCrNi (model 709)}

\section{III-2-1-1. SEM analysis of proton-irradiated $316 \mathrm{H}$ and alloy 709}

Alloy 709 and $316 \mathrm{H}$ irradiated by $2 \mathrm{MeV}$ protons at $670{ }^{\circ} \mathrm{C}$ up to $0.5 \mathrm{dpa}, 1 \mathrm{dpa}$ and $1.5 \mathrm{dpa}$ have been investigated using SEM in conjunction with energy dispersive spectroscopy (EDS) using JEOL JSM-6610. 
Fig. III-2-1 compares secondary electron images of the 6 samples. Oxides form on the surface of $670{ }^{\circ} \mathrm{C}$ 0.5 dpa and 1 dpa proton irradiated alloy 709 , as the dark clusters in 0.5 dpa 709 , and the dark patches in 1 dpa 709. The 1 dpa 709 images show that oxide layer breaks off as irradiation dose increases. After 1.5 dpa irradiation no apparent surface oxide remains. There are significant cracks at surface grain boundaries of 709. Cracks are much less at the surface grain boundary of $316 \mathrm{H}$ than 709 . This is unexpected observation and future investigation are needed with cross-sectional samples when the sample radioactivity decreases to a safe value.

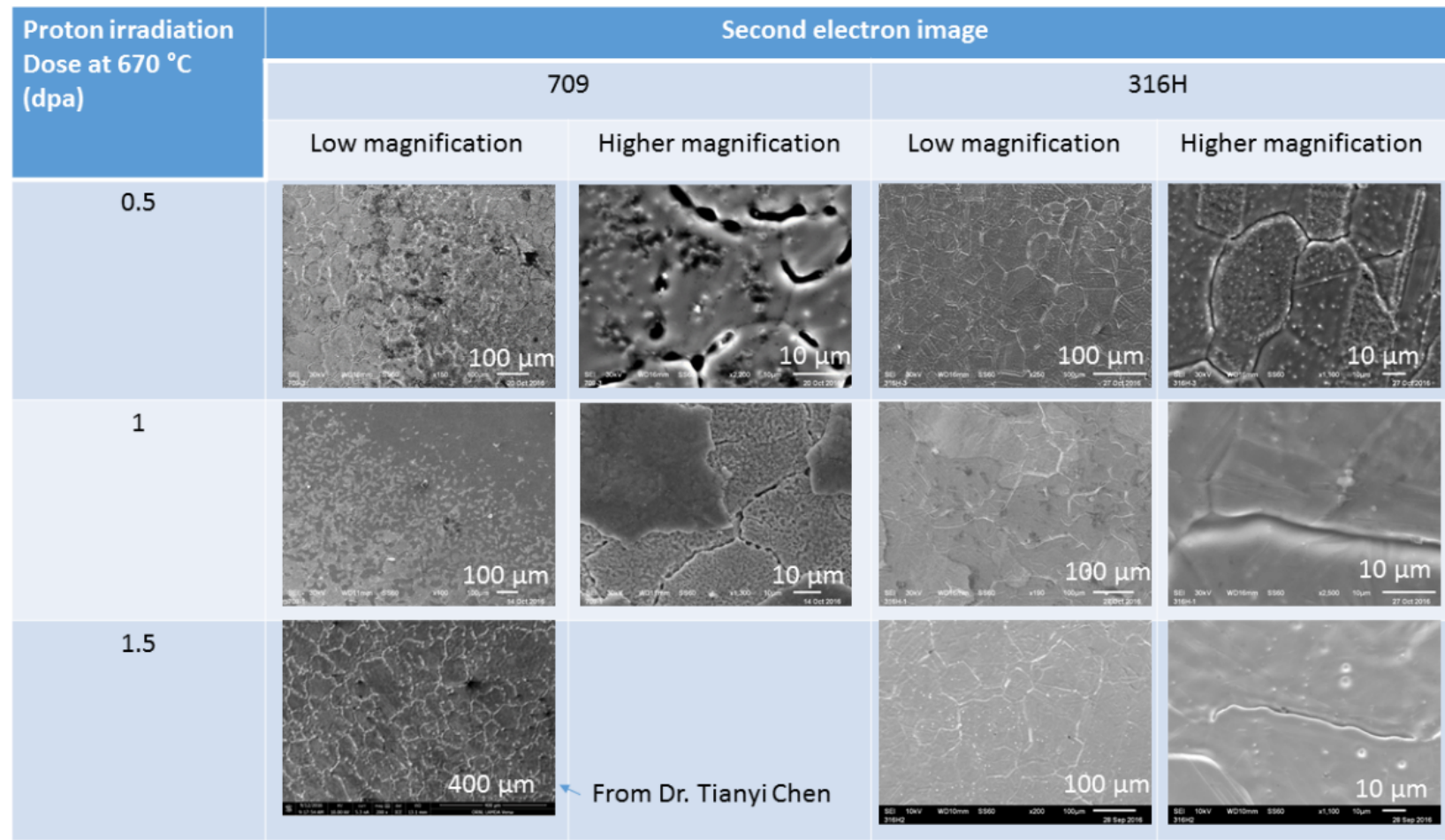

Fig. III-2-1. Secondary electron images of proton-irradiated alloy 709 and 316H.

\section{III-2-1-2. TEM characterization of unirradiated and proton irradiated FeCrNi to 0.01 dpa}

Fig. III-2-2 shows TEM and STEM images of FeCrNi that was covered by masks during proton irradiation to $0.01 \mathrm{dpa}$ at $670{ }^{\circ} \mathrm{C}$. It was not irradiated but experienced the same heating history as the irradiated part, $670{ }^{\circ} \mathrm{C}$ for about $30 \mathrm{~min}$. 


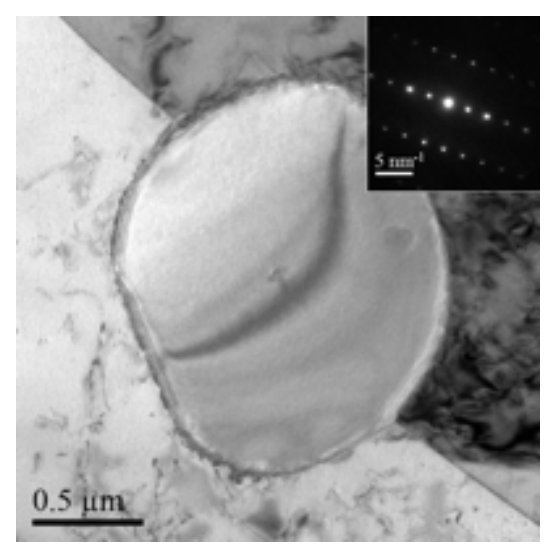

(a)

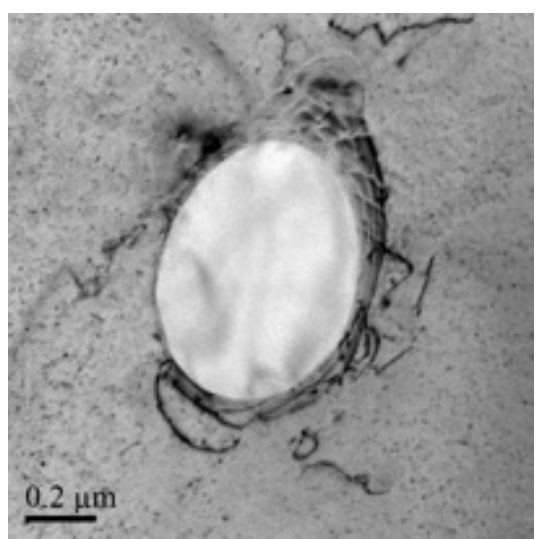

(b)

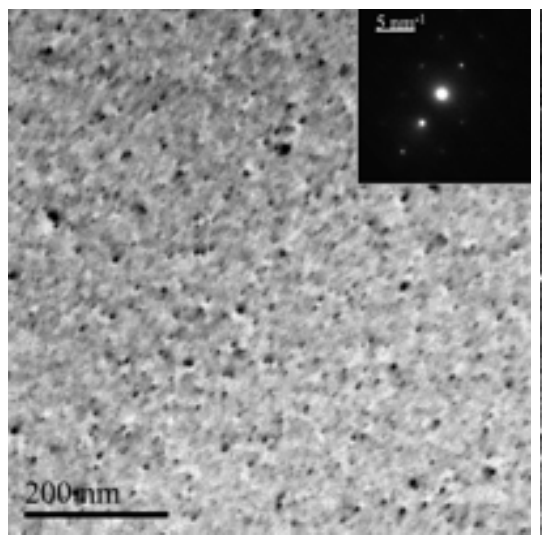

(c)

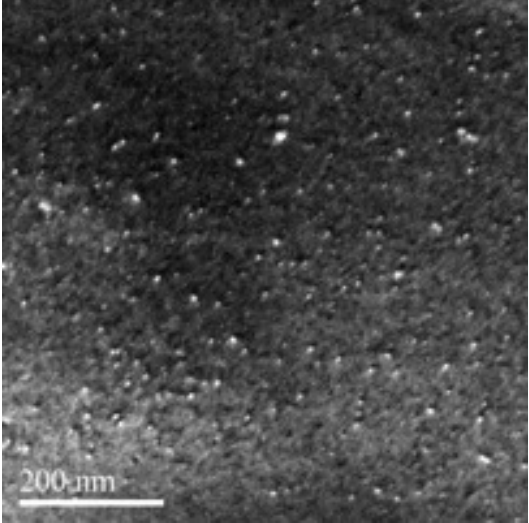

(d)

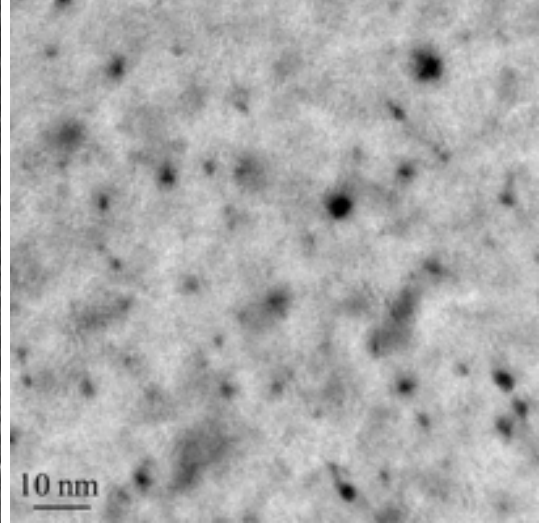

(e)

Fig. III-2-2. TEM and STEM images of reference FeCrNi, unirradiated but experienced the same thermal history (i.e., $670{ }^{\circ} \mathrm{C}$ ). (a-c) Bright field images and diffraction patterns. (d) Weak beam dark field image at the same area of (c). (e) Annular bright field image.

The precipitates in FeCrNi alloy are several hundred nanometers in size, as shown in Fig. III-2-2a and III2-2b. TEM-EDS measured the particle composition in Fig. 2a is $\mathrm{CrO}_{2}$. The composition of the particle in Fig. III-2-2b is $62 \mathrm{Cr}-22 \mathrm{~S}-14 \mathrm{Fe}-2 \mathrm{Ni}$ in atomic percent, close to $\mathrm{Cr}(\mathrm{FeNi})_{4} \mathrm{~S}$.

Fig. III-2-2c to $2-2 \mathrm{e}$ show high density of dark spots in bright field images of $1.7 \pm 0.1 \mathrm{~nm}$ in size, which are speculated to be FIB induced dislocation loops.

Fig. III-2-3 shows TEM and STEM images of FeCrNi after proton irradiation to $0.01 \mathrm{dpa}$ at $670{ }^{\circ} \mathrm{C}$. 


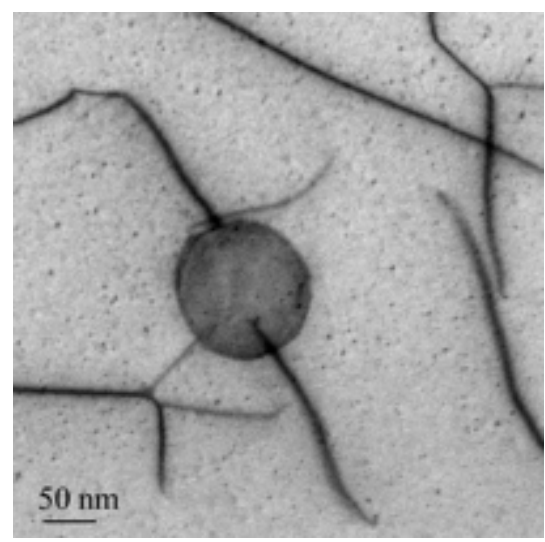

(a)

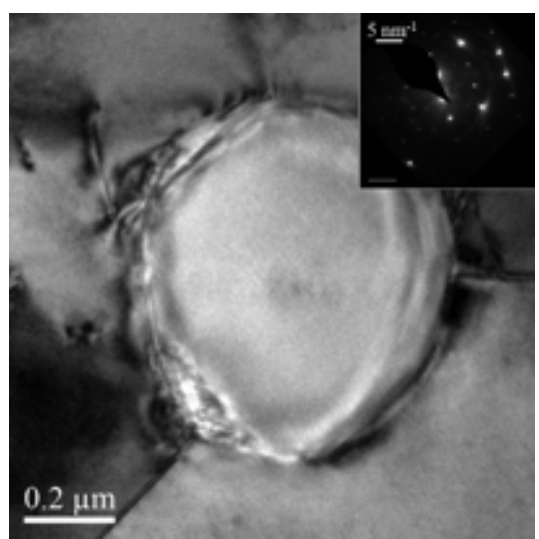

(b)

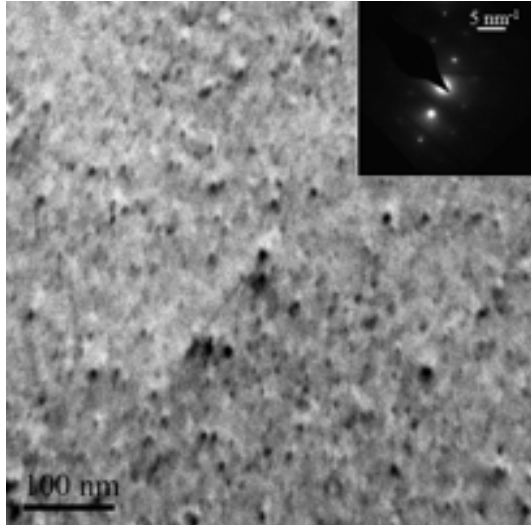

(c)

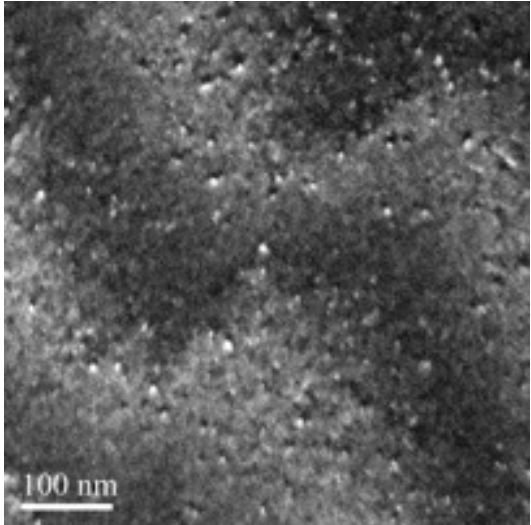

(d)

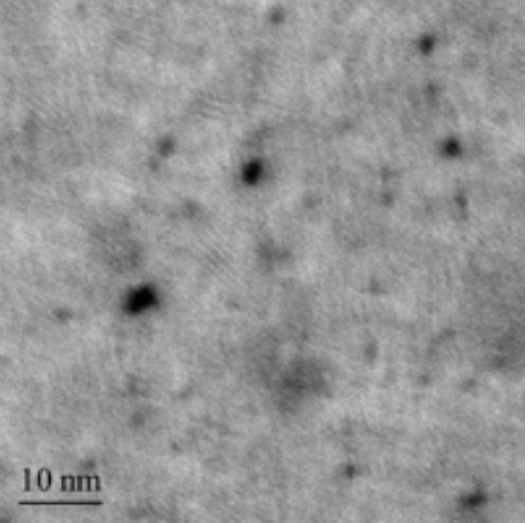

(e)

Fig. III-2-3. TEM and STEM images of FeCrNi irradiated to 0.01 dpa at $670{ }^{\circ} \mathrm{C}$ with proton. (a, e) Annular bright field image. (b, c) Bright field images and diffraction patterns. (d) Weak beam dark field image at the same area of (c).

EDS analysis indicated the precipitates in Fig. III-2-3a to be $\mathrm{Cr}(\mathrm{FeNi})_{x} \mathrm{~S}$, while the particle in Fig. III-2-3b was $\mathrm{Cr}_{2} \mathrm{O}_{3}$. The diffraction pattern in Fig. III-2-3b has diffraction vectors $3.8 \mathrm{~nm}^{-1}$ and $5.6 \mathrm{~nm}^{-1}$. The angle between the two vectors is $93^{\circ}$. The pattern resembles triclinic $\mathrm{Cr}_{2} \mathrm{O}_{3}<011>$ zone diffraction.

Fig. III-2-3c-e show dislocation loop-like contrast in the $670{ }^{\circ} \mathrm{C} 0.01$ dpa proton irradiated FeCrNi. The average size of the spot contrast is $2.0 \pm 0.1 \mathrm{~nm}$.

Fig. III-2-4 shows the TEM and STEM images of reference FeCrNi that was not irradiated but heated at $380^{\circ} \mathrm{C}$. 


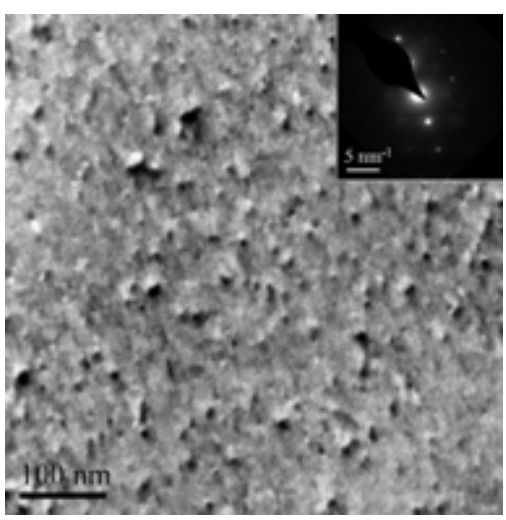

(a)

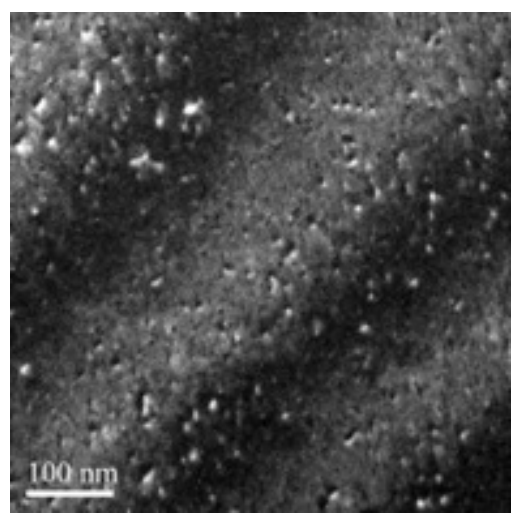

(b)

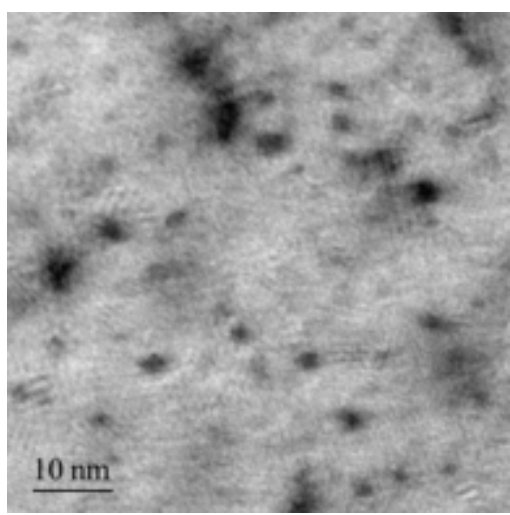

(c)

Fig. III-2-4. TEM and STEM images of reference FeCrNi, unirradiated but heated at $380{ }^{\circ} \mathrm{C}$. (a) Bright field image and diffraction pattern. (b) Weak beam dark field image at the same area of (a). (c) Annular bright field image.

Dislocation loop-like structures were observed in unirradiated FeCrNi alloy, reference to the irradiated $\mathrm{FeCrNi}$ at $380{ }^{\circ} \mathrm{C}$. Their average size is $1.9 \pm 0.1 \mathrm{~nm}$. A $\mathrm{Cr}(\mathrm{FeNi})_{\mathrm{x}} \mathrm{S}$ precipitate was also observed in the sample. Fig. III-2-5 shows STEM images proton irradiated FeCrNi to 0.01 dpa at $380{ }^{\circ} \mathrm{C}$.

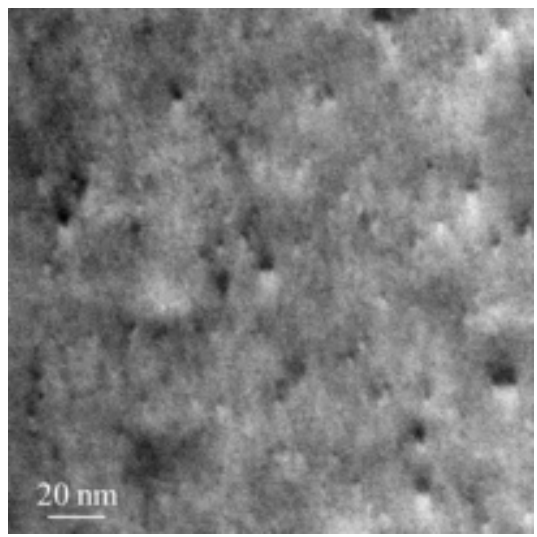

Fig. III-2-5. Annular bright field image of proton irradiated $\mathrm{FeCrNi}$ at $380{ }^{\circ} \mathrm{C}$ to $0.01 \mathrm{dpa}$.

Dislocation loop-like structures exist in proton irradiated $\mathrm{FeCrNi}$ at $380{ }^{\circ} \mathrm{C}$ to $0.01 \mathrm{dpa}$. Precipitates were measured to be either $\mathrm{CrO}_{2}$ or $\mathrm{Cr}(\mathrm{FeNi})_{\mathrm{x}} \mathrm{S}$. 


\section{III-2-1-3. Summary of 0.01 dpa proton irradiation result to $\mathrm{FeCrNi}$}

Small dislocation loop-like structures are present in all of four FeCrNi TEM samples, including two reference samples, two samples irradiated to a damage level of $0.01 \mathrm{dpa}$ at $10 \mu \mathrm{m}$ depth with protons at $670{ }^{\circ} \mathrm{C}$ and $380{ }^{\circ} \mathrm{C}$, respectively. The size of the dislocation-loop like structures in the four samples are similar, about $2 \mathrm{~nm}$ on average. TEM samples were prepared with FIB using $30 \mathrm{keV}, 5 \mathrm{keV}$, and finally 2 $\mathrm{keV} \mathrm{Ga}$ ion milling. It is possible that the dislocation loop-like structures are induced by FIB.

Proton irradiations of $0.01 \mathrm{dpa}$ at $380{ }^{\circ} \mathrm{C}$ and $670{ }^{\circ} \mathrm{C}$ appear not to generate significant structural change.

\section{$\underline{\text { III-2-2. TEM analysis of as-received and } \mathrm{Fe}^{2+} \text {-irradiated alloys } 709 \text { and } 316 \mathrm{H} \text { at } 350{ }^{\circ} \mathrm{C}, 50 \mathrm{dpa}}$}

\section{III-2-2-1. As-received alloy 709}

Fig. III-2-6 shows the surface structure of the as-received alloy 709. The material exhibits uniaxial grains with sizes of over $20 \mu \mathrm{m}$. Comparable fractions of grain boundaries are found to be flat (i.e., coincidence site lattice (CSL) boundaries, including coherent twin boundaries) or curved (i.e. random angle boundaries), and the twin lamella are widespread within the uniaxial grains. Precipitates with bright contrast were occasionally observed on the polished surface, and more frequently in the bulk. The average composition of the as-received sample was measured by EDS (operated at $20 \mathrm{kV}$ ), as follows:

\begin{tabular}{|l|l|l|l|l|l|l|l|l|}
\hline & $\mathrm{Fe}$ & $\mathrm{Cr}$ & $\mathrm{Ni}$ & $\mathrm{Si}$ & $\mathrm{Mn}$ & $\mathrm{Nb}$ & $\mathrm{Mo}$ & $\mathrm{C}, \mathrm{N}$ \\
\hline wt. \% & 54.1 & 19.4 & 23.9 & 0.3 & 0.2 & 0.9 & 1.2 & $<0.1$ \\
\hline
\end{tabular}

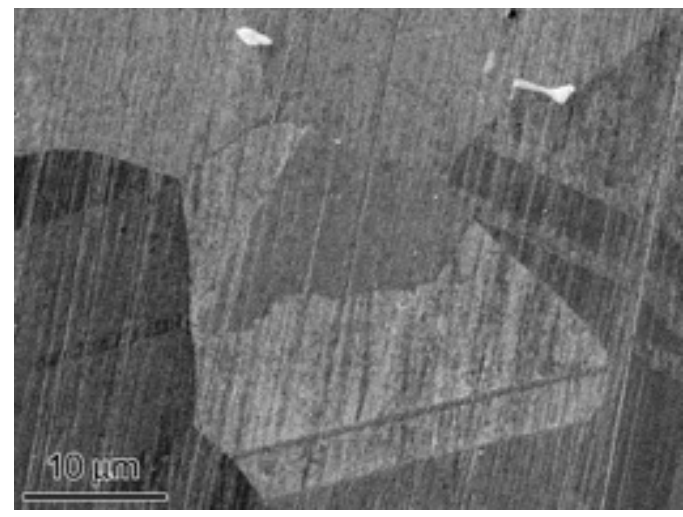

Fig. III-2-6. SEM (Secondary-electron) image of surface morphology of as-received alloy 709. Beam energy was $5 \mathrm{kV}$. 
Cross-sectional TEM specimen was further prepared using FIB. Overview of the as-received microstructure in Fig. III-2-7 shows various features of interest. Nonetheless, current results only addressed two issues, i) segregation of alloying elements at grain boundaries, and ii) composition of precipitate phases.

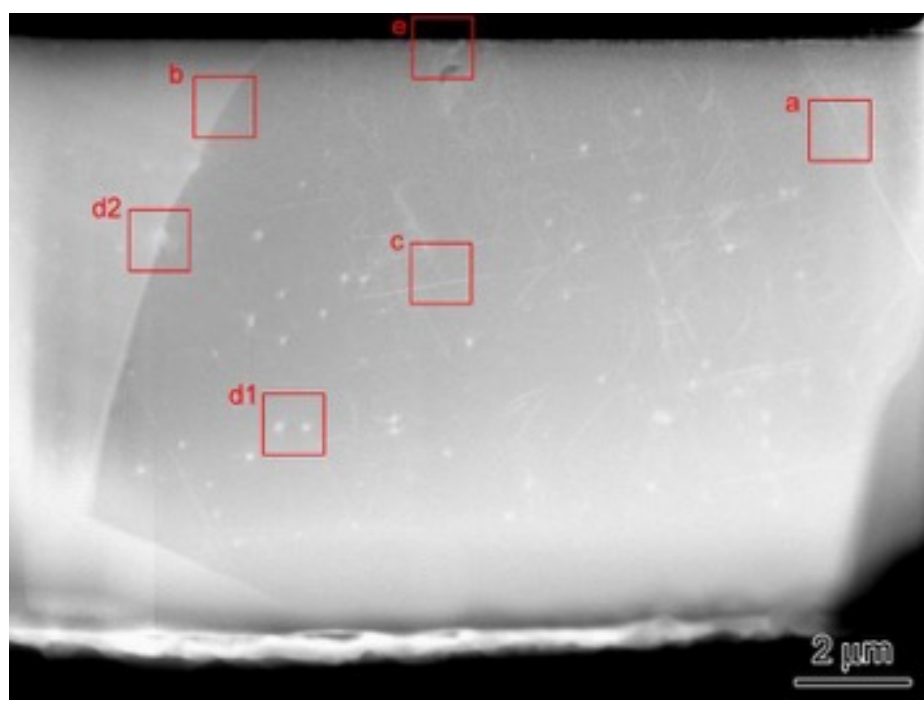

Fig. III-2-7. HAADF-STEM image of a cross-sectional specimen of as-received alloy 709. The microstructural features of interest are marked with boxes. a: coherent twin boundary; b: random angle boundary; c: dislocation lines; d1: precipitate within grains; $\mathrm{d} 2$ : precipitate on boundaries; e: precipitate on surface.

Both special CSL and random angle boundaries were observed in the cross-sectional specimens. Fig. III2-8(a) shows a $\Sigma 3 /$ (111) twin boundary with an atomic-level smooth boundary plane, and Fig. 2-8(b) confirms negligible variation of composition near these CSL boundaries. By contrast, Fig. III-2-8(c) shows a random high-angle boundary in an approximately edge-on orientation. Diffraction analysis (details not shown here) suggested the grain boundary character to be close to $(12 \overline{5}) / 56^{\circ}$, and the boundary plane close to $(\overline{1} 10)$ on the left side and (021) on the right side. Slight segregation of Mo (and Cr) is detected by EDS line-scan, as shown in Fig. 8(d) shows, owing to the relatively loose-packed boundary structure. Interestingly, no segregation of $\mathrm{Nb}, \mathrm{C}$, and $\mathrm{N}$ can be observed, even though precipitate (see following results) is found at the boundary. 

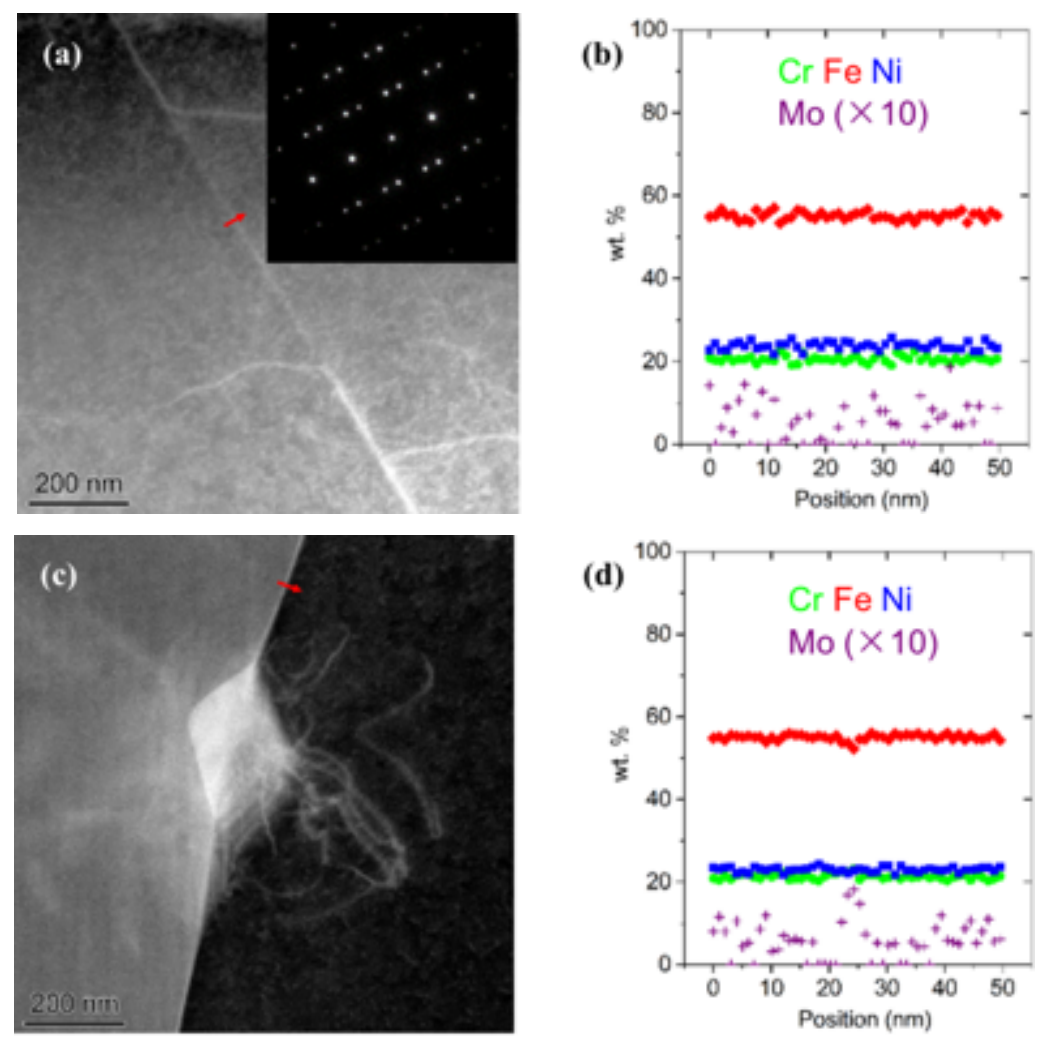

Fig. III-2-8. Segregation of alloying elements at grain boundaries in as-received alloy 709. (a) HAADF image of a coherent twin boundary. Inset: selected-area diffraction pattern. (b) EDS line-scan profiles along the arrow in (a). (c, d) Results of a random high-angle boundary.

Precipitates are found to be widespread in the cross-sectional specimen of as-received alloy 709, with various shapes and locations including grain interior, random high-angle boundary, and surface (see boxes d1, d2, and e in Fig. III-2-7, respectively). EDS line-scans and high-resolution HAADF-STEM images (at various zone axes) were performed to identify the phase and composition of up to 6 precipitates. As shown in Fig. III-2-9, all precipitates studied possess a composition close to $\mathrm{NbC}_{0.5} \mathrm{~N}_{0.5}$ with a MX type (rocksalt) crystal structure. In addition, no evidence of orientation relationship between the precipitates (lattice constant $\sim 4.5 \AA$ ) and the austenite matrix (lattice constant $\sim 3.6 \AA$ ) was observed. 

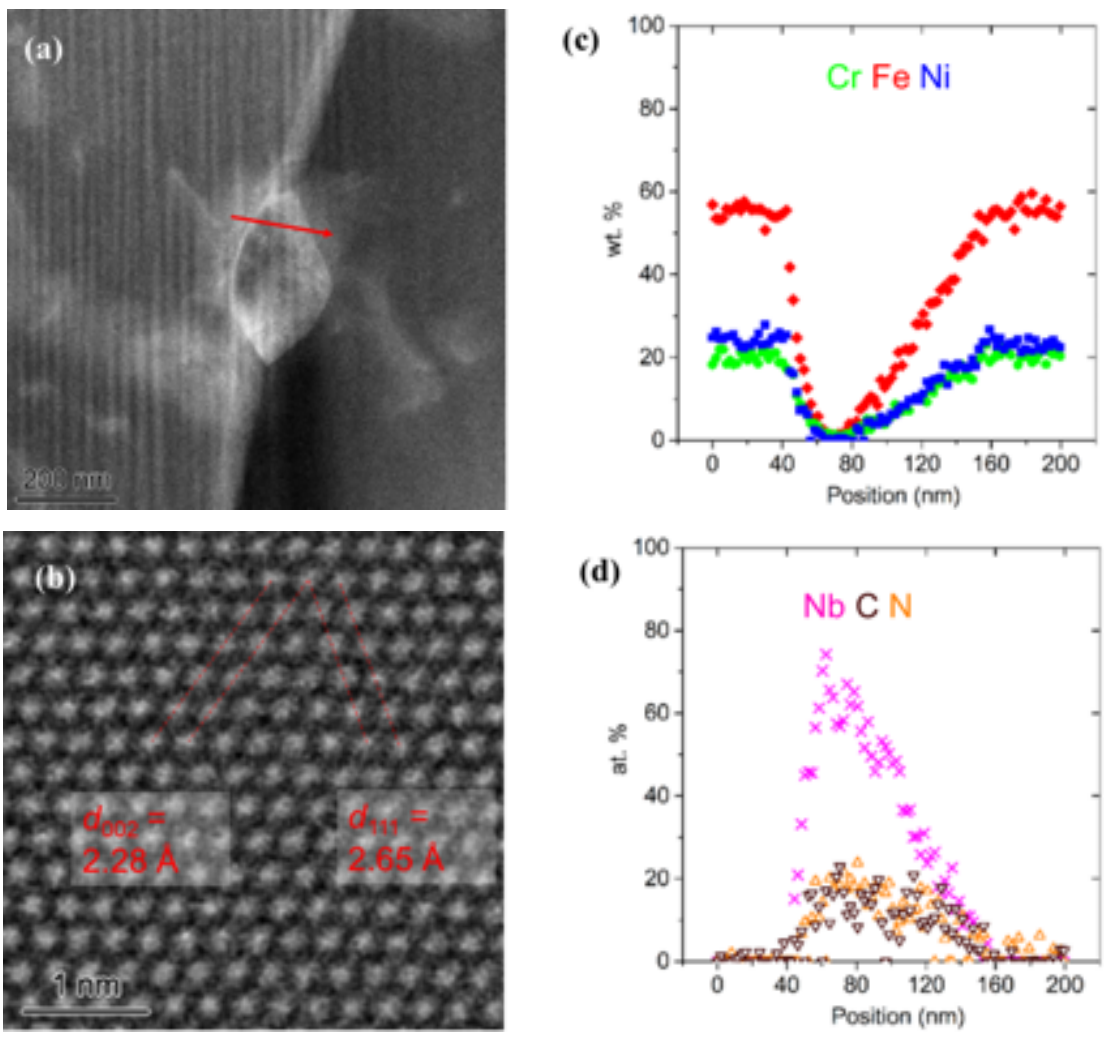

Fig. III-2-9. Characterization of precipitates in as-received alloy 709. (a) HAADF image of a representative precipitate located at grain boundary. (b) HRSTEM image of the precipitate along [110] zone axis. (c, d) EDS line-scan profiles along the arrow in (a).

\section{$\underline{\text { III-2-2-2. } \mathrm{Fe}^{2+} \text {-irradiated } 709 \text { at } 350^{\circ} \mathrm{C} \text { to } 50 \mathrm{dpa}}$}

FigIII-2-10(a) shows the surface morphology of alloy 709 after irradiation with $3.7 \mathrm{MeV} \mathrm{Fe}^{2+}$ ions at $350{ }^{\circ} \mathrm{C}$ to $50 \mathrm{dpa}$ at depth of $0.46 \mu \mathrm{m}$. The grain size is comparable to the as-received material, and twin boundaries were also extensively observed. Oxidation of the original surface was very slight and seems to be dependent on the orientation of exposed grains (details presented later). Cross-sectional TEM specimen of the ionirradiated sample was also prepared using FIB, as represented in FigIII-2-10(b). The surface oxidation layer is confirmed to be very thin, while the damage layer with thickness of $\sim 2 \mu \mathrm{m}$ could be clearly resolved. Grain boundary segregation and precipitates were further characterized and compared with the as-received microstructure. 

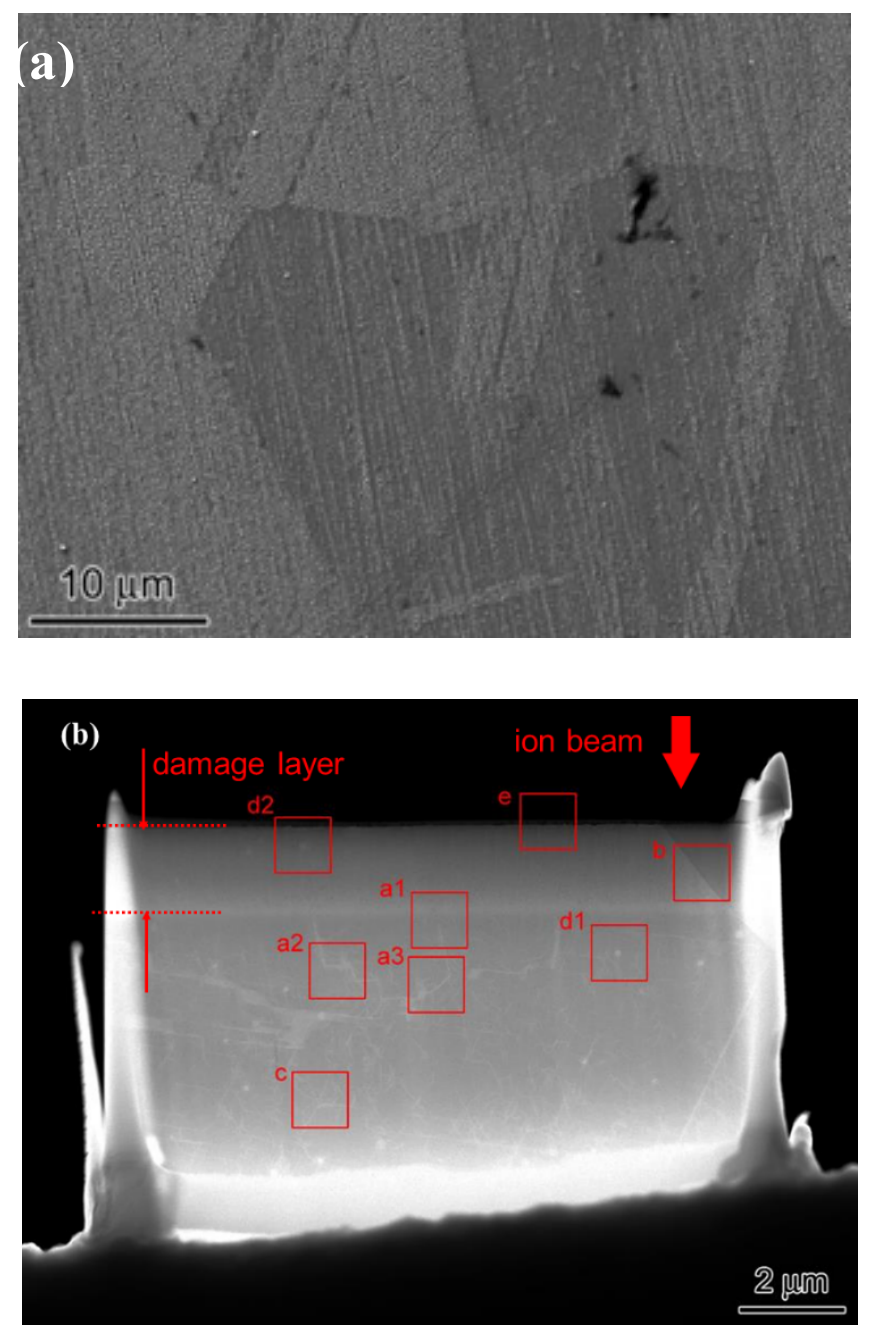

Fig. III-2-10. Overview of iron-irradiated alloy 709. (a) SEM secondary-electron image of surface morphology. Beam energy is $5 \mathrm{kV}$. (b) HAADF-STEM image of cross-sectional specimen. Damage layer shows a distinct contrast, and other microstructural features of interest are marked with boxes. a1: coherent twin boundary; a2: incoherent twin boundary; a3: other CSL boundary; b: random angle boundary; c: dislocation lines; d1: precipitate within grains; d2: precipitate on boundaries; e: surface oxides.

FigIII-2-11(a) shows the surface morphology of ion-irradiated alloy 709 under a higher magnification. Some grains are found to be covered with large amounts of fine particles, while others (with different normal directions) show remarkably cleaner surface comparable to the as-received samples. Nonetheless, cross-sectional view in FigIII-2-11(b) indicates that the irradiated sample surface was uniformly covered with a thin layer of oxide, though larger oxide particles were observed sparsely. Thickness of the particle layer is still below $\sim 100 \mathrm{~nm}$. As shown in FigIII-2-11(c) and FigIII-2-11(d), EDS line-scans and HRSTEM images suggest that the uniform oxide layer is close to $\mathrm{FeCr}_{2} \mathrm{O}_{4}$ (spinel), while the oxide particles are almost $\mathrm{Fe}_{3} \mathrm{O}_{4}$ (spinel). 

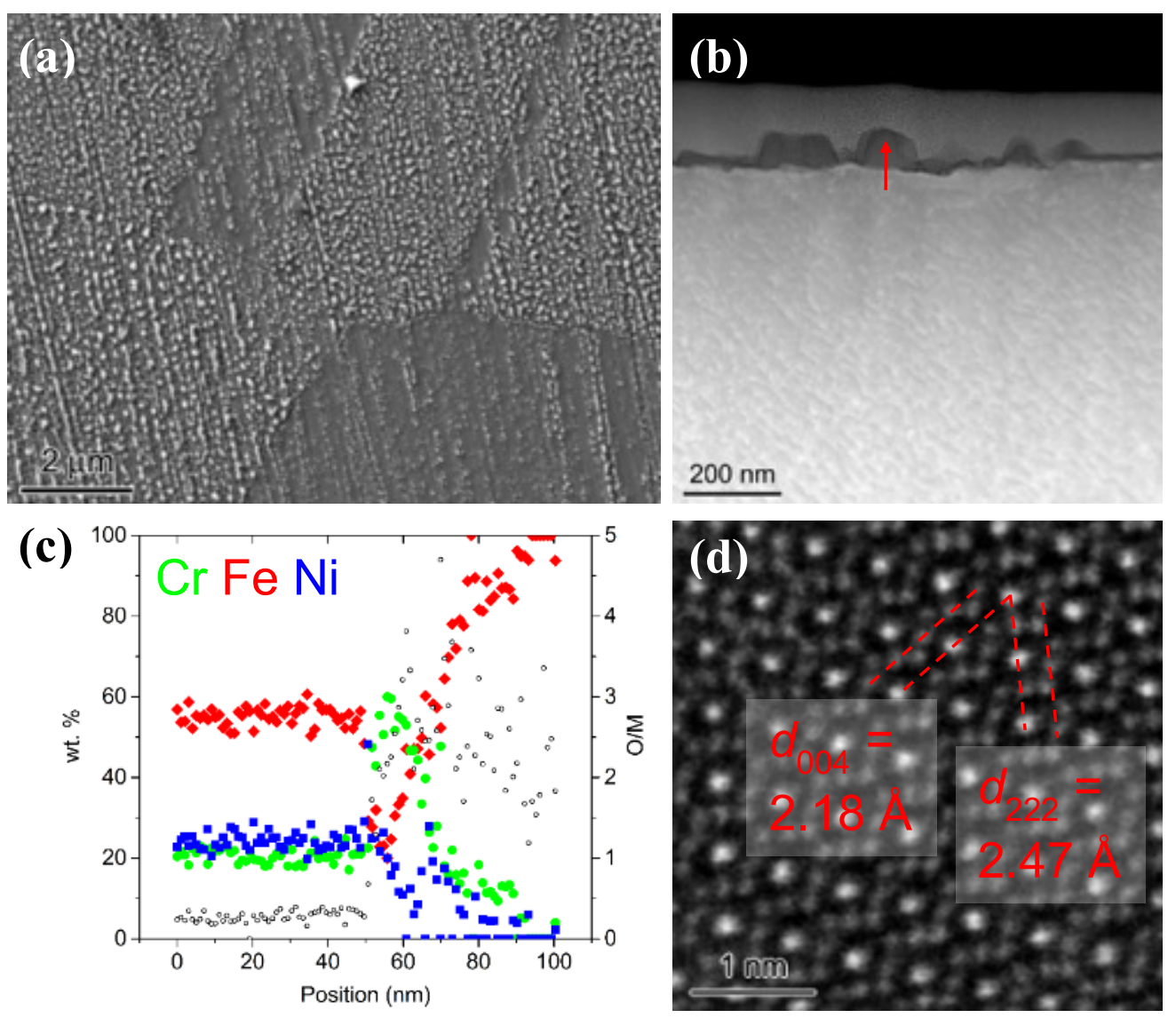

Fig. III-2-11. Characterization of surface oxidation layer of ion-irradiated alloy 709. (a) High-magnification SEM image of surface. (b) HAADF image of near-surface region of cross-sectional specimen with oxide particles. (c) EDS line-scan profiles along the arrow in (b). (d) HRSTEM image of an oxide (spinel) particle along [110] zone axis.

Depth distribution of radiation-induced defects is shown in Fig. III-2-12(a) using a (g, 5g) weak-beam darkfield (WBDF) condition with $\mathbf{g}=1 \overline{1} 1$. Beam direction is close to $[\overline{1} \overline{1} 0]$. A heavily damaged layer with thickness of $\sim 2 \mu \mathrm{m}$, as seen in FigIII-2-10(b), could be resolved. It is qualitatively clear that the defect density reached the maximum at a depth of $\sim 2 \mu \mathrm{m}$, then dropped significantly, and the thickness of damage layer seems to be uniform in grains with different orientations relative to the incident ion beam.

Fig. III-2-12(b-d) shows the method of diffraction contrast analysis to determine the nature of defects. The contrast of the two loops marked in Fig. III-2-12(b-d) is consistent with a Frank loop with $\mathbf{b}=[\overline{1} 11] / 3$ (blue circle) and a perfect loop with $\mathbf{b}=[101] / 2$ (yellow circle), both of interstitial-type. The loop sizes are close to $\sim 10 \mathrm{~nm}$ and are consistent through the damage layer. Moreover, segregation of alloying elements (e.g., 
Mo) around dislocation loops and the widespread dislocation lines were examined, but no compelling evidence has been obtained yet.

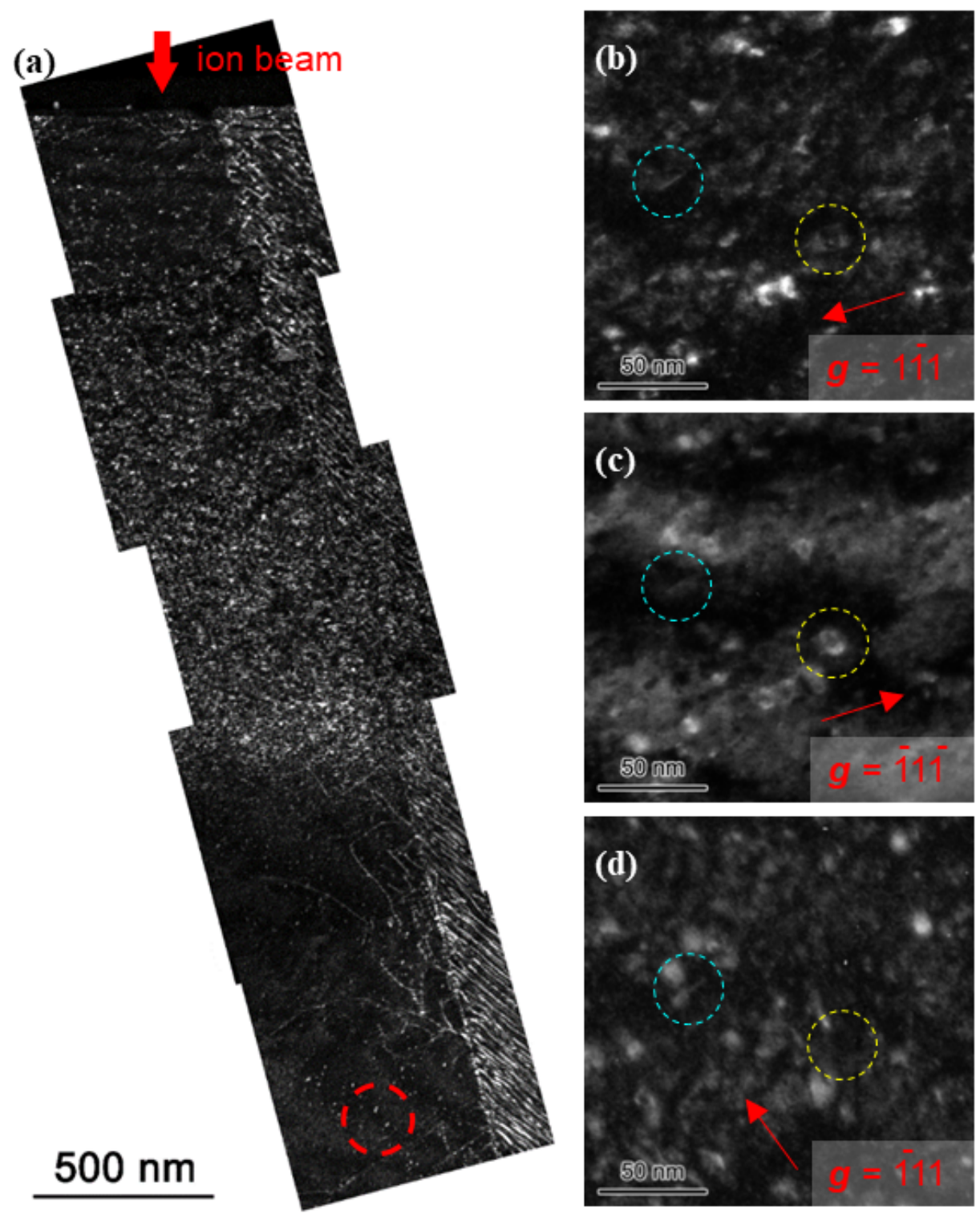

Fig. III-2-12. Diffraction contrast analysis of radiation-induced defects (dislocation loops) in $\mathrm{Fe}^{2+}$-irradiated alloy 709. (a) WBDF image of damage layer using (g, 5g) condition with $\mathbf{g}=1 \overline{1} 1$. Discrete defects (red circle) can be seen beyond the depth of maximum damage. (b-d) WBDF images of the same defects using different (g, 5g) conditions. Interstitial-type Frank loop (blue circle) and perfect loop (yellow circle) can be identified.

We applied rel-rod imaging technique to display Frank dislocation loops which have Burger's vector $\mathrm{a} / 3<111>$ ( $\mathrm{a}$ is the lattice constant). Fig. III-2-13 shows the dislocation loops in $\mathrm{Fe}^{2+}$ irradiated 709 at 0.35 $\mu \mathrm{m}$ under the surface where damage is about 44 dpa from SRIM calculation. Fig. III-2-14 shows the Frank 
loops at damage level about $58 \mathrm{dpa}$. The (11) Frank loops are of $1.3 \times 10^{22} \mathrm{~m}^{-3}$ at $58 \mathrm{dpa}$. Assuming equal

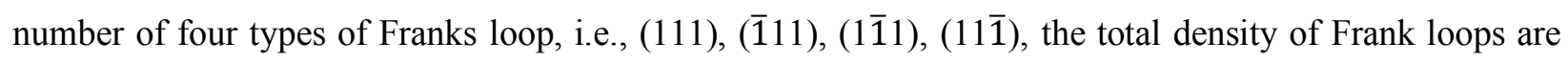
estimated as $5.2 \times 10^{22} \mathrm{~m}^{-3}$ at $58 \mathrm{dpa}$. The average Frank loop size is $14.2 \pm 0.6 \mathrm{~nm}$. Fig. III-2-14(c) shows the Frank loop size distribution.
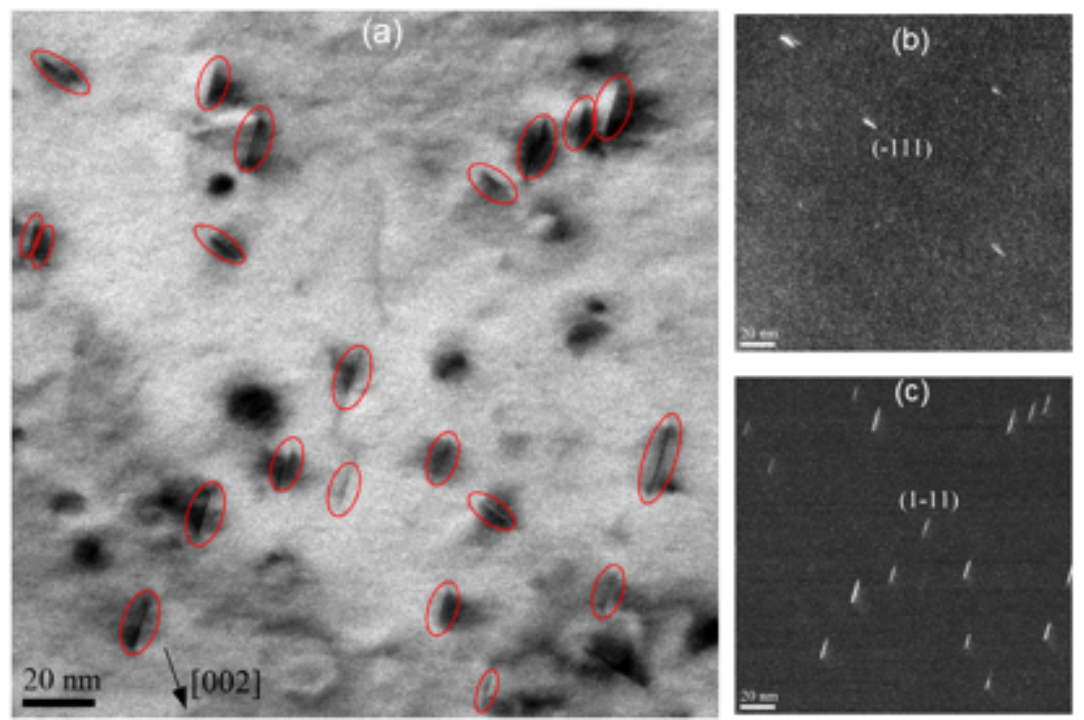

Fig. III-2-13. TEM images of $\mathrm{Fe}^{2+}$ irradiated 709 up to about $44 \mathrm{dpa}, 360{ }^{\circ} \mathrm{C}$ near [110] zone. (a) Bright field image with diffraction vector [002]. Circled are Frank loops. (b) Relrod dark field image displaying $(-111)$ plane Frank loops $(b=a / 3$ [-111]) in the same sample area of (a). (c) Relrod image of (1-11) Frank loops $(b=a / 3[1-11])$.

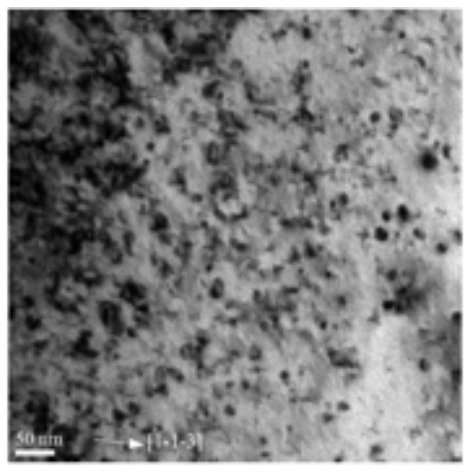

(a)

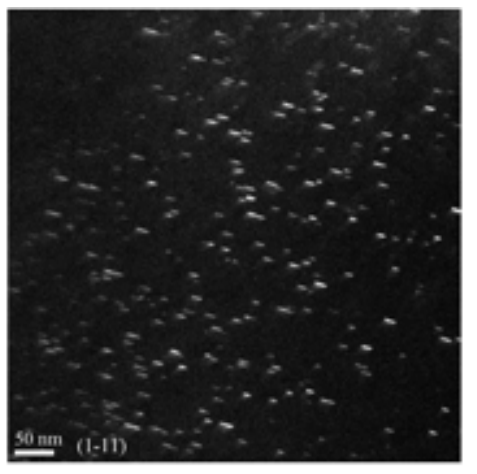

(b)

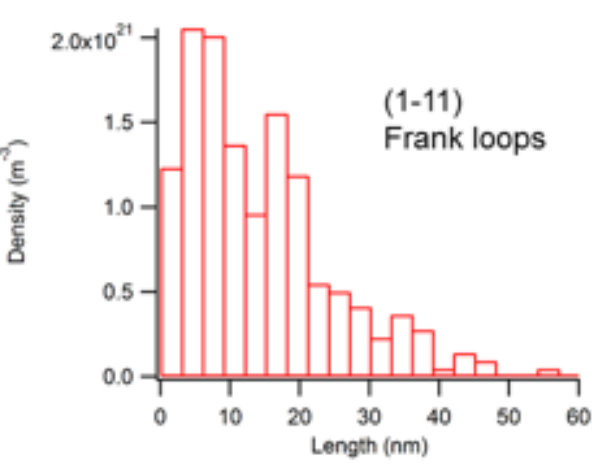

(c)

Fig. III-2-14. TEM images of $\mathrm{Fe}^{2+}$ irradiated 709 up to about $58 \mathrm{dpa}, 360{ }^{\circ} \mathrm{C}$ near [110] zone. (a) Bright field image with diffraction along [1-1-3]. (b) Relrod image of (1-11) Frank loops in the same area of (a). (c) Density and size distribution of (1-11) Frank loops in (b). 
Fig. III-2-15 presents average size and density of Frank loops versus depth from surface. Frank loop size increases with depth up to about peak damage depth and then drops at the end of damage range. Frank loops density varies with locations even of the same depth, as shown in Fig. III-2-15(b).

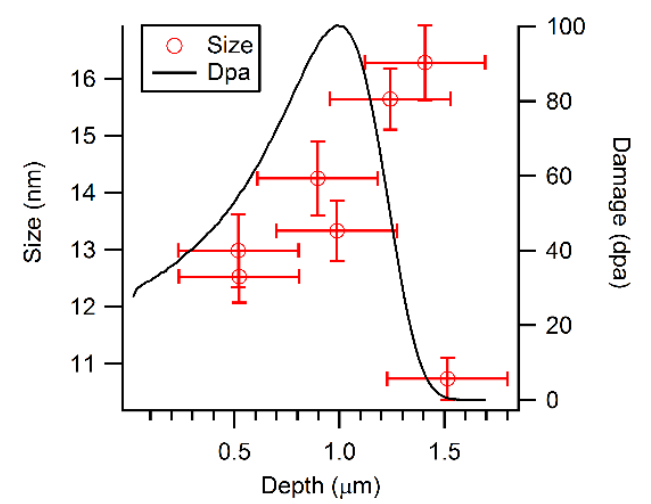

(a)

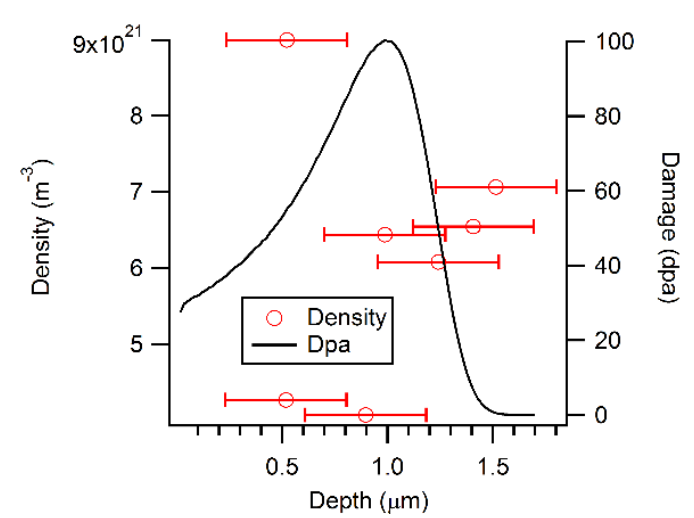

(b)

Fig. III-2-15. TEM measurement of (111) Frank loops in $\mathrm{Fe}^{2+}$ irradiated 709 to 50 dpa at $0.46 \mu \mathrm{m}, 350{ }^{\circ} \mathrm{C}$. (a) Average size. (b) Density (SRIM calculated damage level is also shown).

Fig. III-2-16(a) shows a $\Sigma 3$ / (111) coherent twin boundary within the damage layer of the ion-irradiated sample, and Fig. III-2-16(b) shows that radiation-induced segregation (RIS) of any alloying elements were negligible at these CSL boundaries. By contrast, Fig. III-2-16(c) shows a random high-angle boundary within the damage layer. Diffraction analysis suggests the grain boundary character to be close to [234] / $33^{\circ}$, and the boundary plane close to (331) on the left side and (120) on the right side. A remarkable segregation of $\mathrm{Ni}$ and depletion of $\mathrm{Cr}$ is observed in Fig. III-2-16(d), which is consistent with the RIS observed in other austenitic stainless steels. However, the concentration of Mo was hardly detectable at this boundary. In addition, segregation of other elements $(\mathrm{Nb}, \mathrm{C}$, and $\mathrm{N})$ was also not observed after irradiation.
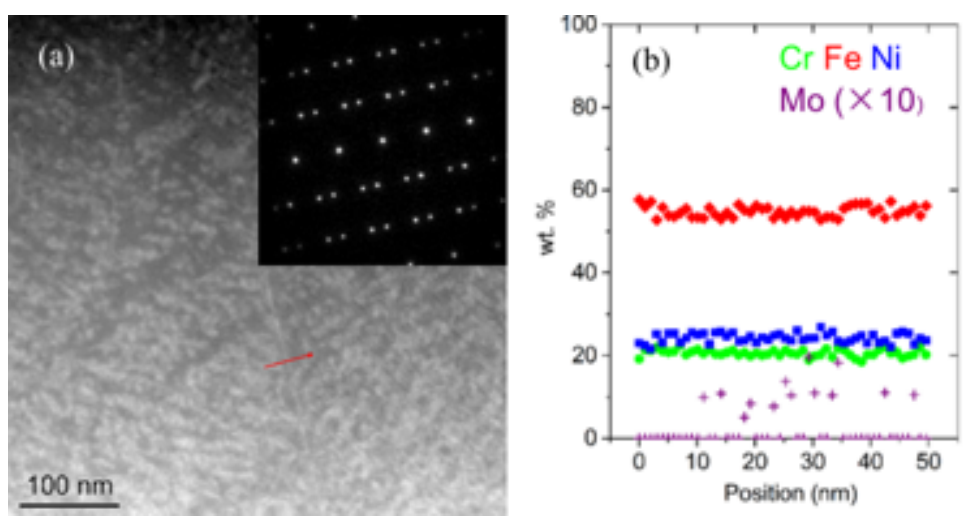

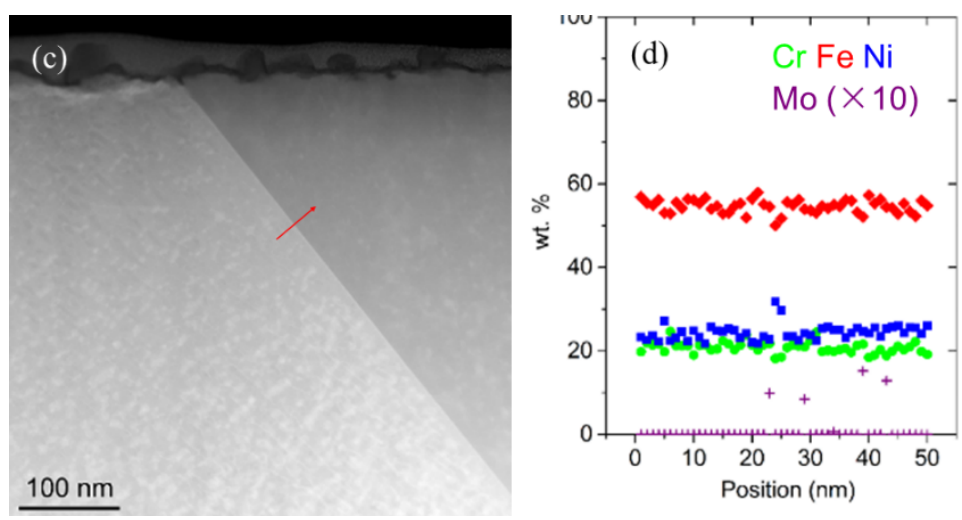

Fig. III-2-16. Segregation of alloying elements at grain boundaries in $\mathrm{Fe}^{2+}$-irradiated alloy 709. (a) HAADF image of a coherent twin boundary. Inset: selected-area diffraction pattern. (b) EDS line-scan profiles along the arrow in (a). (c, d) Results of a random high-angle boundary.

Other than the common $\Sigma 3$ / (111) coherent twin boundary, the cross-sectional specimen of ion-irradiated sample further presents popularity of other types of CSL boundaries, such as $\Sigma 3$ incoherent twin boundary and $\Sigma 9$ boundary, as shown in Fig. III-2-27(a) and Fig. III-2-27(c), respectively. These features were not observed in the as-received sample; however, this may be just due to the limited sampling volume. Another feature of the cross-sectional specimen of ion-irradiated alloy 709 is the high density of linear defects seen in some specific grains (e.g., the lower-left of Fig. III-2-27(a) and the upper-right of Fig. III-2-27(c)), which seem to be edge dislocations along [002] direction and with $\mathbf{b}=[1 \overline{10}] / 2$. The origin of these defects may be FIB induced artifacts $(\underline{18})$.
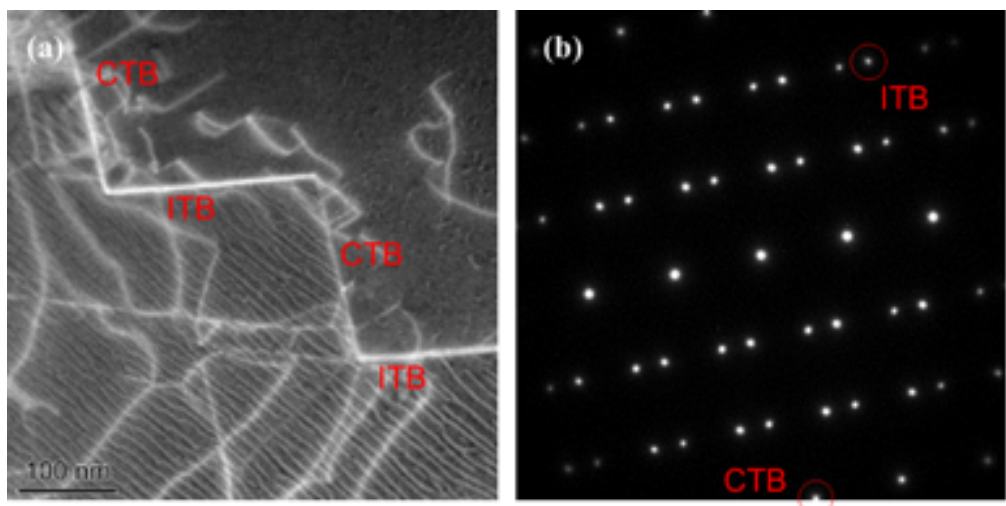

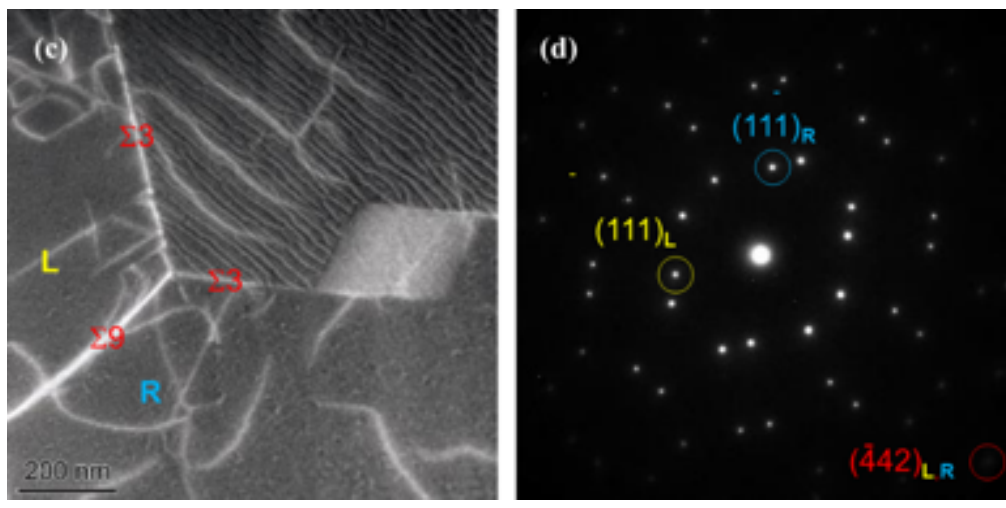

Fig. III-2-27. Various types of CSL boundaries in ion-irradiated alloy 709. (a, b) $\Sigma 3 /(1 \overline{1} 1)$ coherent twin boundary and $\Sigma 3$ incoherent twin boundary. Twin plane is $\overline{2} 23$ on the bottom side and $\overline{(4} 411)$ on the top side. (c, d) $\Sigma 3 /(1 \overline{1} 1)$ coherent twin boundaries and $\Sigma 9 /(\overline{2} 21)$ boundary at a triple junction.

Precipitates were also widespread in the cross-sectional specimen of $\mathrm{Fe}^{2+}$-irradiated alloy 709 . They were observed both within and outside the damage layer, and occasionally observed at grain boundaries (not shown here). As represented in Fig. III-2-38, all precipitates studied yet retain their MX (rocksalt) crystal structure in the as-received sample, and a composition close to $\mathrm{NbC}_{0.5} \mathrm{~N}_{0.5}$ (the $\mathrm{C} / \mathrm{N}$ ratio may vary between precipitates). However, there is some indication that the composition of precipitates may be modified by ion irradiation. In Fig. III-2-3III-2-18(c) and Fig. III-2-38. Characterization of precipitates in Fe2+irradiated alloy 709. (a) HAADF image of a precipitate located within the damage layer. (c) HRSTEM image of the precipitate along [110] zone axis. (b, d) EDS line-scan profiles along the arrow in (a).8(g) the relative weight ratios of $(\mathrm{Cr}, \mathrm{Fe}, \mathrm{Ni}) /(\mathrm{Cr}+\mathrm{Fe}+\mathrm{Ni})$, instead of their absolute contents, are plotted along the EDS line-scan. We notice that the $\mathrm{Cr} /(\mathrm{Cr}+\mathrm{Fe}+\mathrm{Ni})$ ratio was remarkably increased on the precipitate within the damage layer but was almost constant across the precipitate outside the damage layer. This suggests an enrichment of $\mathrm{Cr}$ in the MX precipitates induced by ion irradiation. Nonetheless, precipitates with other crystal structures were not observed.

Size distribution and number density of all precipitates resolved in the cross-sectional specimens were further quantified. Even though the sampling volume (approximately $10 \mu \mathrm{m} \times 8 \mu \mathrm{m} \times 0.2 \mu \mathrm{m}$ ) is still very limited, Fig. III-2-38. Characterization of precipitates in Fe2+-irradiated alloy 709. (a) HAADF image of a precipitate located within the damage layer. (c) HRSTEM image of the precipitate along [110] zone axis. (b, d) EDS line-scan profiles along the arrow in (a).8(i) suggests an increase of mean size (as-received: $\sim 72$ $\mathrm{nm}$; ion-irradiated: $\sim 90 \mathrm{~nm}$ ) and decrease of number density (as-received: $\sim 2.8 \times 10^{12} \mathrm{~cm}^{-3}$; ion-irradiated: $\sim 1.6 \times 10^{12} \mathrm{~cm}^{-3}$ ) of precipitates induced by irradiation. On the other hand, no significant difference was seen in the size and density of precipitates within and outside the radiation damage layer. 

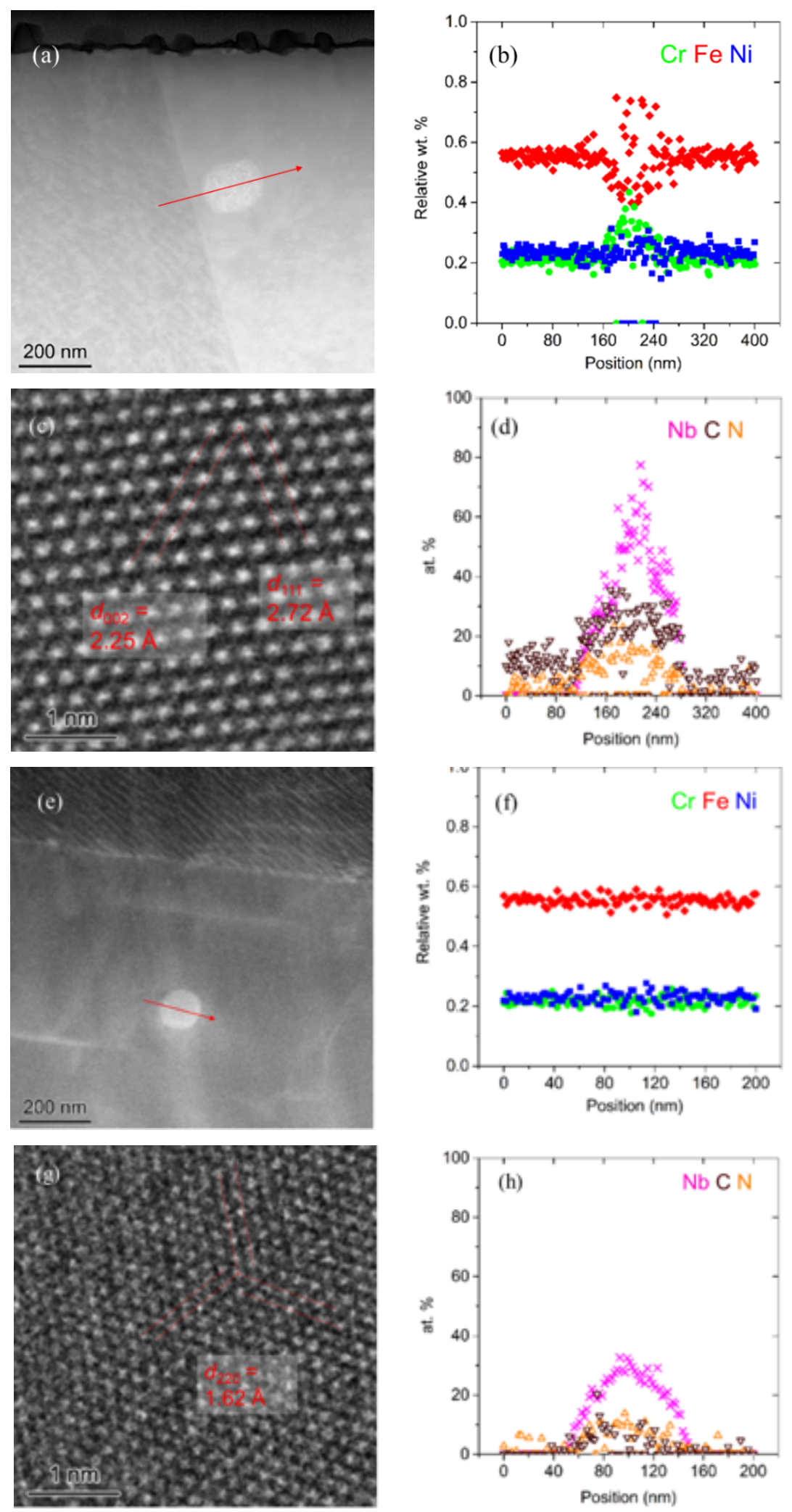
(i)

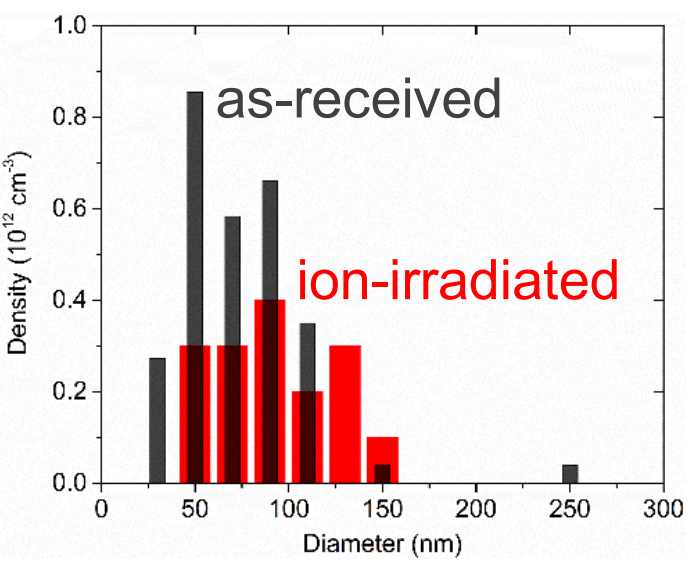

Fig. III-2-38. Characterization of precipitates in $\mathrm{Fe}^{2+}$-irradiated alloy 709. (a) HAADF image of a precipitate located within the damage layer. (c) HRSTEM image of the precipitate along [110] zone axis. (b, d) EDS line-scan profiles along the arrow in (a). (e) HAADF image of a precipitate located outside the damage layer. (g) HRSTEM image of the precipitate along [111] zone axis. (f, h) EDS line-scan profiles along the arrow in (e). (i) Size distribution of precipitates in the cross-sectional specimens of as-received and $\mathrm{Fe}^{2+}-$ irradiated samples.

\section{$\underline{\text { III-2-2-3. } \mathrm{Fe}^{2+} \text {-irradiated } 316 \mathrm{H} \text { at } 350{ }^{\circ} \mathrm{C} \text { to } 50 \mathrm{dpa}}$}

The as-received $316 \mathrm{H}$ is mechanically polished to a surface roughness $<20 \mathrm{~nm}$. After Fe ${ }^{2+}$ irradiation at 50 dpa at $0.46 \mu \mathrm{m}$ depth, $350{ }^{\circ} \mathrm{C}, 316 \mathrm{H}$ surface becomes rough with hill-shaped oxide structure, as shown in Fig. III-2-19.

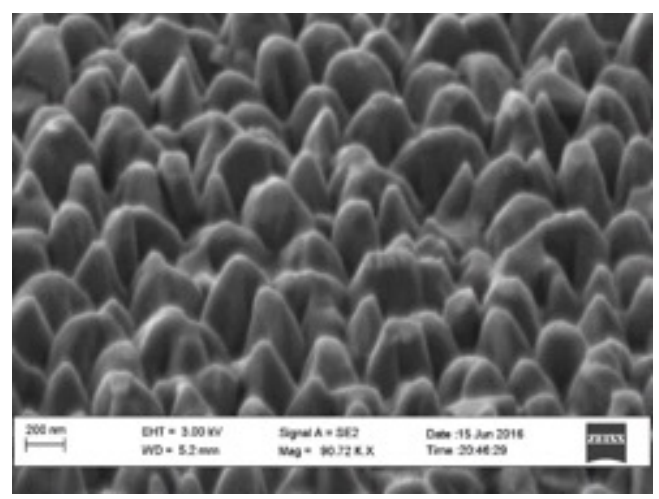

Fig. III-2-19. Secondary electron image of $316 \mathrm{H}$ after $\mathrm{Fe}^{2+}$ irradiation at $50 \mathrm{dpa}$ at $0.46 \mu \mathrm{m}$ depth, $350{ }^{\circ} \mathrm{C}$. Sample is tilted $54^{\circ}$. 
Fig. III-2-20 shows cross-sectional TEM images of $\mathrm{Fe}^{2+}$-irradiated $316 \mathrm{H}$ sample. Irradiation creates a 1.75 $\mu \mathrm{m}$ thick damage layer below the surface, as shown by the dark contrast in Fig. 2-20(a). There are dislocation loops in the damaged zone, as shown by the dark dotty and line contrasts in Fig. III-2-20(a) and (b). No precipitates were observed under the surface.

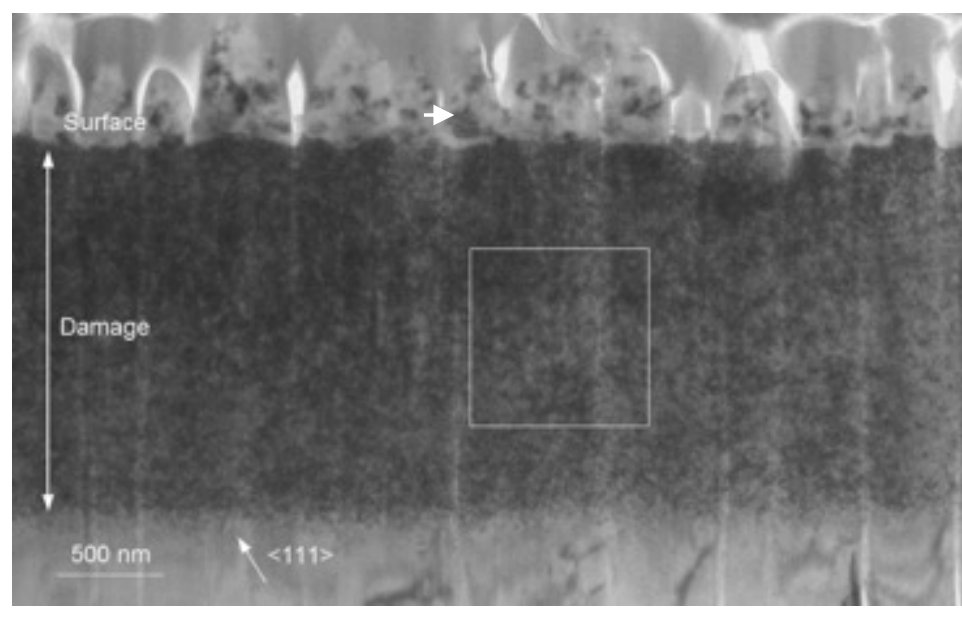

(a)

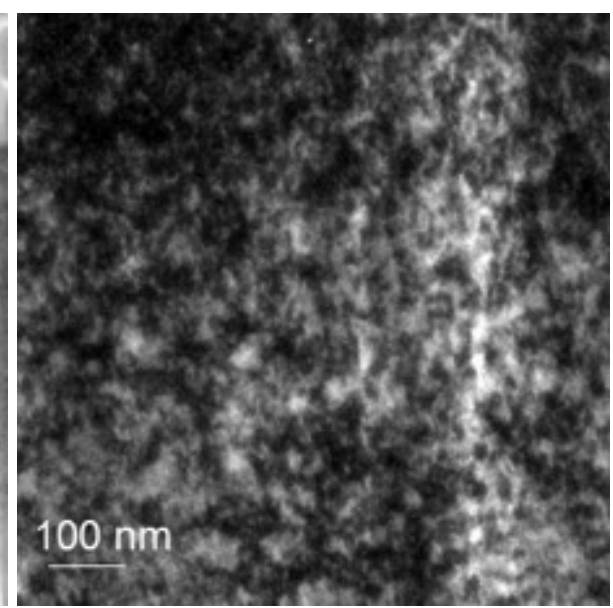

(b)

Fig. III-2-20. TEM image of $316 \mathrm{H}$ after $\mathrm{Fe}^{2+}$ irradiation at $50 \mathrm{dpa}, 350{ }^{\circ} \mathrm{C}$. (a) Bright field image with $\mathrm{g}=<111>$. (b) Higher magnitude image from the square area in (a). The viewing direction is along $<212>$.

Fig. III-2-21 presents composition near a grain boundary in the damaged layer. The grain boundary is enriched in Ni and depleted in Fe, as shown in Fig. III-2-21(b) and (c). We did not observe segregation of $\mathrm{Ni}$ or other elements at grain boundary in the undamaged region.
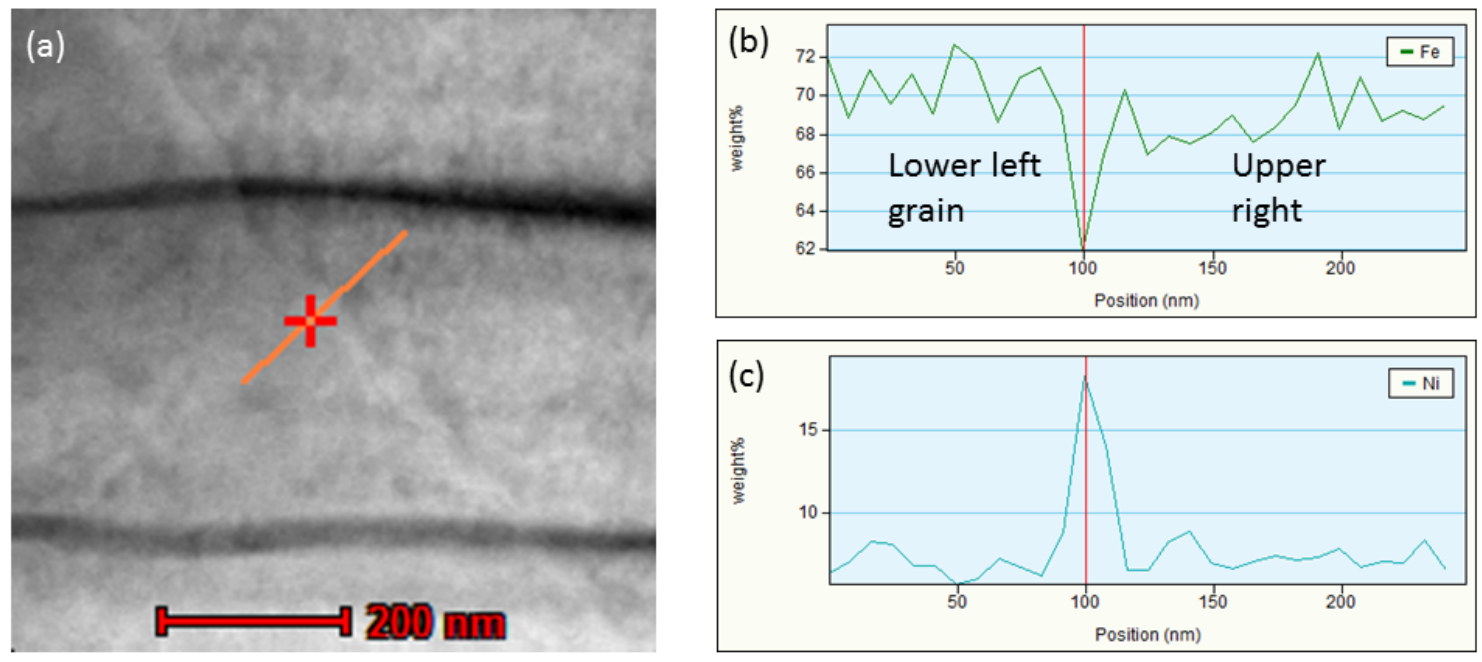
Fig. III-2-21. Composition of the damaged area near grain boundary in $316 \mathrm{H}$ after $\mathrm{Fe}^{2+}$ irradiation at 50 dpa, $350^{\circ} \mathrm{C}$. (a) HAADF image. (b) Fe profile. (c) Ni profile.

Fig. III-2-22 shows cross-sectional TEM images of dislocation loops in $\mathrm{Fe}^{2+}$ irradiated $316 \mathrm{H}$ to 40 - 90 dpa at depths of $0.28-0.86 \mu \mathrm{m}$ (right side close to surface) at $350{ }^{\circ} \mathrm{C}$. Frank loops of Burger's vector a/ $3<\overline{1} 11>$ are shown in Fig. III-2-22(b). The average Frank loops size is $15 \pm 1 \mathrm{~nm}$ at $50 \mathrm{dpa}$. Total density is $8.3 \times 10^{22}$ $\mathrm{m}^{-3}$ at 50 dpa assuming equal density of four types of Frank loops.

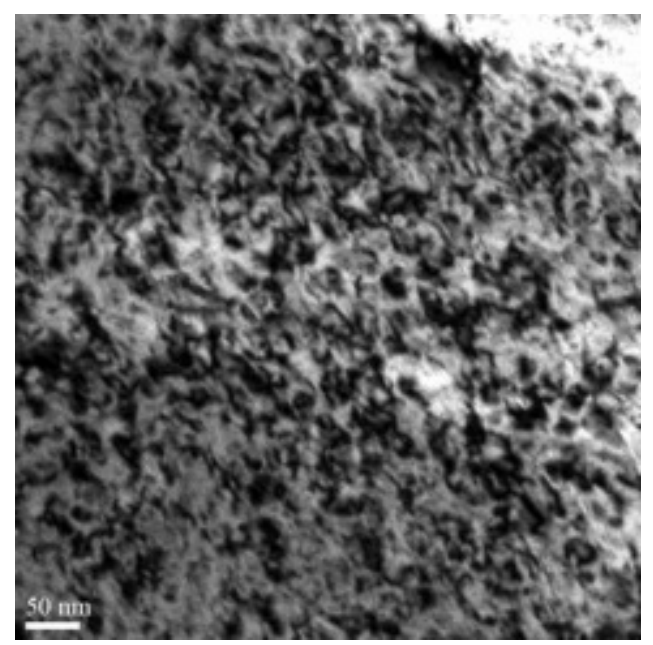

(a)

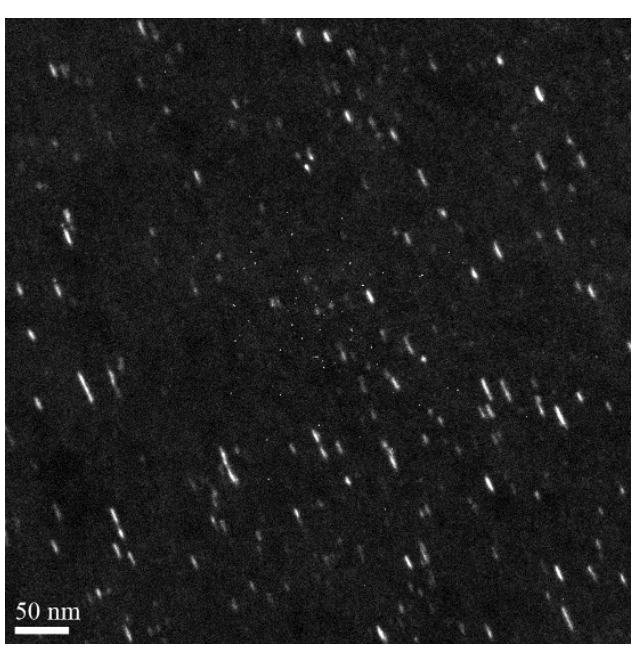

(b)

Fig. III-2-22. [110] zone [11 $1 \overline{3}]$ diffraction images of $350{ }^{\circ} \mathrm{C} \mathrm{Fe}^{2+}$ irradiated $316 \mathrm{H}$. The cross-sectional image center is at a depth of $0.56 \mu \mathrm{m}$, about $0.57 \mathrm{dpa}$. Right side is close to irradiation surface. (a) Bright field image. (b) Rel-rod dark field image of a/3[1̄11] Frank loops.

\section{III-2-2-4. Summary}

A summary of microstructures in as-received and $\mathrm{Fe}^{2+}$-irradiated $316 \mathrm{H}$ and 709 at $350{ }^{\circ} \mathrm{C}$ to 50 dpa is provided below:

1) Alloy 709 has a large fraction of CSL boundaries, e.g. coherent twin boundaries, which are insensitive to RIS. The random high-angle boundaries show slight segregation of Mo in as-received and are subject to segregation of $\mathrm{Ni}$ and depletion of $\mathrm{Cr}$. Radiation-induced segregation of $\mathrm{Ni}$ was observed at grain boundary of $316 \mathrm{H}$.

2) Precipitates were observed to form within grains and on grain boundaries of 709 , all with a rocksalt structure and a composition close to $\mathrm{NbC}_{0.5} \mathrm{~N}_{0.5}$. No other precipitates are formed during ion irradiation, 
while the MX precipitates show substantial ripening. No precipitates were found in $316 \mathrm{H}$ before or after irradiation.

3) Alloy 709 is only slightly oxidized during $\mathrm{Fe}^{2+}$ irradiation. $316 \mathrm{H}$ oxidized severely.

4) Both $\mathrm{Fe}^{2+}$-irradiated $316 \mathrm{H}$ and 709 have a radiation damage layer about $1.75 \mu \mathrm{m}$ thick that contains high density of defects, including interstitial-type Frank loops and perfect loops with sizes $\sim 10 \mathrm{~nm}$. Average Frank loop size is similar in $316 \mathrm{H}$ and 709 , about $15 \mathrm{~nm}$ at $50-58 \mathrm{dpa}$. Higher Frank dislocation loop density is found in $\mathrm{Fe}^{2+}$ irradiated $316 \mathrm{H}$ than in 709.

\section{III-2-3. $\mathrm{Fe}^{2+}$-irradiated 709 and crept/ thermally aged $709(1101,1106)$ at $670{ }^{\circ} \mathrm{C}$ to $50 \mathrm{dpa}$}

\section{III-2-3-1. $\mathrm{Fe}^{2+}$-irradiated 709 at $670{ }^{\circ} \mathrm{C}$ to $50 \mathrm{dpa}$}

Fig. III-2-23 shows cross-sectional STEM images of alloy 709 irradiated with $\mathrm{Fe}^{2+}$ to $50 \mathrm{dpa}(0.46 \mu \mathrm{m}$ depth) at $670{ }^{\circ} \mathrm{C}$. Fig. III-2-23(a) is a high angle annular dark field (HAADF) image. Sample surface was sputtered away during focused ion beam milling. The blue line indicates end of the surface damage layer from $\mathrm{Fe}^{2+}$ irradiation. Particles $\sim 100 \mathrm{~nm}$ and larger are present both in and out of the damaged layer. Arrows indicate such particles in the damaged region.

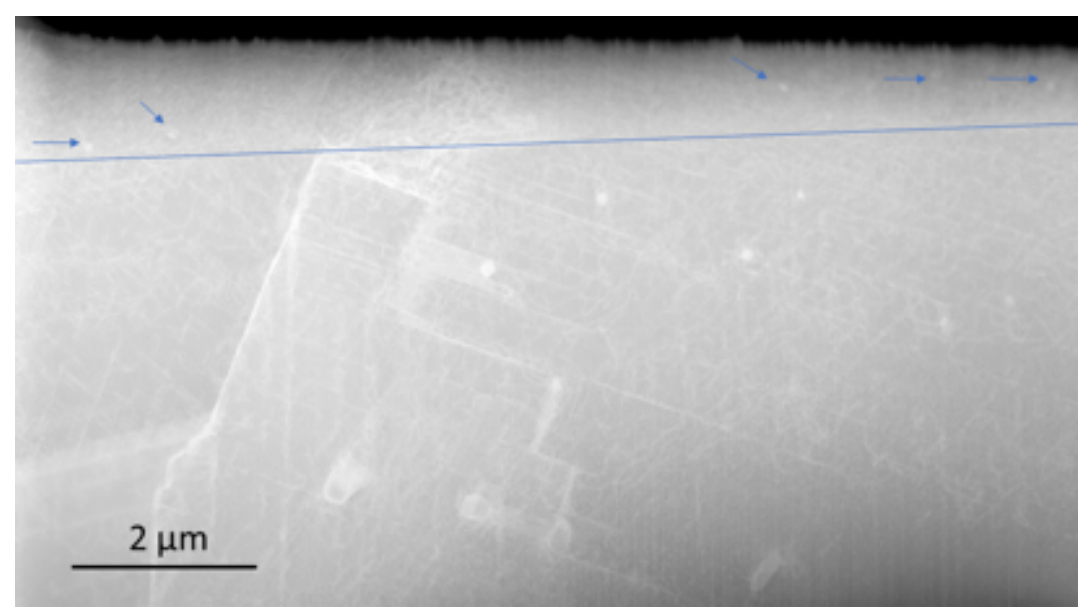

(a) 


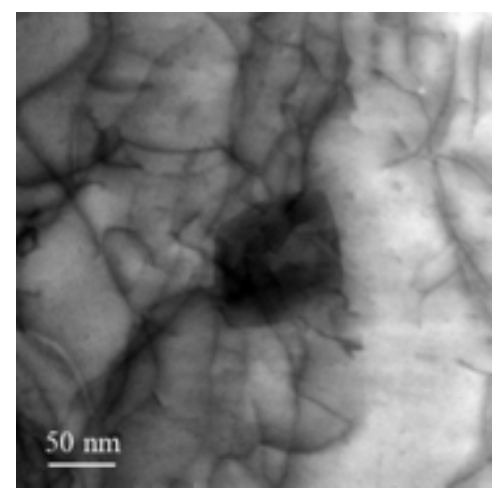

(b)

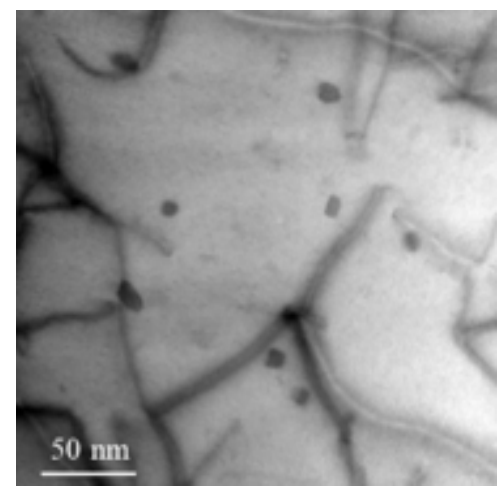

(e)

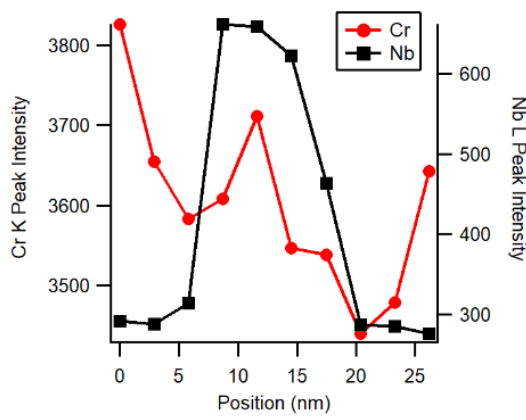

(h)

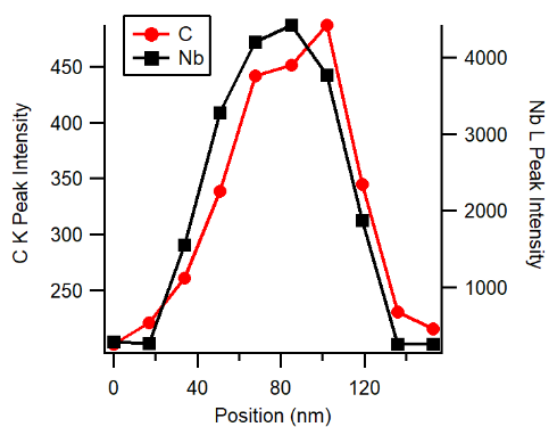

(c)

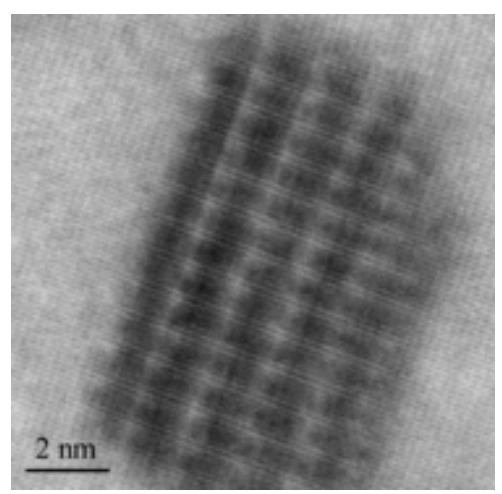

(f)

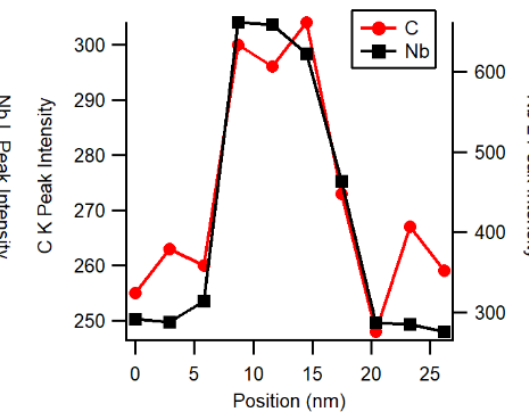

(i)

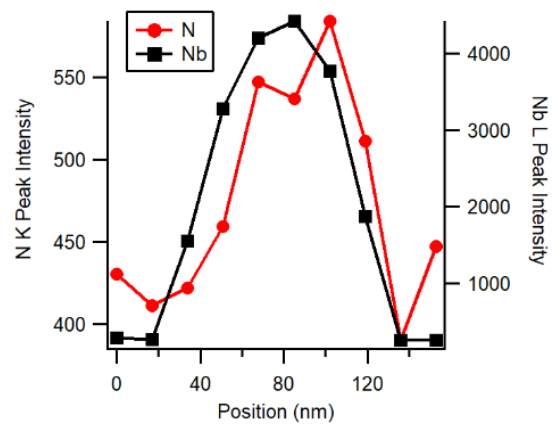

(d)

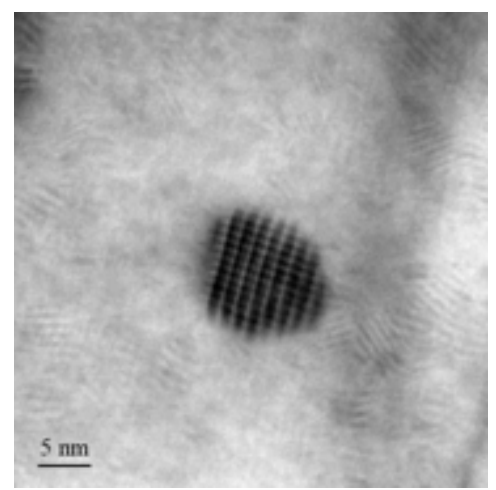

(g)

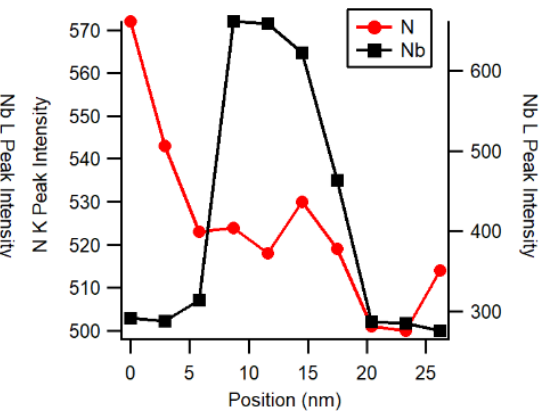

(j)

Fig. III-2-23. STEM and EDS characterization of $670{ }^{\circ} \mathrm{C}, 50 \mathrm{dpa} \mathrm{Fe}^{2+}$ irradiated alloy 709. (a) HAADF image of a cross-sectional TEM sample. Ion irradiation damaged region is from top edge to blue line. Arrows indicate particles of $\sim 100 \mathrm{~nm}$ large. (b) Annular bright field image of a particle $\sim 100 \mathrm{~nm}$ large. (cd) EDS peak intensity profiles cross the particle in (b). (e-g) ABF images of small particles $\sim 10 \mathrm{~nm}$ in the damaged region. (h-j) EDS intensity profiles across the particle in $(\mathrm{g})$.

The particles $\sim 100 \mathrm{~nm}$ in size is shown in Fig. III-2-23 (b-d) is NbCN. There are also small precipitates $\sim$ $10 \mathrm{~nm}$ in size found in the damaged region, as shown in Fig. III-2-23 (e-j). We have not found such particles in undamaged region. The fringe contrast in particles is Moiré fringe produced from electron scattering 
through two difference lattices. Assuming in Fig. III-2-23 (f) the matrix $<211>$ zone $\{111\}$ and $\{220\}$ planes are parallel to two lattice planes in the particle, the Moire fringe spacing is $D=\frac{d_{1} d_{2}}{\left|d_{1}-d_{2}\right|}$. D is 7.925 $\AA$ along matrix FCC Fe plane $\{220\}\left(\mathrm{d}_{1}=1.263 \AA\right)$, then the particle plane distance is $d_{2}=\frac{D d_{1}}{D \pm d_{1}}, 1.09 \AA$ or $1.50 \AA$. For the other plane parallel to matrix $\{111\}\left(\mathrm{d}_{1}=2.062 \AA\right)$, as Moiré fringe has distance $\mathrm{D}=$ $12.41 \AA$, the particle plane distance is $\mathrm{d}_{2}=1.77 \AA$ or $2.47 \AA$.

Fig. III-2-23 (h-j) confirms the $\mathrm{Nb}$ and $\mathrm{C}$ components, and possibly $\mathrm{Cr}$ and $\mathrm{N}$ as well in small precipitates. Z-phase $\mathrm{CrNbN}$ has a tetragonal lattice with lattice parameters $\mathrm{a}=3.037 \AA$ and $\mathrm{c}=7.391 \AA$. Along $<010>$ zone the interplanar distances of Z-phase are $1.85 \AA$ for $\{004\}$ and $1.52 \AA$ for $\{200\}$. They match with Moiré fringe calculation. Because of the presence of $\mathrm{Cr}$ and $\mathrm{N}$ it is speculated that the small particles are Z-phase $\mathrm{CrNbCN}$.

Fig. III-2-24 shows particles segregated at the unirradiated grain boundary. EDS measured them to be $\mathrm{M}_{\mathrm{x}} \mathrm{C}_{\mathrm{y}}$ where $\mathrm{M}$ includes $\mathrm{Cr}, \mathrm{Mn}, \mathrm{Mo}, \mathrm{Nb}$.

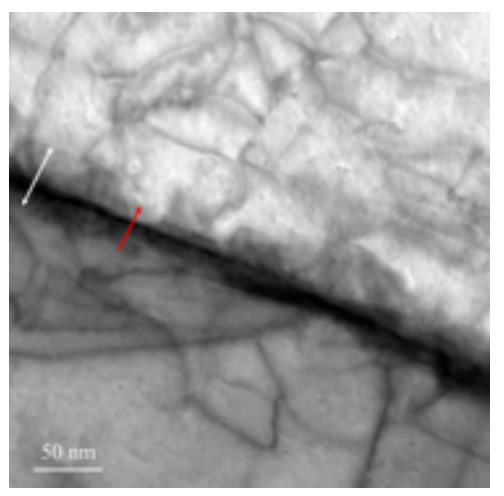

(a)

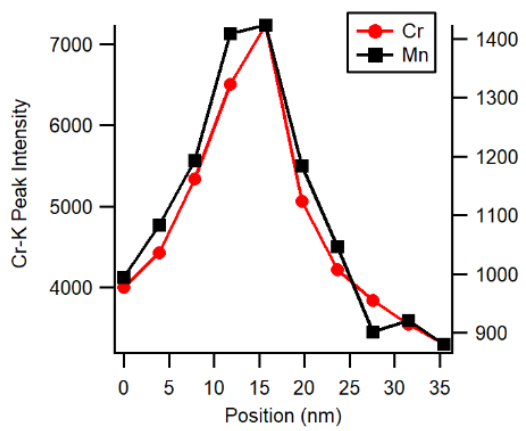

(b)

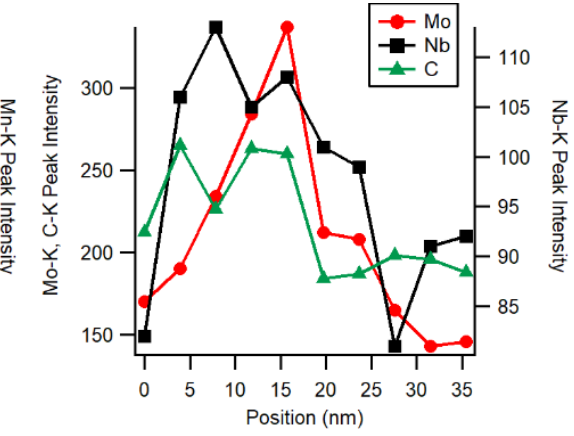

(c)

Fig. III-2-24. Precipitates along unirradiated grain boundary in alloy 709 undergone the same thermal history of $670{ }^{\circ} \mathrm{C} 50 \mathrm{dpa} \mathrm{Fe}^{2+}$ irradiation. (a) $\mathrm{ABF}$ image. White arrow indicates a precipitate. Red arrow is the EDS line scan path. (b) EDS peak intensity.

Fig. III-2-25 shows a grain boundary at $0.6 \mu \mathrm{m}$ depth, about $62 \mathrm{dpa}$. EDS measured Ni, Mn segregation and $\mathrm{Fe}, \mathrm{Cr}$ depletion at the grain boundary. 


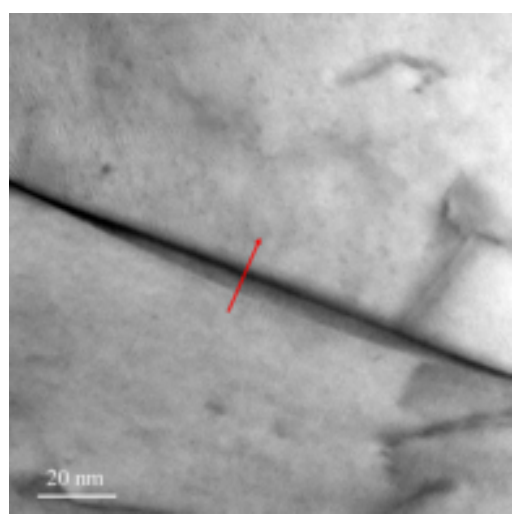

(a)

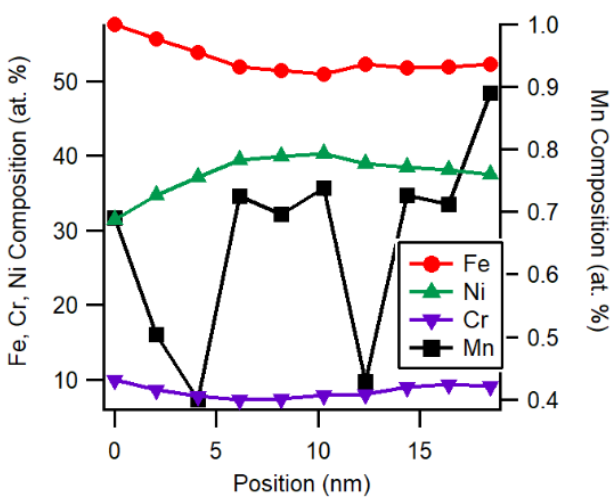

(b)

Fig. III-2-25. Grain boundary in alloy 709 irradiated by $\mathrm{Fe}^{2+}$ to $62 \mathrm{dpa}\left(0.6 \mu \mathrm{m}\right.$ depth) at $670{ }^{\circ} \mathrm{C}$. (a) $\mathrm{ABF}$ image. (b) EDS-measured $\mathrm{Fe}, \mathrm{Cr}, \mathrm{Ni}, \mathrm{Mn}$ compositions along the red arrow in (a).

Fig. III-2-26 shows TEM images of dislocations in the damaged region of 709 from $\mathrm{Fe}^{2+}$ irradiation to 50 dpa at $670{ }^{\circ} \mathrm{C}$. End of the damage region is indicated by the white line in Fig. III-2-26 (a). At left is undamaged sample region. Dislocation density in the damaged region is higher than undamaged region. Fig. 2-26 (b) and (c) are the same damaged area under $<02 \overline{2}>,<1 \overline{1} \overline{1}>$ diffraction, respectively. There are no Frank dislocation loops but dislocation network. Some dislocations in Fig. III-2-26 (b) are not visible in Fig. 26 (c), their Burger's vector is therefore perpendicular to $<1 \overline{1} \overline{1}>$. They are perfect dislocation with $\mathrm{b}=\frac{a}{2}<110>$.

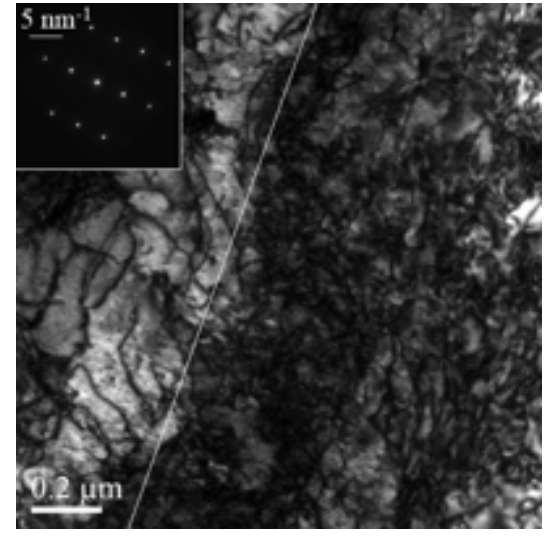

(a)

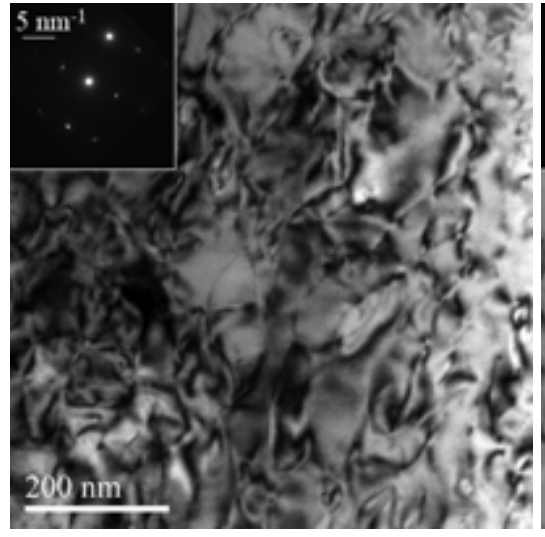

(b)

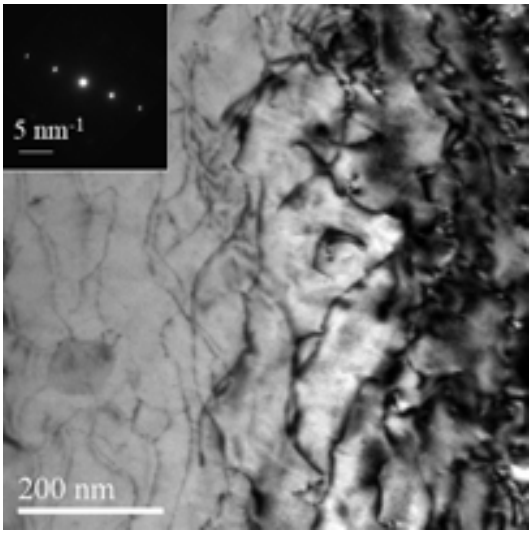

(c)

Fig. III-2-26. TEM bright field images of alloy 709 irradiated to $50 \mathrm{dpa}$ at $670{ }^{\circ} \mathrm{C}$ with $\mathrm{Fe}^{2+}$. The diffraction conditions are: (a) multiple diffraction beams on $<211>$ zone; (b) $\{02 \overline{2}\}$ diffraction; (c) $\{1 \overline{1} \overline{1}\}$ diffraction.

\section{III-2-3-2. $\mathrm{Fe}^{2+}$ ion irradiated 1101 at $670{ }^{\circ} \mathrm{C}$ to $50 \mathrm{dpa}$}


1101 is alloy 709 undergone creep rupture/thermal annealing for 17,106 hours at $600{ }^{\circ} \mathrm{C}$. Fig. III-2-27 shows a cross-sectional image of 1101 after $\mathrm{Fe}^{2+}$ irradiation to $50 \mathrm{dpa}$ at $0.46 \mu \mathrm{m}$ depth at $670{ }^{\circ} \mathrm{C}$. Arrow indicates the $1.7 \mu \mathrm{m}$ damage depth at the surface. Big particles $\sim 1 \mu \mathrm{m}$ long occupy the grain boundary. Smaller particles of a few hundred nanometers are present inside grains. Some inner grain particles align with each other along a straight line, as shown in the bottom grain of Fig. III-2-27. It suggests heterogeneous precipitate formation at piled dislocations. Main irradiation defects are dislocations.

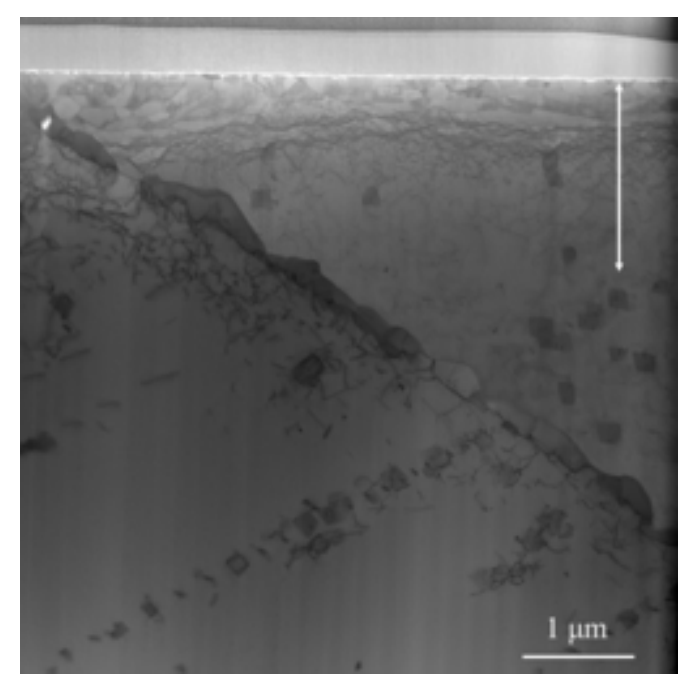

Fig. III-2-27. Annular bright field cross-sectional image of 1101 after $\mathrm{Fe}^{2+}$ irradiation at $670{ }^{\circ} \mathrm{C}$ to 50 dpa. Top grain is nearly along $<211>$ zone. Arrow indicates surface damage region.

Fig. III-2-28 shows an undamaged $\mathrm{M}_{23} \mathrm{C}_{6}$ particle inside a grain in 1101. EDS measured its components are $\mathrm{Cr}, \mathrm{Fe}, \mathrm{Mo}, \mathrm{Nb}$ and $\mathrm{C}$ (Fig. III-2-28c, d). The ratio of metal components are (89.2 \pm 0.4$) \mathrm{Cr}-(6.2 \pm 0.8) \mathrm{Fe}-$ (3.3 \pm 0.1$) \mathrm{Mo}-(0.17 \pm 0.07) \mathrm{Nb}$ (at. \%). The high-resolution image in Fig. III-2-28(b) matches with $\mathrm{Cr}_{23} \mathrm{C}_{6}$ lattice along $<211>$ zone. The orientation relationship between the $\mathrm{M}_{23} \mathrm{C}_{6}$ particle in Fig. III-2-28 (a) and matrix is $<211>_{\text {particle }} / /<211>_{\text {matrix }},<\overline{1} 11>_{\text {particle }} / /<\overline{1} 11>_{\text {matrix }},<02 \overline{2}>_{\text {particle }} / /<02 \overline{2}>_{\text {matrix }}$, i.e., the same lattice orientation for both $\mathrm{M}_{23} \mathrm{C}_{6}$ particle and FCC Fe matrix. 


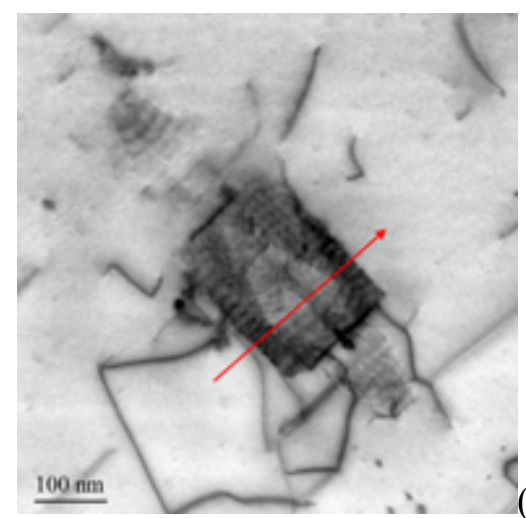

(a)

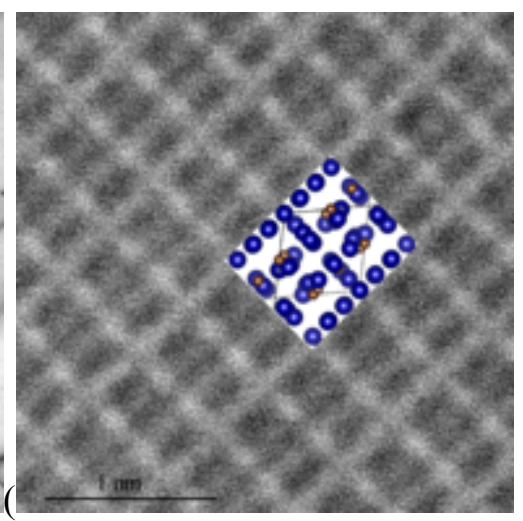

(b)

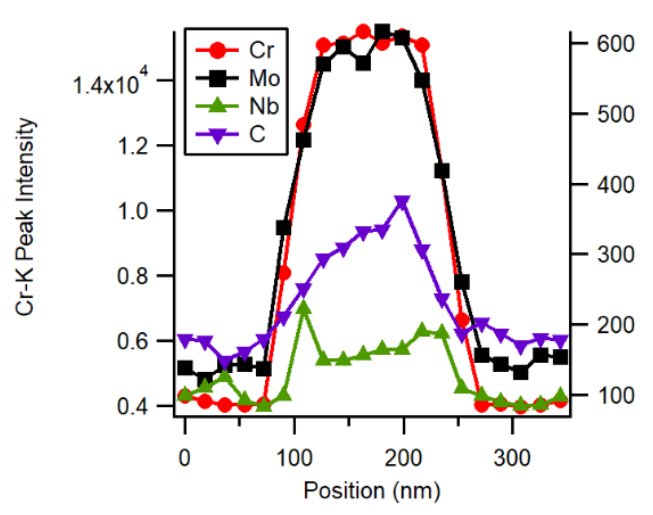

(c)

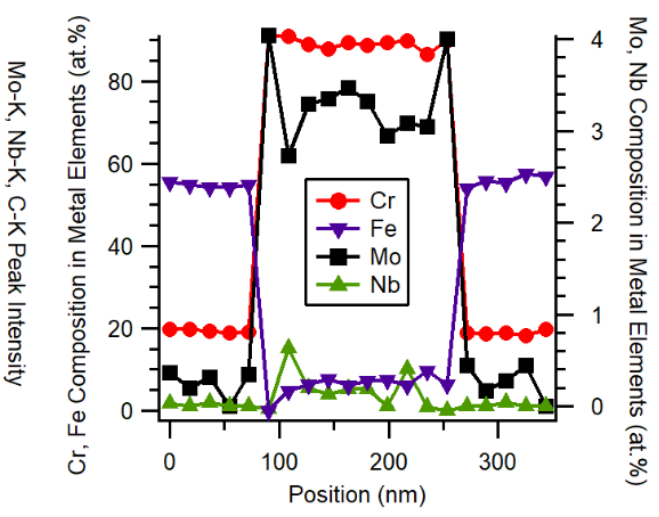

(d)

Fig. III-2-28. TEM characterization of undamaged $\mathrm{M}_{23} \mathrm{C}_{6}$ particles in 1101. (a) Annular bright field image. (b) High resolution high angle annular dark field image with inset of $\mathrm{Cr}_{23} \mathrm{C}_{6}$ atomic column model along $<211>$ (blue spheres as Cr, bronze spheres as C). (c) EDS peak intensity across the red arrow in (a); (d) EDS measured metal composition in all metal components.

Fig. III-2-29 shows two damaged $\mathrm{M}_{23} \mathrm{C}_{6}$ particles inside grain ( $\mathrm{a}, \mathrm{b}, 94 \mathrm{dpa}$ ) or along the grain boundary (c, $\mathrm{d}, 69 \mathrm{dpa})$. The metal component ratio is $(92.2 \pm 1.0) \mathrm{Cr}-(3.5 \pm 1.1) \mathrm{Fe}-(3.1 \pm 0.1) \mathrm{Mo}-(0.07 \pm 0.07) \mathrm{Nb}$, $(83.3 \pm 0.8) \mathrm{Cr}-(13.2 \pm 0.9) \mathrm{Fe}-(2.4 \pm 0.1) \mathrm{Mo}$, for the damaged inner grain particle and grain boundary particle, respectively. 


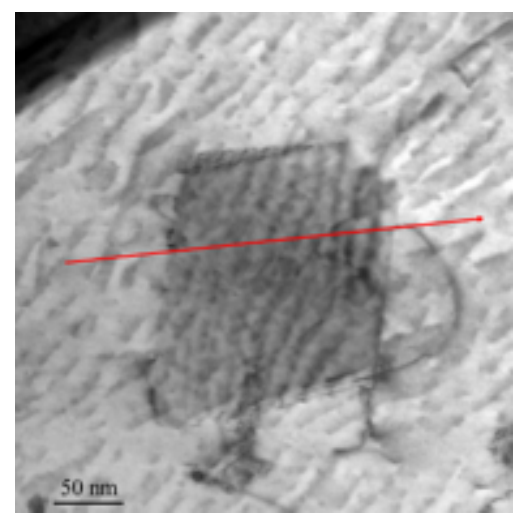

(a)

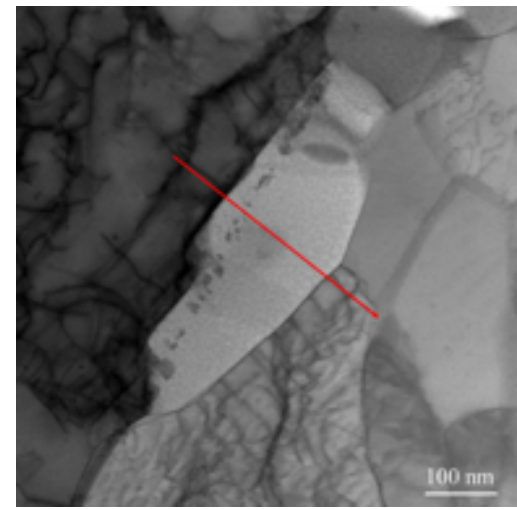

(c)

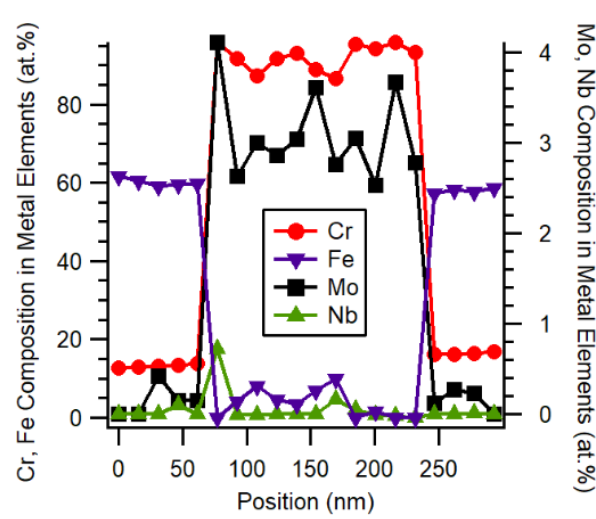

(b)

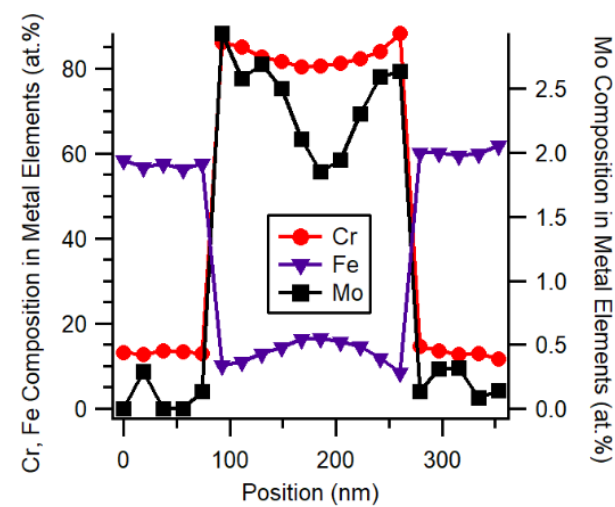

(d)

Fig. III-2-29. TEM characterization of damaged $\mathrm{M}_{23} \mathrm{C}_{6}$ particles in 1101. (a, b) $\mathrm{ABF}$ image and metal component ratio of a damaged particle at $1.08 \mu \mathrm{m}$, about $94 \mathrm{dpa}$. (c, d) A damaged particle at grain boundary, $0.66 \mu \mathrm{m}$ depth, 69 dpa.

Results of $\mathrm{M}_{23} \mathrm{C}_{6}$ particle analysis in Fig.s III-2-28 and III-2-29 suggest that (1) $\mathrm{M}_{23} \mathrm{C}_{6}$ phase in 1101 is mainly composed of $\mathrm{Cr}$ and $\mathrm{C}$, with minor composition of $\mathrm{Fe}, \mathrm{Mo}$, and $\mathrm{Nb}$; (2) $\mathrm{M}_{23} \mathrm{C}_{6}$ at grain boundary has higher concentration of $\mathrm{Fe}$, less $\mathrm{Cr}$, $\mathrm{Mo}$ and $\mathrm{Nb}$ than $\mathrm{M}_{23} \mathrm{C}_{6}$ particles inside grain; (3) Irradiation appeared to drive $\mathrm{Cr}$ into $\mathrm{M}_{23} \mathrm{C}_{6}$ and $\mathrm{Fe}, \mathrm{Nb}$ out of $\mathrm{M}_{23} \mathrm{C}_{6}$.

Fig. III-2-30 shows undamaged particles a few nanometers to about $10 \mathrm{~nm}$ large. They are rich in $\mathrm{Nb}$ from EDS measurement. Moiré fringe space in Fig. III-2-30(b) is $1.27 \mathrm{~nm}$ along matrix $<\overline{1} 11>$ direction. Assuming one particle lattice plane is parallel to matrix (111), the interplanar distance of the particle is calculated from $D d_{1} /\left(D \pm d_{1}\right)$ to be $0.17 \mathrm{~nm}$ or $0.24 \mathrm{~nm}$, which may belong to $\operatorname{NbCN}(\overline{2} 02)(0.16 \mathrm{~nm})$. D, $\mathrm{d}_{1}$ are Moiré fringe space and matrix (111) plane distance $(0.203 \mathrm{~nm})$, respectively. The orientation relationship may be $<323>_{\mathrm{NbCN}} / /<211>_{\text {matrix }},<\overline{2} 02>_{\mathrm{NbCN}} / /<\overline{1} 11>_{\text {matrix }},<\overline{1} 3 \overline{1}>_{\mathrm{NbCN}}$ (plane distance $0.13 \mathrm{~nm}$ ) $/ /<02 \overline{2}>_{\text {matrix }}$ (plane distance $0.12 \mathrm{~nm}$ ). 


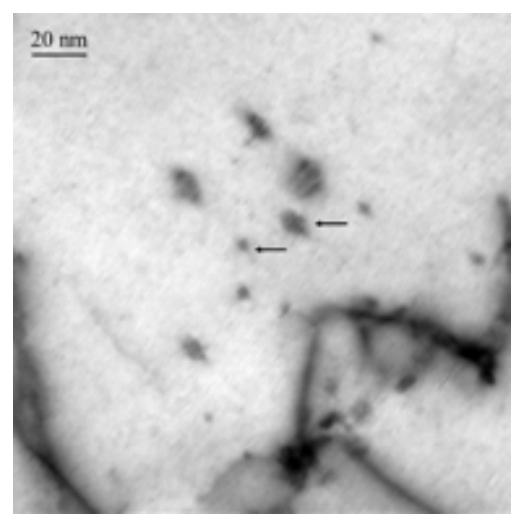

(a)

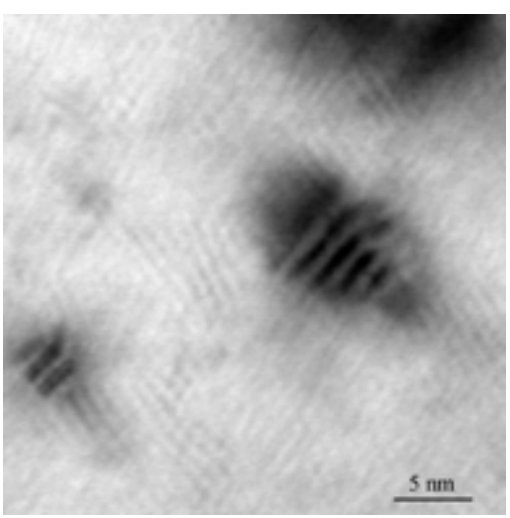

(b)

Fig. III-2-30. Annular bright field image of Nb-rich particles in undamaged 1101. Arrowed indicated particles in (a) are displayed in (b).

Fig. III-2-31 shows a damaged (CrMoNbMn) ${ }_{3} \mathrm{Ni}_{2} \mathrm{Si}$ particle along the grain boundary. The damage level is about 15 dpa post-irradiation peak. Right side of the image has higher damage level. High resolution ABF image matches with $\mathrm{Cr}_{3} \mathrm{Ni}_{2} \mathrm{Si}$ structure along $<211>$ zone (Fig. 2-31b). Compositional profile in Fig. III-231 (c) shows increasing $\mathrm{Cr}$ concentration, and decreasing $\mathrm{Ni}, \mathrm{Mo}, \mathrm{Nb}$ concentration along the electron beam scanning direction, where damage level increased from 6 dpa to $30 \mathrm{dpa}$, suggesting irradiation-induced $\mathrm{Cr}$ enrichment and $\mathrm{Ni}, \mathrm{Mo}, \mathrm{Nb}$ depletion in the $\mathrm{M}_{3} \mathrm{Ni}_{2} \mathrm{Si}$ particle.

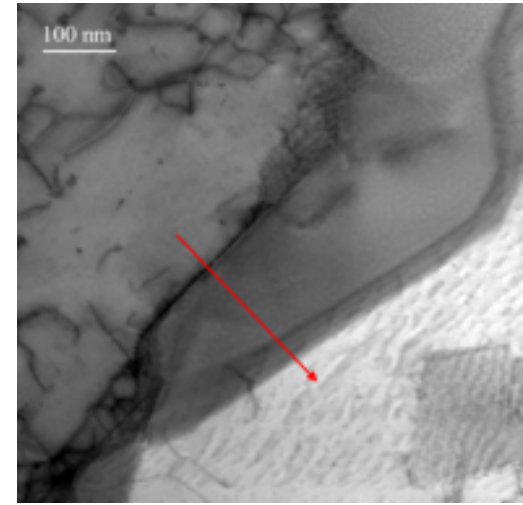

(a)

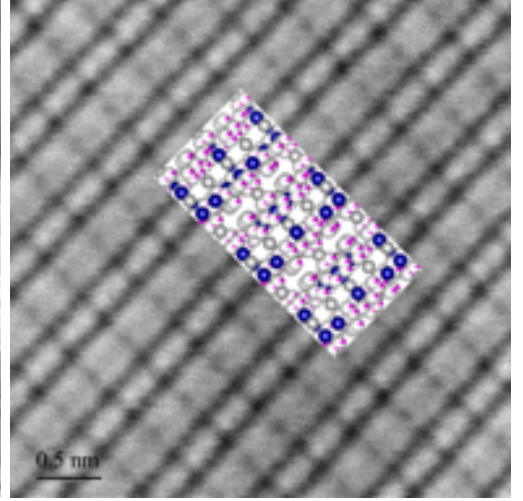

(b)

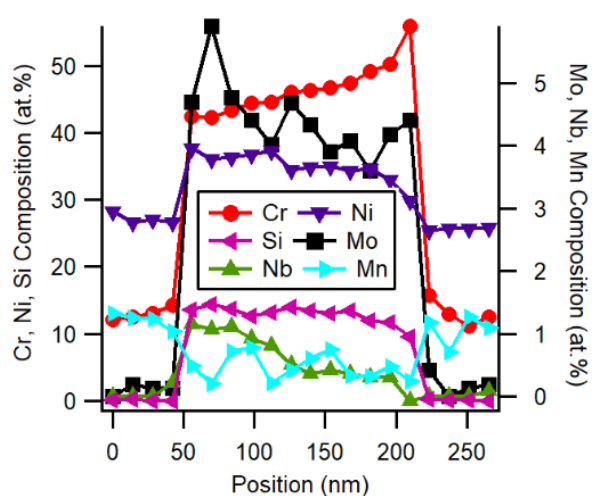

(c)

Fig. III-2-31. Annular bright field images ( $a, b)$, and EDS-measured composition profile of a damaged $(\mathrm{CrMoNbMn})_{3} \mathrm{Ni}_{2} \mathrm{Si}$ particle on grain boundary. EDS was acquired along the red arrow in $(\mathrm{a})$, where the center is located at $1.36 \mu \mathrm{m}$ depth, about $15 \mathrm{dpa}$. Inset in (b) is $\mathrm{Cr}_{3} \mathrm{Ni}_{2} \mathrm{Si}$ atomic column model along <211> zone. Blue spheres are $\mathrm{Ni}$, white and purple are $\mathrm{Cr}$, and gray are $\mathrm{Si}$. 


\section{$\underline{\text { III-2-3-3. As-received and } \mathrm{Fe}^{2+} \text { ion irradiated } 1106 \text { at } 670{ }^{\circ} \mathrm{C} \text { to } 50 \mathrm{dpa}}$}

Sample 1106 is alloy 709 after creep rupture/thermal annealing at $700{ }^{\circ} \mathrm{C}$ for 16,448 hours. To study precipitates in as-received 1106 the sample was mechanically polished, etched in Glyceregia and analyzed using SEM and EDS. Fig. III-2-32 presents a secondary electron image and elemental mapping in atomic percent.
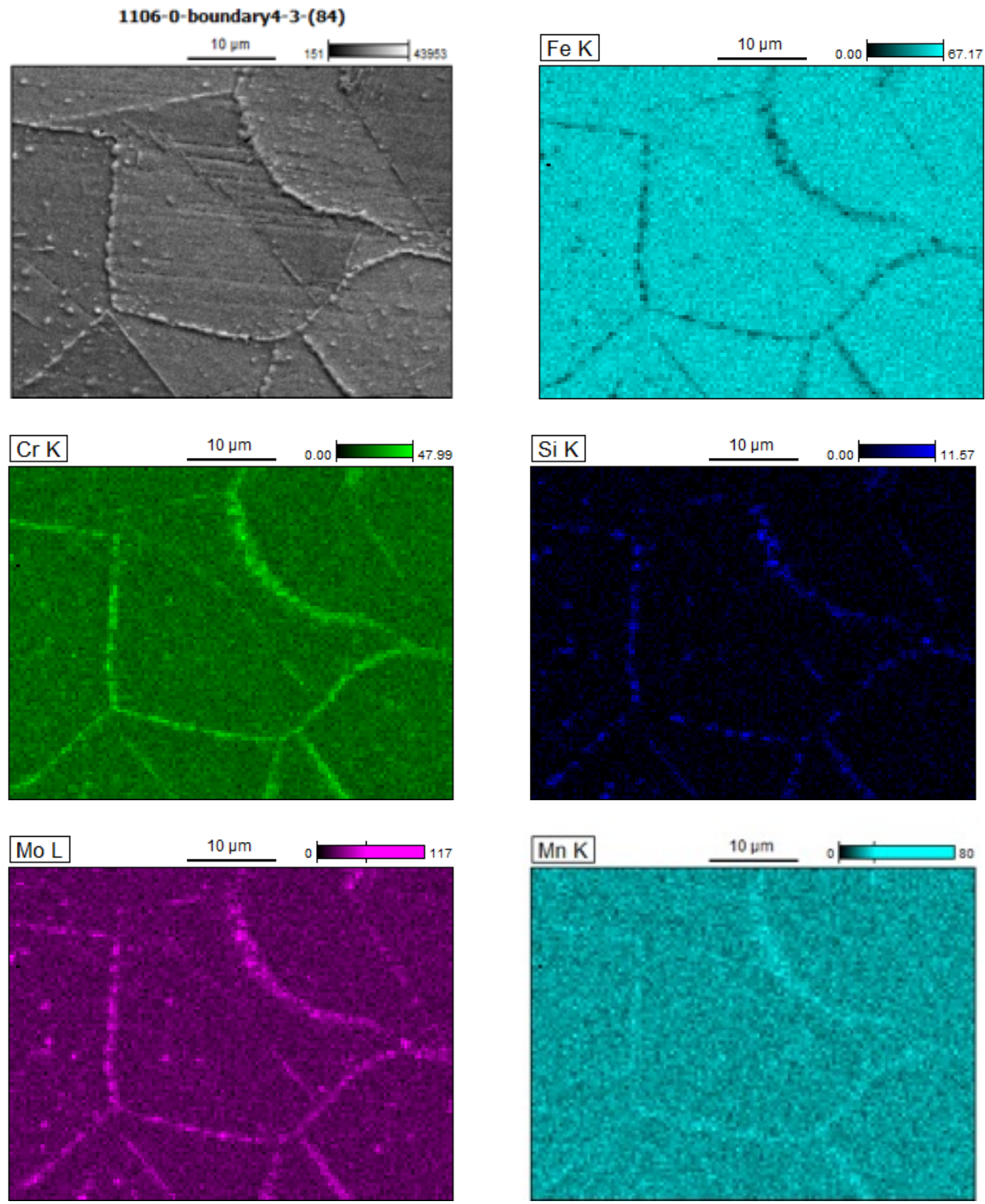
Fig. III-2-32. Secondary electron image (the top left panel) and $\mathrm{Fe}, \mathrm{Cr}, \mathrm{Si}, \mathrm{Mo}$, Mn compositional maps in as-received 1106.

Fig. III-2-32 shows micron-scale particles along the grain boundary and inside grains that are rich in $\mathrm{Cr}$, $\mathrm{Mo}, \mathrm{Mn}$, or Si. There are overlapping between $\mathrm{Cr}$ and Si-rich areas. However, some Cr-rich particles do not have Si composition. Therefore, there are two types of micron-scale particles, Cr-rich and Cr, Si-rich. TEM study of irradiated 1106 (Fig.s 32 and 33) verified those are $\mathrm{M}_{23} \mathrm{C}_{6}$ and $\mathrm{M}_{3} \mathrm{Ni}_{2} \mathrm{Si}$-type particles, where the major component of $\mathrm{M}$ is $\mathrm{Cr}$. SEM measured the average size of micron-scale $\mathrm{M}_{23} \mathrm{C}_{6}$ and $\mathrm{M}_{3} \mathrm{Ni}_{2} \mathrm{Si}$ particles to be $0.8 \mu \mathrm{m}$ and $0.76 \mu \mathrm{m}$, respectively. Occupation of grain boundary site by $\mathrm{M}_{23} \mathrm{C}_{6}$ is about $52 \%$, $43 \%$ by $\mathrm{M}_{3} \mathrm{Ni}_{2} \mathrm{Si}$.

Fig. III-2-33 shows cross-sectional TEM images of 1106-1 irradiated with $\mathrm{Fe}^{2+}$ to 50 dpa at $0.46 \mu$ m depth at $670{ }^{\circ} \mathrm{C}$. Irradiation damage depth is calculated to be $1.6 \mu \mathrm{m}$ using SRIM. The damage depth is shown by an arrow in Fig. III-2-33(a). Dense dislocations are found within $\sim 1.2 \mu \mathrm{m}$ deep surface region. Fig. III-233(b) shows a $<001>$ zone annular bright field (ABF) image of dislocations in the damaged region.

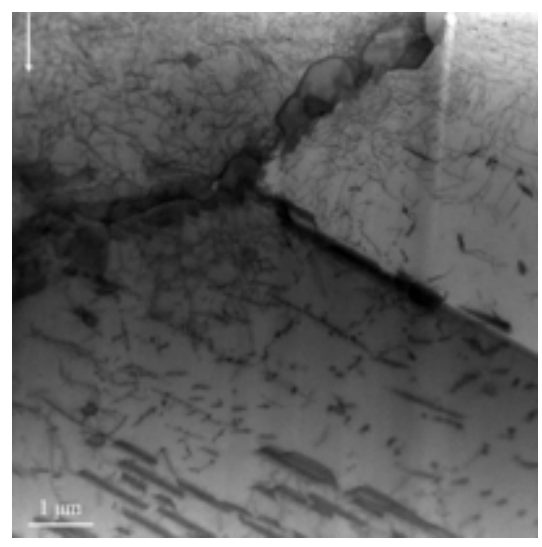

(a)

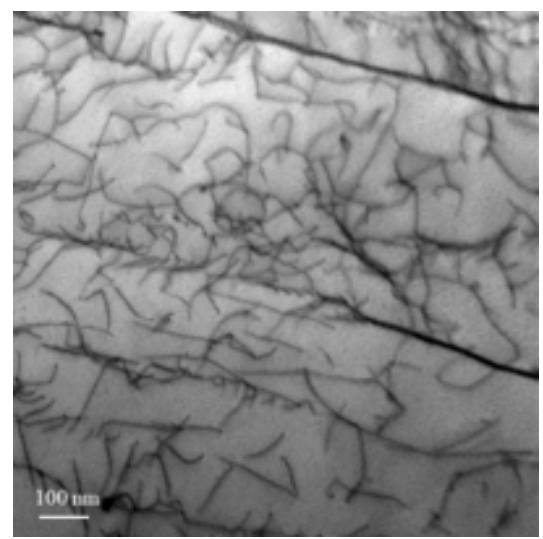

(b)

Fig. III-2-33. STEM characterization of 1106-1, irradiated with $\mathrm{Fe}^{2+}$ to 50 dpa at $0.46 \mu \mathrm{m}$ at $670{ }^{\circ} \mathrm{C}$. (a, b,) ABF images.

Fig. III-2-33(a) shows that large precipitates $\sim 1 \mu \mathrm{m}$ in size are present along the grain boundary. Fig. III2-34(a) shows ABF image of a large particle. Composition of the particle was measured to be $42.0 \mathrm{Cr}$ 35.6Ni-12.3Si-5.5Mo-4.4N-0.2Nb (at. \%) with energy dispersive x-ray spectroscopy (EDS) (Fig. III-2-34b). Electron diffraction pattern of a different $\mathrm{Cr}$, Ni, Si-rich particle is shown in the upper panel of Fig. III-2- 
34(c). The lower panel is a calculated $<001>$ diffraction pattern of $\mathrm{Cr}_{3} \mathrm{Ni}_{2} \mathrm{Si}$ using PDF-4+ 2016. The experimental diffraction pattern includes planes of the same interplanar distance with $\mathrm{Cr}_{3} \mathrm{Ni}_{2} \mathrm{Si}\{022\}(3.75$ $\AA$ ). However, it shows forbidden $\mathrm{Cr}_{3} \mathrm{Ni}_{2} \mathrm{Si}\{002\}$ diffractions. The crystal structure thus may have less symmetry and is slightly different from $\mathrm{Cr}_{3} \mathrm{Ni}_{2} \mathrm{Si}$.

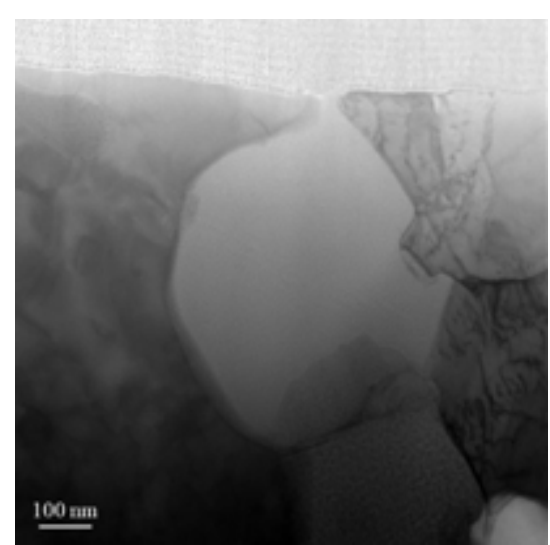

(a)
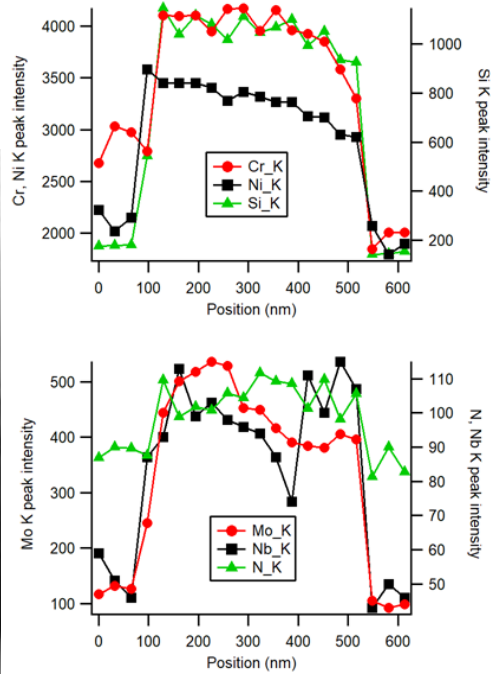

(b)

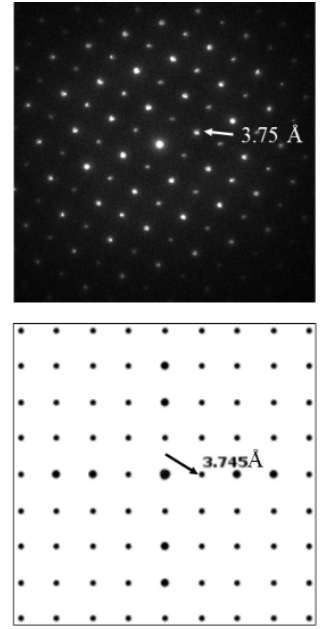

(c)

Fig. III-2-34. TEM characterization of a $(\mathrm{CrMoNb})_{3} \mathrm{Ni}_{2} \mathrm{Si}(\mathrm{N})$ precipitate in $1106-1$, irradiated with $\mathrm{Fe}^{2+}$ to $41 \mathrm{dpa}$ (center of the particle, $0.32 \mu \mathrm{m}$ from irradiation surface) at $670{ }^{\circ} \mathrm{C}$. (a) ABF images; (b) EDS peak intensity profiles; (c) Electron diffraction pattern (upper panel) and calculated $\mathrm{Cr}_{3} \mathrm{Ni}_{2} \mathrm{Si}<001>$ diffraction pattern (lower panel).

Fig. III-2-35(a-b) shows a particle along the grain boundary in the damaged region. EDS verifies it is rich in $\mathrm{Cr}$ and $\mathrm{C}$. The high-resolution image in Fig. III-2-35(b) matches with $\mathrm{Cr}_{23} \mathrm{C}_{6}$ lattice $<123>$ zone (shown in inset) where blue and brown spheres represent $\mathrm{Cr}$ and $\mathrm{C}$ atoms, respectively. There are dark and light contrast domains $\sim 10 \mathrm{~nm}$ in ABF images of the particles, as shown in Fig. III-2-35(a) and (c). Fig. III-235(c) shows another $\mathrm{Cr}$, C-rich particle inside the damaged region. The EDS peak intensity profile shows dark contrast domains have higher Fe concentration and less $\mathrm{Cr}$ than light contrast area, as shown in Fig. III-2-35(d). The $\mathrm{Cr}_{23} \mathrm{C}_{6}$ particles are chemically heterogeneous. 


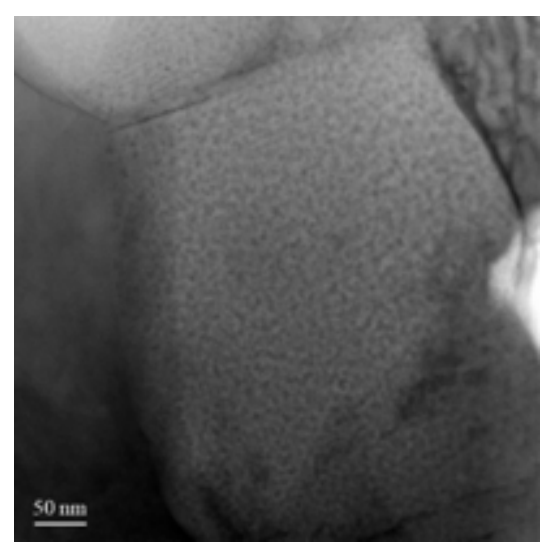

(a)

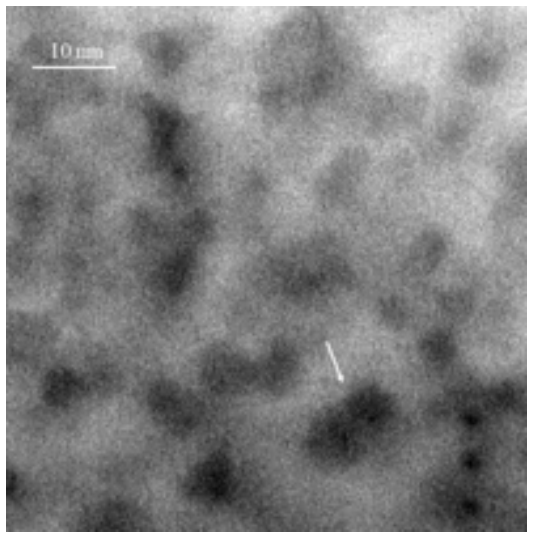

(c)

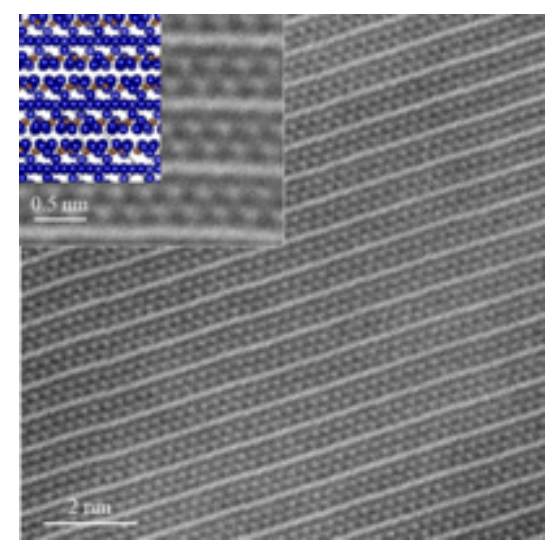

(b)

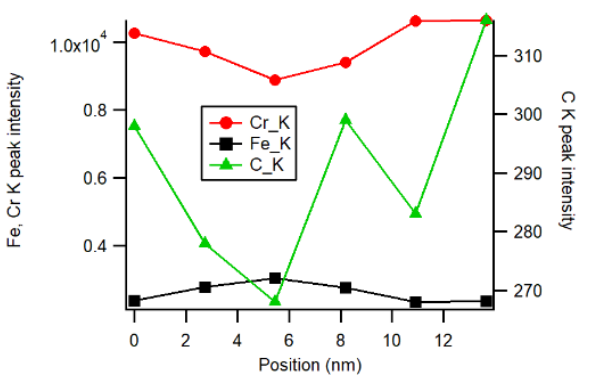

(d)

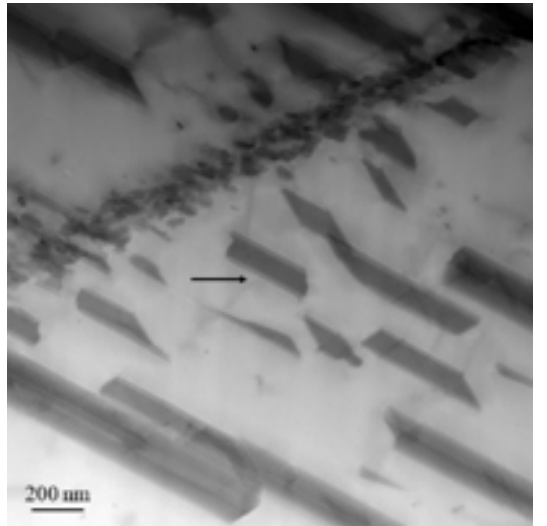

(e)

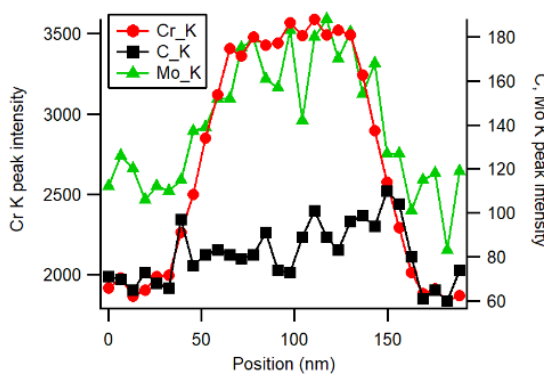

(f)

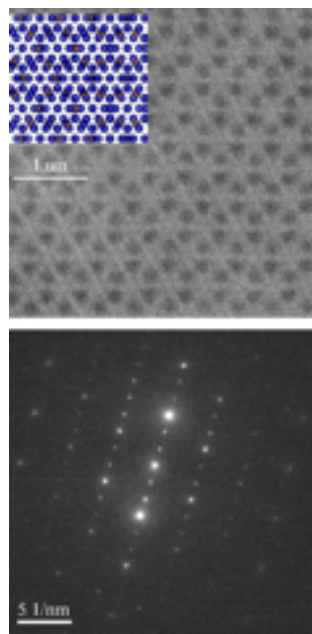

(g)

Fig. III-2-35. TEM characterization of $(\mathrm{CrMo})_{23} \mathrm{C}_{6}$ precipitates in 1106-1, irradiated with $\mathrm{Fe}^{2+}$ to 50 dpa at $0.46 \mu \mathrm{m}$ depth at $670^{\circ} \mathrm{C}$. (a, c, e) ABF images; (b) HAADF image. Inset is $\mathrm{Cr}_{23} \mathrm{C}_{6}$ lattice $<123>$ zone where blue and brown spheres represent $\mathrm{Cr}$ and $\mathrm{C}$ atoms, respectively. (f) EDS peak intensity profile of the precipitate indicated by arrow in (e). (g) Upper panel: HAADF lattice images with inset of $\mathrm{Cr}_{23} \mathrm{C}_{6}<111>$ lattice. Lower panel: electron diffraction patterns. 
Fig. III-2-33(a) and Fig. III-2-35(e-g) show large columnar shape precipitates along the grain boundary and inside grains. Their long axes align with each other. EDS peak intensity profile in Fig. III-2-35(f) shows Cr, Mo, and $\mathrm{C}$ are rich in the precipitates. A high-resolution image and diffraction pattern in Fig. III-2-35(g) correspond to $\mathrm{Cr}_{23} \mathrm{C}_{6}<111>$ lattice and $<123>$ zone diffraction, respectively. The long axis of precipitates is found to be along [110].

Fig. III-2-36(a-c) shows small particles about 20-50 nm large that are composed of $\mathrm{Nb}, \mathrm{Cr}, \mathrm{C}$, and N. These particles align in a row, or align along dislocations, as shown in Fig. III-2-36(c).

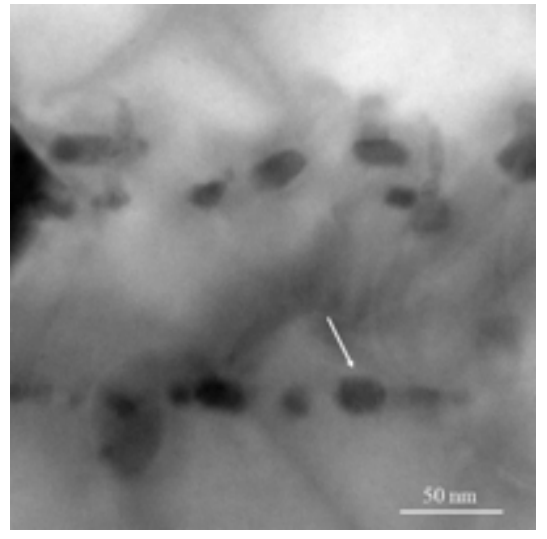

(a)

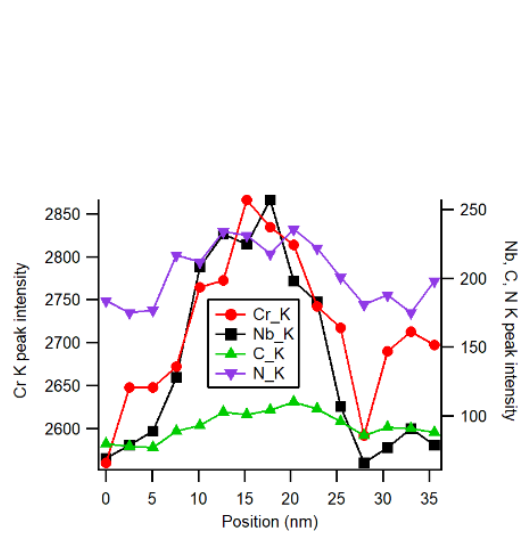

(b)

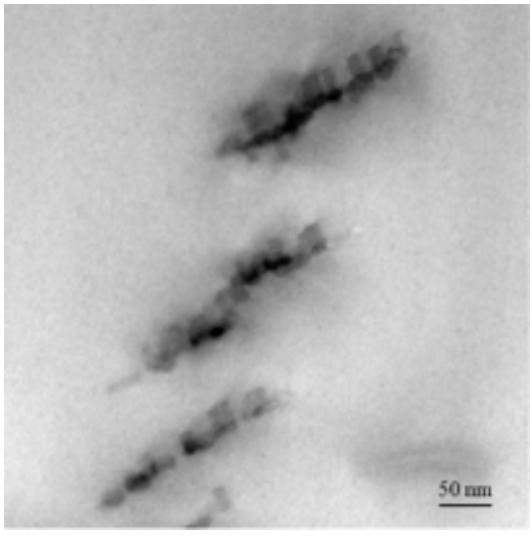

(c)

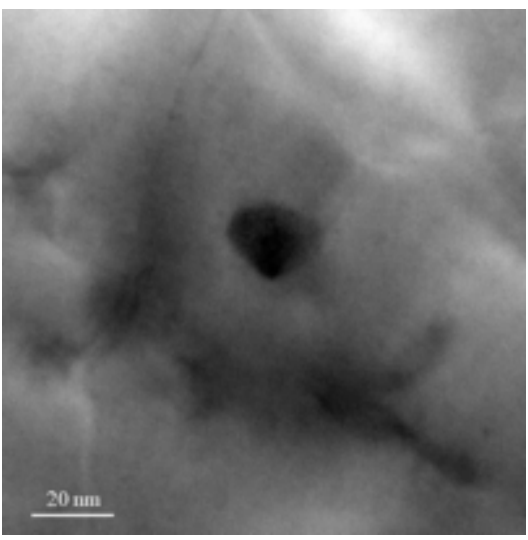

(d)

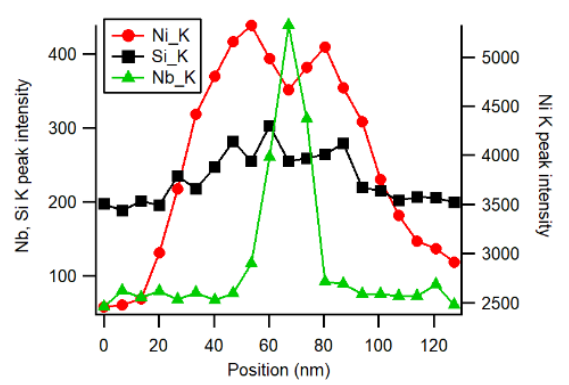

(e) 


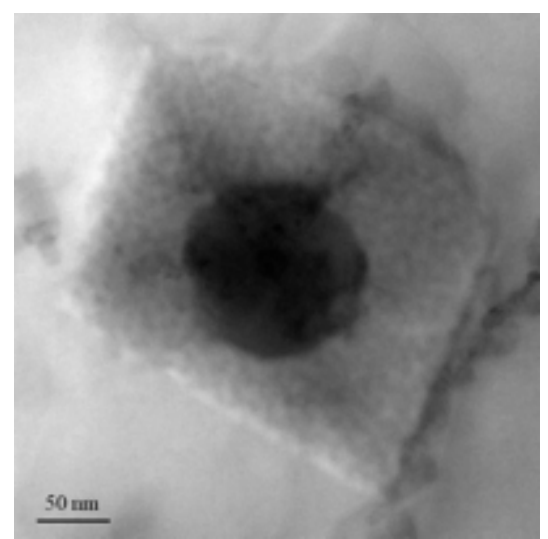

(f)

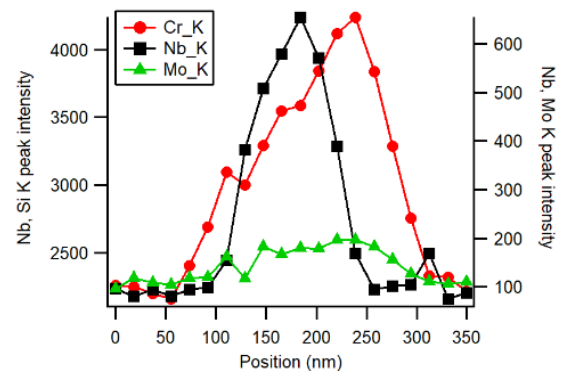

(g)

Fig. III-2-36. TEM characterization of smaller precipitates in 1106-1, irradiated with $\mathrm{Fe}^{2+}$ to 50 dpa at 0.46 $\mu \mathrm{m}$ depth at $670{ }^{\circ} \mathrm{C}$. (a, c, d, f) ABF images; (b, e, g) EDS peak intensity profiles of the particles to the left.

Fig. III-2-36(d-e) shows a particle $\sim 80 \mathrm{~nm}$ composed of $\mathrm{Ni}$ and $\mathrm{Si}$. The core of the particle is rich in $\mathrm{Nb}$. Fig. III-2-36(f-g) shows another particle with a Nb-rich core. However, the particle is composed of Cr, Mo, $\mathrm{C}, \mathrm{N}$ and is possibly $(\mathrm{CrMo})_{23}(\mathrm{CN})_{6}$.

In summary, sample 1106 has large precipitates $\sim 1 \mu \mathrm{m}$ along the grain boundary. They are $(\mathrm{CrMo})_{23}(\mathrm{CN})_{6}$ and $(\mathrm{CrMoNb})_{3} \mathrm{Ni}_{2} \mathrm{Si}(\mathrm{N})$. Columnar $(\mathrm{CrMo})_{23}(\mathrm{CN})_{6}$ particles align with each other along $<110>$ crystalline direction. Smaller particles tens of nanometers large are present inside grains. They include $(\mathrm{CrMo})_{23}(\mathrm{CN})_{6}$, $(\mathrm{CrMoNb})_{3} \mathrm{Ni}_{2} \mathrm{Si}(\mathrm{N}),(\mathrm{NbCr})_{x}(\mathrm{CN})_{y}, \mathrm{Ni}_{\mathrm{x}} \mathrm{Si}_{\mathrm{y}} .(\mathrm{NbCr})_{\mathrm{x}}(\mathrm{CN})_{\mathrm{y}}$ particles appear to align along dislocations. $\mathrm{Nb}$ core is also found in $\mathrm{Ni}_{\mathrm{x}} \mathrm{Si}_{\mathrm{y}}$ particles and some $(\mathrm{CrMo})_{23}(\mathrm{CN})_{6}$ particles.

\section{III-2-3-4. $\mathrm{Fe}^{2+}$ ion irradiated model 709 (FeCrNi) at $670{ }^{\circ} \mathrm{C}, 50 \mathrm{dpa}$}

Fig. III-2-37 shows a cross-sectional image of model 709 (55Fe-20Cr-25Ni in wt. \%) after $\mathrm{Fe}^{2+}$ irradiation at $670{ }^{\circ} \mathrm{C}$ to $50 \mathrm{dpa}$ at $0.46 \mu \mathrm{m}$. Voids are present. Volume increase (swelling) from voids is calculated to be $14 \%$ in the whole damaged region (surface to $1.65 \mu \mathrm{m}$ depth, up to $100 \mathrm{dpa}$ ). 


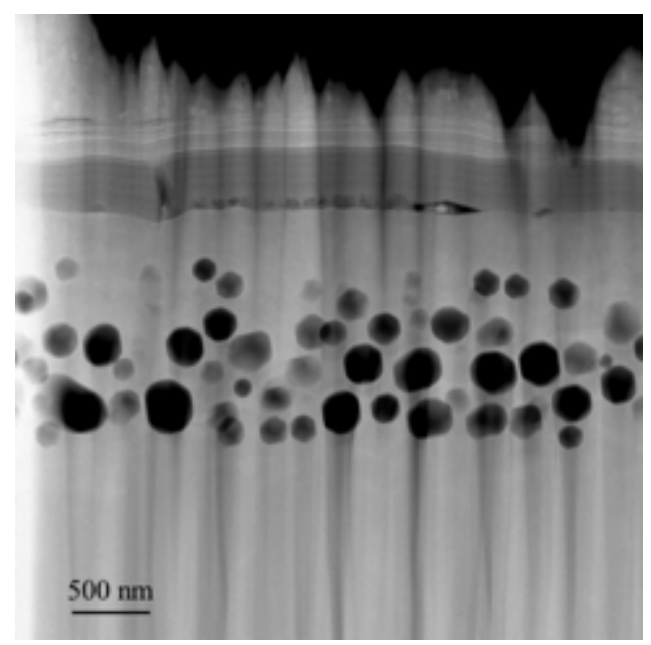

Fig. III-2-37. HAADF cross-sectional image of model 709 after $\mathrm{Fe}^{2+}$ irradiation at $670{ }^{\circ} \mathrm{C}$ to 50 dpa. Fig. III-2-38 shows grain boundary at depth of $0.34 \mu \mathrm{m}$, about $43 \mathrm{dpa}$. Irradiation-induced Ni segregation, $\mathrm{Fe}$ and $\mathrm{Cr}$ depletion at the grain boundary.

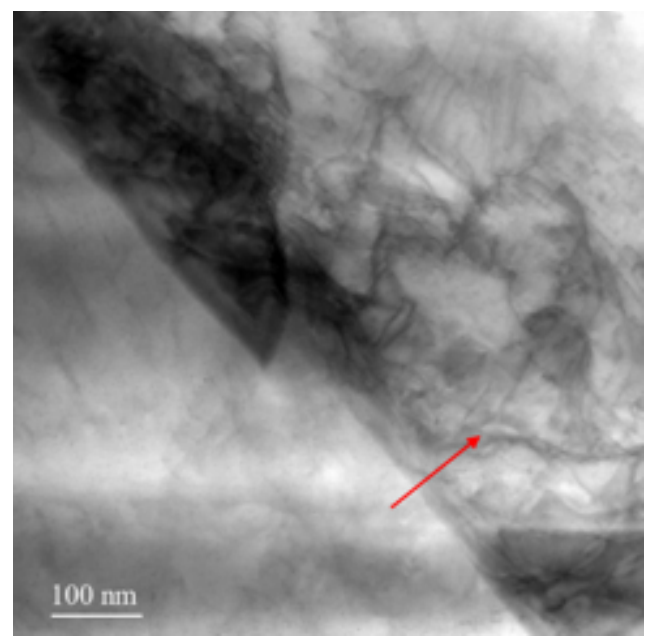

(a)

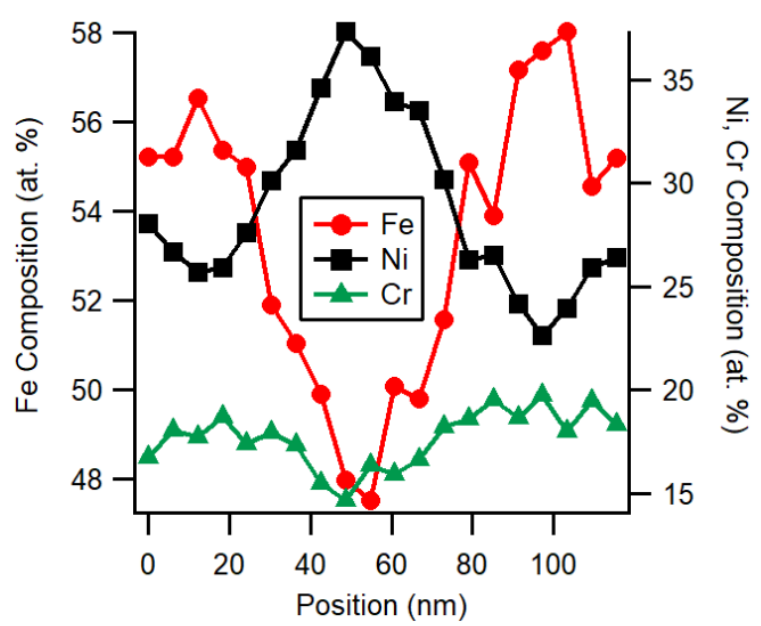

(b)

Fig. III-2-38. Grain boundary in model 709 irradiated by $\mathrm{Fe}^{2+}$ ions at $670{ }^{\circ} \mathrm{C}$ to $43 \mathrm{dpa}(0.34 \mu \mathrm{m}$ depth). (a) ABF image. (b) EDS measured composition along the red arrow in (a).

Fig. III-2-39 show voids at $0.95 \mu \mathrm{m}$ depth, about 99 dpa. Ni enrichment, Fe and $\mathrm{Cr}$ depletion take place near the sidewall of voids. 


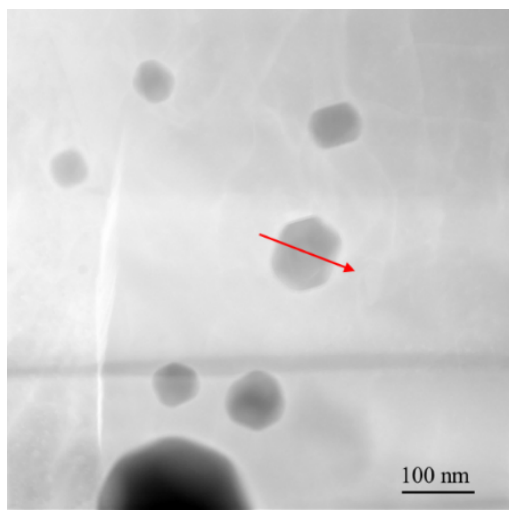

(a)

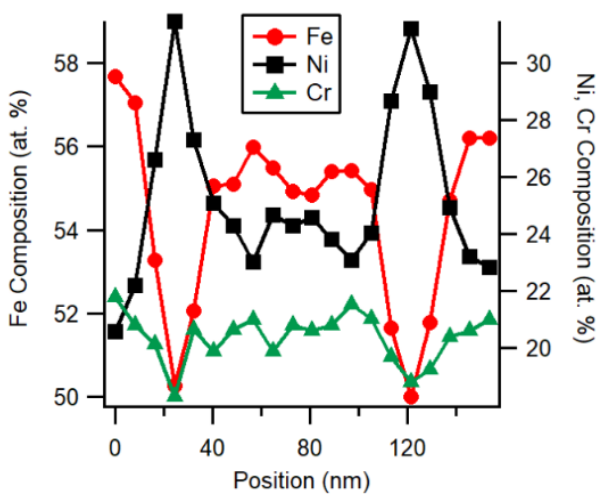

(b)

Fig. III-2-39. Void in model 709 after $\mathrm{Fe}^{2+}$ ion irradiation at $670{ }^{\circ} \mathrm{C}$ to $99 \mathrm{dpa}(0.95 \mu \mathrm{m}$ depth). (a)

HAADF image. (b) EDS measured compositional profile along the red arrow in (a).

\section{III-2-3-5. Summary}

Microstructure of $\mathrm{Fe}^{2+}$ irradiated alloy 709, thermal annealed $709(1101,1106)$ and model 709 to 50 dpa at $670{ }^{\circ} \mathrm{C}$ is summarized below:

1) Dislocations are the main defect. There are no Frank loops.

2) Irradiation-induced $\mathrm{Cr}, \mathrm{Fe}$ depletion, $\mathrm{Ni}, \mathrm{Mn}$ segregation at grain boundary in alloy 709 , and $\mathrm{Cr}, \mathrm{Fe}$ depletion, Ni segregation at the grain boundary and void periphery in model 709 .

3) Irradiation produced new Z-phase $\mathrm{CrNbN} \sim 10 \mathrm{~nm}$ in alloy 709.

4) Precipitates $\mathrm{M}_{23} \mathrm{C}_{6}$ and $\mathrm{M}_{3} \mathrm{Ni}_{2} \mathrm{Si}$ in $1101, \mathrm{M}_{23} \mathrm{C}_{6}, \mathrm{M}_{3} \mathrm{Ni}_{2} \mathrm{Si}, \mathrm{Ni}_{\mathrm{x}} \mathrm{Si}_{\mathrm{y}}$ in 1106 are results of creeprupture/thermal annealing. No new precipitates have been found in 1101 and 1106 after $\mathrm{Fe}^{2+}$ ion irradiation at $670{ }^{\circ} \mathrm{C}$ up to $100 \mathrm{dpa}$ (50 dpa at $0.46 \mu \mathrm{m}$ depth). But irradiation-induced $\mathrm{Cr}$ enrichment in $\mathrm{M}_{23} \mathrm{C}_{6}$ and $\mathrm{M}_{3} \mathrm{Ni}_{2} \mathrm{Si}$.

5) Voids were created in model 709 after rastered ion beam irradiation, but not in alloy 709 and 1101, 1106.

\section{$\underline{\text { III-2-4. As-received and } \mathrm{Fe}^{2+} \text { irradiated } \mathrm{G} 91 \text { and } \mathrm{G92} \text { at } 350{ }^{\circ} \mathrm{C}, 50 \mathrm{dpa}}$}

Grade 92, or G92, is a ferritic alloy of composition Fe-9Cr-2W-0.4Mo-0.4Mn-(VNbCN) in weight percentage. Grade 91, or G91, is a commercial alloy of composition Fe-9Cr-1Mo-0.2V-0.1C-0.1Nb to benchmark G92.

\section{III-2-4-1. As-received G91}


Fig. III-2-40 shows precipitates in as-received G91. Some precipitates are larger than $100 \mathrm{~nm}$ and mainly distributed along the grain boundary, as indicated by arrows in the annular bright field (ABF) image of Fig. III-2-40(a). Other precipitates are about a few tens of nanometers in size, distributed along the grain boundary and inside grains. They display dark contrast in high angle annular dark field (HAADF) image as indicated by arrows in Fig. III-2-40(b).

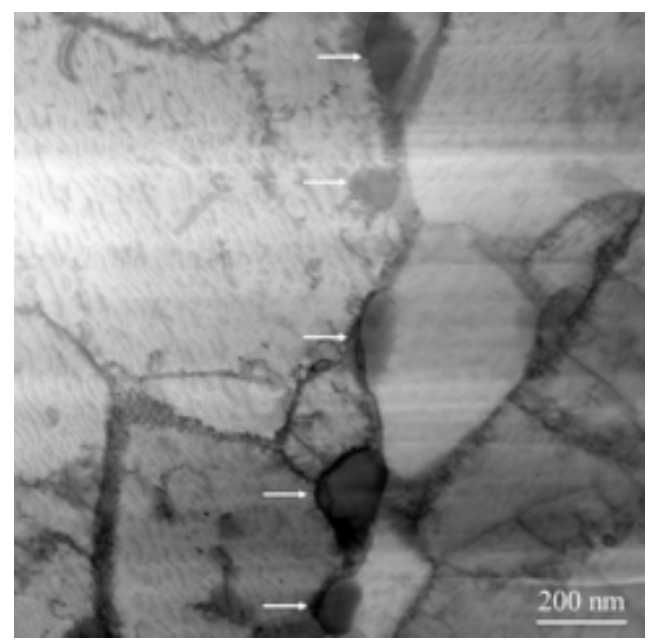

(a)

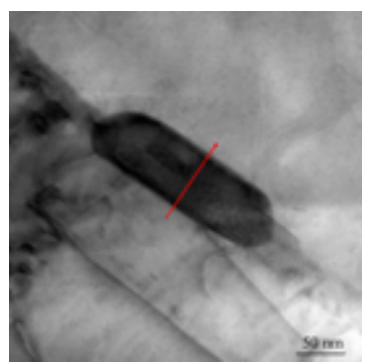

(c)

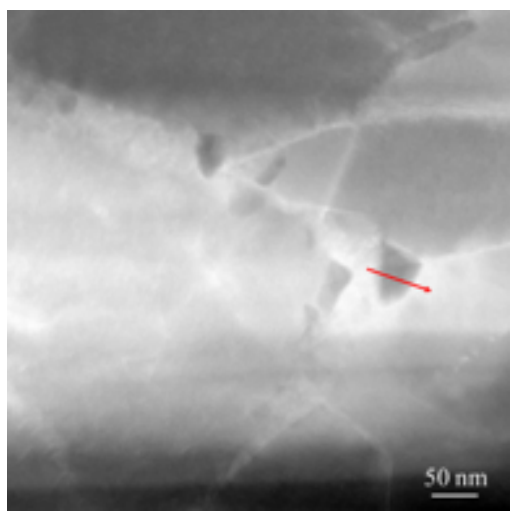

(g)

(d)

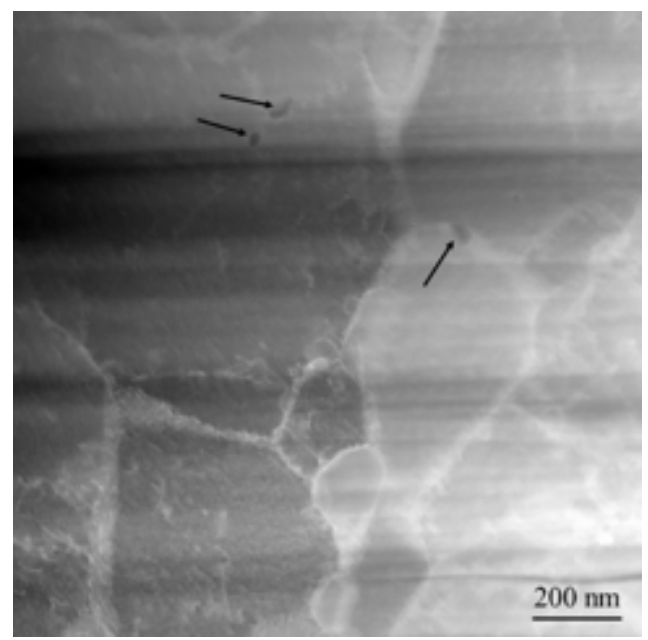

(b)
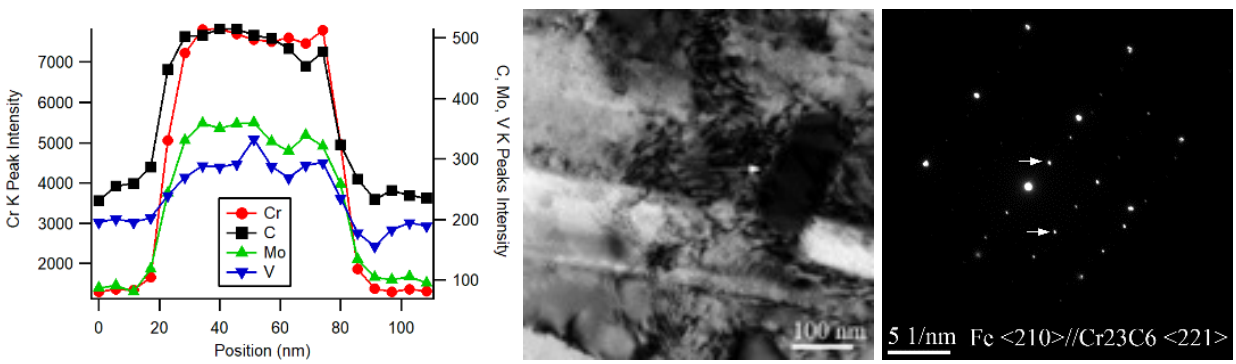

(e)

(f)

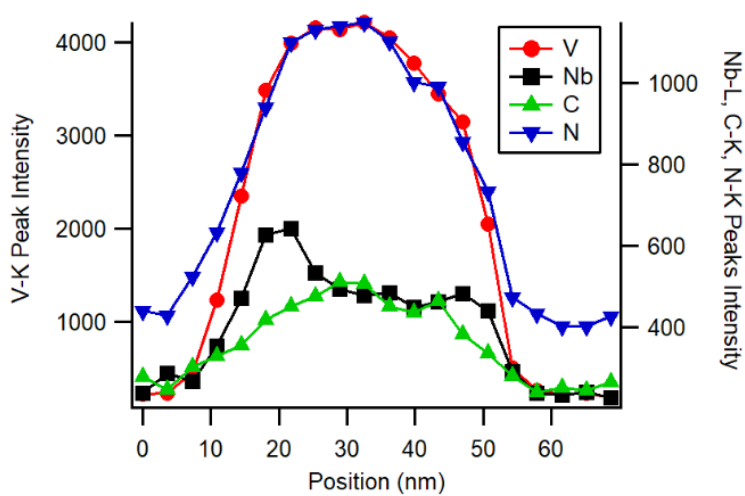

(h) 


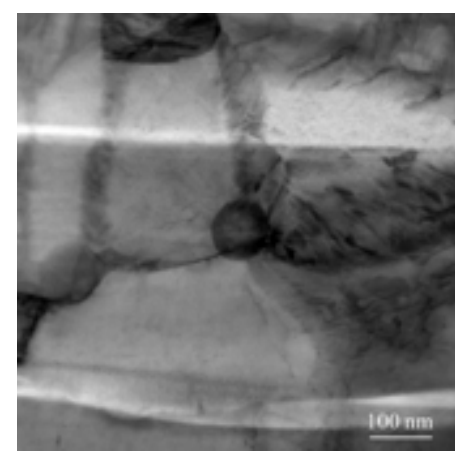

(i)

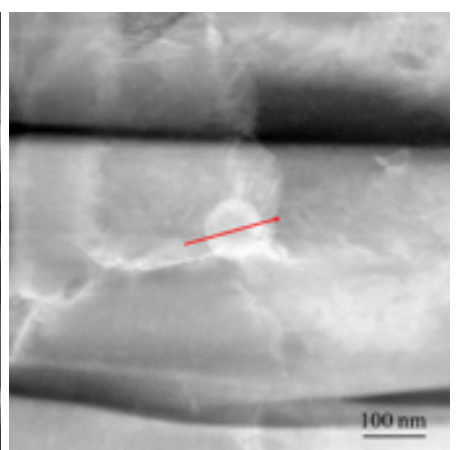

(j)

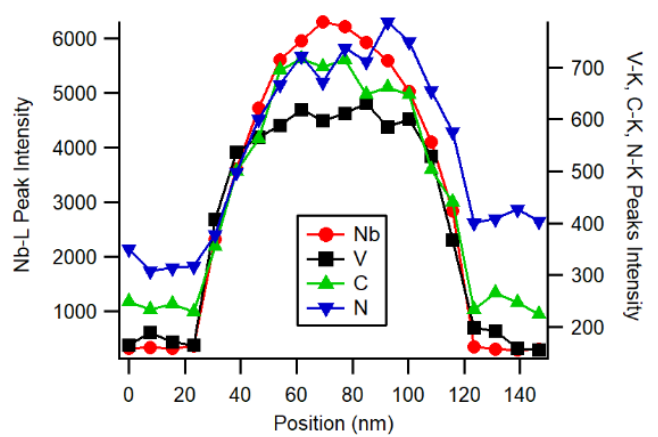

(k)

Fig. III-2-40. TEM characterization of precipitates in as-received G91. (a) Annular bright field (ABF) image. (b) High angle annular dark field (HAADF) image of the same area of (a). (c) ABF image. (d) X-ray energy dispersive spectroscopy (EDS) peak intensity profile along the red arrow in (c). (e) BF image. (f) electron diffraction pattern of the particle indicated by arrow in (e). (g) HAADF image. (h) EDS peak intensity profile along the arrow in (g). (i) ABF image. (j) HAADF image of the same area of (i). (k) EDS peak intensity profile along the arrow in (i).

Fig. III-2-40(c, d) show a large particle and x-ray energy dispersive spectroscopy (EDS) line scan along the particle. The main components are Cr, C with small composition of Mo and V. Fig. 2-40(e, f) show one other large particle and the electron diffraction pattern at the particle region. Arrows in Fig. III-2-40(f) indicate diffraction spots corresponding to $\mathrm{Cr}_{23} \mathrm{C}_{6}<210>$ zone diffraction. The particles a few hundred nanometers large are identified as $(\mathrm{CrMoV})_{23} \mathrm{C}_{6}$.

Fig. III-2-40(g, h) show smaller particles with dark contrast in HAADF images are $\mathrm{V}(\mathrm{Nb}) \mathrm{CN}$. A third type of particle is shown in Fig. III-2-40(i-k). It displays a brighter contrast in HAADF image. EDS analysis shows it is $\mathrm{Nb}(\mathrm{V}) \mathrm{CN}$.

\section{III-2-4-2. As-received G92}

Fig. III-2-41 shows a HAADF image of as-received G92. Precipitate composition was measured with EDS. Like G91, there are small $\mathrm{V}(\mathrm{Nb}) \mathrm{CN}, \mathrm{Nb}(\mathrm{V}) \mathrm{CN}$ precipitates about a few tens of nanometers in size, as indicated by red and black arrows, respectively, in Fig. III-2-41. White arrows indicate $(\mathrm{CrWMoV})_{23} \mathrm{C}_{6}$ particles that are generally larger than $100 \mathrm{~nm}$. 


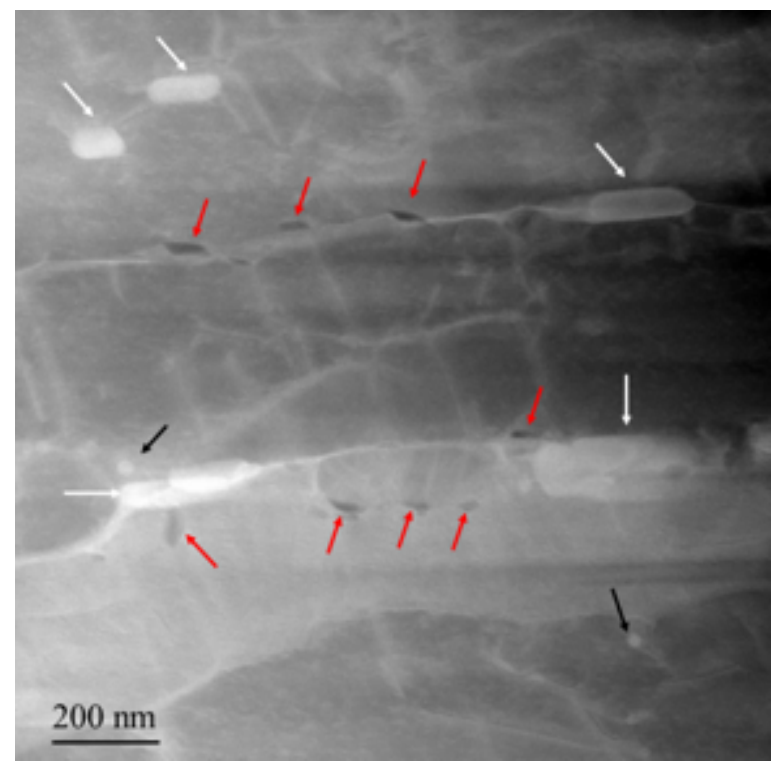

Fig. III-2-41. HAADF image of as-received G92. Precipitates indicated by arrows are: $(\mathrm{CrWMoV})_{23} \mathrm{C}_{6}-$ white arrows, $\mathrm{V}(\mathrm{Nb}) \mathrm{CN}$ - red, $\mathrm{Nb}(\mathrm{V}) \mathrm{CN}$ - black.

As-received G91 and G92 have similar type of precipitates: $\mathrm{M}_{23} \mathrm{C}_{6}$ and $\mathrm{MX}$. The difference is the composition of $\mathrm{M}_{23} \mathrm{C}_{6}$ : $(\mathrm{CrWMoV})_{23} \mathrm{C}_{6}$ in $\mathrm{G} 92$ and $(\mathrm{CrMoV})_{23} \mathrm{C}_{6}$ in $\mathrm{G} 91$.

\section{III-2-4-3. $\mathrm{Fe}^{2+}$ irradiated $\mathrm{G} 91$ at 50 dpa $350{ }^{\circ} \mathrm{C}$}

Fig. III-2-42 shows images of G91 after $\mathrm{Fe}^{2+}$ irradiation at $350{ }^{\circ} \mathrm{C}$ for $50 \mathrm{dpa}$ at $0.46 \mu \mathrm{m}$. There are piled up dislocations, as indicated by red arrows in Fig. III-2-42(a). Fig. III-2-42(b) shows a region of G91 at 50 dpa damage. Sample thickness is about $40 \mathrm{~nm}$. Black spots at the center of the image are dislocation loops. Fig. III-2-42(c) is an annular bright field image along $<110>$ zone at a depth of $0.62 \mu \mathrm{m}$, about 62 dpa. Dislocation loops are mainly $<001>$ type, as indicated by the arrows. The size of dislocation loops is $3.2 \pm 1.8$ $\mathrm{nm}$ at $46 \mathrm{dpa}$ with a density of $9.8 \times 10^{22} \mathrm{~m}^{-3}$ for features $>1.5 \mathrm{~nm}$ and visible along $<110>$ zone. It is smaller than dislocation loops in irradiated G92 (Fig. III-2-46). 


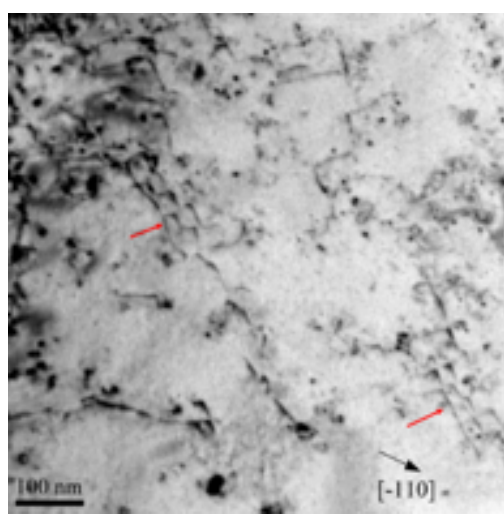

(a)

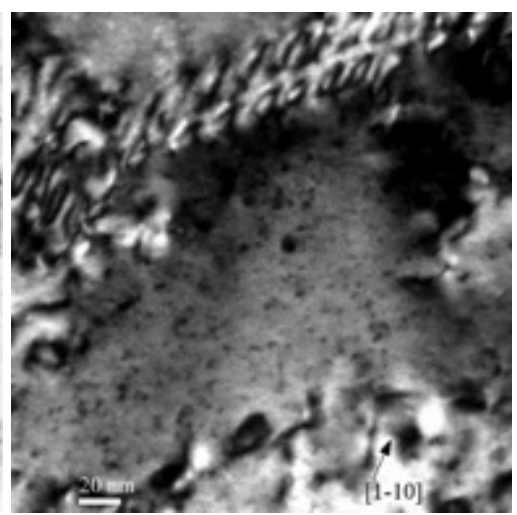

(b)

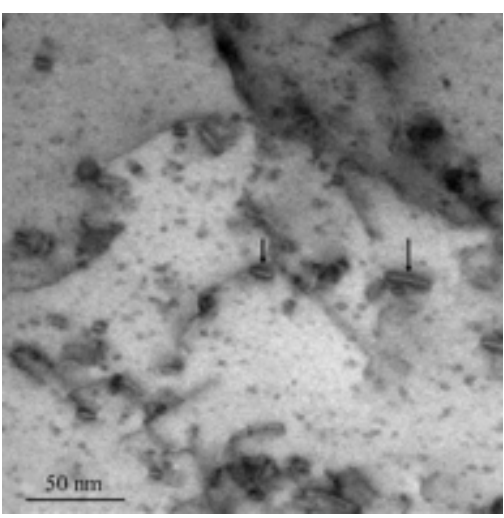

(c)

Fig. III-2-42. Cross-sectional images of G91 after $\mathrm{Fe}^{2+}$ irradiation at $350{ }^{\circ} \mathrm{C}$. (a) BF image. [110] zone (110) diffraction. Center of image is at $0.86 \mu \mathrm{m}$ depth with damage level about $88 \mathrm{dpa}$. (b) BF image. [110] zone (110) diffraction. Image center is at $0.49 \mu \mathrm{m}$ depth, about 50 dpa. (c) ABF image on [110] zone. Arrow indicated $<001>$ dislocation loops.

Fig. III-2-43 shows a $\mathrm{M}_{23} \mathrm{C}_{6}$ particle at a depth of $0.33 \mu \mathrm{m}$, about $41 \mathrm{dpa}$. The electron diffraction pattern in Fig. III-2-43(b) shows amorphous particle and crystalline matrix.

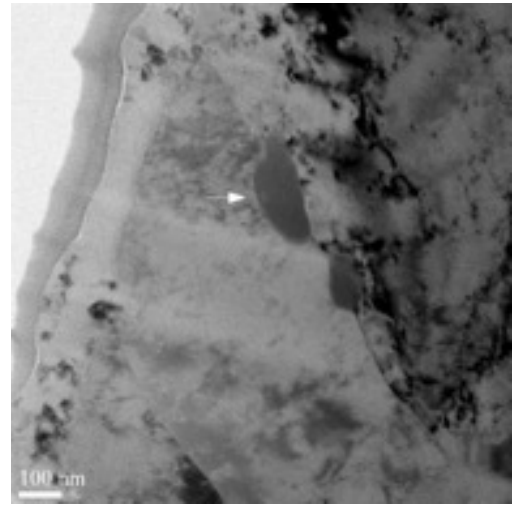

(a)

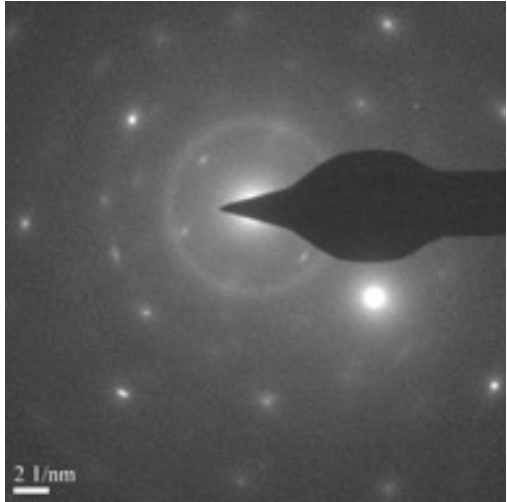

(b)

Fig. III-2-43. (a) Bright field image, (b) Electron diffraction pattern at the arrow indicated $\mathrm{M}_{23} \mathrm{C}_{6}$ particle and surrounding area in (a).

Fig. III-2-44 shows irradiated grain boundaries at 99 dpa (red arrow position) and 77 dpa (blue arrow position). Fig. III-2-44(b, c) shows segregation of $\mathrm{Cr}$, $\mathrm{Si}$, Ni, and depletion of $\mathrm{Fe}$ at the grain boundaries. 


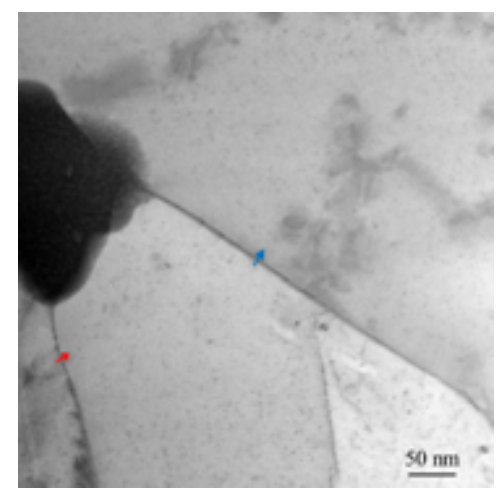

(a)

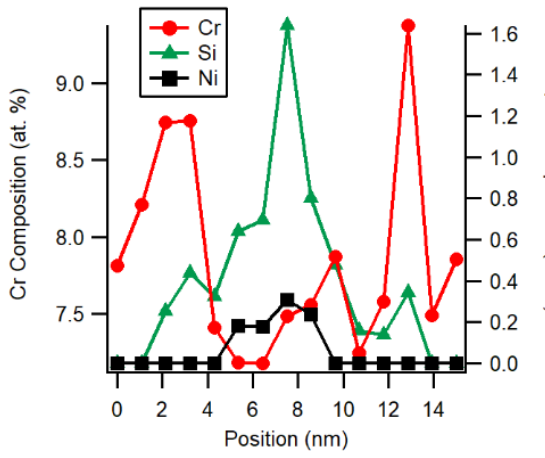

(b)

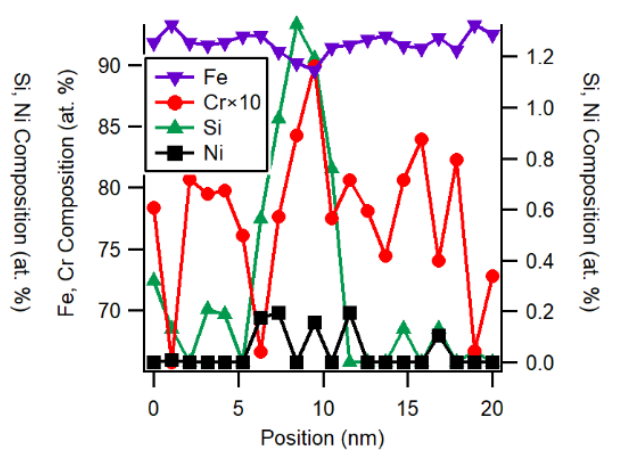

(c)

Fig. III-2-44. Irradiated grain boundary in G91. (a) ABF image. (b) EDS measured compositional profile along the red arrow in (a) at a depth of $0.98 \mu \mathrm{m}$, about $99 \mathrm{dpa}$. (c) Compositional profile along the blue arrow at a depth of $0.77 \mu \mathrm{m}$, about $77 \mathrm{dpa}$.

\section{III-2-4-4. $\mathrm{Fe}^{2+}$ irradiated $\mathrm{G92}$ at 50 dpa $350{ }^{\circ} \mathrm{C}$}

Fig. III-2-45 shows G92 after $3.7 \mathrm{MeV} \mathrm{Fe}^{2+}$ irradiation at $350{ }^{\circ} \mathrm{C}$ for $50 \mathrm{dpa}$ at $0.46 \mu \mathrm{m}$. Irradiation produced a surface damage region $1.9 \mu \mathrm{m}$ deep. $(\mathrm{CrWMoV})_{23} \mathrm{C}_{6}$ and $\mathrm{V}(\mathrm{Nb}) \mathrm{CN}$ particles were found in the damaged region by EDS. A (CrWMo) ${ }_{23} \mathrm{C}_{6}$ particle at $0.88 \mu \mathrm{m}$ depth is shown in Fig. III-2-45(b). The damage level is $90 \mathrm{dpa}$ according to SRIM calculation. Fig. III-2-45(c) is an electron diffraction pattern of the particle, showing the $\mathrm{M}_{23} \mathrm{C}_{6}$ particle is amorphized. Another $\mathrm{M}_{23} \mathrm{C}_{6}$ particle at $0.34 \mu \mathrm{m}$ deep, $42 \mathrm{dpa}$, was also found amorphous.

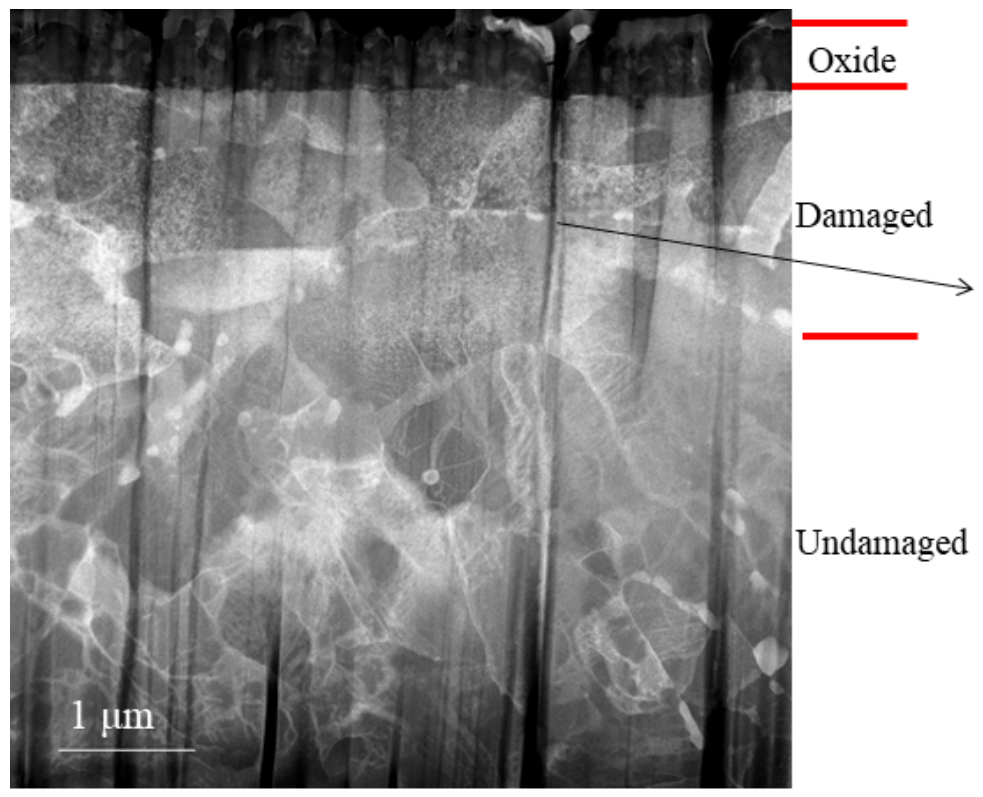

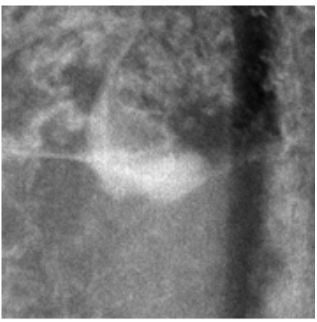

(b)

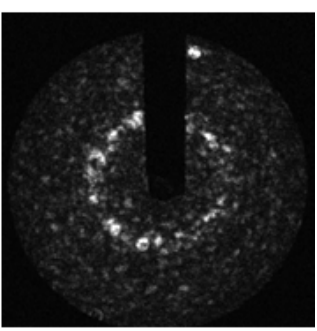

(c)

(a) 
Fig. III-2-45. Cross-sectional TEM images of G92 after $\mathrm{Fe}^{2+}$ irradiation at $350{ }^{\circ} \mathrm{C}$ to 50 dpa at $0.46 \mu \mathrm{m}$ depth. (a) ADF image. (b) ADF image of a particle from arrow indicated position in (a). (c) Nanobeam electron diffraction of the particle in (b).

Fig. III-2-46 (a, b) show BF images of dislocation loops in irradiated G92. The loops in Fig. III-2-46(a) lie on $\{100\}$ planes and $\{111\}$ planes, as indicated by red and blue arrows, respectively. They are two types of loops: one with Burgers vector $<100>$, the other $1 / 2<111>$. Sample thickness at Fig. III-2-46(b) is $87 \pm$ $3 \mathrm{~nm}$, measured with electron energy loss spectroscopy (EELS). The size of dislocation loops is $9.1 \pm 6.4$ $\mathrm{nm}$, with a density of $4.5 \times 10^{22} \mathrm{~m}^{-3}$ at $50 \mathrm{dpa}$.

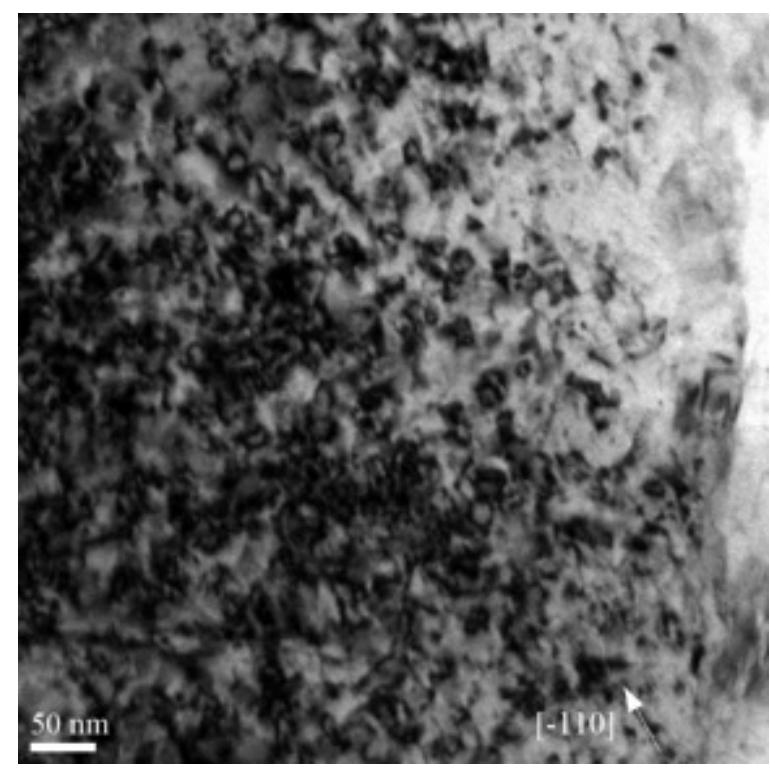

(a)

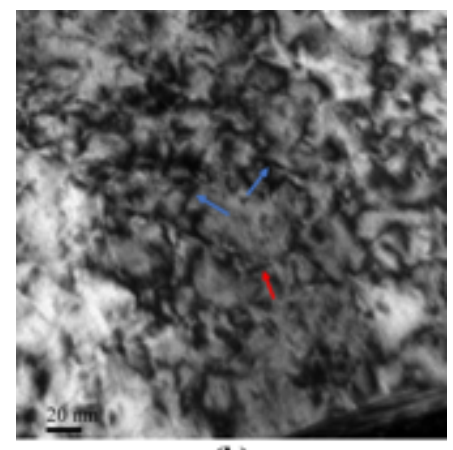

(b)

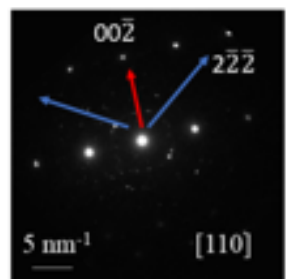

(c)

Fig. III-2-46. (a) BF image under [110] zone (110) two beam diffraction at sample depth $0.58 \mu \mathrm{m}$, corresponding to $58 \mathrm{dpa}$. (b) Higher magnification BF image under [110] zone (110) diffraction at about $0.6 \mu \mathrm{m}$ depth, 59 dpa. (c) Electron diffraction of area in (b).

Fig. III-2-47 shows composition across a grain boundary at a depth of $0.48 \mu \mathrm{m}$, about $50 \mathrm{dpa}$. Ni, $\mathrm{Si}, \mathrm{Cr}$ segregated while Fe depleted at the grain boundary. 


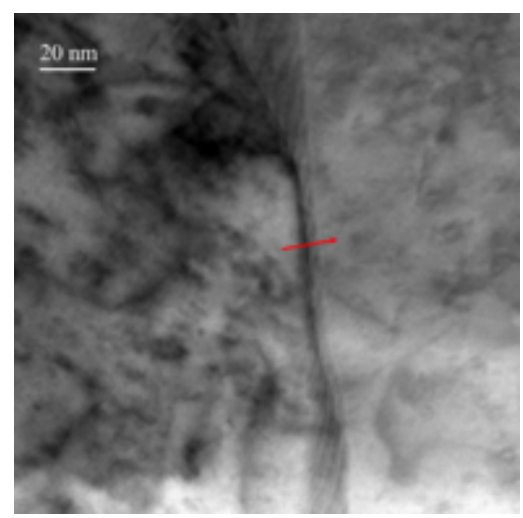

(a)

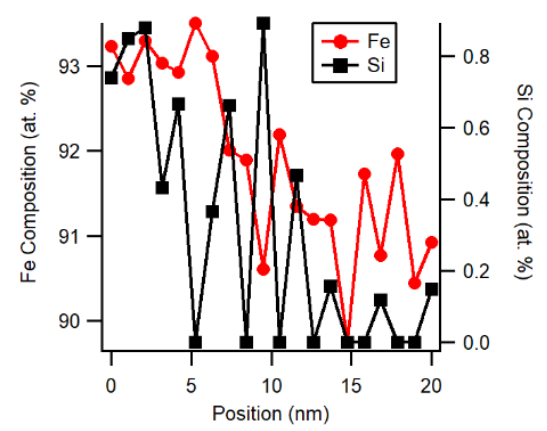

(b)

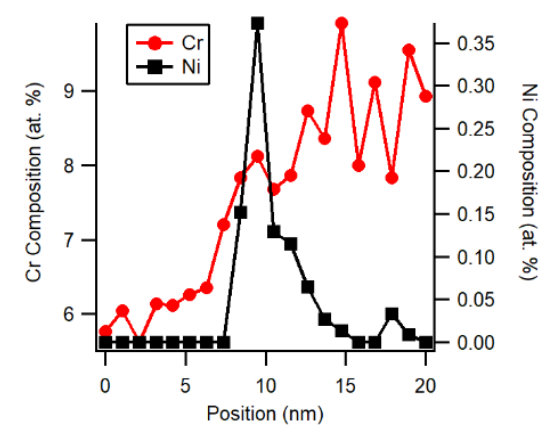

(c)

Fig. III-2-47. (a) ABF image, (b, c) EDS measured compositional profile across the grain boundary along the red arrow in (a). The irradiation dose is about 50 dpa at the image center.

\section{III-2-4-5. Summary}

Microstructures of as-received and irradiated alloys G91 and G92 by $\mathrm{Fe}^{2+}$ irradiation at $350{ }^{\circ} \mathrm{C}$ to 50 dpa are summarized below:

1) Precipitates in as-received $\mathrm{G} 91$ and $\mathrm{G} 92$ are similar: $(\mathrm{CrMoV}){ }_{23} \mathrm{C}_{6},(\mathrm{~V}, \mathrm{Nb})(\mathrm{CN})$ in $\mathrm{G} 91,(\mathrm{CrMoVW}){ }_{23} \mathrm{C}_{6}$ and $(\mathrm{V}, \mathrm{Nb})(\mathrm{CN})$ in $\mathrm{G} 92$.

2) Irradiation amorphized $\mathrm{M}_{23} \mathrm{C}_{6}$ particles in both alloys above about $40 \mathrm{dpa}$.

3) Irradiation-induced $\mathrm{Ni}, \mathrm{Si}, \mathrm{Cr}$ segregation, and Fe depletion at grain boundaries in both alloys.

4) Dislocation loops of $<100>$ and $a / 2<111>$ types developed after irradiation in both alloys. However, dislocation loops in G91 are smaller with higher density than that in G92.

\section{$\underline{\text { III-2-5. Defocused ion beam irradiation of alloy } 709 \text { to } 75 \mathrm{dpa} \text { at } 600{ }^{\circ} \mathrm{C}}$}

One non-rastering/ defocused $3.5 \mathrm{MeV} \mathrm{Fe}^{2+}$ ion beam irradiation was carried out on alloy 709 at $600{ }^{\circ} \mathrm{C}$ to $75 \mathrm{dpa}$ at $0.43 \mu \mathrm{m}$ depth (150 dpa peak damage). Fig. 2-48 shows the cross-sectional images of irradiated 709. The surface damage region, indicated by the white arrows, appear to have similar dislocation density to that of the undamaged region. The dislocation line shapes, however, are different: mostly curved in the damaged region and both straight and curved in the undamaged region (Fig. III-2-48b). There are no Frank loops. Precipitates $\sim 100 \mathrm{~nm}$ in size shown in Fig. III-2-48 are mainly $\mathrm{Nb}(\mathrm{CN})$. One $(\mathrm{NbCr})(\mathrm{CN})$ particle of $100 \mathrm{~nm}$ size was found in the undamaged region. The red arrow in Fig. III-2-48 (b) indicates a $(\mathrm{CrMnMo})_{\mathrm{x}} \mathrm{C}_{\mathrm{y}}$ particle at the unirradiated grain boundary. 


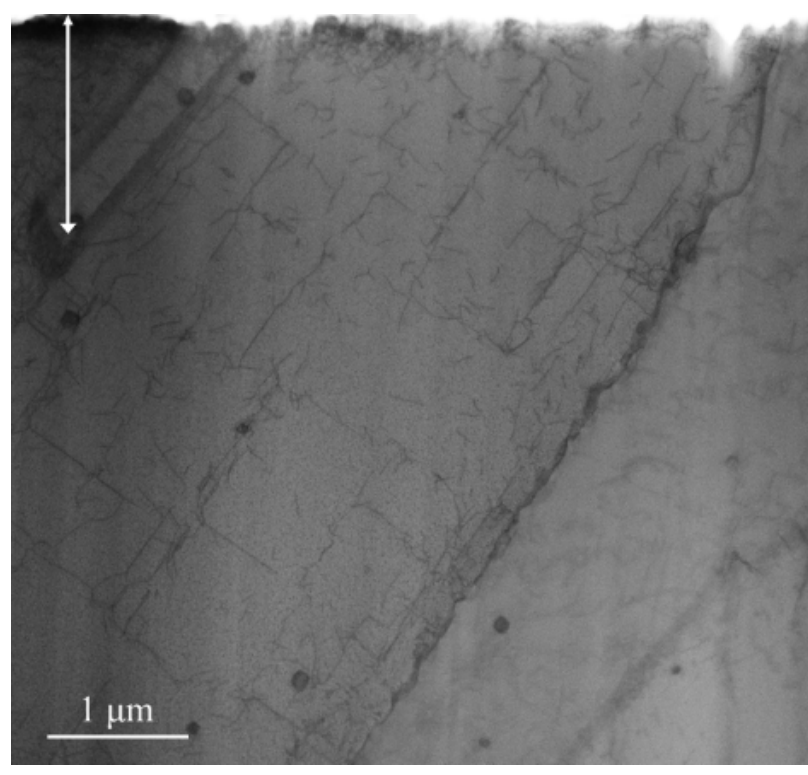

(a)

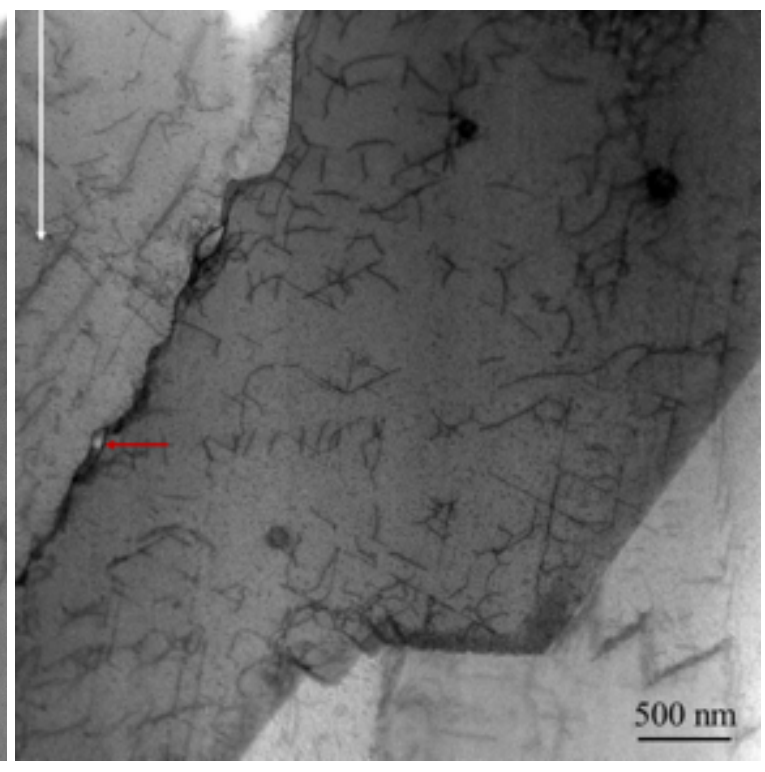

(b)

Fig. III-2-48. ABF cross-sectional images of $600^{\circ} \mathrm{C} \mathrm{Fe}^{2+}$ irradiated 709 with defocused ion beam. White arrows indicate the damaged depth. (a) A lower magnification image. (b) A higher magnification image with the central grain on $<110>$ zone.

Fig. III-2-49 shows grain boundary composition in both irradiated region (Fig. III-2-49 a) and unirradiated region (Fig. III-2-49 b). The measured grain boundary in Fig. 2-49 (a) is at 0.3 $\mu \mathrm{m}$ depth, about 64 dpa. Ni and Si segregation is found in the irradiated grain boundary. Fig. III-2-49 (b) shows that Ni segregation and Cr depletion also took place in the unirradiated grain boundary.
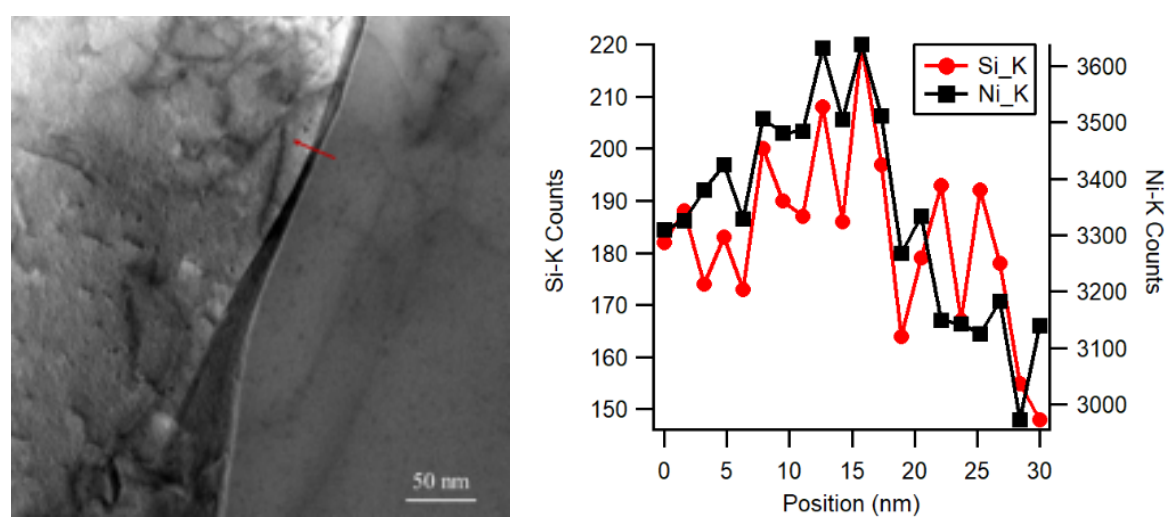

(a) 

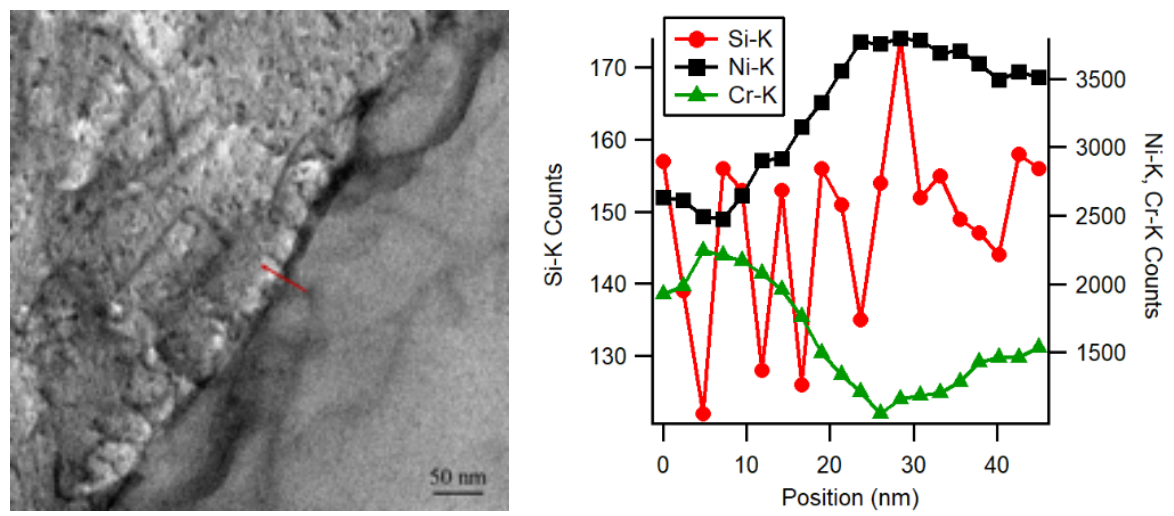

(b)

Fig. III-2-49. ABF image (left panels) and EDS peak intensity (right panels) of grain boundary in the irradiated region (a) and unirradiated region (b) of 709.

In summary, defocused ion beam irradiation of 709 at $600{ }^{\circ} \mathrm{C}$ to 75 dpa resulted in dislocations. Si and $\mathrm{Ni}$ segregation was found at the irradiated grain boundary. Thermal annealing during irradiation at $600{ }^{\circ} \mathrm{C}$ for 24.0 hours generated $(\mathrm{CrMoMn})_{\mathrm{x}} \mathrm{C}_{\mathrm{y}}$ particles at the grain boundary. Si segregation and $\mathrm{Cr}$ depletion were also found at the unirradiated grain boundary.

NiSi-rich particles $\sim 100 \mathrm{~nm}$ in size have been reported in defocused $\mathrm{Fe}^{2+}$ beam irradiated 709 at $600{ }^{\circ} \mathrm{C}$ with the same beam energy, fluence and flux (19). Such particles have not been found in this study.

\section{III-2-6. A new swelling measurement method with TEM and EELS}

We have developed a method to measure irradiation-induced swelling when voids are too small to be detected in TEM images, using plasmon energy loss spectroscopy (EELS). Fig. III-2-50(a) shows the annular dark field (ADF) image of $\mathrm{Fe}^{2+}$ irradiated $316 \mathrm{H}$ up to $100 \mathrm{dpa}$ at $350{ }^{\circ} \mathrm{C}$. Fig. 2-50(b) shows an EELS spectrum collected at $1.84 \mu \mathrm{m}$ depth along the red line in Fig. III-2-50(a). From the intensity ratio of zero loss peak and plasmon peak, the sample thickness was calculated to be $0.79 \lambda$, where $\lambda$ is the electron inelastic mean free path. The experimental data was fitted in $\mathrm{f}(\mathrm{x})=\mathrm{y} 0+\mathrm{A} \times \exp \left\{-\left[\left(\mathrm{x}-\mathrm{x}_{0}\right) / \text { width }\right)^{2}\right)+\mathrm{B} \times \mathrm{x}$. The fitting function is sought to match data trend near the top of plasmon peak without considering physical meaning. It yields plasmon peak energy $25.95 \mathrm{eV}$. 


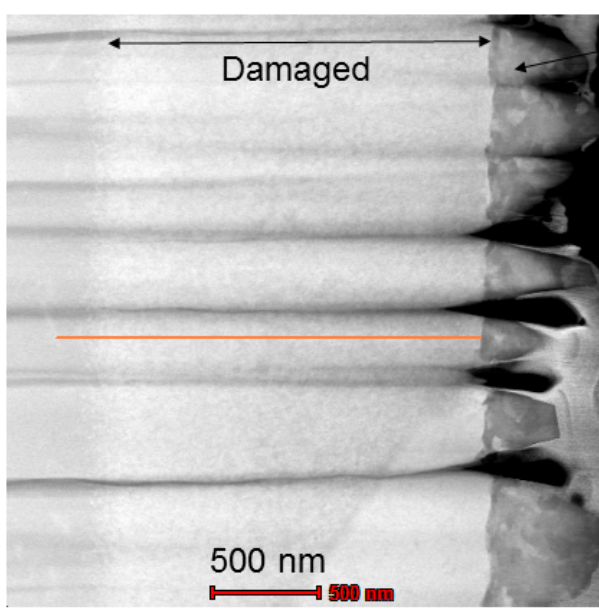

(a)

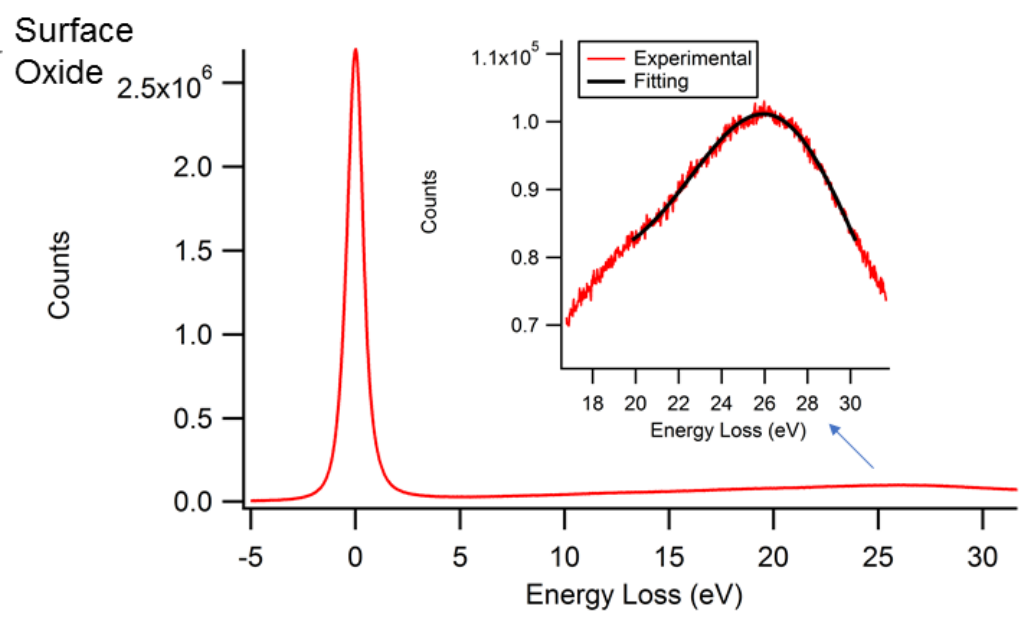

(b)

Fig. III-2-50. $\mathrm{Fe}^{2+}$ irradiated $316 \mathrm{H}$ up to $100 \mathrm{dpa}$ at $350^{\circ} \mathrm{C}$. (a) Annular dark field image. (b) EELS spectrum acquired at a given point along the red line in (a). Fifty spectra were acquired at fifty points equally spaced along the line. Fitting of plasmon peak top region was performed using $f(x)=y 0+A \times \exp \{-[(x-$ $\left.\mathrm{x}_{0}\right) /$ (width $\left.)^{2}\right)+\mathrm{B} \times \mathrm{x}$.

Assuming valence electrons to be free moving electrons, the square of plasmon peak energy $\mathrm{E}_{\mathrm{p}}{ }^{2}$ is proportional to valence electron volume density $\rho$. A TEM sample is a thin membrane usually about 100 $\mathrm{nm}$ thick. It inevitably contains a surface layer of either oxide, sample preparation damage or other structures having different electron density from intrinsic material. Fig. III-2-51 shows a schematic crosssection of a TEM specimen. $\rho$ and t represent valence electron density and sample thickness, respectively.

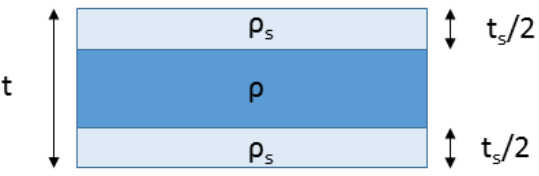

Fig. III-2-51. A schematic cross section of the TEM specimen showing intrinsic base material with valence electron density $\rho$ and surface layer with electron density $\rho_{\mathrm{s}}$ and thickness $t_{\mathrm{s}}$. The total thickness is t.

Plasmon energy is related to the average electron density:

$E_{p}^{2}=C \times \bar{\rho}=C \times \frac{\rho\left(V-V_{s}\right)+\rho_{s} V_{s}}{V}=C \times \frac{\rho\left(t-t_{s}\right)+\rho_{s} t_{s}}{t}=C\left[\rho-\left(\rho-\rho_{s}\right) \frac{t_{s}}{t}\right]$

Where $\mathrm{C}$ is a constant. Fig. III-2-52(a) plots $\mathrm{E}_{\mathrm{p}}{ }^{2}$ versus depth of EELS data. From the difference of $\mathrm{E}_{\mathrm{p}}{ }^{2}$ between damaged and undamaged materials, swelling is determined as $\frac{E_{p, u}^{2}}{E_{p, d}^{2}}-1$ and is shown in Fig. 2-52(b). SRIM calculated ion concentration is also plotted. SRIM calculation uses $3.7 \mathrm{MeV} \mathrm{Fe}^{2+}$ into $316 \mathrm{H}$ (Fe 
balance-17Cr-10Ni-2Mo-2Mn in weight percentage, $7.86 \mathrm{~g} / \mathrm{cm}^{3}$ ) and displacement energy values of $40 \mathrm{eV}$ for $\mathrm{Fe}, \mathrm{Cr}, \mathrm{Ni}, \mathrm{Mn}$ and $60 \mathrm{eV}$ for Mo.

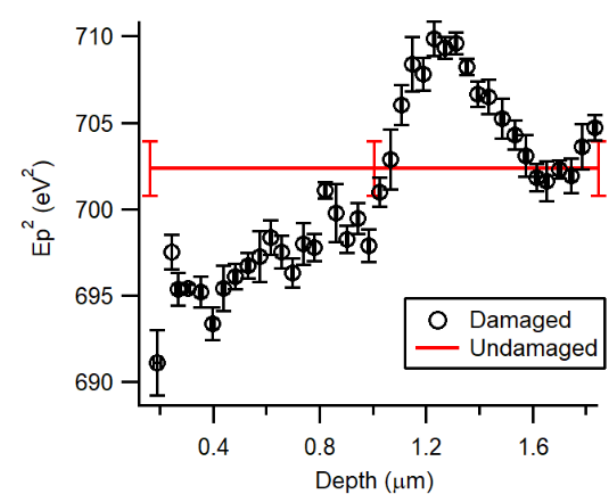

(a)

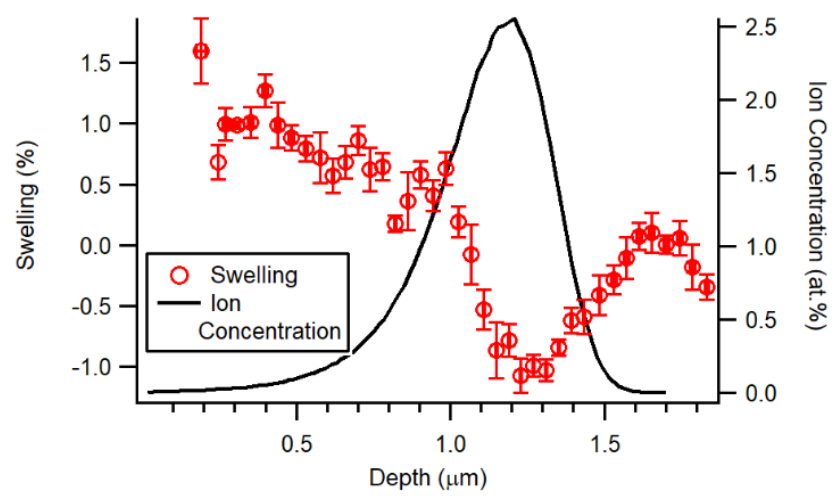

(b)

Fig. III-2-52. Swelling measurement of $\mathrm{Fe}^{2+}$ irradiated $316 \mathrm{H}$ up to 100 dpa at $350{ }^{\circ} \mathrm{C}$. (a) Plasmon peak energy square vs. depth in the damaged region after sample thickness correction. (b) Swelling profile (ion concentration is obtained from SRIM calculations).

Swelling appears to correlate inversely with ion implantation depth profile, i.e., large at the surface and gradually decreasing with depth. Near the implantation peak material is denser than intrinsic state. It swells at depths beyond implantation peak, but the magnitude of swelling is small. On average swelling is $0.15 \pm$ $0.05 \%$ at depths of $0.16-1.85 \mu \mathrm{m} 316 \mathrm{H}$ after $\mathrm{Fe}^{2+}$ irradiation up to $100 \mathrm{dpa}$ at $350{ }^{\circ} \mathrm{C}$.

\section{III-3. Mechanical Property Testing of Alloys}

Ion-irradiated alloys have been characterized with nanoindentation, including 709, FeCrNi (model 709), 316H, G91, G92, and three creep-ruptured 709 samples designated as 1101 (thermally aged for 17,106 hours at $\left.600{ }^{\circ} \mathrm{C}\right)$, and $1106\left(16,448\right.$ hours at $\left.700{ }^{\circ} \mathrm{C}\right)$. Iron irradiation generated a surface damage layer about $1.5 \mu \mathrm{m}$ thick. Tables III-3-1 to III-3-3 list the nanohardness at indenter displacement of $1 \mu \mathrm{m}$ of the undamaged and irradiation damaged samples.

Table III-3-1. Nanohardness at $1 \mu \mathrm{m}$ indent displacement of unirradiated and irradiated alloys 709, 316H, and FeCrNi (model 709).

\begin{tabular}{|l|l|l|l|l|l|}
\hline Ion & & Dpa & Hardness $(\mathrm{GPa}) 316 \mathrm{H}$ & 709 & FeCrNi \\
\hline
\end{tabular}




\begin{tabular}{|l|l|l|l|l|l|l|l|l|}
\hline & $\begin{array}{l}\mathrm{T} \\
\left({ }^{\circ} \mathrm{C}\right)\end{array}$ & & Unirradiated & Irradiated & Unirradiated & Irradiated & Unirradiated & Irradiated \\
\hline $\mathrm{Fe}^{2+}$ & 350 & 50 & $2.93 \pm 0.06$ & $3.67 \pm 0.05$ & & $2.80 \pm 0.04$ & & $2.2 \pm 0.1$ \\
\hline $\mathrm{Fe}^{2+}$ & 350 & 15 & $2.1 \pm 0.1$ & $2.4 \pm 0.1$ & $2.48 \pm 0.08$ & $2.8 \pm 0.1$ & & \\
\hline $\mathrm{Fe}^{2+}$ & 350 & 2.5 & $2.4 \pm 0.1$ & $2.9 \pm 0.1$ & $2.40 \pm 0.09$ & $2.71 \pm 0.06$ & & \\
\hline $\mathrm{Fe}^{2+}$ & 670 & 50 & $2.6 \pm 0.3$ & $2.6 \pm 0.2$ & $2.7 \pm 0.1$ & $2.7 \pm 0.1$ & $1.94 \pm 0.06$ & $1.7 \pm 0.1$ \\
\hline
\end{tabular}

Table III-3-2. Nanohardness at $1 \mu \mathrm{m}$ indent displacement of unirradiated and irradiated samples 1101, 1105, and 1106.

\begin{tabular}{|l|l|l|l|l|l|l|l|l|}
\hline Ion & T & Dpa & \multicolumn{4}{l}{ Hardness $(\mathrm{GPa}) 1101$} & 1105 & 1106 \\
\cline { 4 - 9 } & $\left({ }^{\circ} \mathrm{C}\right)$ & & Unirradiated & Irradiated & Unirradiated & Irradiated & Unirradiated & Irradiated \\
\hline $\mathrm{Fe}^{2+}$ & 350 & 15 & $2.01 \pm 0.09$ & $2.28 \pm 0.09$ & & $2.7 \pm 0.1$ & $2.42 \pm 0.09$ & $2.7 \pm 0.1$ \\
\hline $\mathrm{Fe}^{2+}$ & 350 & 2.5 & $2.4 \pm 0.1$ & $2.8 \pm 0.2$ & $2.4 \pm 0.1$ & $2.75 \pm 0.08$ & $2.3 \pm 0.1$ & $2.5 \pm 0.1$ \\
\hline $\mathrm{Fe}^{2+}$ & 670 & 50 & $2.97 \pm 0.06$ & $3.0 \pm 0.1$ & & $3.0 \pm 0.1$ & $2.4 \pm 0.1$ & $2.5 \pm 0.1$ \\
\hline
\end{tabular}

Table III-3-3. Nanohardness at $1 \mu \mathrm{m}$ indent displacement of unirradiated and irradiated alloys G91, G92.

\begin{tabular}{|c|c|c|c|c|c|c|}
\hline \multirow[t]{2}{*}{ Ion } & \multirow{2}{*}{$\begin{array}{l}\mathrm{T} \\
\left({ }^{\circ} \mathrm{C}\right)\end{array}$} & \multirow[t]{2}{*}{ Dpa } & \multicolumn{2}{|c|}{ Hardness (GPa) G91 } & \multicolumn{2}{|l|}{ G92 } \\
\hline & & & Unirradiated & Irradiated & Unirradiated & Irradiated \\
\hline $\mathrm{Fe}^{2+}$ & 350 & 50 & & $3.6 \pm 0.1$ & & $3.45 \pm 0.09$ \\
\hline $\mathrm{Fe}^{2+}$ & 350 & 15 & $2.71 \pm 0.06$ & $3.16 \pm 0.04$ & $2.79 \pm 0.07$ & $2.99 \pm 0.08$ \\
\hline $\mathrm{Fe}^{2+}$ & 350 & 2.5 & $2.72 \pm 0.04$ & $2.78 \pm 0.05$ & $2.61 \pm 0.06$ & $2.72 \pm 0.07$ \\
\hline $\mathrm{Fe}^{2+}$ & 670 & 50 & $2.81 \pm 0.07$ & $2.83 \pm 0.07$ & & $2.71 \pm 0.09$ \\
\hline
\end{tabular}

Tables III-3-4 to III-3-6 list irradiation-induced hardening defined as percentage of hardness increase from unirradiated samples to irradiated samples.

Table III-3-4. $\mathrm{Fe}^{2+}$ irradiation-induced hardening at indent displacements of $0.5 \mu \mathrm{m}$ and $1 \mu \mathrm{m}$ in alloys 709 , 316H, and $\mathrm{FeCrNi}$ (model 709).

\begin{tabular}{|c|c|c|c|c|c|c|c|c|}
\hline \multirow[t]{2}{*}{ Ion } & \multirow{2}{*}{$\begin{array}{l}\mathrm{T} \\
\left({ }^{\circ} \mathrm{C}\right)\end{array}$} & \multirow[t]{2}{*}{ Dpa } & \multicolumn{2}{|c|}{ Hardening (\%) $316 \mathrm{H}$} & \multicolumn{2}{|l|}{709} & \multicolumn{2}{|l|}{$\mathrm{FeCrNi}$} \\
\hline & & & $0.5 \mu \mathrm{m}$ & $1 \mu \mathrm{m}$ & $0.5 \mu \mathrm{m}$ & $1 \mu \mathrm{m}$ & $0.5 \mu \mathrm{m}$ & $1 \mu \mathrm{m}$ \\
\hline $\mathrm{Fe}^{2+}$ & 350 & 50 & & $25 \pm 3$ & & & & \\
\hline $\mathrm{Fe}^{2+}$ & 350 & 15 & $23 \pm 9$ & $15 \pm 10$ & $22 \pm 6$ & $13 \pm 6$ & & \\
\hline
\end{tabular}




\begin{tabular}{|l|l|l|l|l|l|l|l|l|}
\hline $\mathrm{Fe}^{2+}$ & 350 & 2.5 & $27 \pm 7$ & $21 \pm 9$ & $17 \pm 4$ & $13 \pm 5$ & & \\
\hline $\mathrm{Fe}^{2+}$ & 670 & 50 & & $-2 \pm 12$ & $2 \pm 12$ & $2 \pm 6$ & & $-13 \pm 7$ \\
\hline
\end{tabular}

Table III-3-5. $\mathrm{Fe}^{2+}$ irradiation-induced hardening at indent displacements of $0.5 \mu \mathrm{m}$ and $1 \mu \mathrm{m}$ in samples 1101,1105 , and 1106 .

\begin{tabular}{|l|l|l|l|l|l|l|l|l|}
\hline Ion & T & Dpa & \multicolumn{2}{l}{ Hardening (\%) 1101 } & $\mathbf{1 1 0 5}$ & $\mathbf{1 1 0 6}$ \\
\cline { 4 - 9 } & $\left({ }^{\circ} \mathbf{C}\right)$ & & $0.5 \mu \mathrm{m}$ & $1 \mu \mathrm{m}$ & $0.5 \mu \mathrm{m}$ & $1 \mu \mathrm{m}$ & $0.5 \mu \mathrm{m}$ & $1 \mu \mathrm{m}$ \\
\hline $\mathrm{Fe}^{2+}$ & 350 & 15 & $29 \pm 9$ & $13 \pm 7$ & & & $11 \pm 12$ & $12 \pm 7$ \\
\hline $\mathrm{Fe}^{2+}$ & 350 & 2.5 & $13 \pm 5$ & $14 \pm 9$ & $32 \pm 11$ & $13 \pm 7$ & $17 \pm 8$ & $7 \pm 8$ \\
\hline $\mathrm{Fe}^{2+}$ & 670 & 50 & & $0.4 \pm 4.9$ & & & $6 \pm 6$ & $6 \pm 8$ \\
\hline
\end{tabular}

Table III-3-6. $\mathrm{Fe}^{2+}$ irradiation-induced hardening at indent displacements of $0.5 \mu \mathrm{m}$ and $1 \mu \mathrm{m}$ in alloys G91, G92.

\begin{tabular}{|c|c|c|c|c|c|c|}
\hline \multirow[t]{2}{*}{ Ion } & \multirow{2}{*}{$\begin{array}{l}\mathbf{T} \\
\left({ }^{\circ} \mathbf{C}\right)\end{array}$} & \multirow[t]{2}{*}{ Dpa } & \multicolumn{2}{|c|}{ Hardening (\%) G91 } & \multicolumn{2}{|l|}{ G92 } \\
\hline & & & $0.5 \mu \mathrm{m}$ & $1 \mu \mathrm{m}$ & $0.5 \mu \mathrm{m}$ & $1 \mu \mathrm{m}$ \\
\hline $\mathrm{Fe}^{2+}$ & 350 & 15 & $25 \pm 6$ & $16 \pm 3$ & $17 \pm 5$ & $7 \pm 4$ \\
\hline $\mathrm{Fe}^{2+}$ & 350 & 2.5 & $9 \pm 4$ & $2 \pm 2$ & $10 \pm 5$ & $4 \pm 4$ \\
\hline $\mathrm{Fe}^{2+}$ & 670 & 50 & & $0.6 \pm 3.6$ & & \\
\hline
\end{tabular}

Fig. III-3-1 shows hardening of alloys by $\mathrm{Fe}^{2+}$ irradiation at $350{ }^{\circ} \mathrm{C}$. For clear view of the pictures, deviation is not plotted and is listed in tables 4-6.

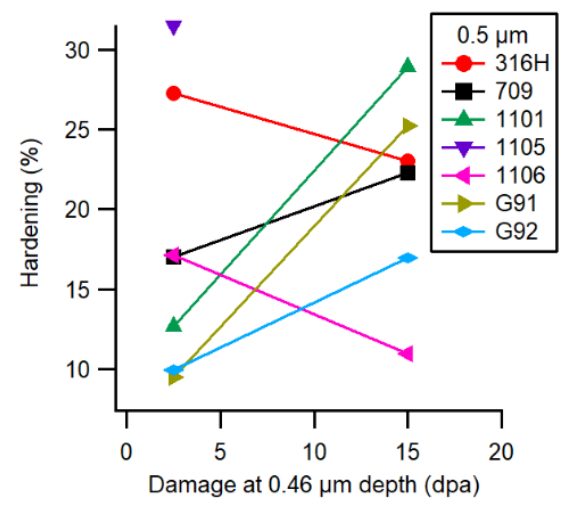

(a)

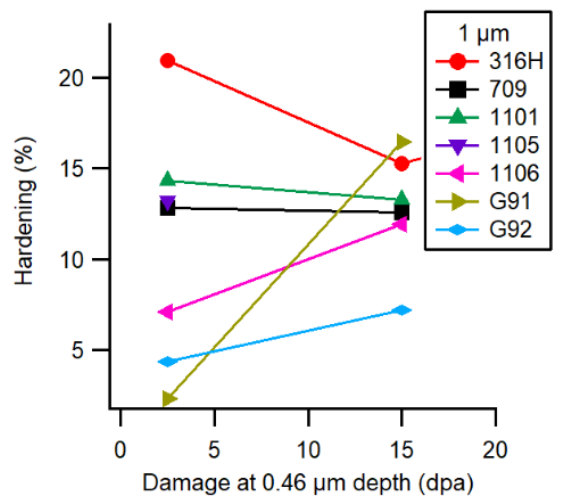

(b)

Fig. III-3-1. $\mathrm{Fe}^{2+}$ ion irradiation-induced hardening at $350{ }^{\circ} \mathrm{C}$ from nanoindentation measurements. Indent displacements are $0.5 \mu \mathrm{m}$ (a) and $1 \mu \mathrm{m}$ (b). 


\section{Results}

1. Irradiation at $350{ }^{\circ} \mathrm{C}$ from nominal 2.5 dpa to 50 dpa increased the hardness of all measured alloys.

2. Irradiation-induced hardening is insignificant at $670{ }^{\circ} \mathrm{C} 50$ dpa for most measured alloys. $\mathrm{FeCrNi}$ was softened possibly due to void growth.

3. Comparing hardening data at $350{ }^{\circ} \mathrm{C} \mathrm{Fe}^{2+}$ irradiation up to $50 \mathrm{dpa}, 709<316 \mathrm{H}, \mathrm{G} 92 \leq \mathrm{G} 91,1106$ $<709 \leq 1101$.

\section{Experimental details}

A Hysitron TI-950 TriboIndenter with a Berkovich tip and a High Load transducer was used to measure hardness of alloys. Measurement was made on both irradiated and masked area. The masked area did not experience irradiation but experienced the same thermal history as the irradiated area. Ten indentation measurements were performed at each displacement. Fig.s III-3-2 to III-3-4 show the results of nanohardness testing.

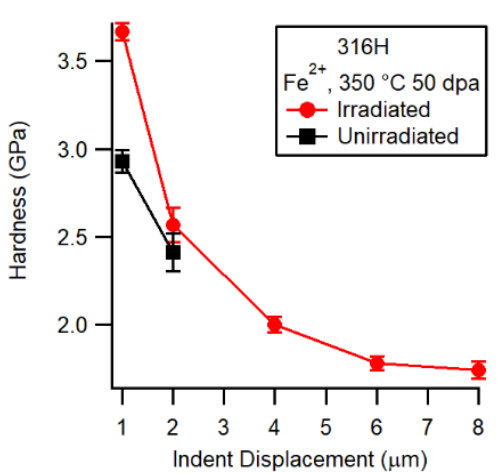

(a)

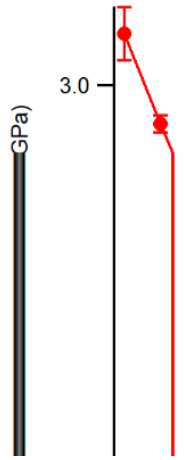

(b)

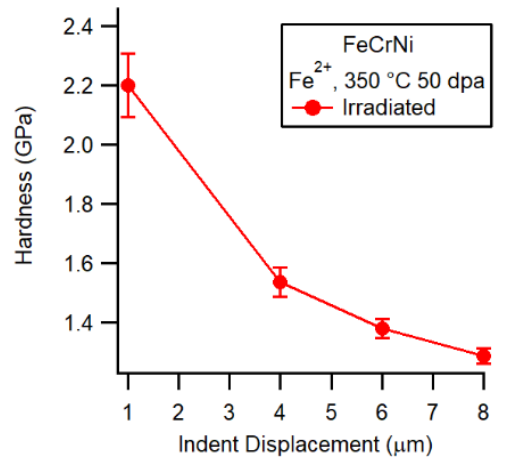

(c)

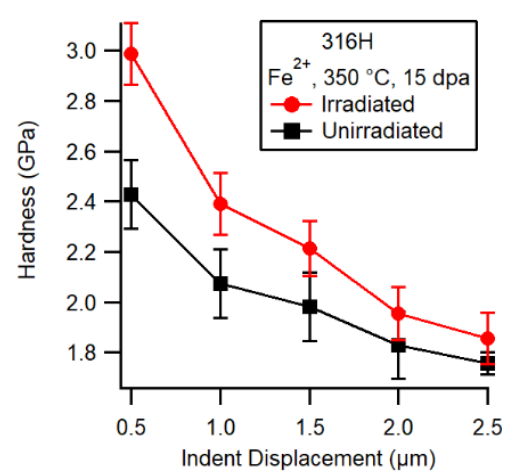

(d)
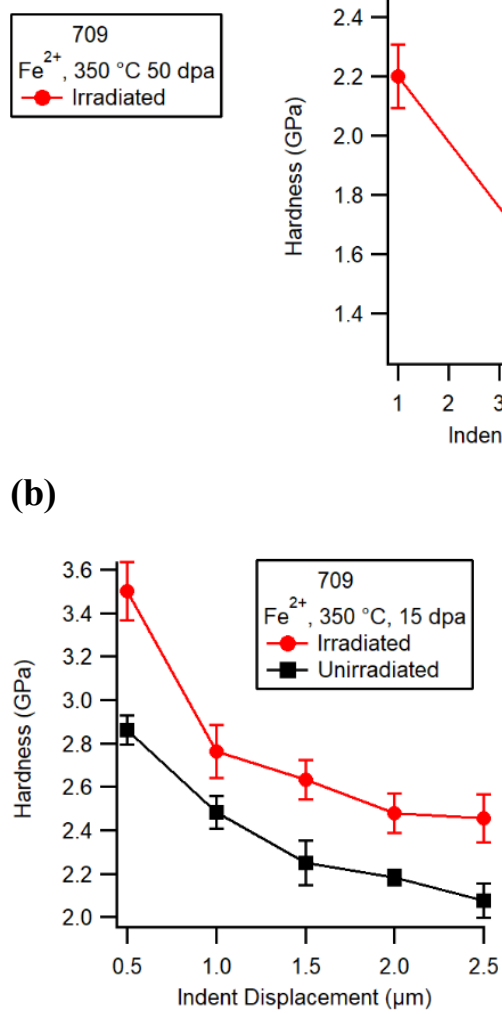

(e) 


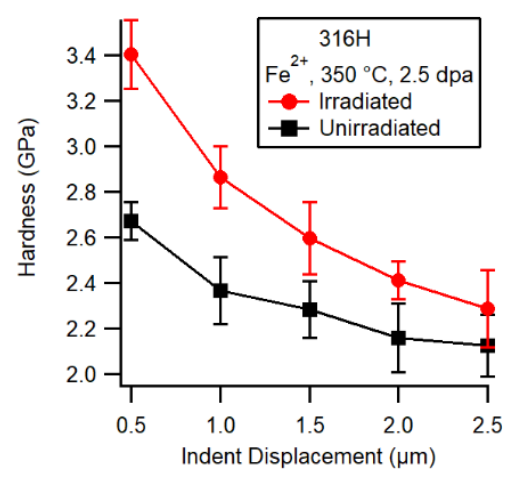

(f)

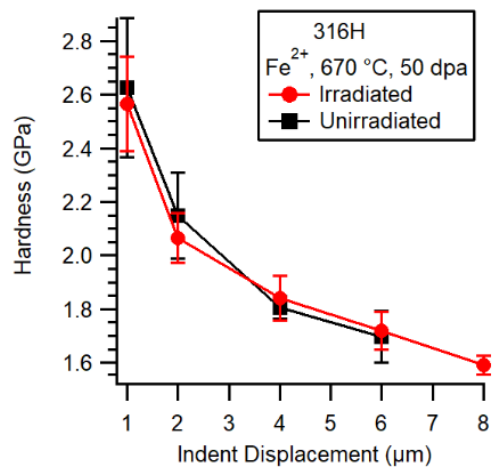

(h)

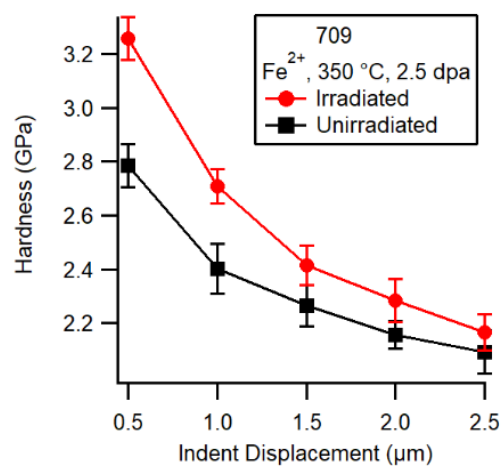

(g)

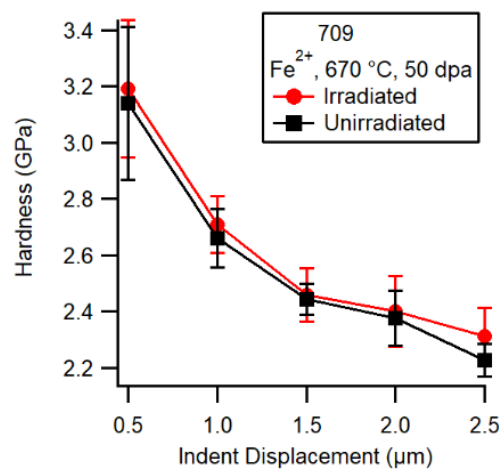

(i)

Fig. III-3-2. Nanohardness of unirradiated and $\mathrm{Fe}^{2+}$ irradiated samples 709, 316H, and FeCrNi. (a-c) 350 ${ }^{\circ} \mathrm{C} 50$ dpa. (d-e) $350{ }^{\circ} \mathrm{C} 15$ dpa. (f-g) $350{ }^{\circ} \mathrm{C} 2.5$ dpa. (h-i) $670{ }^{\circ} \mathrm{C} 50 \mathrm{dpa}$.

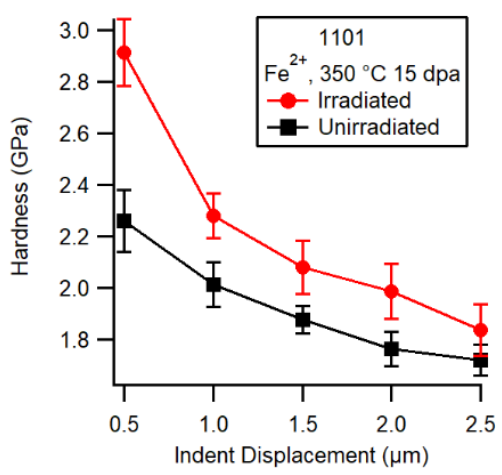

(a)

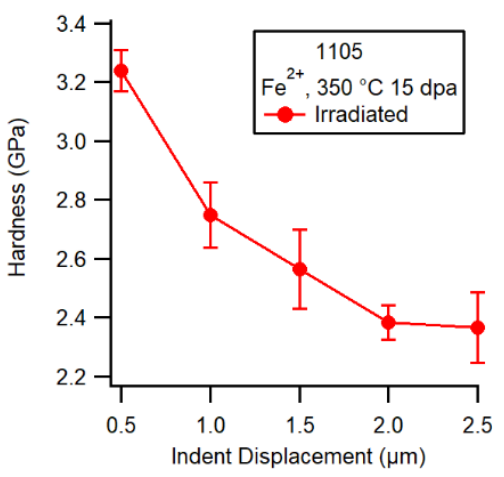

(b)

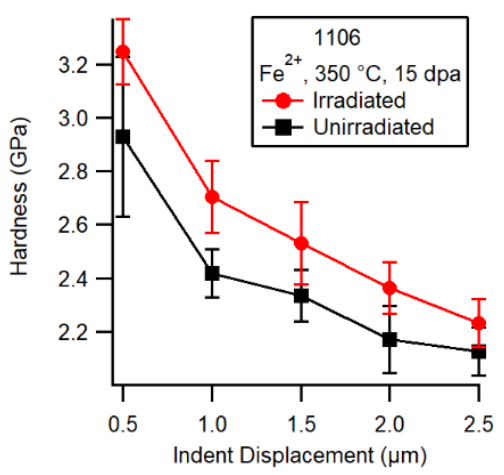

(c) 


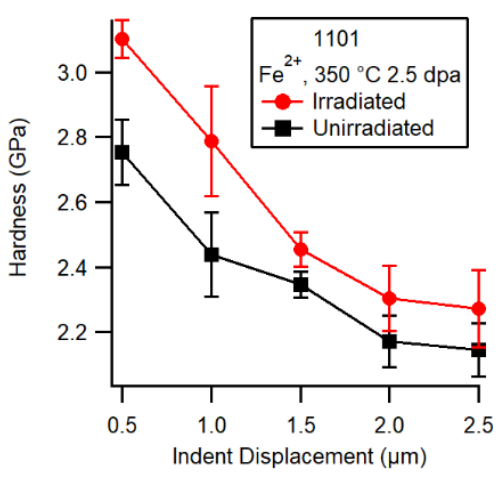

(d)

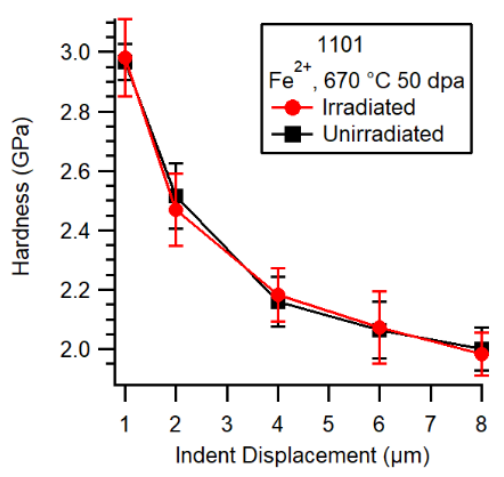

(g)

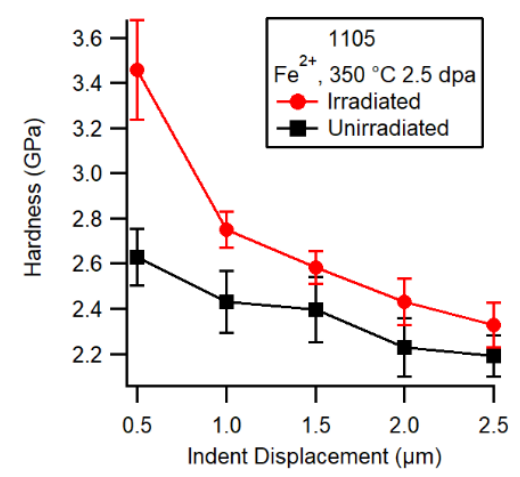

(e)

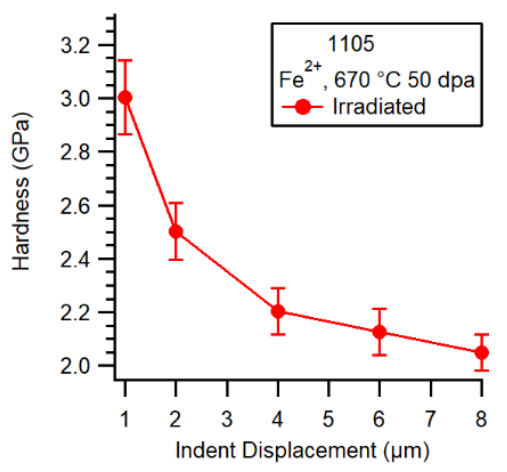

(h)

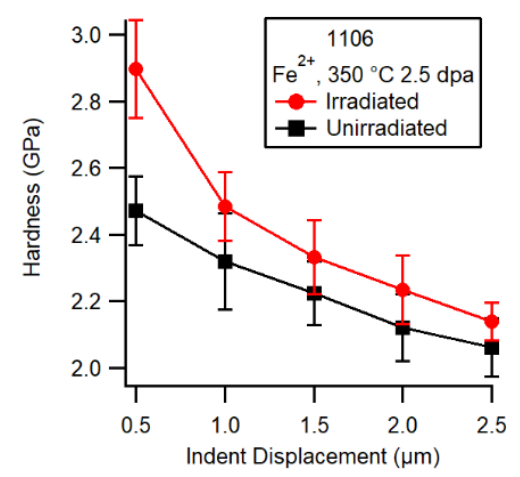

(f)

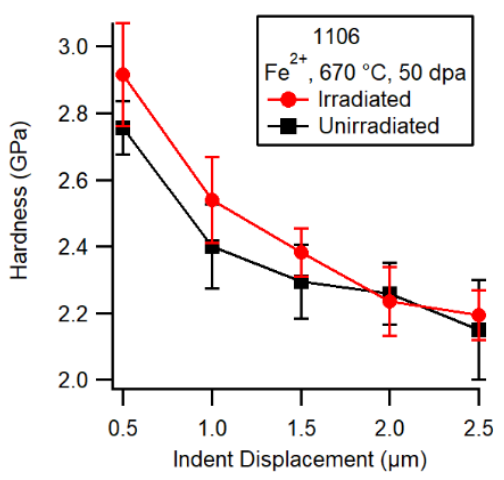

(i)

Fig. III-3-3. Nanohardness of unirradiated and $\mathrm{Fe}^{2+}$-irradiated samples 1101, 1105, and 1106. (a-c) $350{ }^{\circ} \mathrm{C}$ 15 dpa. (d-f) $350{ }^{\circ} \mathrm{C} 2.5$ dpa. (g-i) $670{ }^{\circ} \mathrm{C} 50$ dpa.

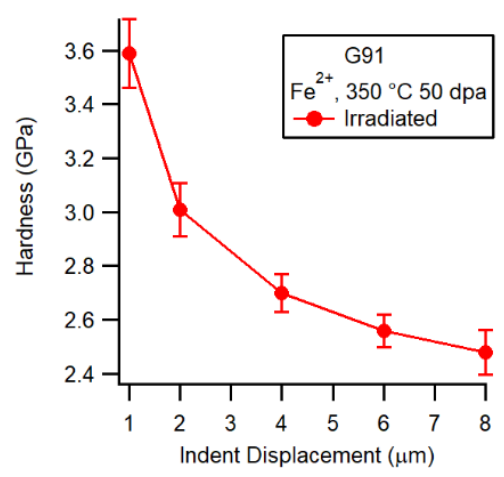

(a)

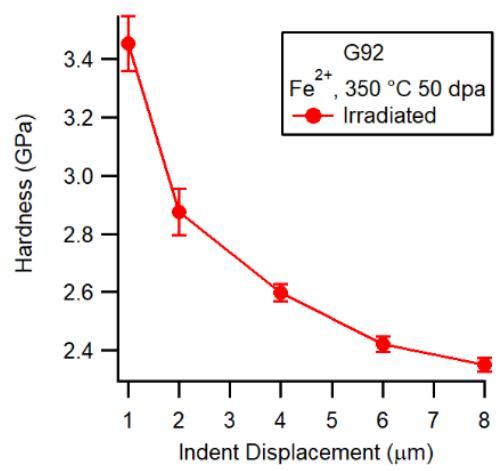

(b) 


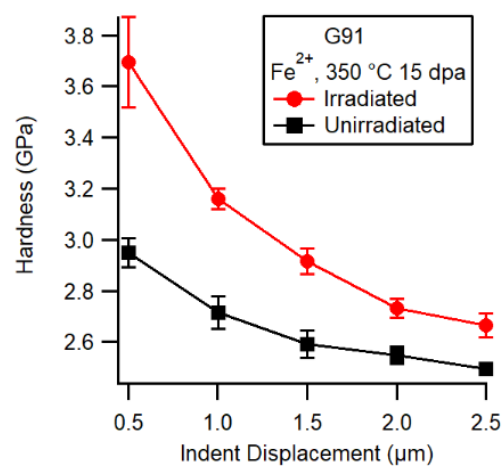

(c)

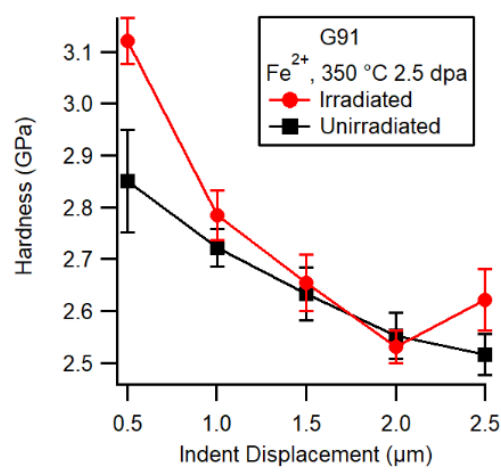

(e)

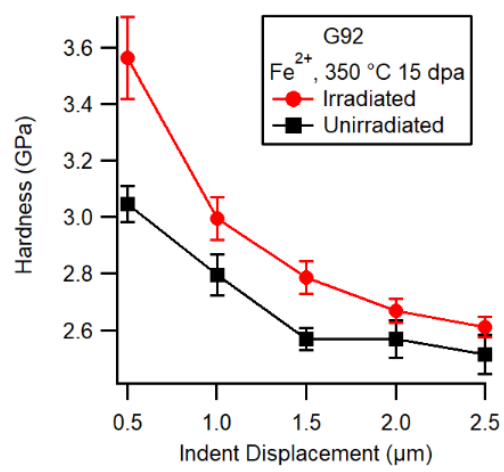

(d)

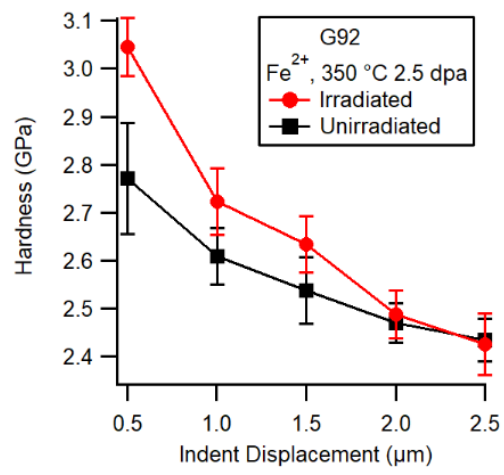

(f)

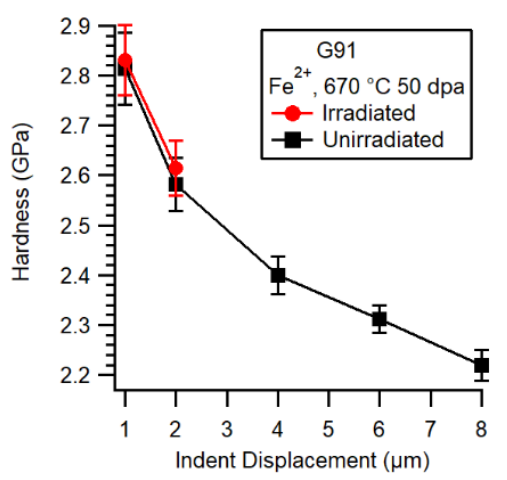

(g)

Fig. III-3-4. Nanohardness of unirradiated and $\mathrm{Fe}^{2+}$-irradiated samples G91 and G92. (a-b) $350{ }^{\circ} \mathrm{C} 50$ dpa. (c-d) $350{ }^{\circ} \mathrm{C} 15$ dpa. (e-f) $350{ }^{\circ} \mathrm{C} 2.5$ dpa. (g) $670{ }^{\circ} \mathrm{C} 50 \mathrm{dpa}$. 


\section{MODELING AND SIMULATIONS}

\section{IV-1 Interaction between Displacement Cascades and Dislocations}

(Published in Computational Materials Science)

In nuclear power plants, many structural components are under the influence of intense radiation, which can result in permanent damage in materials, such as radiation-induced hardening (RIH), embrittlement, and creep. The initial stage of radiation damage, particularly the defect production from displacement cascades, has been extensively studied using molecular dynamics (MD) simulations in bulk bcc, fcc and hcp metals (20-28). The number of surviving defects after displacement cascade depends on the energy of the PKA atom (29-31), and sometimes sub-cascade events may occur (2). In addition, the size distribution of the surviving defects is also influenced by the PKA energies, such as in bcc iron $(\underline{29}, \underline{33})$.

As the microstructure evolves as a function of irradiation dose, the dislocations and dislocation loops could become the dominant defects in materials $(\underline{34}, \underline{35})$. Because of the presence of these defects in materials, the displacement cascade processes may interact with these defects, leading to a different defect production rate, which is needed in the mean field rate theory model to accurately describe the defect evolution for predictions of long-term material performance. However, to our best knowledge, the influence of dislocations or dislocation loops on displacement cascades is not extensively studied, and our understanding of this is rather limited, especially compared with the extensive displacement cascade simulations in bulk materials. Because of the presence of the dislocation, the defects may go into the dislocation and eventually may lead to different defect production efficiency and distributions. An MD simulation of interactions between cascades and an edge dislocation in $\mathrm{Zr}$ suggests that the presence of the edge dislocation can promote the nucleation of vacancy clusters and can even help to generate an experimental-scale vacancy $\operatorname{loop}(\underline{36})$.

In addition, the displacement cascade processes will influence the dislocation structure $(\underline{37}, \underline{38})$, which may subsequently lead to pinning of dislocations. Conventional radiation-induced hardening mainly focuses on the interactions between a dislocation and obstacles created by the radiation $(\underline{39}, \underline{40})$. For instance, immobile dislocation loops or voids could serve as obstacles to dislocation motion, leading to RIH ( $\underline{41-43})$. This is usually accompanied by the loss of ductility and fracture toughness, which is identified as one of the major challenges that limits the lifetime of structural materials. Early theories of RIH are based on an elastic theory description of the interaction between a single dislocation and an obstacle and are empirical or semi-empirical. The dislocation barrier model (44) was developed based on geometrical consideration and has been applied to the description of strong obstacles. Friedel-Kroupa-Hirsch (FKH) developed an 
alternative model for weak obstacles $(\underline{45}, \underline{46})$. However, these models do not address the potential hardening effect caused by the structural change of dislocation cores.

In this study, we investigate the interactions between dislocations and displacement cascades using MD simulations in Fe-20Cr-25Ni alloy. The Fe-20Cr-25Ni is the base system of Alloy 709 (47, 48), which is currently considered as a candidate of structural materials for next generation nuclear reactors (49). Particularly in this study, the effect of dislocations on the surviving defect number is determined. The structural changes of dislocations caused by displacement cascades are analyzed at the atomic scale. Finally, the Peierls stress simulations are carried out to study the hardening effect of displacement cascades on dislocations. The rest of the paper is organized as follows. Section 2 contains the edge and screw dislocation models, simulation setups, visualization, analysis tools, and the defect counting method. Section 3 contains the results of the cascade simulations and Peierls stress calculations. A summary is given in section 4 .

\section{$\underline{\text { IV-1-1. Methodology and Simulation Setup }}$}

\section{a. Generation of Edge and Screw Dislocations}

In order to allow accurate Peierls Stress simulations and to avoid any potential surface effects, a dislocation model that has periodic boundary conditions (PBC) in not only the dislocation line direction but more importantly in the dislocation gliding direction is used. Specifically, the periodic array of dislocations (PAD) model proposed initially by Daw and Baskes $(\underline{50})$ is followed. The PAD model has been widely used in previous studies to create edge and screw dislocations $(\underline{51-56})$. The following sections detail how to construct an edge and screw dislocation using the PAD model.

\section{b. Edge Dislocation Model}

The schematic of creating an edge dislocation is shown in Fig. 1. We first divide the perfect crystal into two half crystals, the upper (blue) and the lower (red) crystals. The spacing b shown in Fig.1 represents the length of the Burger's vector. The number of atomic planes within spacing b (a Burger's vector) is determined by the crystalline structures (bcc, fcc, hcp). Initially, we have an equal number of planes in the upper and lower crystals. Then, the planes within one spacing $b$ in the lower part of the crystal are removed. The length of the lower crystal in the y-direction becomes $(\mathrm{N}-1)^{*} \mathrm{~b}$. In order to reduce the strain effects on the simulation box, a scheme developed by Osetsky (57) et al. is employed. Following this approach, the length of the upper crystal in the $y$-direction is changed by $-b / 2$ and the length of the lower crystal in the $y$ direction is changed by $+\mathrm{b} / 2$. By doing so, the PBCs in both dislocation line direction (x-direction) and 
dislocation gliding direction (y-direction) are achieved. Although the dislocation may interact with its own periodic image, the interaction can be easily controlled by increasing the simulation cell size in the $x / y$ direction.
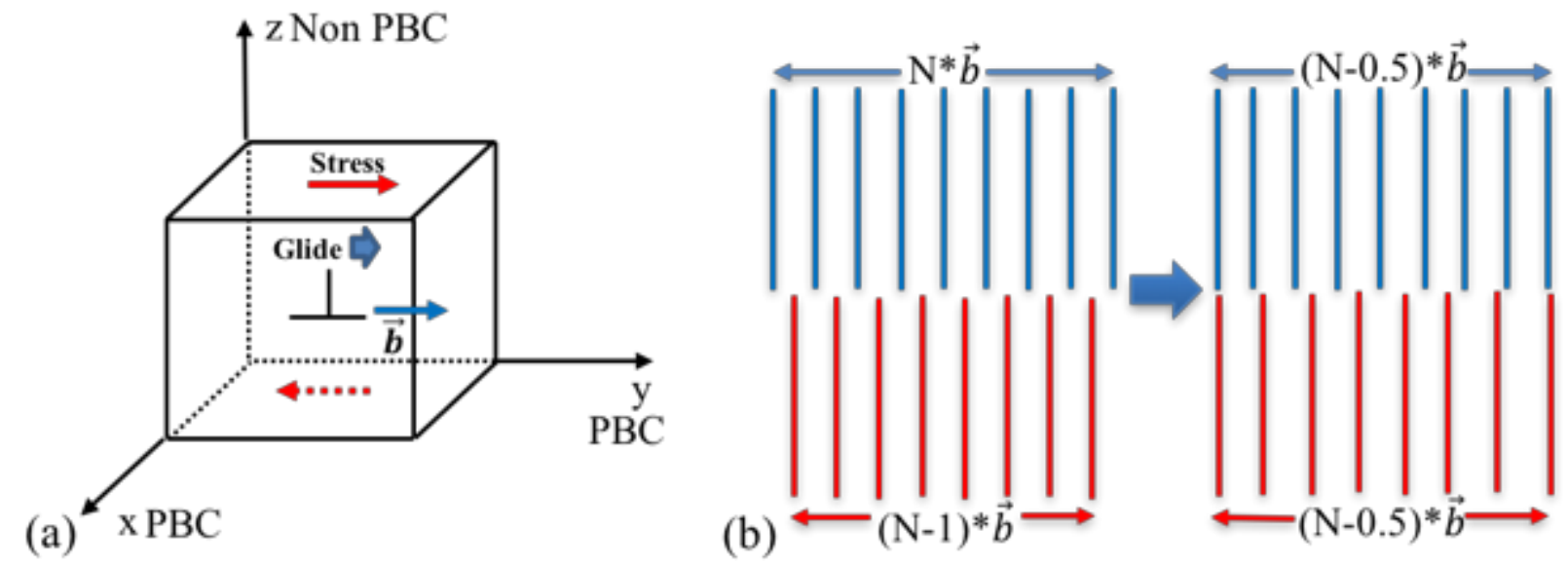

Fig. 1 (a) Schematic of an edge dislocation in a simulation box. (b) The method used to create an edge dislocation.

\section{c. Screw Dislocation Model}

Compared with achieving PBC in the gliding direction for an edge dislocation, the implementation of PBC in the gliding direction for a screw dislocation is more complicated. The schematic of constructing a screw dislocation is shown in Fig. 2(a), also following the PAD model (5ㅗ). The initial displacements of a screw dislocation determined by isotropic elasticity theory ( $\underline{58})$ is given in Eq. 1,

$$
u_{x}=b \cdot \frac{\theta}{2 \pi}=b \cdot \tan ^{-1}\left(\frac{z}{y}\right) / 2
$$

The dislocation line and Burger's vector are along the $\mathrm{x}$-direction, and the dislocation gliding direction is along the y-direction as shown in Fig. 2(a). PBC in the x-direction is achieved inherently because of the independence of $u_{x}$ on $\mathrm{x}$. However, PBC in the $\mathrm{y}$ direction is broken because of the $\pm \mathrm{b} / 2$ shift in the $\mathrm{x}$ direction across the $\pm \mathrm{y}$ boundaries. To achieve PBC in the $\mathrm{y}$ direction, $\mathrm{a} \pm \mathrm{b} / 2$ displacement can be added to the $x$ coordinates when atoms cross the $\pm y$ boundaries as shown in Fig. 2(b). In Fig. 2(b), the blue lines represent the upper half $y-z$ planes, and the red dotted lines represent the lower half y-z planes. Specifically, we can see that the $x$ coordinates in the upper half crystal at the $y$-boundary is shifted by $1 / 2 b$, while the $x$ coordinates in the lower half crystal at the y-boundary is shifted by $-1 / 2 \mathrm{~b}$. In addition, this is essentially equivalent to applying a shear strain to the simulation box, especially when the strain is small, which is 
employed in this study. So, a small shear strain is applied in the x-direction (y-axis is tilted) to achieve this shifted boundary condition. When $\mathrm{L}_{\mathrm{x}} / \mathrm{L}_{z}$ ratio is smaller, the effect of the tilted simulation cell on Peierls stress is minimized. After testing, $\mathrm{L}_{\mathrm{x}} / \mathrm{L}_{\mathrm{z}}$ should be less than 0.5 in order to obtain the correct Peierls stress behavior.
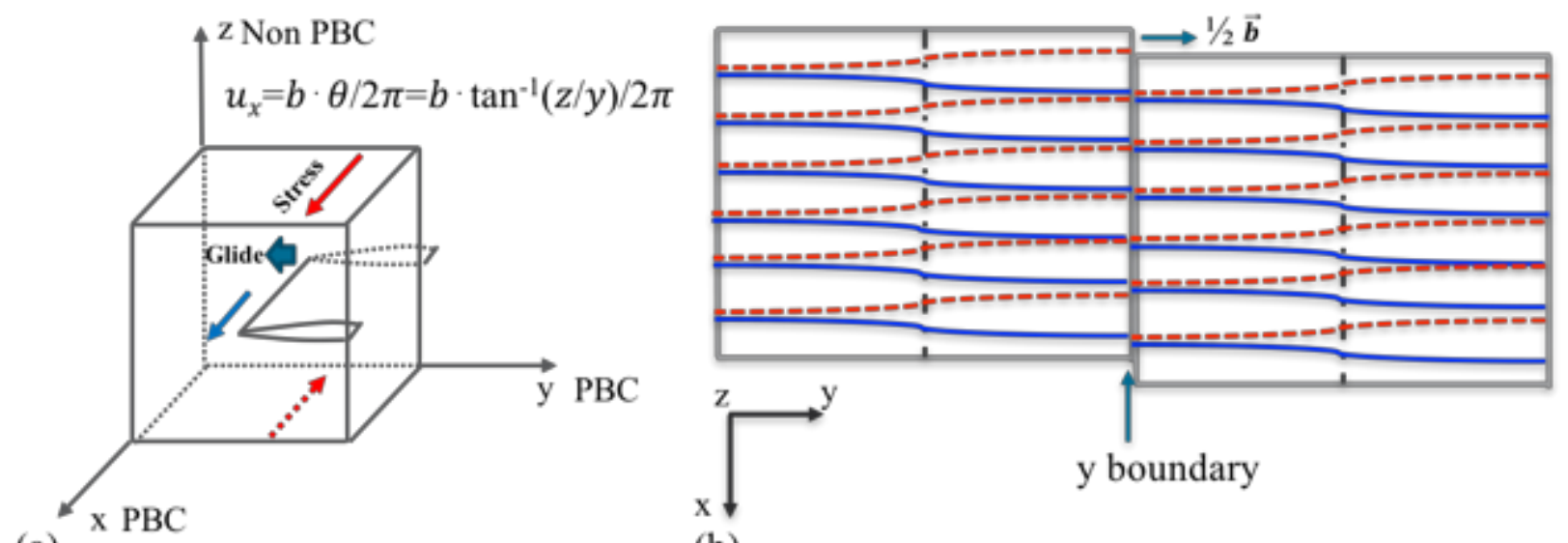

(b)

Fig. 2 (a) Schematic of a screw dislocation in a simulation box. (b) Achieving periodic boundary condition by shifting $\mathrm{x}$ coordinates by $+1 / 2 \mathrm{~b}$ or $-1 / 2 \mathrm{~b}$ when atoms cross the boundary in y-direction ( $\underline{55}$.

\section{Cascade Simulations}

The schematic of a cascade simulation cell is shown in Fig. 3. The simulation cell contains one dislocation in the center. The energy of the PKA is $10 \mathrm{KeV}$, and the simulation temperature is $300 \mathrm{~K}$. When the PKA is placed close to the dislocation within $30 \AA$, the cascade event will directly interact with the dislocation. While when the PKA is placed far away from the dislocation, the cascade will not interact with the dislocation so that it is the same as the scenario of cascade events in the perfect crystal. For each scenario, 12 independent cases are simulated. Within the 12 simulated cases, the position of the PKA changes while the direction of the PKA remains the same. The orientation of the simulation cell is based on the dislocation type. The details of the simulation cell orientations and the sizes of the simulation cells used in our study are shown in Table. 1. Based on the above orientation setup, the $\mathrm{x}$-axis is along the dislocation line, and the $y$-axis is along the dislocation gliding direction for all the simulated systems. As mentioned previously, all the simulated systems have PBCs in the $\mathrm{x}$ and $\mathrm{y}$ directions and a non-periodic condition in the z-direction. LAMMPS is used as the molecular dynamics engine (59). The system contains around 3.2 million atoms. The interatomic potential in the form of embedded-atom method (EAM) developed by Bonny et al. ( $\underline{60})$ is employed for fcc Fe-Ni-Cr alloy systems. The alloy elements are randomly distributed. The ZieglerBiersack-Littmark (ZBL) potential ( $\underline{61})$ is used for describing short-range interactions for a high-energy 
collision between atoms. During cascade simulations, an adaptive time step method ( $\underline{59})$, is used to ensure the maximum displacement of atoms per time step less than $0.014 \AA$.

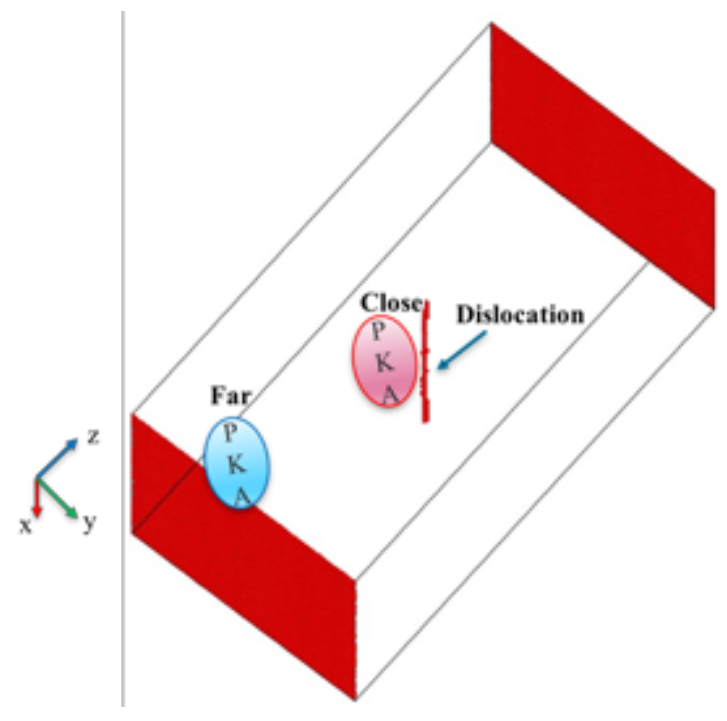

Fig. 3 Schematic of the cascade simulations.

Table. 1 Type of dislocations, orientations and size of the simulation cells.

\begin{tabular}{|l|l|l|l|}
\hline & $\mathrm{x}$ & $\mathrm{y}$ & $\mathrm{Z}$ \\
\hline Fcc edge $1 / 2<110>\{111\}$ & $<11-2>, 27.2 \mathrm{~nm}$ & $<1-10>, 26.2 \mathrm{~nm}$ & $<111>, 53.1 \mathrm{~nm}$ \\
\hline Fcc screw $1 / 2<110>\{111\}$ & $<-110>, 26.4 \mathrm{~nm}$ & $<1-12>, 27.2 \mathrm{~nm}$ & $<111>, 53 \mathrm{~nm}$ \\
\hline
\end{tabular}

\section{Peierls Stress Simulation}

Peierls stress simulations are carried out to investigate any potential hardening effect caused by the interaction between dislocations and cascade events. The schematic of the Peierls stress simulation for edge and screw dislocations are shown in Fig. 1(a) and Fig. 2(a) respectively. The Peierls stress simulations are carried out using molecular static calculations. Conjugate gradient is used to find the relaxed atomic configurations. For both of edge and screw dislocations, the top and bottom layers are fixed to be a rigid block. The thickness of the layer needs to exceed the range of the interatomic potentials. We apply strain to the top rigid block and keep the bottom rigid block immobile. The applied shear strain at each step is $4 * 10^{-5}$. For edge dislocation as shown in Fig. 1(a), the applied strain is along the y direction (Burger's vector direction), and the gliding direction is also along the y-direction. While for screw dislocation shown in Fig. 2(a), the applied strain is along the x-direction (Burger's vector direction) and the gliding direction is along the y-direction. 


\section{Analysis and Visualization Tools}

Common Neighbor Analysis (CNA) is used to distinguish the atoms in fcc, bcc, hcp and other environments $(\underline{62}, \underline{63})$. Wigner-Seitz analysis is used to count the number of interstitials and vacancies caused by the cascade $(\underline{64})$. OVITO is used as the visualization software ( $\underline{65})$, and the Dislocation Analysis Algorithm (DXA) implemented in OVITO is used to extract dislocation lines and identify their corresponding Burger's vectors $(\underline{66})$.

\section{Defect Counting Method}

The defect analysis in these systems which contain complicated defects is delicate. We will demonstrate how the defects are analyzed after the interaction between cascades and dislocations. Fig. 4 shows the atomic structure of dislocations after cascade simulations. First, the total number of defects of interstitial $\left(\mathrm{I}^{\dagger}\right)$ and vacancy $\left(\mathrm{V}^{\dagger}\right)$ are calculated using Wigner-Seitz analysis. As shown in Fig. 4 highlighted by the red circle, some portion of the defects move into dislocations or form dislocation loops well connected to the original dislocation. We define this portion of the defects as $\mathrm{I}^{\mathrm{d}}$ and $\mathrm{V}^{\mathrm{d}}$. The other portion of the defects created by cascades resides in the material's matrix, which are defined as $\mathrm{I}^{\mathrm{m}}$ and $\mathrm{V}^{\mathrm{m}}$. So, $\mathrm{I}^{\mathrm{t}}$ equals $\left(\mathrm{I}^{\mathrm{m}}+\mathrm{I}^{\mathrm{d}}\right)$ and $\mathrm{V}^{\mathrm{t}}$ equals $\left(\mathrm{V}^{\mathrm{m}}+\mathrm{V}^{\mathrm{d}}\right)$. 

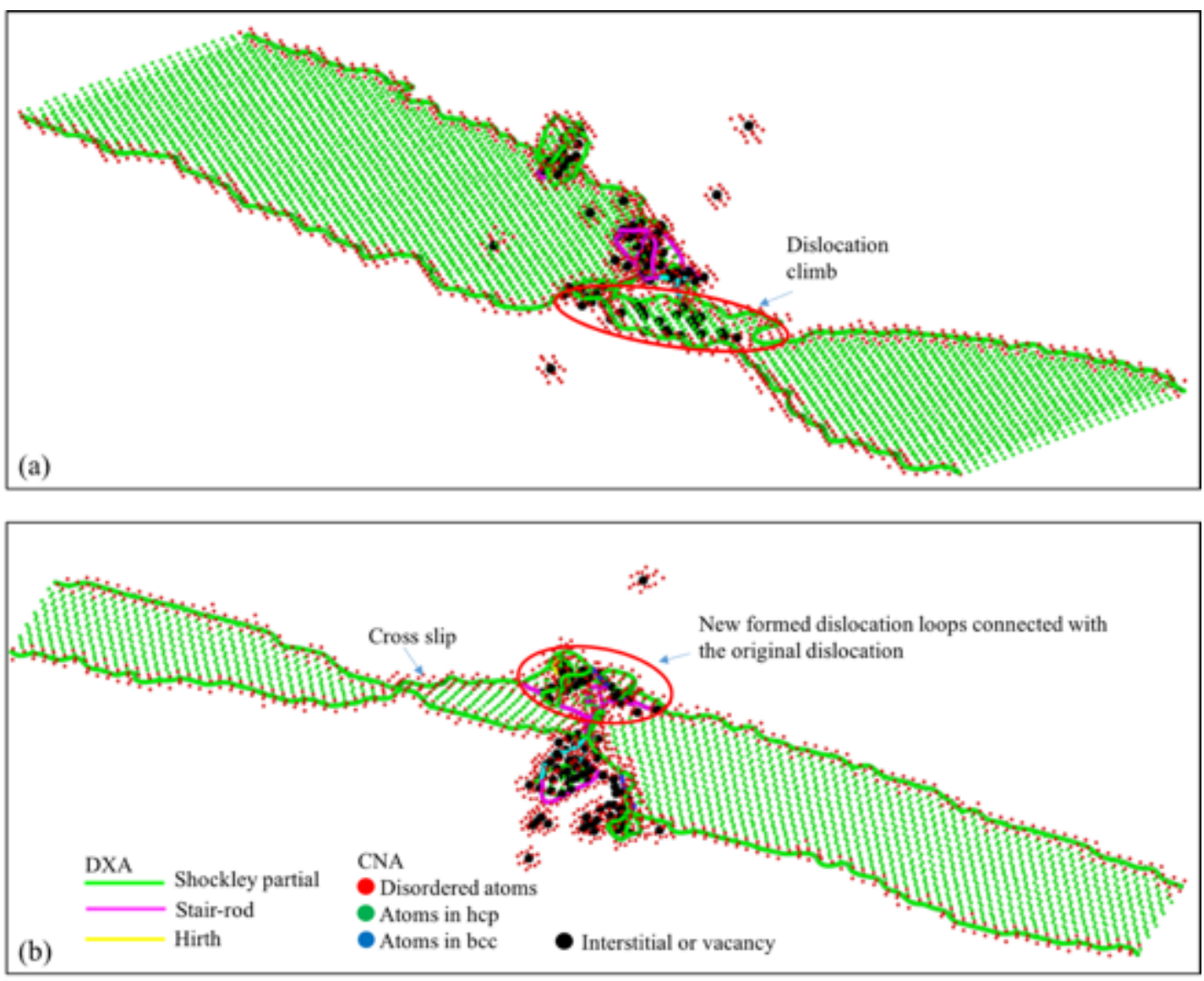

Fig. 4 Illustration of atomic structures of edge and screw dislocations after cascade simulations for Fe-20Cr25Ni alloy. (a) The atomic structure of an edge dislocation after a cascade simulation. (b) The atomic structure of a screw dislocation after a cascade simulation. The atoms in the fcc environment have been removed. The black atoms are either interstitials or vacancies calculated by Wigner-Seitz analysis.

\section{IV-1-2. Simulation Results}

In this section, the cascade simulation results of $\mathrm{Fe}-20 \mathrm{Cr}-25 \mathrm{Ni}$ alloy system are analyzed from two perspectives. One aspect is the defect production in terms of number of defects, interstitials, and vacancies. The other aspect is the cascade induced atomic structural changes of the dislocations.

\section{a. The Influence of Dislocations on Defect Production}

Fig. 5 shows the number of defects generated by the cascade for Fe-20Cr-25Ni alloy. The data point is the average number of defects of twelve independent simulations. And the error bars represent the standard deviation. In Fig. 5 (a), "Close" means that the cascade interacts with the dislocation and "Far" means the 
cascade does not interact with the dislocation. As described in section 2.5 , the defects that go into dislocations or form dislocation loops well connected to the original dislocations are counted separately from the defects that formed in the material's matrix. From Fig. 5 (a), it can be seen that cascades tend to generate more total defects $\left(\mathrm{I}^{\mathrm{t}}+\mathrm{V}^{\dagger}\right)$ when they interact with both edge and screw dislocations in Fe-20Cr$25 \mathrm{Ni}$. Due to the statistical variation, the difference is insignificant. The interaction between cascades and dislocations results in the structural changes of the dislocations, and defects can go into dislocations and form dislocation loops intertwined with the original dislocations. Comparatively, Fig. 5 (b), there are less surviving defects which are still left in the material's matrix after the cascades, excluding the defects that go into the dislocations or form dislocation loops well connected to the original dislocations (" $1 / 2$ Close" vs $I^{\mathrm{m}}$ ). If we only focus on the surviving defects generated in the matrix, the number of defects $\left(\mathrm{I}^{\mathrm{m}}\right.$ plus $\mathrm{V}^{\mathrm{m}}$ in Fig. 5 (b)) is actually less than that in the "Far" (non-interacting) cases for both edge and screw dislocations. So the defect production efficiency in the materials with high dislocation density is lower than the bulk case. For edge dislocations, an almost equal number of interstitials $\left(\mathrm{I}^{\mathrm{d}}\right)$ and vacancies $\left(\mathrm{V}^{\mathrm{d}}\right)$ move into the dislocation or form dislocation loops well connected to the original dislocation as shown in Fig. 5(b). For screw dislocations, more interstitials move into dislocation or form dislocation loops well connected to the original dislocation. Further discussions of defect populations are given in 3.1.2.
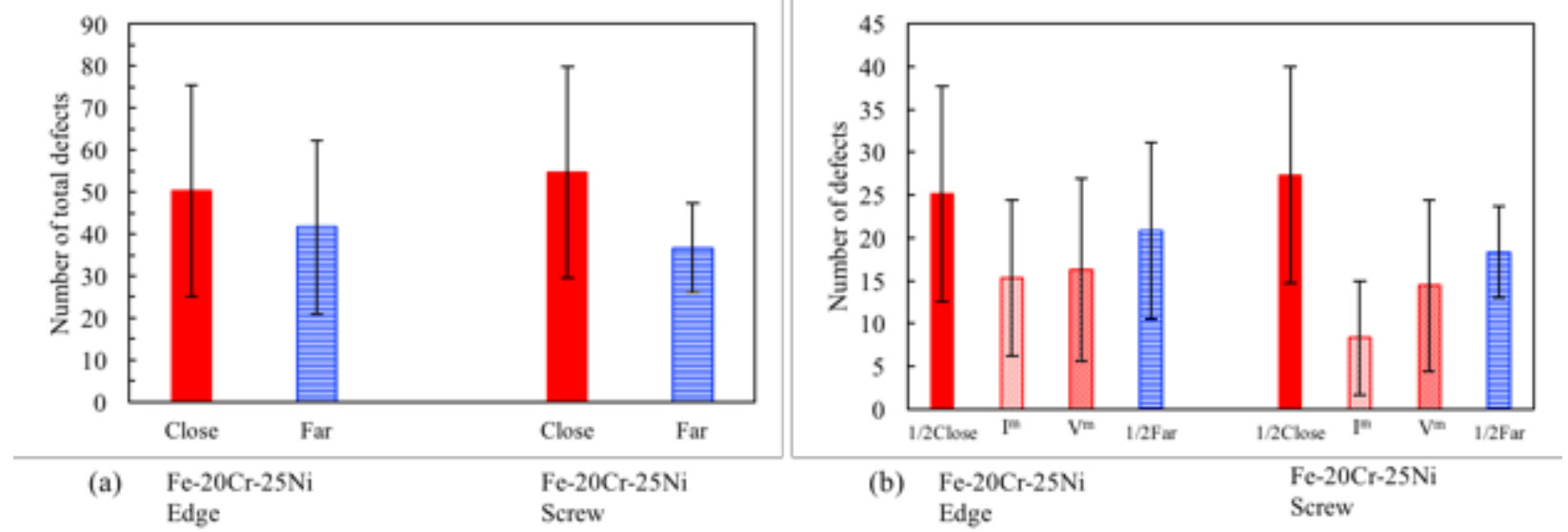

Fig. 5 The number of defects generated by the cascade for Fe-20Cr-25Ni, when the PKA is placed close to and far away from the dislocations. (a) For "Close" and "Far" cases, the number of defects equals to the number of interstitials (I) plus vacancies (V). (b) " $1 / 2$ Close" and " $1 / 2$ Far" represent the number of interstitials (I) or Vacancies (V). The " $\mathrm{I}$ " " and " $\mathrm{V}$ "m" represent the number of interstitials and vacancies that do not move into dislocations nor form dislocation loops that well connected to the original dislocations, respectively. 


\section{IV-1-2-2 Atomic Structural Changes of Dislocations}

Fig. 6 shows the atomic structures of edge and screw dislocations before and after a cascade simulation for Fe-20Cr-25Ni alloy, using the CNA analysis to extract the dislocation, defect, and stacking fault structures. DXA analysis is used to construct dislocations and extract the information on dislocation type and Burger's vector. The Fe-20Cr-25Ni alloy has a fcc lattice. As a result, the full dislocation slips into two Shockley partials connected by the stacking fault after relaxation. The dislocation dissociation can be described as

$\frac{1}{2}[10 \overline{1}] \rightarrow \frac{1}{6}[2 \overline{1} \overline{1}]+\frac{1}{6}[11 \overline{2}]$. As a result, the initial dislocation structures after relaxation before interacting with cascade for both edge and screw dislocations are two partial dislocations with stacking faults in between as shown in Fig. 6 (a) and (e).

For an edge dislocation, first, the cascade eliminates some of the stacking fault as shown in Fig. 6 (b). The PKA introduces extra high energy into the system. As a result, part of the stacking fault structure become amorphous as a result of the cascade processes and changes to perfect fcc lattice when it cools down. So the cascade has the potential ability to reduce the stacking fault structures. Second, the interaction between a cascade and an edge dislocation causes stair-rod dislocations (Lomer-Cottrell lock) to form, see the magenta dislocation line in Fig. 6 (b). The dislocation reaction to form Lomer-Cottrell lock can be described as $\frac{1}{6}[\overline{1} 21]+\frac{1}{6}[2 \overline{1} \overline{1}] \rightarrow \frac{1}{6}[110]$. The stair-rod dislocation is sessile. The formation of stair-rod dislocations can make the dislocation structure more difficult to glide. In addition, a small amount of Hirth dislocations also forms. Third, the cascade facilitates dislocation climb as shown in Fig. 6 (b) and (d). The dislocation climb shown in Fig. 6 induced by the cascade is a negative climb. For negative climb, an additional row of atoms is added to the extra half plane. While for positive climb, a row of atoms is removed from the extra half plane. So, for the negative climb to happen, the edge dislocation needs to absorb interstitials, while the edge dislocation needs to absorb vacancies to have a positive climb. The preference of positive or negative climb is related to the type of defects that go into dislocations.

For screw dislocations, the interaction shares many similarities with edge dislocations. Part of the stacking fault structure is eliminated by the cascade as shown in Fig.6 (f). The stair-rod dislocation also forms due to the interaction between a screw dislocation and a cascade, as shown in Fig. 6 (f). Unlike the dislocation climb of edge dislocations, the screw dislocation may cross slip when interacting with a cascade as shown in Fig. 6 (f) and (h). The screw dislocations cross-slip from (111) plane to (1-1-1) plane. Out of the total 12 
cases, five cases of the cross-slip behaviors have been observed. The formation of stair-rod dislocations and the cross slip of screw dislocations may further hinder the motion of the screw dislocations.
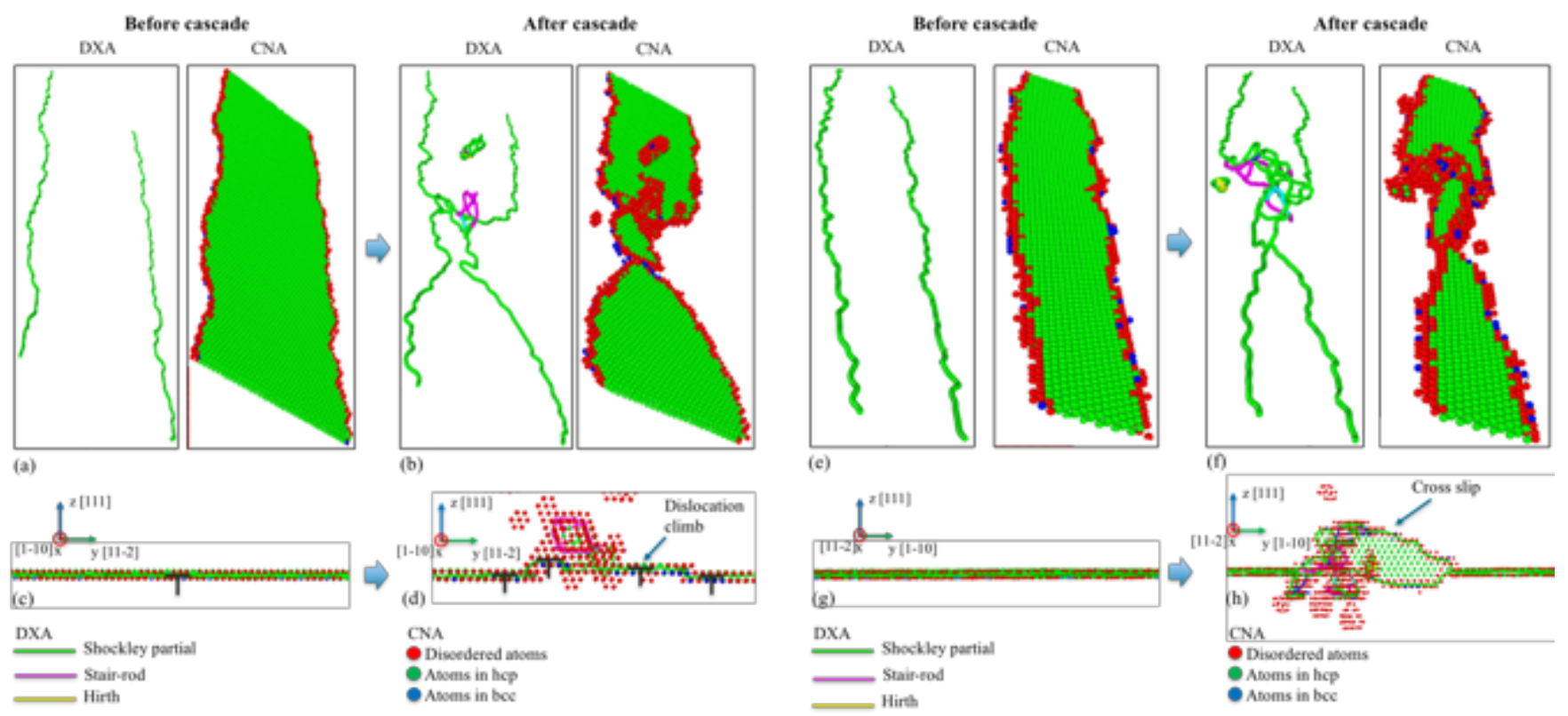

Fig. $6(\mathrm{a}, \mathrm{b})$ The atomic structure of an edge dislocation. (c,d) The atomic structure of an edge dislocation from [1-10] perspective (parallel to the gliding plane). (e,f) The atomic structure of a screw dislocation. $(\mathrm{g}, \mathrm{h})$ The atomic structure of a screw dislocation from [11-2] perspective (parallel to the gliding plane).

The structural changes of the dislocation cores are shown in Fig. 7. Three out of twelve cases of edge and screw dislocations are exhibited. For edge dislocations, from Fig. 7 (a) to (c), both vacancy and interstitial loops well connected to dislocations form as a result of dislocation climb. The availability of vacancies and interstitials determines whether positive climb (vacancy loop) or negative climb (interstitial loop) can form. In our 12 simulated cases of edge dislocations, the possibility of positive climb and negative climb is almost equal. It explains the nearly equal number of interstitials $\left(I^{t}-I^{m}\right)$ and vacancies $\left(V^{t}-V^{m}\right)$ being absorbed by edge dislocations in our 12 simulated cases. For screw dislocations, as shown from Fig. 7 (d) to (f), more interstitial loops well connected to the dislocations form in our 12 simulated cases, which explains less surviving interstitials $\left(\mathrm{I}^{\mathrm{m}}\right)$ in materials matrix. However, the surviving defect population may vary depending on the position and direction of the PKA with respect to the dislocation line. 

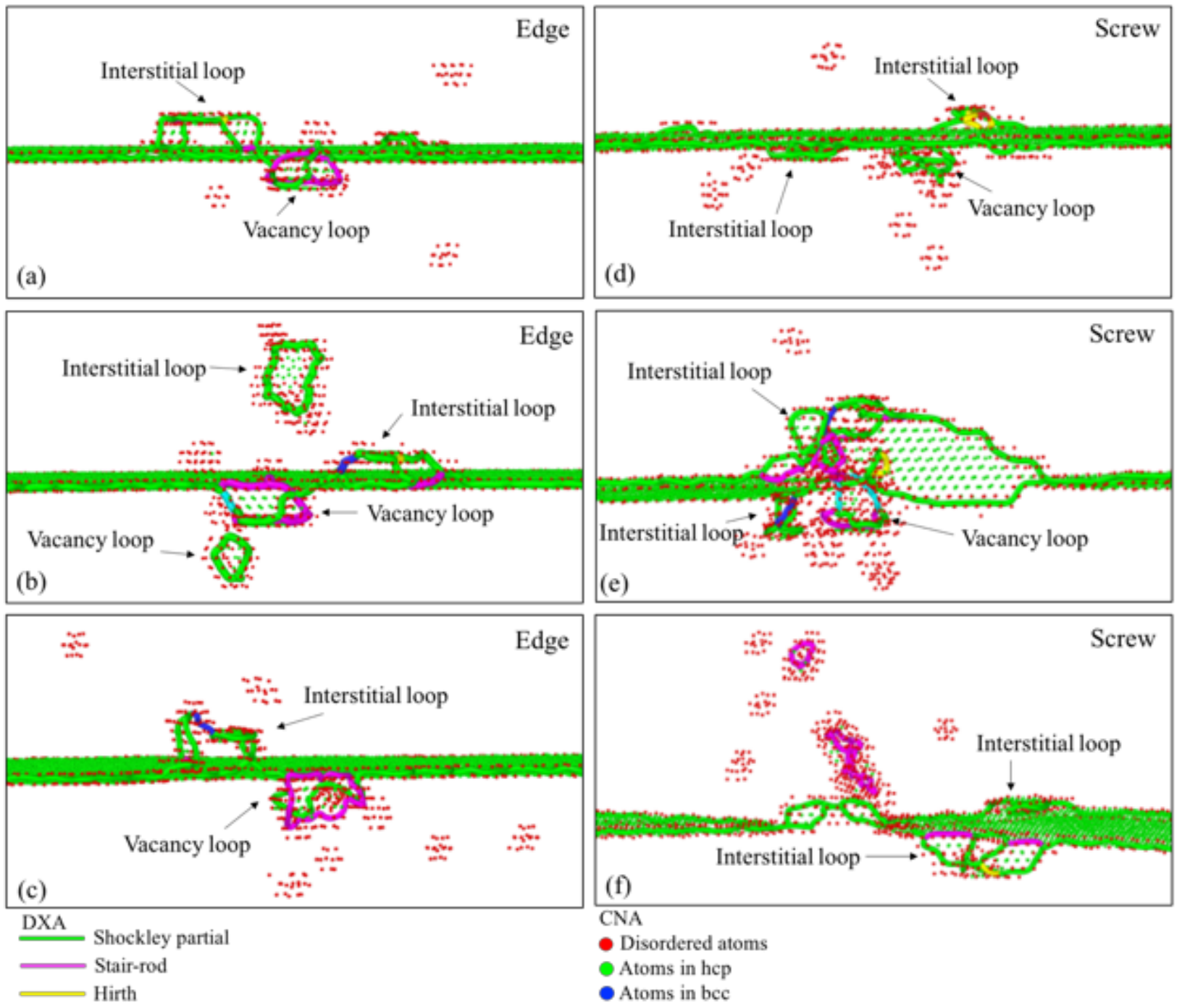

Fig. 7 CNA and DXA analysis of the dislocations' structure after interacting with cascades. (a-c) Edge dislocation. (e-f) screw dislocation. Atoms in fcc environment have been removed.

\section{$\underline{\text { IV-1-3. Peierls Stress Simulation }}$}

After interacting with a cascade, the Peierls stress simulations are carried out to evaluate the effects of displacement cascades on dislocation motion. For each scenario, three cases are tested. The tested dislocation structures contain the structures shown in Fig. 6 and two additional cases. Fig. 8 shows the comparison of Peierls stress before and after cascade. The stress required to move edge and screw dislocations both increases. In section 3.1, the assumption that the formation of stair-rod dislocations (sessile), radiation-induced dislocation climb and cross-slip can contribute to dislocation hardening is confirmed by the Peierls stress simulations. The structural changes of the dislocations caused by a cascade 
make it more difficult for dislocations to glide or cross-slip. From the Peierls stress point of view, radiationinduced cross-slip in screw dislocations causes more hardening than the radiation induced dislocation climb in edge dislocations. From Fig. 9 (a) to (b), the edge dislocation shows almost no bowing out before it starts to glide. While for screw dislocations when cross slip happens, due to the pinning defect, the dislocation bowing out can be clearly observed as shown from Fig. 9 (c) to (d). So, the atomic structural changes of dislocations caused by cascades lead to more hardening for screw dislocations than edge dislocations.

The Peierls stress simulation confirms the hardening effects as a result of the atomic structural changes of dislocations caused by displacement cascades. And the number of surviving defects in materials matrix when interacting with dislocations is slightly less than that of perfect bulk materials. So, when dislocations are present, the hardening effects estimated based on the traditional RIH models that consider the interactions between dislocations and surviving defects in materials may decrease slightly. While, additional hardening effects arising from the atomic structural changes of dislocations cannot be ignored, especially for screw dislocation in this material.
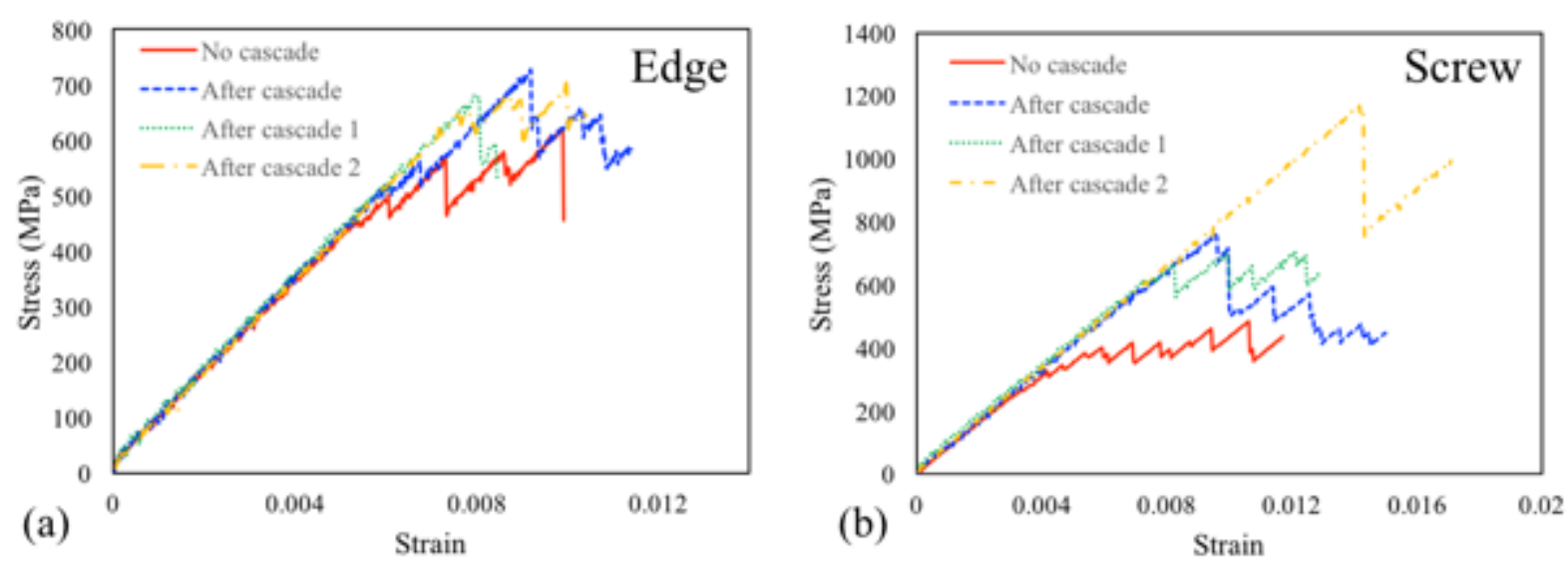

Fig. 8 Comparison of Peierls stress before and after cascade for Fe-20Cr-25Ni alloy. (a) Edge dislocation. (b) Screw dislocation. 


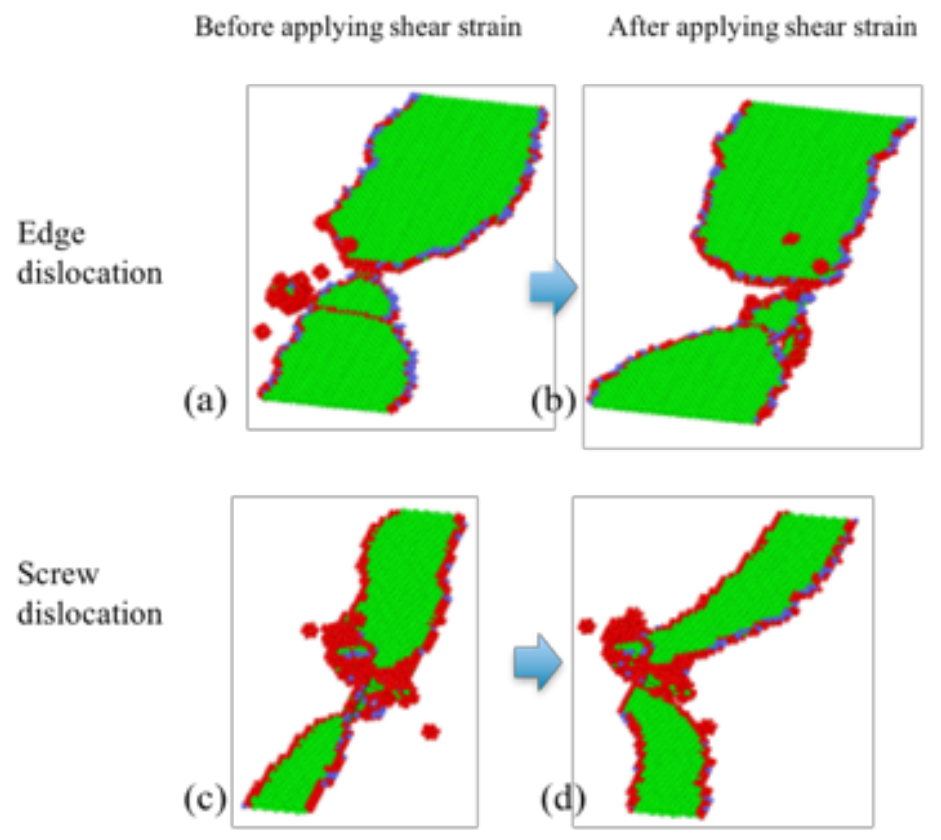

Fig. 9 Atomic structure of edge and screw dislocations in Peierls stress simulation. (a,b) Edge dislocation before and after applying shear strain. (c,d) Screw dislocation before and after applying shear strain.

\section{IV-1-4. Summary}

Cascade simulations and Peierls stress simulations are carried out to study the interaction between displacement cascades and edge and screw dislocations in the Fe-20Cr-25Ni alloy. Due to the presence of dislocations, the defect production efficiency changes. The cascade tends to generate more total defects when interacting with dislocations. However, a portion of these defects are in the form of defect clusters or dislocation loops that are entangled with the original dislocations, resulting in less surviving defects in the material's matrix compared with that of the non-interacting (pristine case). Since the surviving defects in the materials matrix may migrate and interact with other defects in the system, leading to microstructural evolution and properties changes, this change in defect production efficiency needs to be properly considered in upper scale models, such as mean-field rate theory. In addition, dislocation climb and crossslip have been observed for edge dislocations and screw dislocations, respectively, because of displacement cascades. The sessile stair-rod dislocations also form because of interactions between cascades and dislocations.

The dislocation core structures also undergo significant changes because of the cascade, which serve as additional contributions to RIH compared to the conventional dislocation-obstacle interaction models. The Peierls stress simulations confirm this additional hardening effect. The interaction between cascades and 
other defects in materials, such as grain boundaries, voids, and precipitates, may also influence the defect production efficiency and microstructural changes of irradiated materials. Therefore, this study provides insight into how defect production and extended defects are correlated, especially when total influence is high, which needs to be taken into account for modeling long-term performance of irradiated structural alloys.

\section{IV-2 Dynamics of Point Defect near Dislocations}

\section{(Published in Physical Review Materials)}

The dislocation-point defect interaction (DPDI) has a strong impact on the microstructural evolution and plasticity of materials (67-72), including behavior such as impurity segregation around dislocations and creep. The DPDI has two interrelated aspects. On the one hand, the presence of point defects near dislocations may influence dislocation properties. For instance, point defects could act as obstacles to dislocation glide $(\underline{73})$ or alter the structure of the dislocation core $(\underline{74})$, leading to strengthening and hardening. In addition, the absorption or emission of point defects controls dislocation motion through creating kinks and jogs (75), and dislocation creep at low stresses by influencing the dislocation climb

processes (76). On the other hand, the strain field exerted by dislocations affects the migration of point defects and causes a drifted and correlated diffusion of point defects around dislocations in alloys $(\underline{77}, \underline{78})$. This drifted diffusion leads to the formation of defect clusters and the segregation of impurity atoms near dislocations, forming the so-called Cottrell atmospheres ( $\underline{77})$.

The effects of the DPDI are enhanced in radiation environments $(\underline{79}, \underline{80})$ and by high temperatures, where collision cascades introduce a large number of point defects and point defect mobility is enhanced, respectively. Radiation effects such as void swelling $(\underline{81})$, radiation-induced segregation $(\underline{82}, \underline{83})$, radiationinduced creep ( $\underline{84})$, and radiation-induced embrittlement/hardening $(\underline{71}, \underline{81}, \underline{85-87})$ are controlled by the underlying atomistic interactions between point defects and dislocations. Therefore, understanding the mutual interaction between point defects and dislocations is essential to control the mechanical properties and performance of structural materials and to tailor their radiation resistance for nuclear energy applications. In addition, a fundamental understanding of the DPDI may also contribute to fields where defects dominate the materials performance, such as solid oxide fuel cells and batteries $(\underline{88}, \underline{89})$.

Compared with our understanding of defect stability near dislocations based on defect formation energies and binding energies ( $\underline{90}$ ), relatively little is known about the transport properties and dynamics of point defects in the presence of a dislocation. One of the difficulties is to determine the saddle point energies 
(SPs) and corresponding migration energy barriers (MEB) in a systematic way, which is rather complicated and computationally demanding. Bilby (91) and Cottrell (22) provided the first description of the DPDI using elasticity theory, by considering the elastic interaction of the strain field of the dislocation and the strain introduced by the dilatation volume of the point defect to reach approximate solutions. Another commonly used approximation is to estimate the MEBs based on the binding energies of point defects. This approximation has been commonly used to study the DPDI (3-96). It should be noted that both the BilbyCottrell model and the binding energy approximation are based on properties of local minimum configurations in the potential energy landscape, and no information of the transition state is considered.

In principle, a single MEB can be computed using the drag $(\underline{97})$, nudged elastic band (NEB) $(\underline{98}, \underline{99})$ or the dimer (100) methods, but until now it has been computationally prohibitive to calculate the SP configuration for all the different local atomic configurations caused by the presence of dislocations. The usage of these transition state search algorithms is limited when the number of degrees of freedom is high (101). To overcome this limitation attempts involving artificial neural networks (102-104), and genetic algorithms (105) have been made. In these methods, they use training sets to predict the SP energy of different local atomic configuration without obtaining the actual MEBs. These artificial intelligence methods are promising but strongly depend on having a proper training set and require an a priori knowledge of hundreds of thousands of SP energies.

In this work, we have taken advantage of the recently developed Self-Evolving Atomistic Kinetic Monte Carlo (SEAKMC) (101, 106-109) method with improved algorithm and efficiency to systematically calculate the actual SP energies as a function of position with respect of the dislocation core for vacancies and the family of $<110>$ self-interstitial atom (SIA) dumbbells in the presence of a single straight screw or edge dislocation in bcc iron. The rest of the paper is organized as the following, the system setup and computational details are given in section 2 . The results of this study are presented in section 3 . First, we present the saddle point configuration of point defects in bulk bcc iron in section 3.1, the results for the screw dislocation in section 3.2, and edge dislocation in 3.3. We examine the anisotropy of diffusion in section 3.4. We employ the obtained data to perform kinetic Monte Carlo simulations (KMC) and study point defect trajectories in section 3.5. The results for the different types of defects and dislocations are compiled in the Supplementary Material. Section SM1 Contains the results for a vacancy near a screw dislocation, section SM2 a vacancy near an edge dislocation, SM3 a dumbbell near a screw dislocation, SM4 a dumbbell near an edge dislocation and SM5 the anisotropy of diffusion. 


\section{$\underline{\text { IV-2-1 Simulation Setup and Computational Details }}$}

\section{IV-2-1-1 Dislocation Models}

The screw dislocation has a Burgers vector $1 / 2<111>$, and the dislocation line lies in the [111] direction in bcc iron. The initial screw dislocation structure was created by displacing the atoms according to linear isotropic elasticity theory $(\underline{75}, \underline{110})$ and subsequently relaxed using interatomic potentials to obtain a stable configuration. The geometric center of the screw dislocation should be aligned to the point of those with 3 fold symmetry. Particularly, we used the Ackland potential of bcc iron (111) since it gives the correct description of the dislocation core $(\underline{112})$.

The Burgers vector of the edge dislocation is $1 / 2[111]$ with slip plane (1 $1 \overline{1} 0)$, and dislocation line direction is $[11 \overline{2}]$. The edge dislocation was created by the procedure described by Ossetsky et al. $(\underline{113})$. The perfect crystal is divided into two halves. Initially, we have an equal number of planes in the upper and lower crystals. Planes within one spacing $b$ in the lower part of the crystal are removed. In the lower half of the crystal, the length in the Burgers vector direction becomes $(N-1) * b$. The one-plane mismatch tends to bend the crystal out of the rectangular shape. For practical simulations, however, the crystal must be constrained to remain rectangular so a periodical boundary condition can be applied. This constraint introduces extra stress to the dislocation. To minimize this effect the upper crystal is shrunk by $-b / 2$ in the $y$-direction and the lower elongated by $+b / 2$ according to $(\underline{113})$. In Fig. 1, we show the coordinate system for both screw and edge dislocations, and the projection on the plane perpendicular to the dislocation line, where we show the migration directions and the first and second nearest neighbors. 

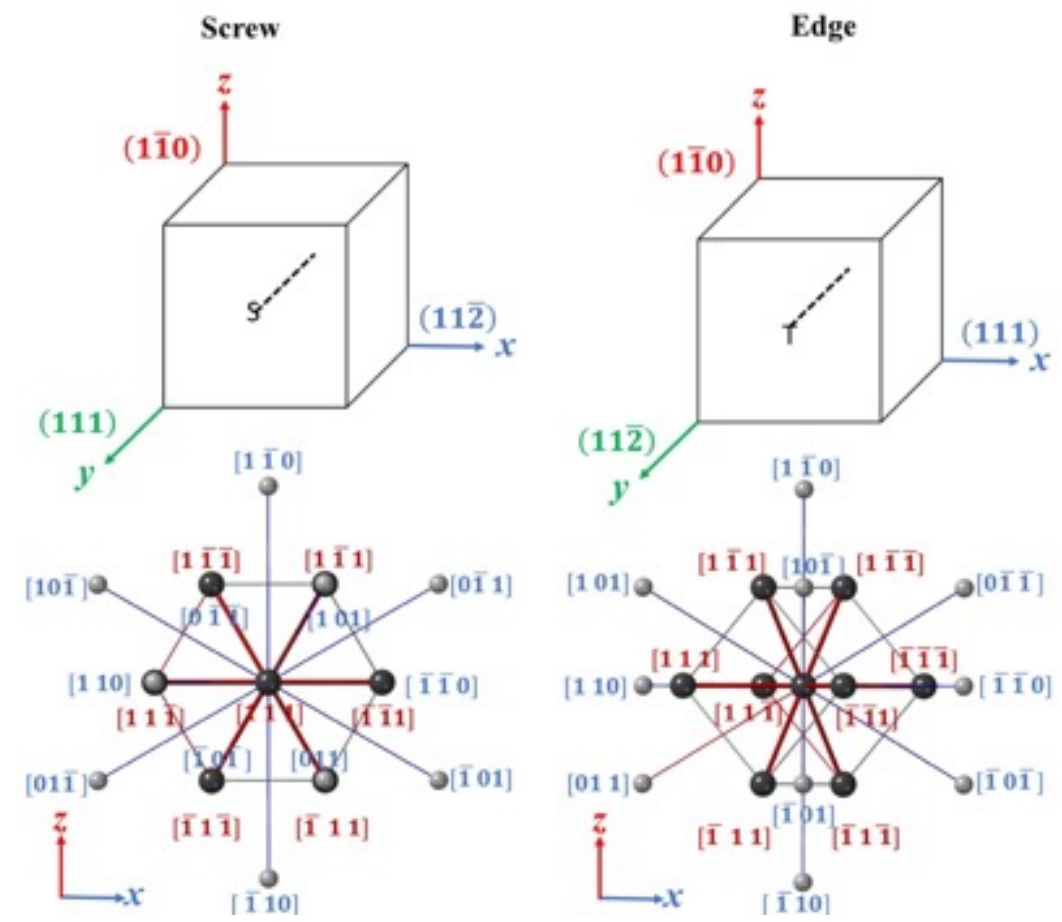

Fig. 1: The upper portion of the Fig. shows the coordinate systems used for screw and edge dislocations. The dislocation line for both dislocations is along the $y$-direction. The lower portion of the Fig. shows a projection of the plane perpendicular to the dislocation line; the first nearest neighbors are shown as black atoms, and the second nearest neighbors as small silver atoms. The $<111>$ migration directions are shown with thick red lines, and the $<110>$ directions with thin blue lines.

\section{IV-2-1-2 Simulation Setup}

The geometry of the simulation box is a rectangular parallelepiped with the axis of $\langle 111\rangle,\langle 110\rangle$, and $\langle 112\rangle$. These directions are chosen based on the slip system of bcc iron. In particular, we chose the (111), (11 $\overline{2})$ and $(1 \overline{1} 0)$ directions. The dislocation line was assigned to the $y$-direction and the $(1 \overline{1} 0)$ direction was assigned to $z$. The block of atoms has been made infinite in the $x$ and $y$ directions by applying periodic boundary conditions, thus having an infinitely long dislocation, and an infinite array of parallel dislocations. The dimension of our crystal was chosen to minimize the interaction between image dislocations such as at the boundary of the box where the strain field is negligible. The system sizes for both screw and edge dislocations are given in Table 1, and Fig. 2 shows a schematic of the simulation cell for an edge dislocation. 

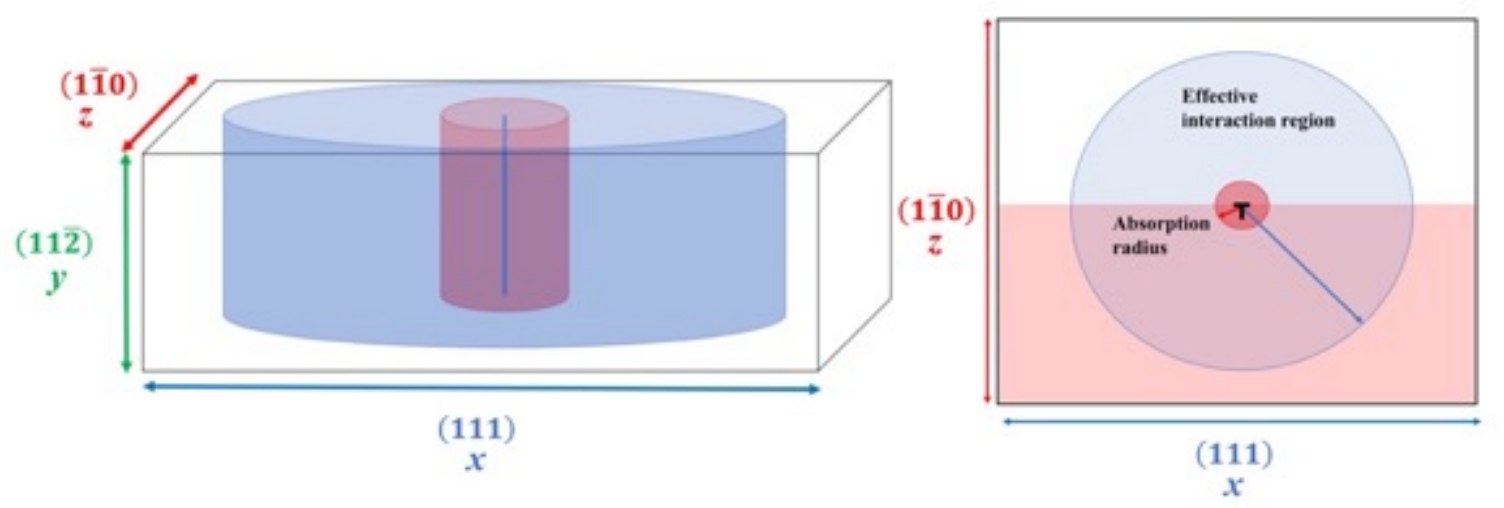

Fig. 2: (a) Simulation cell used in this study for edge dislocation. (b) Top view of the simulation cell.

Table 1. Simulation system size.

\begin{tabular}{|lcccc|}
\hline \multicolumn{5}{c|}{ Simulation box size } \\
& $\mathrm{x}<112>(\AA)$ & $\mathrm{y}<111>(\AA)$ & $\mathrm{z}<110>(\AA)$ & Number of atoms \\
& & & & \\
\hline Edge & 227 & 35 & 226 & 153720 \\
Screw & & & & \\
& 210 & 40 & 200 & 144000 \\
& & & & \\
\hline
\end{tabular}

To investigate the DPDI, we have chosen atoms within a certain radius (R) to the dislocation line, and have denominated this region as the "effective interaction region". Systematically we investigated one defect at a time within this effective interaction region. We have studied a vacancy and a $\langle 110\rangle$ dumbbell since it is the most stable interstitial defect in bulk iron. We have calculated the SP energies for all the $\langle 1 \overline{1} 0\rangle$ dumbbell

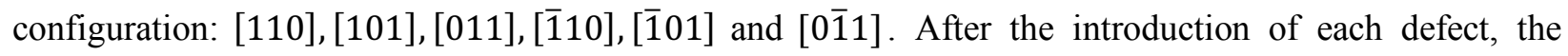
system is relaxed, and then the SP search is performed.

\section{IV-2-1-3 Saddle Point Searches using SEAKMC}


We have performed the SP search using SEAKMC. SEAKMC is an atomistic on-the-fly KMC method (101, 108). On-the-fly refers to the fact that SP configurations and energies are determined as the system evolves. SEAKMC focuses on defect interaction and evolution with atomistic fidelity and only requires an input structure and interatomic potential as input without assuming potential defect migration mechanisms and energies. SEAKMC utilizes the Dimer method $(114,115)$ to search the SP directly without knowledge of the final state a priori. The Dimer method is based on the harmonic approximation of transition state theory (HTST) $(100,110)$. We have used the SP configuration of the bulk of each defect as a starting guess of the SP configuration in the presence of a dislocation, which results in a multiple order of magnitude of improvement in the SP search efficiency. The SP energy was determined to a precision of $1 \mathrm{meV}$.

\section{$\underline{\text { IV-2-2 Results and Discussions }}$}

\section{IV-2-2-1 Saddle Point Sampling of Point Defects in the Bulk BCC Iron}

First, we have calculated SP configurations in bulk bcc iron for vacancies and dumbbells. The SP searches for a vacancy predominately result in eight SPs associated with first nearest neighbor jumps, located along the $<111>$ directions (Fig. 3a). Comparatively, the SP distribution around a $<110>$ interstitial dumbbell (Fig. 3b) is much more complicated than the vacancy case. Several sets of SPs that correspond to different transition states are found, including two different sets that correspond to first nearest neighbor migrations with a translation-rotation mechanism. Of these first nearest neighbor migrations, one set corresponds to the nearest neighbors that lie in the direction of the dumbbell and the other set to migrating to the neighbor perpendicular to the dumbbell. Besides first nearest neighbor migrations, we found SPs that correspond to pure rotations, one set of SPs to a $<111>$ crowdion and one set to $<110>$ rotations.
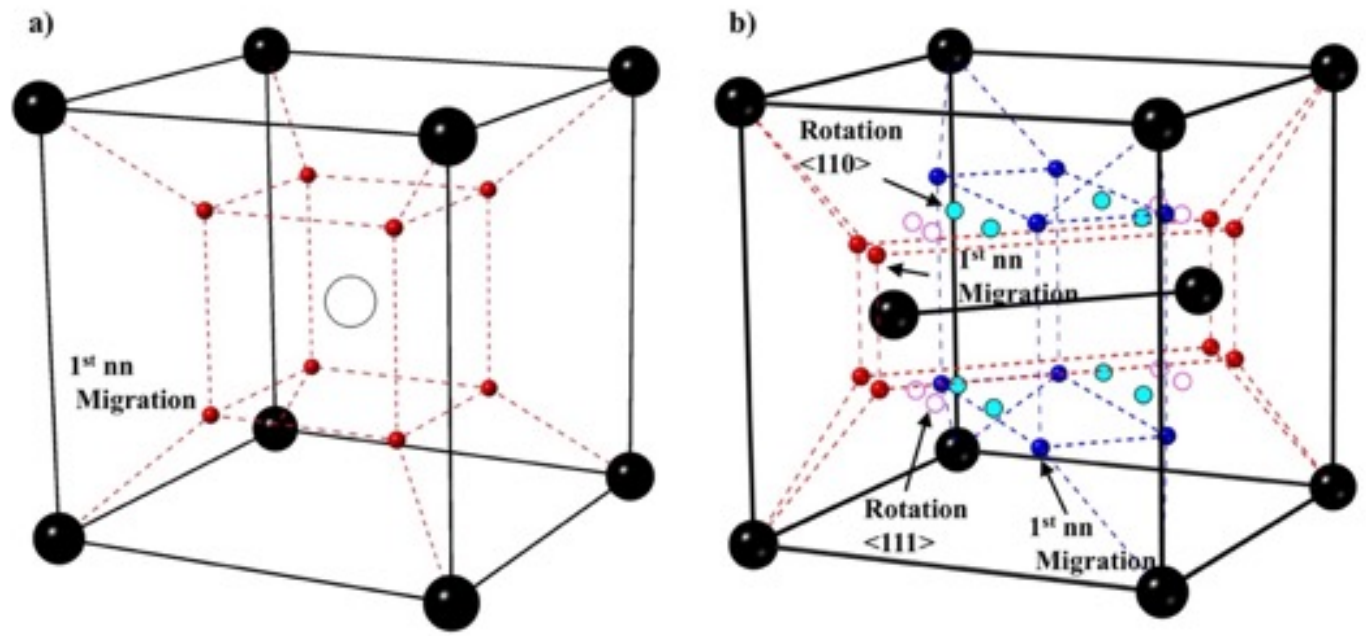
Fig. 3: SP configuration in bulk Fe for (a) vacancy (b) $<110>$ dumbbell. The SPs represented by red and blue spheres correspond to first nearest neighbor migrations, the light green circles to rotations to a different member of the $<110>$ family, and the pink circles rotations to $<111>$ crowdion.

\section{IV-2-2-2 Screw Dislocation}

Dislocations act as sinks for point defects ( $\underline{79})$, and thus it is generally expected that migration of point defects towards the dislocation core is more favorable, and energy barriers towards the dislocation have a smaller value. However, from Fig. 4 with the SP data obtained from SEAKMC, we find that the MEBs towards the dislocation core are not necessarily smaller than the values of other directions, and the migration energy variation exhibits a complex and non-linear dependence as a function of distance to the dislocation core. The change of the migration energy as a function of position for the different migration directions for a vacancy in a screw dislocation environment is presented in Fig. 4. In this Fig., we are plotting the relative energy with respect to the bulk migration energy; we have done the same for all the Fig.s in this section. The symmetry observed in Fig. 4 is related to the nature of the migration jumps. In the screw dislocation system, migration in the [111] and [ $[\overline{1} \overline{1} \overline{1}]$ directions correspond to migration in the dislocation line direction. According to elasticity theory, the stress component in the dislocation line direction is zero, and thus we expect little change in the MEB in these directions as shown in Fig. 4. The migration to the [1111] and $[1 \overline{1} \overline{1}]$ nearest neighbors are mirrored by each other, as can be appreciated from Fig. 1, and hence their energy maps are mirrors of each other (the same applies for their negative counterparts). The most significant change in the MEB value is in the [11 $\overline{1}]$ and [ $[\overline{1} \overline{1} 1]$ directions since they have the smallest components along the dislocation line direction. As expected, the most significant difference in the saddle point energy is close to the dislocation core, and it decreases farther away from the core.
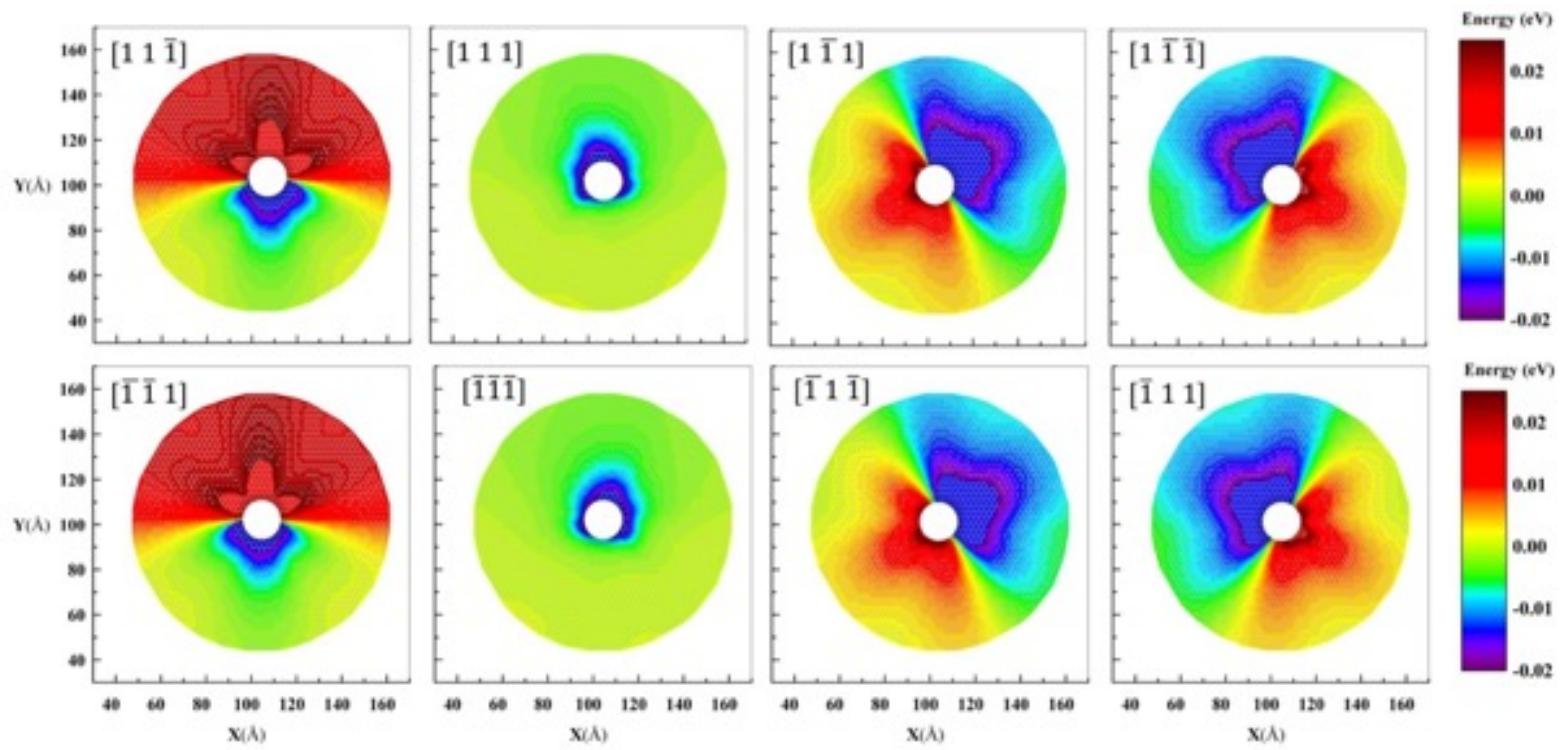
Fig. 4: Migration energy maps of nearest neighbor migration for a vacancy in the presence of a screw dislocation.

The case of a [101] dumbbell near a screw dislocation is shown in Fig. 5. In this case, the energy maps become more complicated because of the directional nature of the dumbbell. There are six different cases for the $<110>$ dumbbell family, and more details are given in the Supplementary Material section SM3. In this case, when a dumbbell migrates along the dislocation line, it interacts with not only the strain field in the migration direction but also with other components of the strain field due to the directional nature of the defect. Just as in the vacancy case, the change in the migration energy is more pronounced close to the dislocation core. It is possible to observe that the difference in magnitude with respect to the bulk value is larger for the dumbbell case, since dumbbells introduce a larger distortion in the system than vacancies. Surprisingly, the energy maps for all directions look similar, there are in fact differences between the migration directions, but they do not display a particular behavior for each direction such as in the vacancy cases. The difference among different direction can be seen in the diffusion anisotropy Fig. (Fig. 11). The complexity to understand the change in MEB not only arises from the directional nature of the dumbbell, but also in that the migration mechanism involves both translation and rotation.
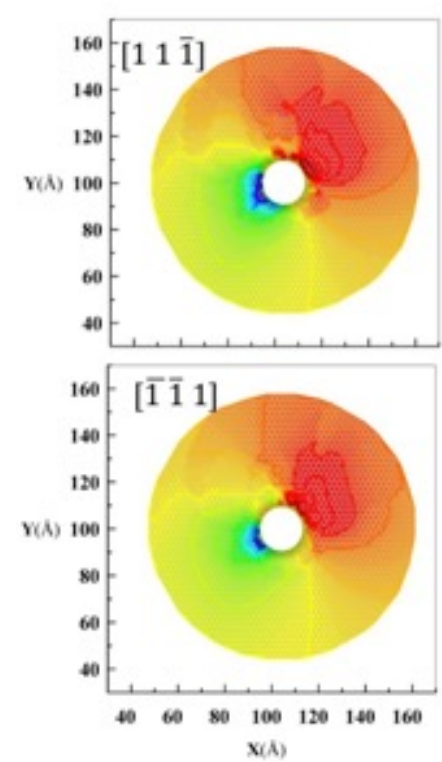
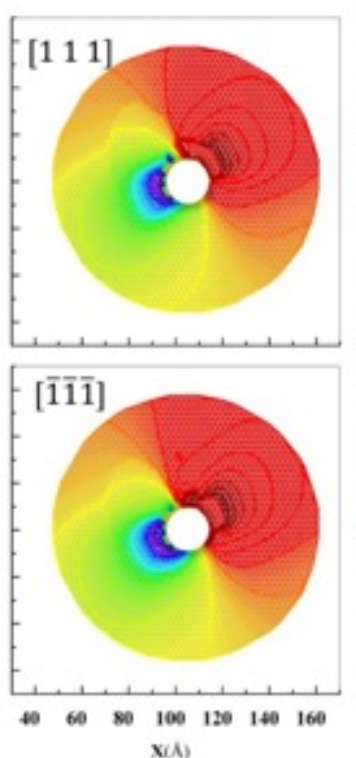
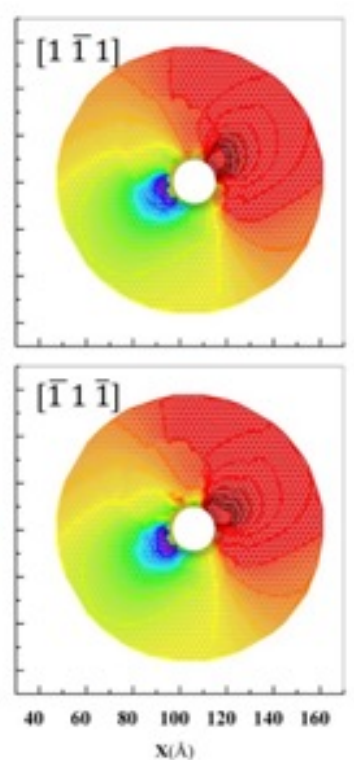
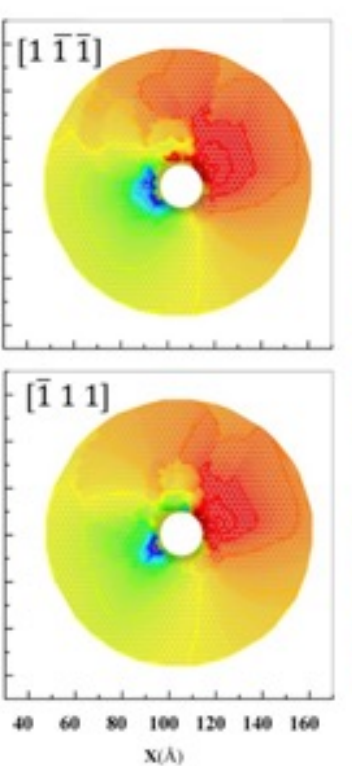

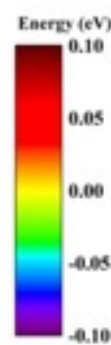

Eacrov $(e V)$

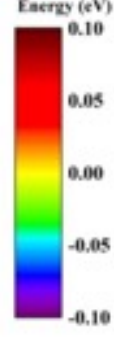

Fig. 5: Migration energy barrier maps of different nearest neighbor migration directions for a [101] dumbbell in the presence of a screw dislocation. 
Fig. 6 shows the migration energy changes for all members of the $<110>$ family migrating in the [111] direction. The symmetry relations observed in the Fig. are due to the direction of the dumbbells with respect to the dislocation core. This effect can be appreciated in the energy plots of the [101] and [0 $\overline{1} 1]$ dumbbells, which are mirrors of each other; a similar relationship is found between the [101] and [011] dumbbells. The directions containing a negative index have no components in the dislocation line direction, while the directions with all positive indices have components in the dislocation line direction. This results in the directions with all positive indices having a smaller change in the migration energy compared to the directions with a negative index, since the stress component along the dislocation line is negligible, which results in essentially no interaction with the dumbbell in this particular direction.

[101]

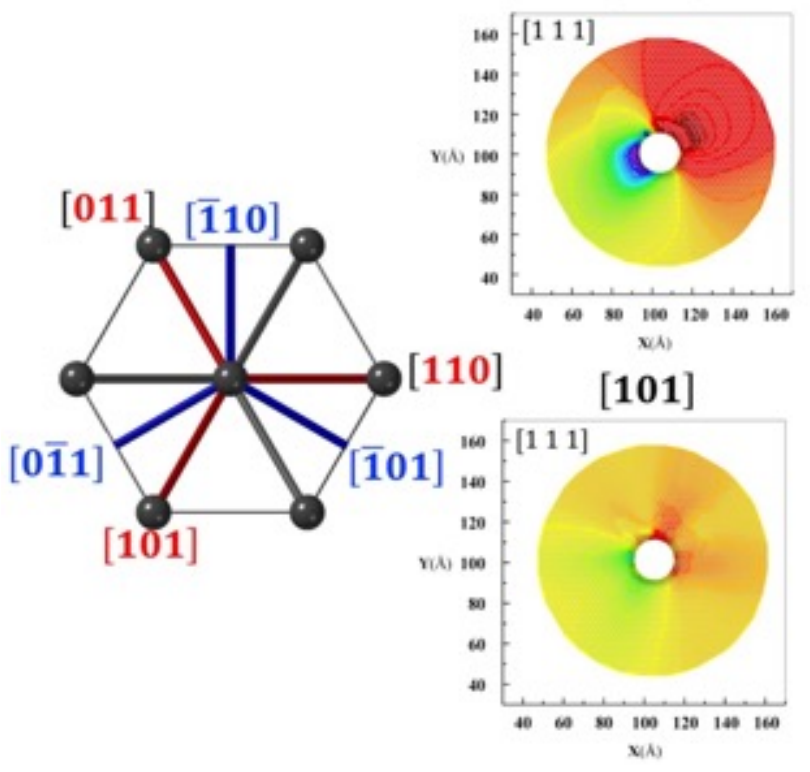

[110]

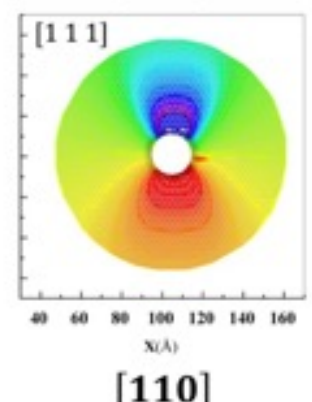

[110]

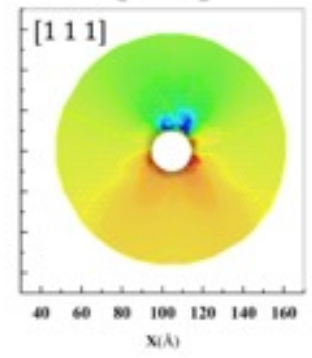

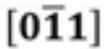

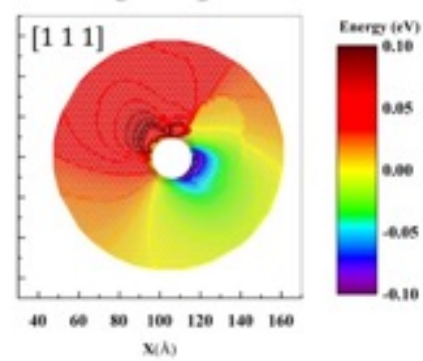

[011]

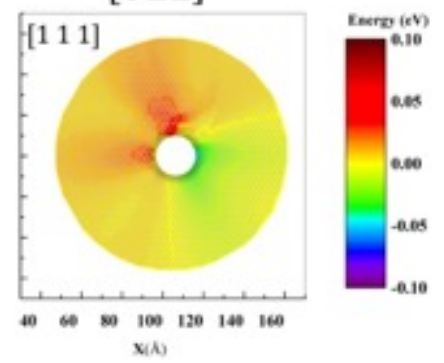

Fig. 6: Migration energy barrier maps for different members of the $<110>$ dumbbell family in the [111] migration direction.

As it was mentioned in section 4.1, we also found saddle points that correspond to the rotation from one $<110>$ type dumbbell to a different member of the $<110>$ family. In Fig. 7 we show the change of the energy barrier for a rotation of [101] dumbbell as a function of position to a screw dislocation. The plots show that there is a significant dependence of rotation energies with respect of position. There are regions where the rotation energies are reduced compared with the bulk case, resulting in faster rotations near dislocation core, such as the bulk and green regions in the bottom two Fig.s of Fig. 7. In comparison, certain regions lead to slower rotation, e.g. the red regions in the bottom two Fig.s of Fig. 7, also indicating that rotations to particular dumbbell configuration occur more often than other directions. Compared with the 
results of first near neighbor jump, the presence of dislocations influences not only the rate of jumping but also the rate of dumbbell rotations, resulting in complex defect dynamics that are challenging for conventional techniques and methods.

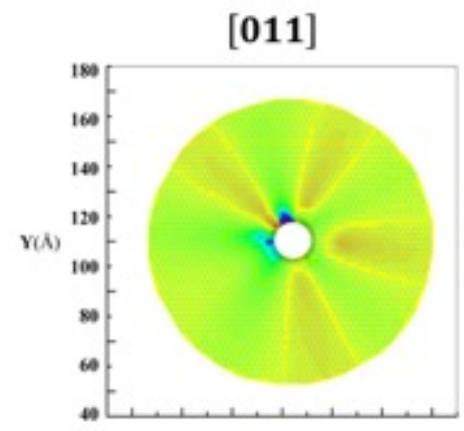

$[\mathbf{0 1} 1]$

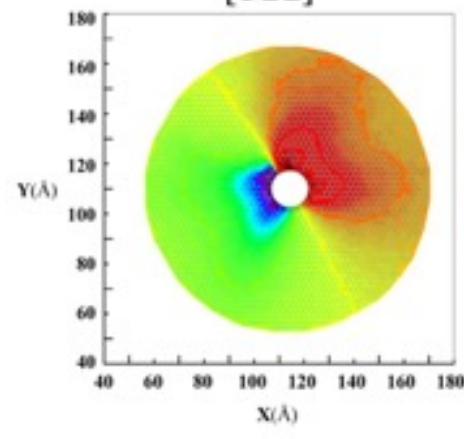

[110]

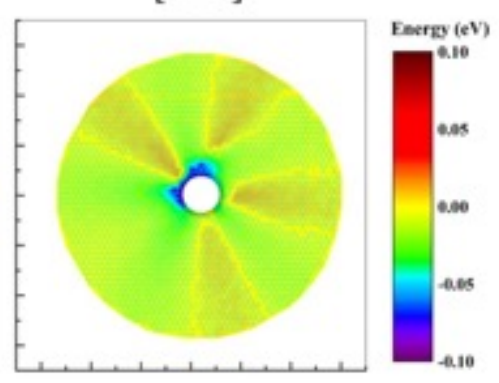

[110]

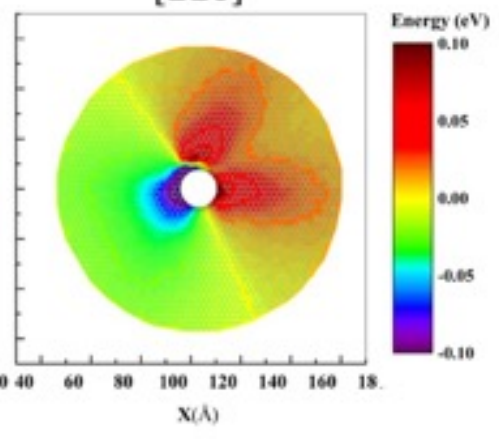

Fig. 7: Migration energy barrier for a [101] dumbbell rotation to different members of the $<110>$ family near a screw dislocation.

\section{IV-2-2-3 Edge Dislocation}

Fig. 8 shows the relative migration energies as a function of position for the different migration directions of a vacancy in an edge dislocation environment. Because of the slip system of an edge dislocation, there are no longer migration jumps in the dislocation line directions. In comparison, the migration jumps in the [111] and $[\overline{1} \overline{1} \overline{1}]$ directions correspond to migration along the glide direction. In these directions, the effects of the compressive and tensile stress field in the different regions of the edge dislocation are more evident compared with changes in migration energy among all migration directions

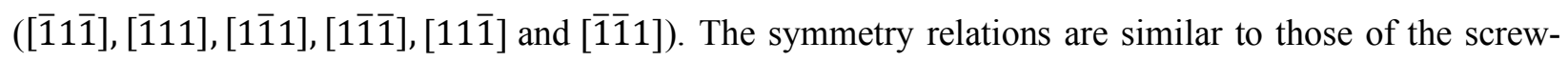

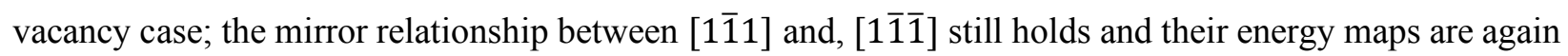
mirrors of each other. 

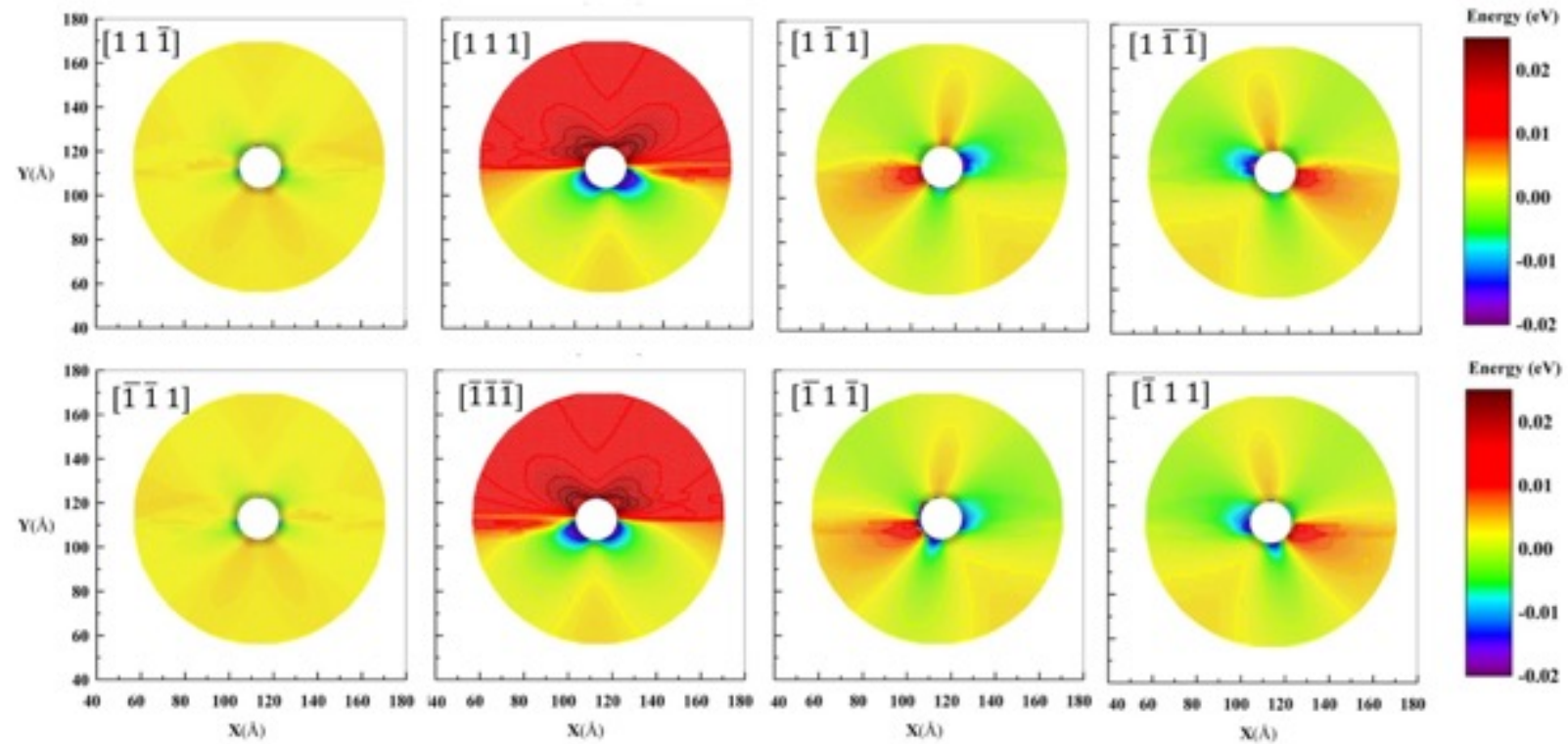

Fig. 8: Migration energy barrier maps of different nearest neighbor migration directions for a vacancy in the presence of an edge dislocation.

Fig. 9 shows the migration energies of an [101] dumbbell near an edge dislocation. Just as with the screw case, the SP energy maps strongly depend on the configuration of the dumbbell. The mirror symmetry

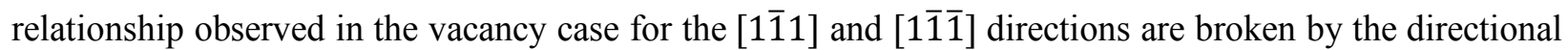
nature of the dumbbell (except for the [110] and [110] dumbbell configurations where mirror symmetry still exists, see Supplementary Material section SM4). It can be observed that for both screw and edge dislocations, the change in migration energy for dumbbells is greater than for vacancies due to their larger distortion in the lattice. For the vacancy case, we have attempted to relate the migration energies to the strain/stress field by fitting the SP energies to analytical expressions, but none of them yield reasonable agreement with the SP data. The trends displayed in the energy maps between the screw and edge dislocations are significantly different, partially due to the strain fields generated by each type of dislocation. 

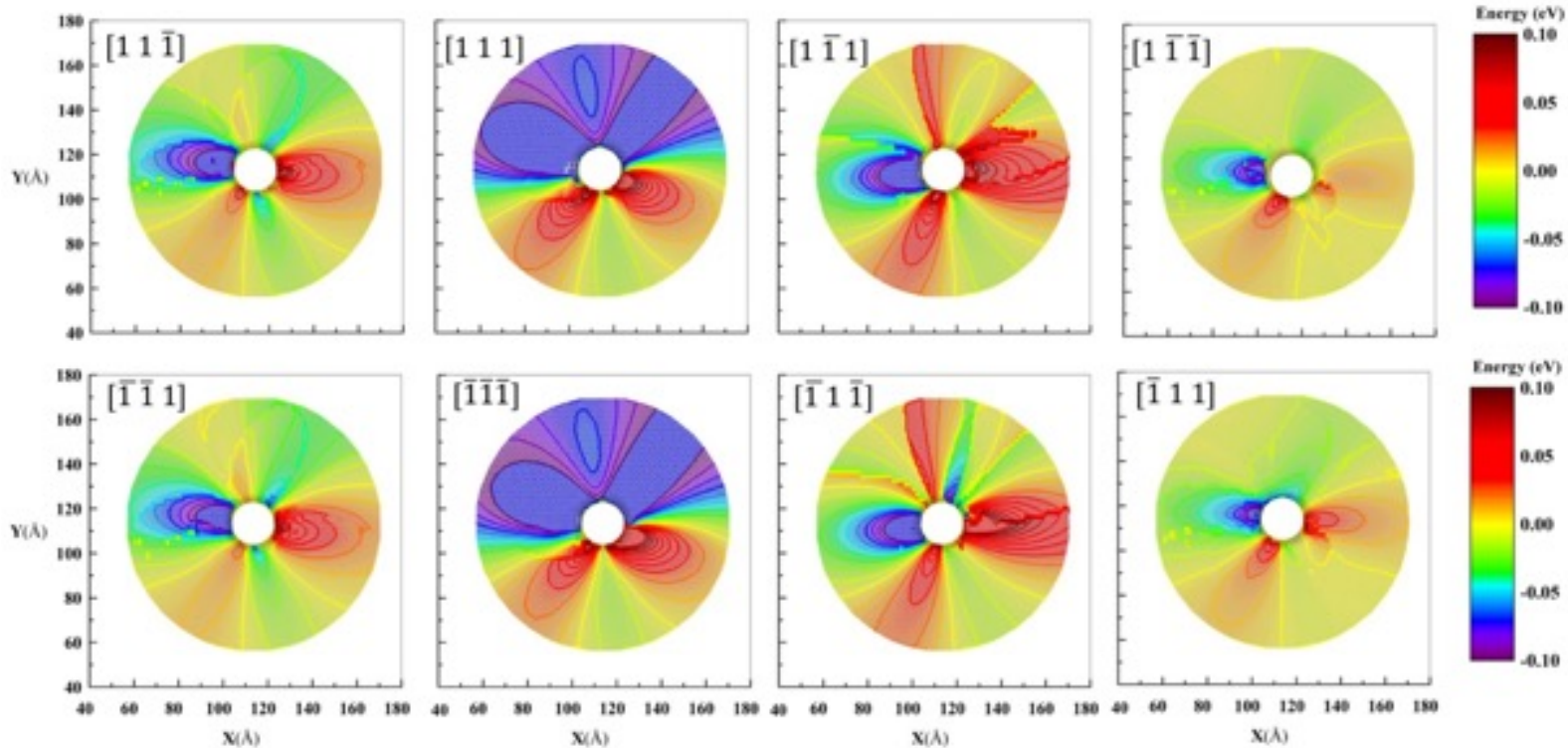

Fig. 9: Migration energy barrier maps of different nearest neighbor migration directions for a [101] dumbbell in the presence of an edge dislocation.

In Fig. 10 we show the change of the energy barrier for a rotation of [101] dumbbell as a function of position near an edge dislocation. Similar to the screw dislocation case, these plots show rotations energies have a strong dependence on the position of the defect. Particularly, in the bottom two Fig.s we can observe rotations get slower as we approach the dislocation core from the upper half, but become faster if we approach the dislocation from the lower half of the system. Compared with the two upper Fig.s (in Fig. 10), we can see that rotations of [011] and [110] dumbbell occur more often in the areas that correspond to slower rotations for $[0 \overline{1} 1]$ and $[\overline{1} 10]$. 


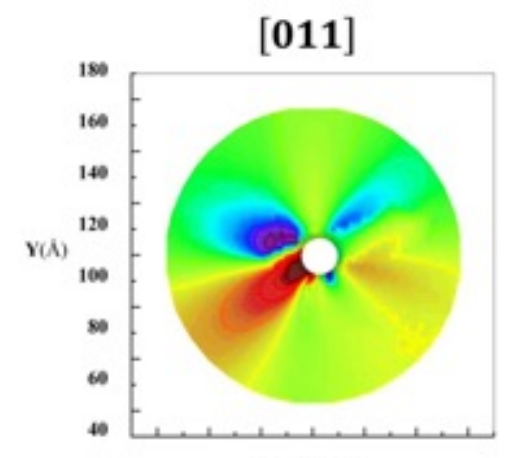

[011]

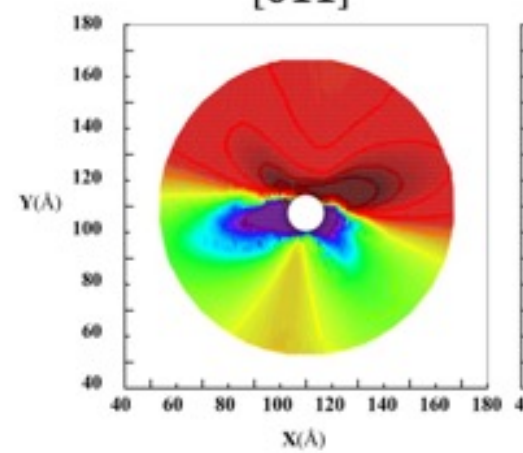

[110]

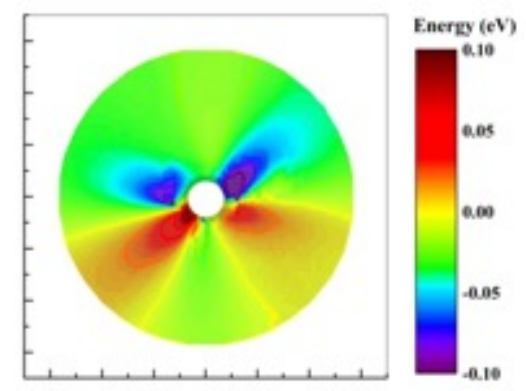

[110]

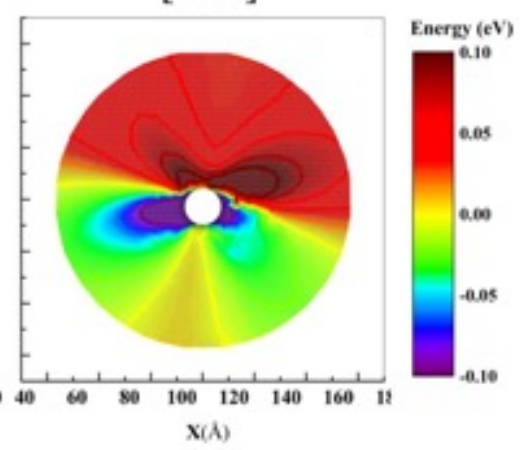

Fig. 10: Migration energy barrier for a [101] dumbbell rotation to different members of the $<110>$ family near an edge dislocation.

\section{IV-2-2-4 Diffusion Anisotropy}

In the bulk, point defect migration exhibits a random walk motion; the presence of the dislocation changes the SP configurations and energies, resulting in a certain migration direction having a higher probability than the other directions. This leads to anisotropic diffusion. To analyze the diffusion anisotropy, we have taken the difference between the smallest and largest SP energy values as a function of position with respect of the dislocation core for both screw and edge dislocations as shown in Fig. 11. In general, dumbbell defects have a higher anisotropy of diffusion due to the directional nature of the defect and the larger strain it introduces. The anisotropy of diffusion leads to more complex diffusion paths. Particularly, the strong diffusion anisotropy of dumbbells near both edge and screw dislocations indicates they will likely have preferred migration paths. 


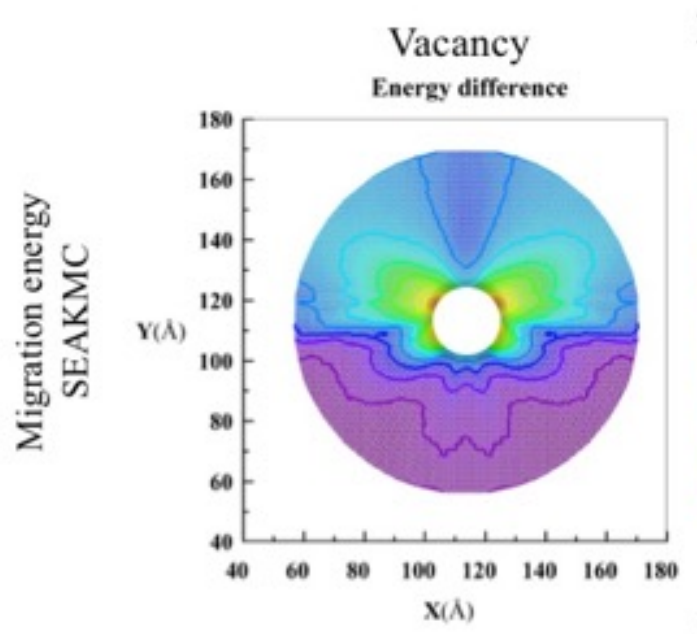

Edge dislocation Dumbbell
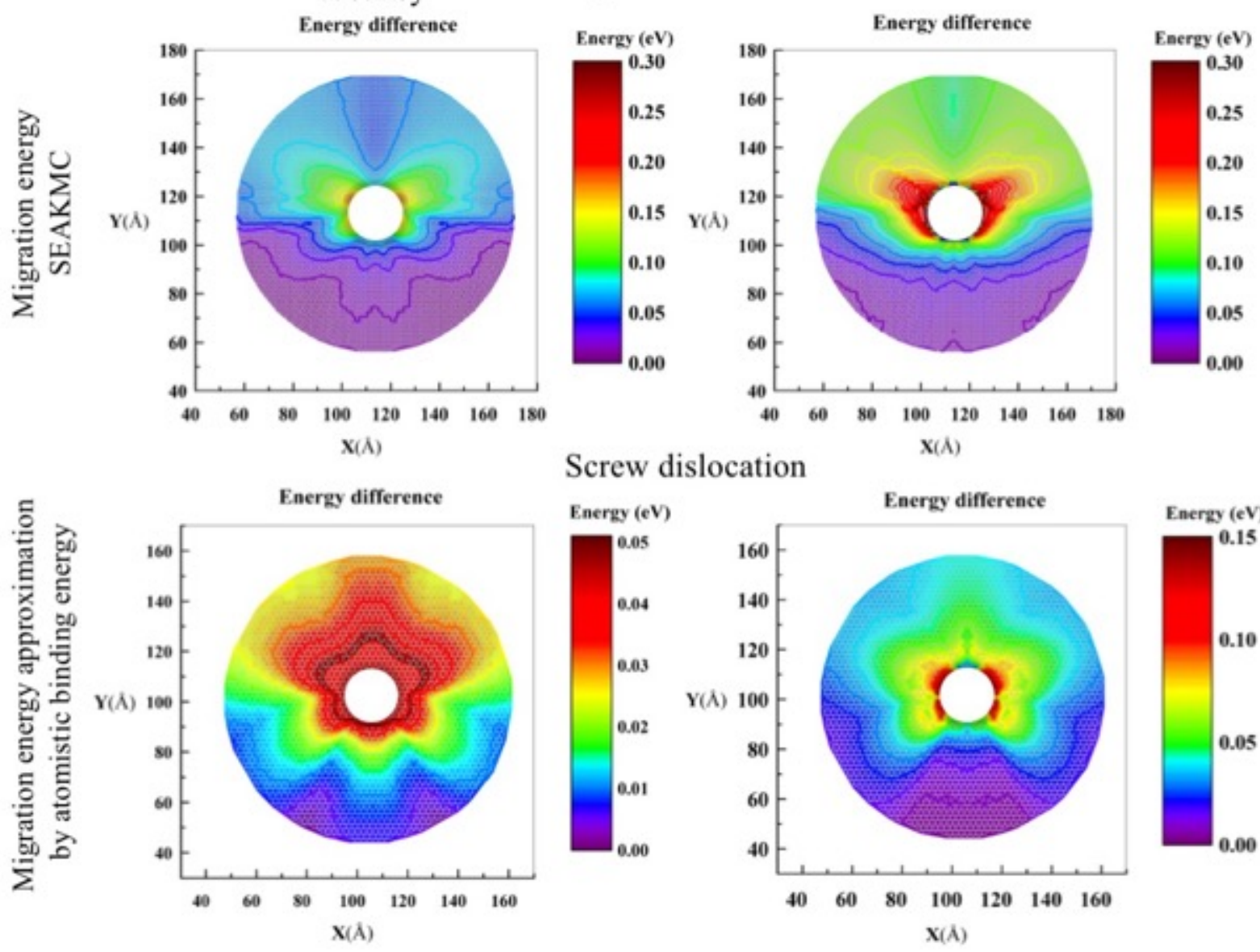

\section{Screw dislocation}
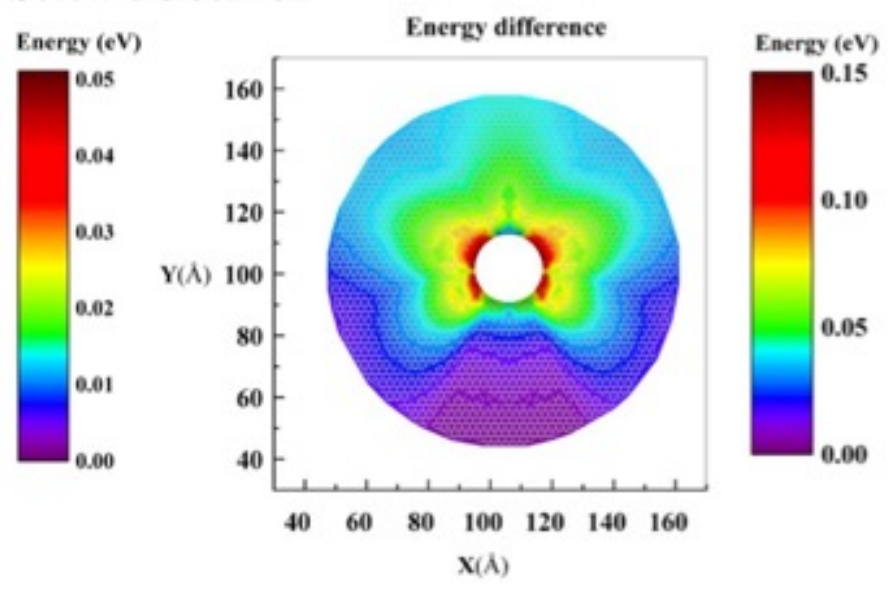

Fig. 11: Anisotropy of diffusion for vacancies and dumbbells for an edge and screw dislocation.

From the SP searches, we can also obtain the direction of the SP with the lowest energy barrier at each position and construct the "most probable migration maps". This type of plots permits visualization of what would be the most probable migration of a point defect as a function of position with respect to the dislocation core. These directions will be more often followed at low temperatures, where the effect of the difference between energy barriers is more prominent. As the temperature rises, the migration of point defects approaches random walk diffusion. The most probable migration maps for a vacancy and a dumbbell in a screw dislocation environment are given in Fig. 12, in which the vacancy case is in good agreement with the results of Sivak et al. $(\underline{95}, \underline{96})$ where the strain field is small. In contrast, our dumbbell results are dramatically different from Sivak et al. $(95, \underline{96})$. Fig 12(b) is the most probable migration map for the $[\overline{1} 10]$ dumbbell. It should be noted that there is a different map for each different member of the $<110>$ dumbbell family. Since the migration mechanism involves translation and rotation at every jump the 
most probable path, the overall most probable path is determined by the most probable maps for all dumbbell configurations.
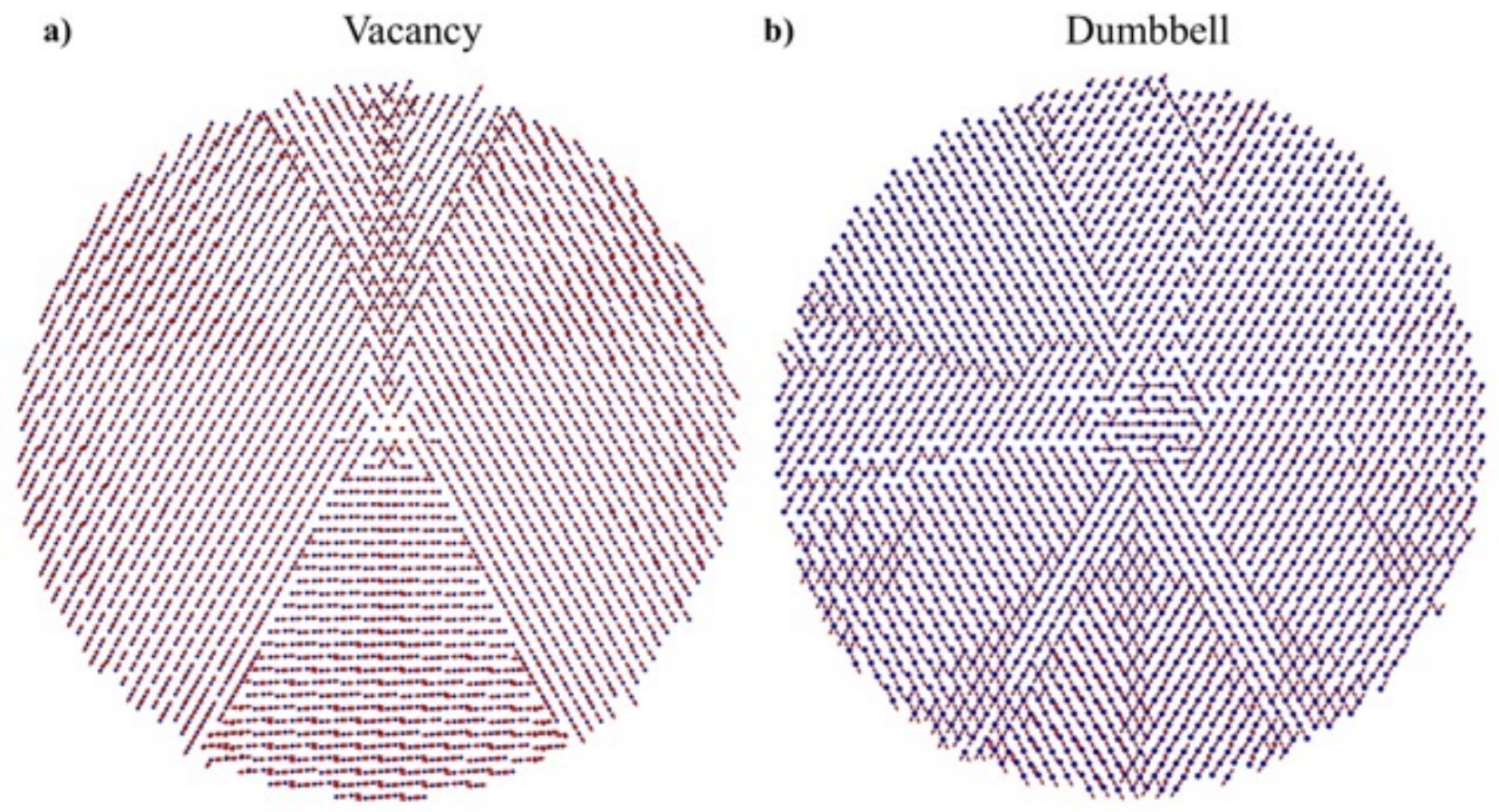

Fig. 12: (a) Most probable migration map for a vacancy (b) most probable migration map for a [1110] dumbbell, in a screw dislocation environment.

\section{IV-2-2-5 KMC Simulations of Defect Trajectories}

The data obtained in this study can be used as an input for kinetic Monte Carlo (KMC) simulations, allowing realistic migration paths. For each position of interest, we performed 10,000 KMC simulations. We found that the diffusion of a defect near dislocations is highly anisotropic and strongly correlated, significantly deviating from a simple symmetric random walk. This correlated behavior is shown in Fig. 13, where we have plotted several migration trajectories of dumbbell defects for both screw and edge dislocations and compared with random walk trajectories. Using $\mathrm{KMC}$, we have identified the regions in which each type of defect is more efficiently absorbed by the dislocation core. We have obtained the time required by each defect to be absorbed by the dislocation and divided it by the time required to reach the dislocation core by a simple symmetric random walk. This ratio denotes the deviations of the migration behavior from a random walk diffusion by the presence of the dislocation. We show the absorption time for a vacancy and dumbbell to reach the dislocation core of a screw dislocation with the obtained barriers and with a random walk respectively in Fig 13e and Fig.13f. Blue zones denote regions where vacancies are absorbed more efficiently, and red zones denote region where dumbbells are more efficiently absorbed. Interestingly, we 
find that the region where a vacancy is absorbed more efficiently coincides with the compressive field of the dislocations, and dumbbells must migrate to a tensile zone to be able to find a path to reach the dislocation core, as can be seen from the trajectories. This behavior will be more accentuated at low temperature and become less prominent as temperature increases (e.g. room temperature), for this reason we performed the simulations at $\mathrm{T}=100 \mathrm{~K}$ and enhance the preference between barriers. As it has been shown, the accurate migration energy data used in the KMC simulations has a deep impact on the defect trajectory, thus allowing a realistic estimation of important parameters such as of the lifetime of point defects (how long it takes to be absorbed by the dislocation), sink strength and dislocation bias. The diffusion mechanism of dumbbells is rather complex, involving translation, rotations and the effect of different dumbbell configuration. The individual migration energy maps change drastically for different directions and do not show a direct relationship with the strain field of dislocations. However, the overall effects from all these mechanisms and all dumbbell configurations produce diffusion trajectories that are related to the strain fields of dislocations. For instance, the 3-fold symmetry is recovered for the screw dislocation and the effects of the compressive/tensile regions are appreciated in the edge case (Fig. 13). These observations may provide basis to allow the development of simple models to describe the dynamics of point defects near dislocations in materials. 
Screw

a)

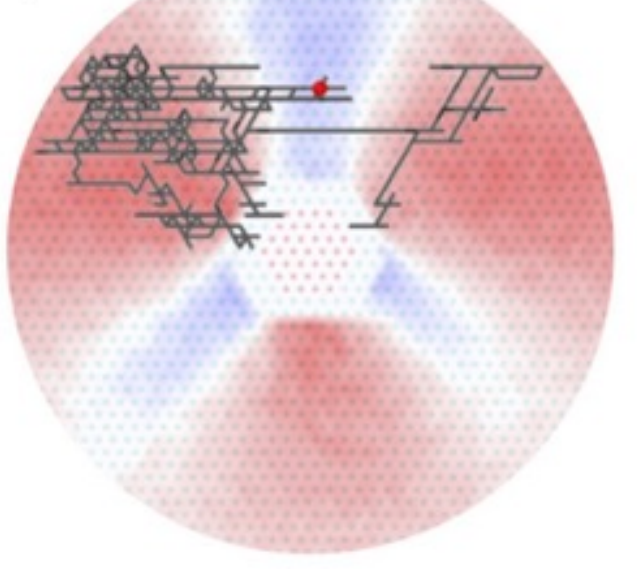

c)

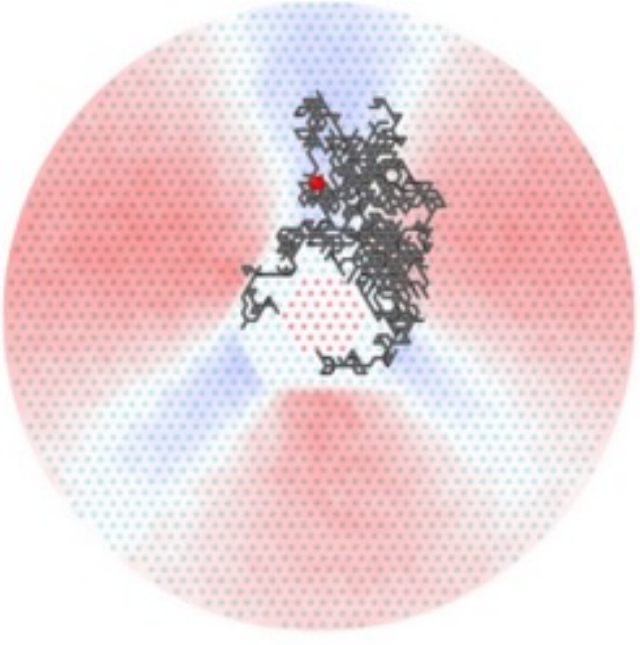

e)

\section{Screw vacancy}

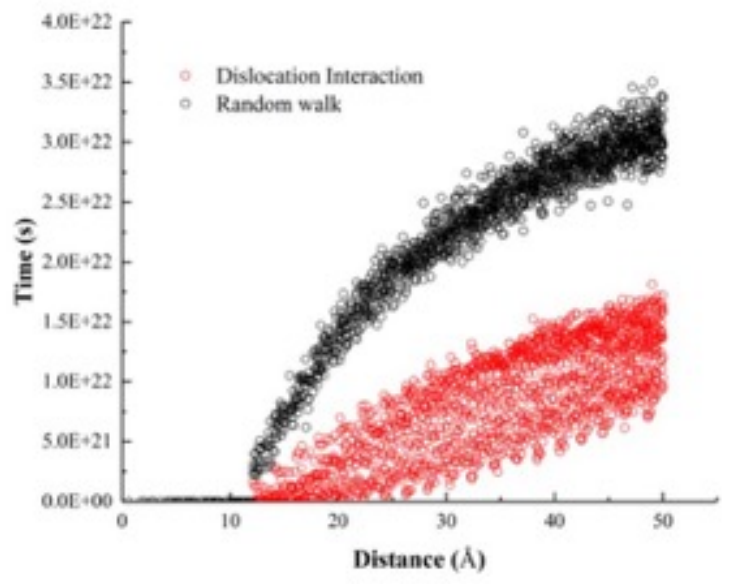

f) b)

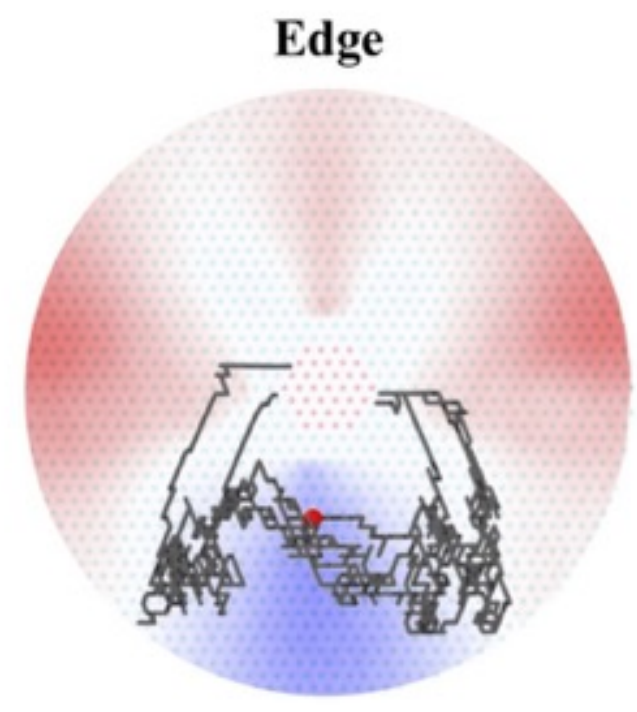

d)

\author{
Random walk
}
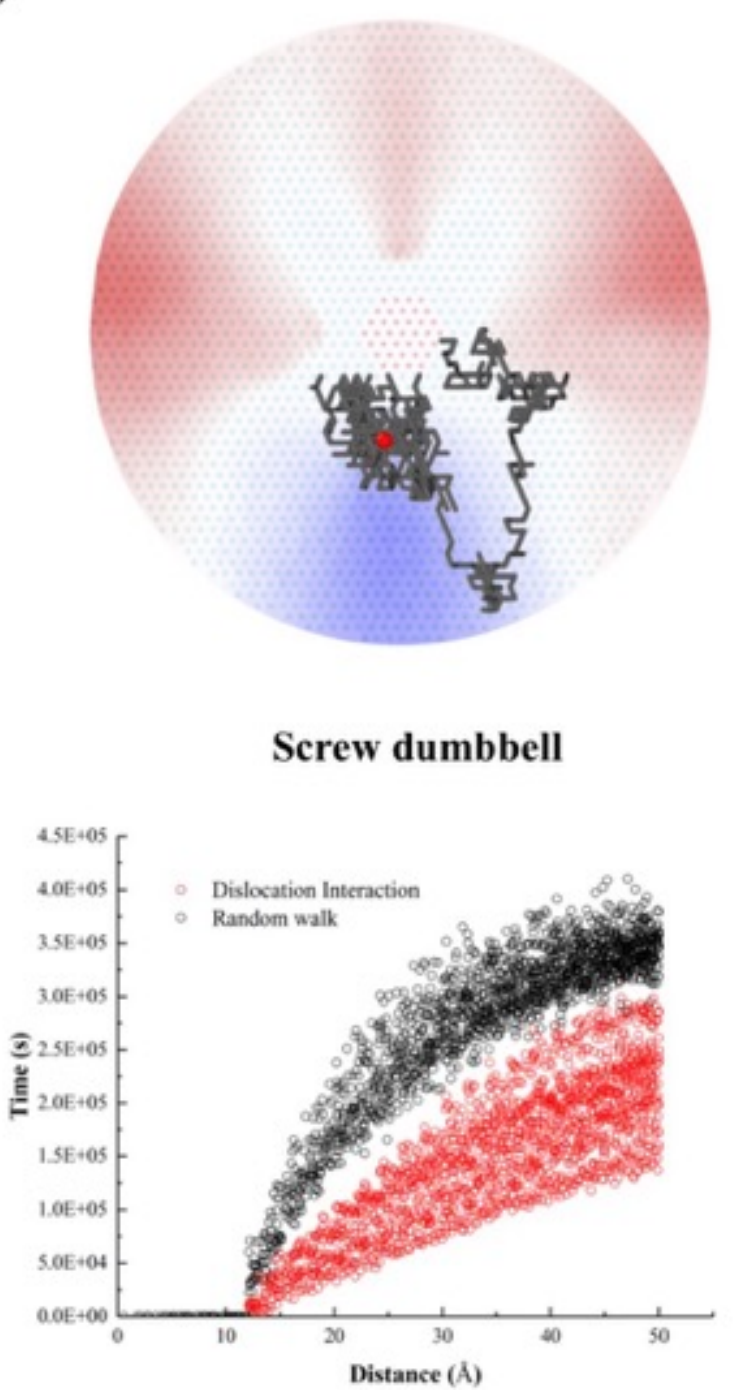
Fig. 13: Dumbbell migration path around a (a) screw (b) edge dislocation, (c) random walk of a dumbbell in a screw dislocation, (d) random walk of a dumbbell in an edge dislocation. The large red sphere represents the dumbbell starting position. The dislocation core is represented by the red colored atoms. (e) Time of absorption for a vacancy near a screw dislocation, and for random walk diffusion (f) time of absorption for a dumbbell near a screw dislocation and for random walk diffusion.

\section{$\underline{\text { IV-2-3. Summary }}$}

In this work, we have presented the actual MEBs and SP configurations for a vacancy and a dumbbell as a function of position in the presence of a (screw/edge) dislocation. The SEAKMC approach captures the complexity of the migration mechanisms of point defects, and the effect of different local atomic environments introduced by dislocations, as we have shown in the first nearest neighbor migration and rotations energy barrier plots. Based on the migration energy maps, we find that the atomistic processes of the dislocation-point defect interaction (for both vacancy and interstitial) are highly anisotropic and correlated. The anisotropy of diffusion is appreciated with the "most probable migration" maps and by defect trajectories. For instance, a dumbbell around an edge or screw dislocation must escape the compressive region of the dislocations to be absorbed. This study provides critical information on how to capture the real dynamics of point defects near complex defects (e.g., dislocations, dislocation loops, grain boundaries) and the results in this study can be used as an input for coarser scale models, such as mean field rate theory. This study also provides the basis for investigations of material properties that depend on the interaction between dislocations and point defects, such as void swelling and creep, that are of interest for various practical applications. 


\section{SUPPORTED AND CONTRIBUTING STUDENTS AND POSTDOCS}

\section{At the University of Tennessee Knoxville}

- Luis Casillas-Trujillo (Graduate Student), now a postdoc researcher at Linköping University, Sweden

- Liubin Xu (Graduate Student)

- Dylan Doizer (Undergraduate Student)

- Courtney Dennis (Undergraduate Student)

- Chris Walker (Undergraduate Student), now a graduate student at Texas A\&M

- Zizhe Lu (Postdoc), now research scientist at TCL Company

\section{At the University of Wisconsin Madison}

- Beata Tyburska-Püschel (Research Scientist), now Scientist at German Aerospace Center

- Kelsey Amundson (Undergraduate Student), now a graduate student at the UC-Berkeley

- McKinleigh McCabe (Undergraduate Student), now an engineer at Sargent \& Lundy

- Josh Mueller (Undergraduate Student), now a graduate student at Colorado School of Mines

- Soham Shah (Undergraduate Student), now a graduate student at the UW-Madison

- Samantha Joers (Undergraduate Student)

- Carter Tesch (Undergraduate Student), now at GKN Center Metals

- Kyle Blomstrand (Undergraduate Student), now an engineer at Framatome

- John Patrick Lacy (Undergraduate Student)

\section{At the Oak Ridge National Laboratory}

- Tianyi Chen (Postdoc), now assistant Professor at Oregon State University 


\section{PUBLICATIONS}

(Incomplete list)

1. Z. Lu, L. Xu, T. Chen, L. Tan and H. Xu*, "Interactions between Displacement Cascade and Dislocation and Their Influences on Peierls Stress in Fe-20Cr-25Ni alloys", Computational Materials Science, Accepted

2. L. Casillas-Trujillo, A.S. Ervin, L. Xu, A. Barashev, H. Xu*, "Point Defect Interaction with Dislocations in bcc Iron", Physical Review Materials, 2, 103604, (2018) DOI:

10.1103/PhysRevMaterials.2.103604

3. T. Chen, Y. Yang, L. He, B. Tyburska-Pushel, K. Sridaran, H. Xu, L. Tan, "Enhanced Diffusion of Cr in 20Cr-25Ni Type Alloys under Proton Irradiation at 670 C", Nuclear Materials and Energy, 17, 142-146 (2018) DOI: 10.1016/j.nme.2018.10.001

4. A. Ervin, H. Xu*, "Mesoscale Simulations of Radiation Damage Effects in Materials: a SEAKMC Perspective", Computational Materials Science, 150, 180-189 (2018) DOI:

10.1016/j.commatsci.2018.03.054

5. L. Casillas-Trujillo, L. Xu, H. Xu*, "Compositional Effects on Ideal Shear Strength in Fe-Cr Alloys", Journal of Alloys and Compounds 720, 466-472 (2017) DOI: 10.1016/j.jallcom.2017.05.167

6. T. Chen, L. Tan, Z. Lu, and H. Xu, "The Effect of Grain Orientation on Nanoindentation Behavior of Model Austenitic Alloy Fe-20Cr-25Ni”, Acta Materialia, 138, 83-91 (2017) DOI:

10.1016/j.actamat.2017.07.028

Conference Presentations

1. H. Xu et al, "Dislocation Bias and Sink Strength in bcc Fe based on Mesoscale Defect Dynamics", The Nuclear Materials (NuMat) Conference, Seattle, WA, October 2018

2. A.S. Ervin, L. Casillas-Trujillo, H. Xu, "Dislocation Loop Bias in bcc Fe", TMS, Phoenix, AZ March 2018

3. T. Chen, L. He, J. Burns, Y. Wu, C. Knight, K. Sridharan, H. Xu, L. Tan, Microstructure and mechanical properties of ATR-irradiated alloys D9 and NF709, NuMat2018: The Nuclear Materials Conference, Seattle, WA, USA, Oct. 14-18, 2018.

4. T. Chen, L. He, J. Burns, Y. Wu, C. Knight, K. Sridharan, H. Xu, L. Tan, Microstructure and mechanical properties of ATR-irradiated alloys D9 and NF709, NuMat2018: The Nuclear Materials Conference, Seattle, WA, USA, Oct. 14-18, 2018.

5. (Keynote) H. Xu et al., "Mesoscale Simulations of Interaction between Point Defect and Dislocation in bcc Iron using SEAKMC", Chinese Materials Conference, Yinchuan, China, July 2017 
6. (Invited) H. Xu et al., "Interactions between Point Defects and Dislocations in bcc Iron using SEAKMC", 2017 International Symposium on Multiscale Modelling and Simulation of Materials, Shenyang, China, July 2017

7. H. Xu et al, "Integrated Computational and Experimental Study of Radiation Damage Effects in Alloy 709”, Spring MRS meeting, Phoenix, AZ, US, April 2017

8. H. Xu et al, "Dynamics of Interaction between Point Defects and Dislocations in bec Iron using SEAKMC Simulations", TMS Annual Meeting, San Diego, CA, U.S. Feb 2017

9. L. Casillas-Trujillo, H. Xu, "Dynamics of Interactions between Point Defects and Dislocations in bcc Iron”, MRS spring meeting, Phoenix, AZ, April 2017

10. L. He, R. Mo, B. Tyburska-Pueschel, K. Sridharan, H. Xu, T. Chen, L. Tan, "Ion Irradiation Defects in Austenitic Alloy 709 and Ferritic-Martensitic Steel Grade 92 for Nuclear Applications", Spring MRS Meeting, Phoenix, AZ, 2017

11. L. He, H. Xu, L. Tan, P. Voyles, K. Sridharan, "Nanometer-Scale Swelling Depth Profile in IonIrradiated Stainless Steels”, Microscopy \& Microanalysis Meeting, St. Louis, MO, 2017

12. T. Chen, L. Tan, L. He, B. Tyburska-Püschel, K. Sridharan, Microstructural evolution in Fe-20Cr$25 \mathrm{Ni}$ austenitic alloys under proton irradiation at $670^{\circ} \mathrm{C}$, ANS Transactions (2017).

13. T. Chen, L. Tan, K. Sridharan, H. Xu, Effect of proton irradiation on deformation mechanisms in model alloy Fe-20Cr-25Ni, TMS $2017146^{\text {th }}$ Annual Meeting \& Exhibition, San Diego, CA, USA, Feb. 26 - Mar. 2, 2017.

14. H. Xu et al. , "Ideal Shear Strength of Iron-based Alloys from First Principles Calculations", Spring MRS Meeting, San Francisco, CA, 2015 


\section{REFERENCE}

1. L. Tan et al., Microstructural evolution of neutron-irradiated T91 and NF616 to similar to 4.3 dpa at 469 degrees C. Journal of Nuclear Materials 493, 12-20 (2017).

2. M.G. Horsten, E.V. van Osch, D.S. Gelles, M. L. Hamilton, in Effects of Radiation on Materials: 19th International Symposium, ASTM STP 1366, M.L. Hamilton, A.S. Kumar, S.T. Rosinski, M. L. Grossbeck, Eds. (American Society for Testing and Materials, West Conshohocken, 2000), pp. 14.

3. C. Topbasi, A. T. Motta, M. A. Kirk, In situ study of heavy ion induced radiation damage in NF616 (P92) alloy. J Nucl Mater 425, 48-53 (2012).

4. Y. Huang et al., Microstructural evolution in proton irradiated NF616 at $773 \mathrm{~K}$ to $3 \mathrm{dpa} . J \mathrm{Nucl}$ Mater 442, S800-S804 (2013).

5. J.T. Venard, J. R. Weir, In-reactor stress-rupture properties of a $20 \mathrm{Cr}-25 \mathrm{Ni}$, columbium-stabilized steel, Flow and Fracture of Metals and Alloys in Nuclear Environments. ASTM STP No.380, 269 (1965).

6. J.T. Busby, T.R. Allen, R.D. Carter, E.A. Kenik, G. S. Was, Dose dependence of radiation induced segregation in proton irradiated austenitic alloys. MRS Proceedings 439, 563 (1996).

7. D.L. Damcott, G.S. Was, S. M. Bruemmer, Proton irradiation induced grain boundary segregation in austenitic stainless steels. MRS Proceedings 373, 131 (1994).

8. C. Taylor, Precipitation in 20 Cr-25 Ni type stainless steel irradiated at low temperatures in a thermal reactor (AGR): Dimensional stability and mechanical behavior of irradiate metals and alloys. V. 1. (1983).

9. A. N. Hughes, J. R. Caley, The Effects of Neutron Irradiation at Elevated Temperatures on the Tensile Properties of Some Austenitic Stainless Steels. Journal of Nuclear Materials 10, 60-62 (1963).

10. J. a. W. Venard, J, In-reactor stress-rupture properties of a 20Cr-25Ni, columbium-stabilized steel: Flow and fracture of metals and alloys in nuclear environments. (ASTM International, 1965).

11. H. J. a. S. MacLean, Kumar and Hyde, Timothy A, Irradiation Test Plan for the ATR National Scientific User Facility-University of Wisconsin Pilot Project. (2008).

12. B. a. T. Kim, Lizhen and $\mathrm{Xu}, \mathrm{C}$ and Yang, Yong and Zhang, Xuan and Li, Meimei, Microstructural evolution of NF709 (20Cr--25Ni--1.5 MoNbTiN) under neutron irradiation. Journal of Nuclear Materials 470, 229-235.

13. L. T. T. Chen, L. He, B. Tyburska-Püschel, K. Sridharan, Microstructrual evolution in Fe-20Cr$25 \mathrm{Ni}$ austenitic alloys under proton irradiation at $670^{\circ} \mathrm{C}$. Transactions of the American Nuclear Society 117, 581-583 (2017). 
14. W. C. Oliver, G. M. Pharr, An Improved Technique for Determining Hardness and ElasticModulus Using Load and Displacement Sensing Indentation Experiments. Journal of Materials Research 7, 1564-1583 (1992).

15. L. Tan, J. T. Busby, H. J. M. Chichester, K. Sridharan, T. R. Allen, Thermomechanical treatment for improved neutron irradiation resistance of austenitic alloy (Fe-21Cr-32Ni). Journal of Nuclear Materials 437, 70-74 (2013).

16. G. S. Was, Fundamentals of Radiation Materials Science:metals and alloys. (2017).

17. F. A. Garner, Irradiation performance of cladding and structural steels in liquid metal reactors, chap 6. In: Frost BRT Materials science and technology (Wiley Online Library New York, 1984), vol. 10A.

18. M. Andrzejczuk, T. Plocinski, W. Zielinski, K. J. Kurzydlowski, TEM characterization of the artefacts induced by FIB in austenitic stainless steel. J Microsc 237, 439-442 (2010).

19. L. X. Stubbins J, "Fundamental studies of irradiation-induced modifications in microstructural evolution and mechanical properties of advanced alloys," (2018).

20. T. D. Delarubia, R. S. Averback, H. Hsieh, R. Benedek, Molecular-Dynamics Simulation of Displacement Cascades in Cu and Ni - Thermal Spike Behavior. J Mater Res 4, 579-586 (1989).

21. D. J. Bacon, T. D. Delarubia, Molecular-Dynamics Computer-Simulations of Displacement Cascades in Metals. Journal of Nuclear Materials 216, 275-290 (1994).

22. D. J. Bacon, F. Gao, Y. N. Osetsky, The primary damage state in fcc, bcc and hep metals as seen in molecular dynamics simulations. Journal of Nuclear Materials 276, 1-12 (2000).

23. W. J. Phythian, R. E. Stoller, A. J. E. Foreman, A. F. Calder, D. J. Bacon, A Comparison of Displacement Cascades in Copper and Iron by Molecular-Dynamics and Its Application to Microstructural Evolution. Journal of Nuclear Materials 223, 245-261 (1995).

24. L. Malerba, Molecular dynamics simulation of displacement cascades in alpha-Fe: A critical review. Journal of Nuclear Materials 351, 28-38 (2006).

25. A. J. E. Foreman, W. J. Phythian, C. A. English, The Molecular-Dynamics Simulation of Irradiation Damage Cascades in Copper Using a Many-Body Potential. Philosophical Magazine a-Physics of Condensed Matter Structure Defects and Mechanical Properties 66, 671-695 (1992).

26. R. E. Stoller, A. F. Calder, Statistical analysis of a library of molecular dynamics cascade simulations in iron at $100 \mathrm{~K}$. Journal of Nuclear Materials 283, 746-752 (2000).

27. R. E. Voskoboinikov, Molecular dynamics simulations of radiation damage in D0(19) Ti3Al intermetallic compound. Nucl Instrum Meth B 307, 25-28 (2013).

28. R. E. Voskoboinikov, Y. N. Osetsky, D. J. Bacon, Computer simulation of primary damage creation in displacement cascades in copper. I. Defect creation and cluster statistics. Journal of Nuclear Materials 377, 385-395 (2008). 
29. K. P. Zolnikov, A. V. Korchuganov, D. S. Kryzhevich, Molecular dynamics simulation of primary radiation damage in Fe-Cr alloy. J Phys Conf Ser 774, 012130 (2016).

30. M. Tikhonchev, V. Svetukhin, A. Kadochkin, E. Gaganidze, MD simulation of atomic displacement cascades in Fe-10 at.\%Cr binary alloy. Journal of Nuclear Materials 395, 50-57 (2009).

31. K. L. Wong, J. H. Shim, B. D. Wirth, Molecular dynamics simulations of point defect interactions in Fe-Cr alloys. Journal of Nuclear Materials 367, 276-281 (2007).

32. R. E. Stoller, The role of cascade energy and temperature in primary defect formation in iron. Journal of Nuclear Materials 276, 22-32 (2000).

33. R. J. M. Konings, T. R. Allen, R. Stoller, S. Yamanaka, Comprehensive Nuclear Materials PREFACE. Comprehensive Nuclear Materials, Vol 1: Basic Aspects of Radiation Effects in Solids/Basic Aspects of Multi-Scale Modeling, Xxi-Xxii (2012).

34. S. I. Choi, J. H. Kim, RADIATION-INDUCED DISLOCATION AND GROWTH BEHAVIOR OF ZIRCONIUM AND ZIRCONIUM ALLOYS - A REVIEW. Nuclear Engineering and Technology 45, 385-392 (2013).

35. S. J. Zinkle, Y. Matsukawa, Observation and analysis of defect cluster production and interactions with dislocations. Journal of Nuclear Materials 329-333, 88-96 (2004).

36. W. Zhou, J. Tian, J. Zheng, J. Xue, S. Peng, Dislocation-enhanced experimental-scale vacancy loop formation in hcp Zirconium in one single collision cascade. Sci Rep-Uk 6, 21034 (2016).

37. R. E. Voskoboinikov, Interaction of collision cascades with an isolated edge dislocation in aluminium. Nucl Instrum Meth B 303, 125-128 (2013).

38. R. E. Voskoboinikov, MD simulations of collision cascades in the vicinity of a screw dislocation in aluminium. Nucl Instrum Meth B 303, 104-107 (2013).

39. L. Tan et al., Microstructural Evolution of Type 304 and 316 Stainless Steels Under Neutron Irradiation at LWR Relevant Conditions. Jom-Us 68, 517-529 (2016).

40. H. Watanabe, S. Masaki, S. Masubuchi, N. Yoshida, Y. Kamada, Radiation induced hardening of ion irradiated RPV steels. Journal of Nuclear Materials 417, 932-935 (2011).

41. B. N. Singh, A. J. E. Foreman, H. Trinkaus, Radiation hardening revisited: role of intracascade clustering. J Nucl Mater 249, 103-115 (1997).

42. C. Deo, C. Tom, R. Lebensohn, S. Maloy, Modeling and simulation of irradiation hardening in structural ferritic steels for advanced nuclear reactors. J Nucl Mater 377, 136-140 (2008).

43. S. J. Zinkle, G. S. Was, Materials challenges in nuclear energy. Acta Mater 61, 735-758 (2013).

44. A. K. Seeger, in Second UN Conference on Peaceful Uses of Atomic Energy. (United Nations, New York, 1958), vol. 6, pp. 250.

45. F. Friedel, Dislocations. (Pergamon, New York, 1974). 
46. F. Kroupa, P. B. Hirsch, Elastic Interaction between Prismatic Dislocation Loops and Straight Dislocations. Discuss Faraday Soc, 49-\& (1964).

47. M. Kikuchi et al., Effects of Nb-Content and C-Content on High-Temperature Strength of 25Percent-Ni-20-Percent-Cr Austenitic Steel - Study of High-Strength Austenitic Heat Resisting Steel .4. T Iron Steel I Jpn 25, B163-B163 (1985).

48. D. S. Smith, N. J. Lybeck, J. K. Wright, R. N. Wright, Thermophysical properties of Alloy 709. Nuclear Engineering and Design 322, 331-335 (2017).

49. M. McMurtrey, L. Carroll, J. Wright, "Microstructural Effects on Creep-Fatigue Life of Alloy 709," (Idaho National Lab.(INL), Idaho Falls, ID (United States), 2017).

50. M. S. Daw, S. M. Foiles, M. I. Baskes, The Embedded-Atom Method - a Review of Theory and Applications. Mater Sci Rep 9, 251-310 (1993).

51. J. P. Chang, V. V. Bulatov, S. Yip, Molecular dynamics study of edge dislocation motion in a bcc metal. J Comput-Aided Mater 6, 165-173 (1999).

52. D. Rodney, G. Martin, Dislocation pinning by small interstitial loops: A molecular dynamics study. Physical Review Letters 82, 3272-3275 (1999).

53. D. Rodney, G. Martin, Dislocation pinning by glissile interstitial loops in a nickel crystal: A molecular-dynamics study. Phys Rev B 61, 8714-8725 (2000).

54. Y. N. Osetsky, D. J. Bacon, B. N. Singh, B. Wirth, Atomistic study of the generation, interaction, accumulation and annihilation of cascade-induced defect clusters. Journal of Nuclear Materials 307, 852-861 (2002).

55. D. Rodney, Molecular dynamics simulation of screw dislocations interacting with interstitial frank loops in a model FCC crystal. Acta Materialia 52, 607-614 (2004).

56. H. J. Lee, J. H. Shim, B. D. Wirth, Molecular dynamics simulation of screw dislocation interaction with stacking fault tetrahedron in face-centered cubic Cu. J Mater Res 22, 2758-2769 (2007).

57. Y. N. Osetsky, D. J. Bacon, An atomic-level model for studying the dynamics of edge dislocations in metals. Model Simul Mater Sc 11, 427-446 (2003).

58. J. P. Hirth, J. Lothe, Theory of Dislocations. (McGraw-Hill, New York, 1967-1968).

59. S. Plimpton, Fast Parallel Algorithms for Short-Range Molecular-Dynamics. J Comput Phys 117, 1-19 (1995).

60. G. Bonny, D. Terentyev, R. C. Pasianot, S. Ponce, A. Bakaev, Interatomic potential to study plasticity in stainless steels: the FeNiCr model alloy. Modelling and Simulation in Materials Science and Engineering 19, 085008 (2011).

61. J. F. Ziegler, M. D. Ziegler, J. P. Biersack, SRIM - The stopping and range of ions in matter (2010). Nucl Instrum Meth B 268, 1818-1823 (2010). 
62. H. Jonsson, H. Andersen, ICOSAHEDRAL ORDERING IN THE LENNARD-JONES LIQUID AND GLASS. Physical Review Letters 60, 2295-2298 (1988).

63. A. Clarke, H. Jonsson, STRUCTURAL-CHANGES ACCOMPANYING DENSIFICATION OF RANDOM HARD-SPHERE PACKINGS. Physical Review E 47, 3975-3984 (1993).

64. K. Nordlund et al., Defect production in collision cascades in elemental semiconductors and fcc metals. Phys Rev B 57, 7556-7570 (1998).

65. A. Stukowski, Visualization and analysis of atomistic simulation data with OVITO-the Open Visualization Tool. Modelling and Simulation in Materials Science and Engineering 18, 015012 (2010).

66. A. Stukowski, Structure identification methods for atomistic simulations of crystalline materials. Modelling and Simulation in Materials Science and Engineering 20, 045021 (2012).

67. C. Azevedo, A review on neutron-irradiation-induced hardening of metallic components. Engineering Failure Analysis 18, 1921-1942 (2011).

68. A. Brailsford, R. Bullough, The theory of sink strengths. Philosophical Transactions of the Royal Society of London A: Mathematical, Physical and Engineering Sciences 302, 87-137 (1981).

69. D. Braski, H. Schroeder, H. Ullmaier, The effect of tensile stress on the growth of helium bubbles in an austenitic stainless steel. J. Nucl. Mater. 83, 265-277 (1979).

70. G. Greenwood, A. Foreman, D. Rimmer, The role of vacancies and dislocations in the nucleation and growth of gas bubbles in irradiated fissile material. J. Nucl. Mater. 1, 305-324 (1959).

71. D. R. Trinkle, C. Woodward, The chemistry of deformation: How solutes soften pure metals. Science 310, 1665-1667 (2005).

72. H. Ullmaier, The influence of helium on the bulk properties of fusion reactor structural materials. Nucl. Fusion 24, 1039 (1984).

73. D. Hull, D. J. Bacon, Introduction to dislocations. (Butterworth-Heinemann, 2001).

74. W. Wolfer, M. Baskes, Interstitial solute trapping by edge dislocations. Acta Metall. 33, 20052011 (1985).

75. D. Hull, D. J. Bacon, Introduction to dislocations. (Pergamon Press Oxford, 1984), vol. 257.

76. J. G. Harper, L. A. Shepard, J. E. Dorn, Creep of aluminum under extremely small stresses. Acta Metall. 6, 509-518 (1958).

77. A. H. Cottrell, B. Bilby, Dislocation theory of yielding and strain ageing of iron. Proceedings of the Physical Society. Section A 62, 49 (1949).

78. S. Hu, L. Chen, Solute segregation and coherent nucleation and growth near a dislocation - a phase-field model integrating defect and phase microstructures. Acta Mater. 49, 463-472 (2001).

79. G. S. Was, Fundamentals of radiation materials science: metals and alloys. (Springer, 2016). 
80. D. R. Olander, "Fundamental aspects of nuclear reactor fuel elements: solutions to problems," (California Univ., Berkeley (USA). Dept. of Nuclear Engineering, 1976).

81. C. Cawthorne, E. Fulton, Voids in irradiated stainless steel. Nature 216, 575-576 (1967).

82. P. Okamoto, L. Rehn, Radiation-induced segregation in binary and ternary alloys. J. Nucl. Mater. 83, 2-23 (1979).

83. H. Wiedersich, P. Okamoto, N. Q. Lam, A theory of radiation-induced segregation in concentrated alloys. J. Nucl. Mater. 83, 98-108 (1979).

84. W. Wolfer, Correlation of radiation creep theory with experimental evidence. J. Nucl. Mater. 90, 175-192 (1980).

85. L. Mansur, Theory and experimental background on dimensional changes in irradiated alloys. Journal of Nuclear Materials 216, 97-123 (1994).

86. B. Singh, A. Foreman, H. Trinkaus, Radiation hardening revisited: role of intracascade clustering. J. Nucl. Mater. 249, 103-115 (1997).

87. H. Trinkaus, B. Singh, A. Foreman, Segregation of cascade induced interstitial loops at dislocations: possible effect on initiation of plastic deformation. J. Nucl. Mater. 251, 172-187 (1997).

88. K. K. Adepalli, J. Yang, J. Maier, H. L. Tuller, B. Yildiz, Tunable Oxygen Diffusion and Electronic Conduction in SrTiO3 by Dislocation - Induced Space Charge Fields. Adv. Funct. Mater. 27, (2017).

89. E. Navickas et al., Dislocations Accelerate Oxygen Ion Diffusion in La0. 8Sr0. 2MnO3 Epitaxial Thin Films. ACS nano 11, 11475-11487 (2017).

90. M. Nastar, F. Soisson, Radiation-Induced Segregation-1.18. (2012).

91. B. Bilby, On the interactions of dislocations and solute atoms. Proceedings of the Physical Society. Section A 63, 191 (1950).

92. A. Cottrell, Report of a Conference on Strength of Solids. Physical Society, London 30, (1948).

93. E. Hayward, C. Deo, B. P. Uberuaga, C. N. Tomé, The interaction of a screw dislocation with point defects in bcc iron. Philos. Mag. 92, 2759-2778 (2012).

94. V. Shastry, T. D. De La Rubia, Interaction between point defects and edge dislocation in BCC iron. TRANSACTIONS-AMERICAN SOCIETY OF MECHANICAL ENGINEERS JOURNAL OF ENGINEERING MATERIALS AND TECHNOLOGY 121, 126-128 (1999).

95. A. Sivak, V. Chernov, N. Dubasova, V. Romanov, Anisotropy migration of self-point defects in dislocation stress fields in BCC Fe and FCC Cu. J. Nucl. Mater. 367, 316-321 (2007).

96. A. Sivak, V. Romanov, V. Chernov, Diffusion of self-point defects in body-centered cubic iron crystal containing dislocations. Crystallography reports 55, 97-108 (2010). 
97. G. Henkelman, G. Jóhannesson, H. Jónsson, in Theoretical Methods in Condensed Phase Chemistry. (Springer, 2002), pp. 269-302.

98. G. Henkelman, H. Jónsson, Improved tangent estimate in the nudged elastic band method for finding minimum energy paths and saddle points. The Journal of chemical physics 113, 99789985 (2000).

99. G. Henkelman, B. P. Uberuaga, H. Jónsson, A climbing image nudged elastic band method for finding saddle points and minimum energy paths. The Journal of chemical physics 113, 99019904 (2000).

100. G. Henkelman, H. Jónsson, A dimer method for finding saddle points on high dimensional potential surfaces using only first derivatives. The Journal of chemical physics 111, 7010-7022 (1999).

101. H. Xu, R. E. Stoller, L. K. Béland, Y. N. Osetsky, Self-evolving atomistic kinetic monte carlo simulations of defects in materials. Computational Materials Science 100, 135-143 (2015).

102. N. Castin, L. Malerba, Calculation of proper energy barriers for atomistic kinetic Monte Carlo simulations on rigid lattice with chemical and strain field long-range effects using artificial neural networks. The Journal of chemical physics 132, 074507 (2010).

103. F. Djurabekova et al., Artificial intelligence applied to atomistic kinetic Monte Carlo simulations in $\mathrm{Fe}-\mathrm{Cu}$ alloys. Nuclear Instruments and Methods in Physics Research Section B: Beam Interactions with Materials and Atoms 255, 8-12 (2007).

104. F. Soisson et al., Atomistic Kinetic Monte Carlo studies of microchemical evolutions driven by diffusion processes under irradiation. J. Nucl. Mater. 406, 55-67 (2010).

105. R. Domingos, G. Cerchiara, F. Djurabekova, L. Malerba, Artificial intelligence applied to simulation of radiation damage in ferritic alloys. Applied Artificial Intelligence, Genova, Italy, 29-31 (2006).

106. L. K. Béland, Y. N. Osetsky, R. E. Stoller, H. Xu, Kinetic activation-relaxation technique and self-evolving atomistic kinetic Monte Carlo: Comparison of on-the-fly kinetic Monte Carlo algorithms. Computational Materials Science 100, 124-134 (2015).

107. H. Xu, Y. N. Osetsky, R. E. Stoller, Simulating complex atomistic processes: On-the-fly kinetic Monte Carlo scheme with selective active volumes. Physical Review B 84, 132103 (2011).

108. H. Xu, Y. N. Osetsky, R. E. Stoller, Self-evolving atomistic kinetic Monte Carlo: fundamentals and applications. J. Phys.: Condens. Matter 24, 375402 (2012).

109. H. Xu, R. E. Stoller, Y. N. Osetsky, D. Terentyev, Solving the Puzzle of $\langle 100\rangle$ Interstitial Loop Formation in bcc Iron. Phys. Rev. Lett. 110, 265503 (2013).

110. J. Weertman, J. R. Weertman, Elementary dislocation theory. (1966).

111. G. Ackland, M. Mendelev, D. Srolovitz, S. Han, A. Barashev, Development of an interatomic potential for phosphorus impurities in $\alpha$-iron. J. Phys.: Condens. Matter 16, S2629 (2004). 
112. S. Chiesa, M. Gilbert, S. Dudarev, P. Derlet, H. Van Swygenhoven, The non-degenerate core structure of a $1 / 2\langle 111\rangle$ screw dislocation in bcc transition metals modelled using Finnis-Sinclair potentials: The necessary and sufficient conditions. Philosophical Magazine 89, 3235-3243 (2009).

113. Y. N. Osetsky, D. J. Bacon, An atomic-level model for studying the dynamics of edge dislocations in metals. Modelling and simulation in materials science and engineering 11, 427 (2003).

114. A. Heyden, A. T. Bell, F. J. Keil, Efficient methods for finding transition states in chemical reactions: Comparison of improved dimer method and partitioned rational function optimization method. The Journal of chemical physics 123, 224101 (2005).

115. J. Kästner, P. Sherwood, Superlinearly converging dimer method for transition state search. The Journal of chemical physics 128, 014106 (2008).

116. R. Malek, N. Mousseau, Dynamics of Lennard-Jones clusters: A characterization of the activation-relaxation technique. Physical Review E 62, 7723 (2000). 